\title{
Obstetric simulation
}

Citation for published version (APA):

Sørensen, J. L. (2016). Obstetric simulation: designing simulation-based medical education and the role of physical fidelity. [Doctoral Thesis, Maastricht University]. Datawyse / Universitaire Pers Maastricht. https://doi.org/10.26481/dis.20160601js

Document status and date:

Published: 01/01/2016

DOI:

10.26481/dis.20160601js

Document Version:

Publisher's PDF, also known as Version of record

\section{Please check the document version of this publication:}

- A submitted manuscript is the version of the article upon submission and before peer-review. There can be important differences between the submitted version and the official published version of record.

People interested in the research are advised to contact the author for the final version of the publication, or visit the DOI to the publisher's website.

- The final author version and the galley proof are versions of the publication after peer review.

- The final published version features the final layout of the paper including the volume, issue and page numbers.

Link to publication

\footnotetext{
General rights rights.

- You may freely distribute the URL identifying the publication in the public portal. please follow below link for the End User Agreement:

www.umlib.nl/taverne-license

Take down policy

If you believe that this document breaches copyright please contact us at:

repository@maastrichtuniversity.nl

providing details and we will investigate your claim.
}

Copyright and moral rights for the publications made accessible in the public portal are retained by the authors and/or other copyright owners and it is a condition of accessing publications that users recognise and abide by the legal requirements associated with these

- Users may download and print one copy of any publication from the public portal for the purpose of private study or research.

- You may not further distribute the material or use it for any profit-making activity or commercial gain

If the publication is distributed under the terms of Article $25 \mathrm{fa}$ of the Dutch Copyright Act, indicated by the "Taverne" license above, 
The research reported here was carried out at

\section{Mastricht University in Leading}

In the School of Health Professions Education

\section{SHE Education}

In the context of the research school

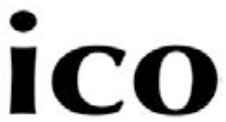

(Interuniversity Center for Educational Research)

(C) copyright Jette Led Sørensen, Maastricht 2016

Printing: Datawyse | Universitaire Pers Maastricht

ISBN 9789461595591 


\title{
Obstetric simulation Designing simulation-based medical education and the role of physical fidelity
}

\author{
DISSERTATION \\ to obtain the degree of Doctor at Maastricht University, \\ on the authority of the Rector Magnificus, Prof. Dr. L.L.G. Soete \\ in accordance with the decision of the Board of Deans, \\ to be defended in public \\ on Wednesday the $1^{\text {st }}$ of June 2016 , at 16.00 hours \\ Minderbroedersberg 4-6, Maastricht University
}

by

Jette Led Sørensen 


\section{Supervisors}

Professor Cees van der Vleuten

Professor Bent Ottesen, University of Copenhagen, Denmark

\section{Assessment Committee}

Professor Jan-Joost Rethans, chair

Professor Berit Eika, University of Aarhus, Denmark

Professor Ide Heyligers

Professor Fedde Scheele, Vrije University, Amsterdam

Professor Laurents Stassen 


\section{"I have never tried that before, so I think I should definitely be able to do that" Pippi Longstocking}

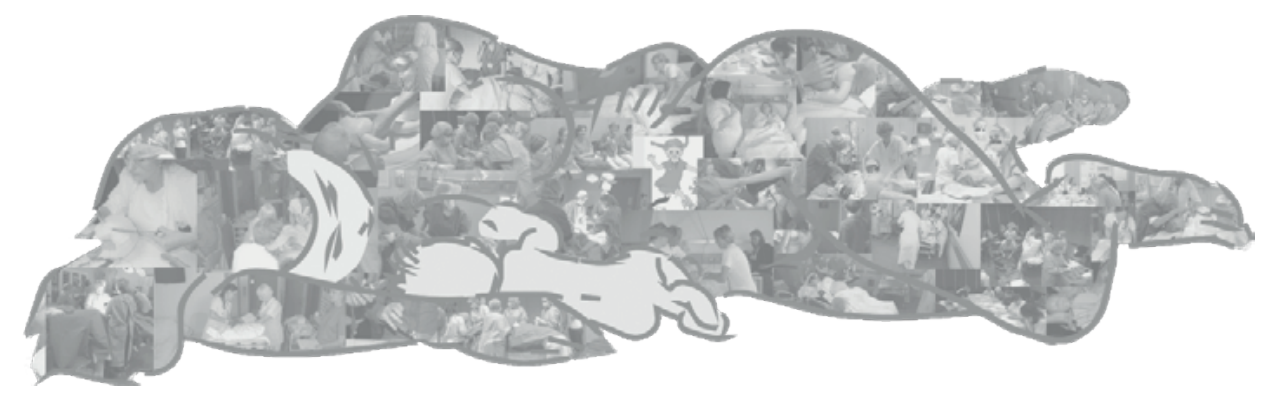

Jette Led Sørensen created the idea for this collage. The original drawing is by Henry Thelander (1902-1986) and Eva Kristine Hedtoft did the graphic design. 


\section{Abbreviations}

ANCOVA: analysis of covariance

CA: Cognitive Appraisal

$\mathrm{Cl}$ : Confidence interval

CS: Cesarean section

CTG: Cardiotocography

DK: Denmark

$\mathrm{Hb}$ : Hemoglobin

HELLP: Hemolysis, Elevated Liver enzymes, Low Platelets count

ICC: Intraclass correlation coefficient

IPE: Inter-professional education

ICMJE: International Committee of Medical Journal Editors

IMI: Intrinsic motivation inventory

ISS: In situ simulation

JMC: Juliane Marie Centre for Children, Women and Reproduction

KOS-test: Knowledge of skills test

MCQ: Multiple-choice question

MPE: Multi-professional education

PPB: Postpartum bleeding

PPH: Postpartum haemorrhage

OSS: Off site simulation

RBC: Red blood cell

RCT: Randomised controlled trial

$\mathrm{RH}$ : Rigshospitalet

SAQ: Safety Attitudes Questionnaire

SMBE: Simulation-based medical education

SD: Standard Deviation

STAI: Stress-Trait Anxiety Inventory

TEAM: Team Emergency Assessment Measure

UK: United Kingdom 


\section{TABLE OF CONTENTS}

CHAPTER 1

CHAPTER 2

CHAPTER 3

CHAPTER 4

CHAPTER 5
Introduction

The implementation and evaluation of a mandatory multiprofessional obstetric skills training program

Jette Led Sørensen, Ellen Løkkegaard, Marianne Johansen, Charlotte Ringsted, Svend Kreiner, Sean McAleer. Published in Acta Obstet Gynecol Scand 2009;88:1107-17.

Evaluation of multi-professional obstetric skills training for postpartum haemorrhage

49

Veronika Markova, Jette Led Sørensen, Charlotte Holm, Astrid Norgaard, Jens Langhoff-Roos. Published in Acta Obstet Gynecol Scand 2012; 91:346-52.

Unannounced in situ simulation of obstetric emergencies: staff perceptions and organisational impact

63

Jette Led Sørensen, Pernille Lottrup, Cees van der Vleuten, Kristine Sylvan Andersen, Mette Simonsen, Pernille Emmersen, Bent Ottesen. Published in Postgrad Med J 2014;90:622-9.

Development of knowledge tests for multi-disciplinary emergency training: a review and an example 89 Jette Led Sørensen, Line Thellensen, Jeanett Strandbygaard, Kira D. Svendsen, Karl Bang Christensen, Marianne Johansen, Pernille Langhoff-Roos, Kim Ekelund, Bent Ottesen, Cees van der Vleuten. Published in Acta Anaesthesiol Scand 2015;59:123-33.

CHAPTER 6 Part I 'In situ simulation' versus 'off site simulation' in obstetric emergencies and their effect on knowledge, safety attitudes, team performance, stress, and motivation: study protocol for a randomized controlled trial 109 Jette Led Sørensen, Cees van der Vleuten, Jane Lindschou, Christian Gluud, Doris $\emptyset$ stergaard, Vicki Leblanc, Marianne Johansen, Kim Ekelund, Charlotte Krebs Albrechtsen, Berit Woetmann Pedersen, Hanne Kjærgaard, Pia Weikop and Bent Ottesen. Published in Trials 2013;14:220. 
CHAPTER 6 Part II Simulation based multi-professional obstetric anaesthesia training conducted in situ versus off site leads to similar individual and team outcomes - a randomised educational trial Jette Led Sørensen, Cees van der Vleuten, Susanne Rosthoj, Doris $\emptyset$ stergaard, Vicki Leblanc, Marianne Johansen, Kim Ekelund, Liis Starkopf, Jane Lindschou, Christian Gluud, Bent Ottesen. Published in BMJ Open 2015;5:e008344.

\section{CHAPTER 7}

Clarifying the learning experiences of healthcare professionals with in situ and off site simulation-based medical education: a qualitative study Jette Led Sørensen, Laura Emdal Navne, Helle Max Martin, Bent Ottesen, Charlotte Krebs Albrechtsen, Berit Woetmann Pedersen, Hanne Kjærgaard, Cees van der Vleuten.

Published in BMJ Open 2015;5:e008345.

Twelve tips for choice of simulation setting and design of simulation-based medical education Jette Led Sørensen, Doris Østergaard, Vicki Leblanc, Bent Ottesen, Lars Konge, Peter Dieckman, Cees van der Vleuten. Submitted, September 2015.

Samenvatting (summary in Dutch) 225

Dansk resume (summary in Danish) 233

$\begin{array}{ll}\text { Acknowledgement } & 241\end{array}$

Valorisation $\quad 245$

$\begin{array}{ll}\text { Curriculum vitae } & 255\end{array}$

$\begin{array}{ll}\text { SHE dissertations series } & 257\end{array}$ 


\section{CHAPTER 1}

\section{Introduction}




\section{Introduction}

The intrinsic dual function of a labour ward in creating a relaxed atmosphere for normal childbirth while simultaneously being prepared for life-threatening emergencies makes it a challenging workplace that requires flexible, highly knowledgeable staff skilled in clinical problem solving and ability to multi-disciplinary cooperation [1-4]. A high level of communication and excellent cooperation skills are also necessary when interacting with labouring women [1,3,5-7]. Simulation-based medical education is a complex intervention and despite the growing number of studies, knowledge gaps still exist and many key elements of simulation-based training remain to be analysed in depth to improve the field. This thesis addresses how various aspects of obstetric simulationbased medical education interfere and impact outcomes.

\section{What is simulation?}

Simulation-based medical education can be broadly and simply defined: “... a person, device, or set of conditions which attempts to present education and evaluation problems authentically. The student or trainee is required to respond to the problems as he or she would under natural circumstances" [8]. Simulation technologies can, for instance comprise products such as high-tech virtual reality simulators, full-scale mannequins, plastic models, instructed patients, animals, animal products and human cadavers.

The key advantages of simulation-based medical education include avoidance of patient risks, the needs of the participants and team determine the training agenda, the environment is safe and failing is permissible. Tasks and scenarios can be created according to demand, training can be tailored to individuals or teams and skills can be practised repeatedly. In addition, learning can focus on a particular team, on the whole procedure or on specific components of a procedure [8-14].

The literature highlights specific principles in simulation-based team training, including critical aspects such as identifying teamwork skills to focus training content, allowing the desired team-based learning outcomes and organisational resources to guide the process, and ensuring the relevance of training to the transfer environment $[10,15,16]$. In addition applying feedback, assessing learning and behaviours on the job and doing evaluations based on clinical outcomes are also important $[15,16]$.

\section{Multi-professional and multi-disciplinary obstetric simulation}

This thesis focuses specifically on simulation-based medical education in obstetric emergencies, e.g. clinical management of shoulder dystocia, severe postpartum bleeding, severe preeclampsia, neonatal resuscitation and emergency caesarean section. Labour wards are challenging workplaces where patient safety and medical litigation are high on the agenda [17]. In emergency situations, managing labouring women may 
require the involvement of several healthcare professional groups. The primary care team in the delivery room consists of a midwife and an auxiliary nurse. In the event of an obstetric emergency more experienced midwives and obstetricians are called upon. As an obstetric emergency unfolds, involvement of an anaesthesiologist, a nurse anaesthetist, operating room nurses and a neonatologist may become necessary. When the parturient woman is severely ill, involvement of both medical and surgical specialists may be required to deal with an ordinary situation that has become potentially life threatening and calls for multi-professional and multi-disciplinary clinical management (figure 1.1). Teams created for specific clinical situations are known as ad hoc on-call teams $[18,19]$.

Figure 1.1 Illustration of patient journey when the labouring woman undergoes either an emergency caesarean section or experiences postpartum bleeding. The three columns represent the physical space (delivery ward, operation theatre, postnatal ward) where communication and handover between various healthcare professionals are necessary. The circles and ovals represent the individual healthcare professionals involved in care of the patient and illustrate how some staff works solely on a specific ward while others work across wards. Grey colour represents the obstetric team and black colour the operation anaesthesia team. These healthcare professionals also represent the ad hoc on-call team that is responsible for high risk deliveries. Other healthcare professionals (e.g. neonatologists) can also be involved but are not mentioned in this figure.

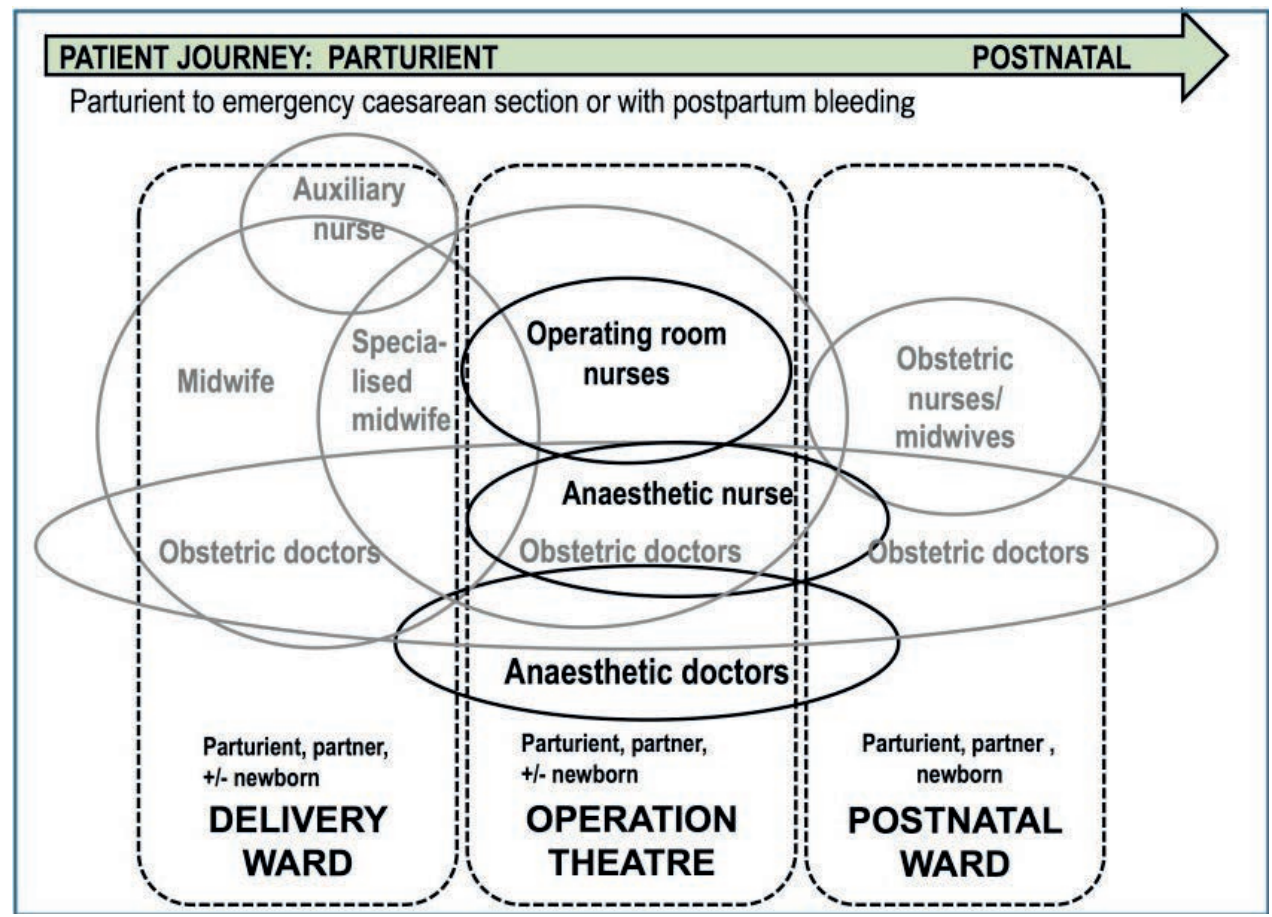

These rare and complex clinical obstetric emergencies require complex skills, but their rarity means training and learning about them in real-life clinical practice is virtually 
difficult. Consequently, there is a need for simulation-based medical education in obstetric emergencies.

Conducted in a clinical hospital environment, the studies comprising this thesis all include simulation-based medical education applied in a multi-professional or multidisciplinary postgraduate context. In 1988 the World Health Organization defined multi-professional education as "the process by which a group of students (or workers) from the health-related occupations with different educational backgrounds learn together during certain periods of their education, with interaction as an important goal, to collaborate in providing preventive, curative, rehabilitative and other health-related services." [20]. The term inter-professional education is also used and is considered to overlap with multi-professional, hence we use them interchangeably [21,22]. The terms inter-disciplinary and multi-disciplinary are broader and include healthcare workers within various medical disciplines and specialities. Multi-disciplinary teams have responsibility for the same patient but team members have different duties, which is why they receive different types of training. Multi-disciplinary teams openly share decision making, expectations for care, aims for the team and exhibit mutual respect for one another [23].

\section{What do we know about simulation effectiveness?}

Reviews on simulation-based medical education conclude that in comparison with no intervention, the use of technology-enhanced simulation in the education of health professionals has a large effect on outcomes such as knowledge, skills and behaviours and a moderate effect on patient-related outcomes [6,8,10,24-32]. Less effect is found for team-based simulation-based medical education as there is a lack of team-based metrics and mastery standards that are translatable to the clinical environment [33].

A review of simulation-based medical education concluded that further research is needed in the areas of instructional design, outcome measurement, and translational and implementation sciences in the context of simulation [10]. Cook et al. conclude that future research should clarify the mechanisms of effective simulation-based education, i.e. what works, for whom and in what context [34].

From the literature it can be concluded that simulation-based medical education on labour wards is essential and that multi-professional and multi-disciplinary team training is important due to the complexities of the skills trained and the rareness of highrisk clinical events.

A systematic review [5] of programmes in acute obstetric emergencies identified 97 articles, eight of which evaluated simulation-based teamwork training programmes in acute obstetric emergencies, only few of which were considered to be of sufficiently good quality $[5,35,36]$. Some randomised trials $[37,38]$ have been added since Merien et al's [5] 2010 review. Recent reviews [6,7] sum up publications on obstetric simula- 
tion and conclude that a transition needs to be made from examining whether training works to how and why training works, but also that the research agenda must expand to include understanding the role context plays in training and how and why different programmes are associated with different outcomes [6].

We use a training transfer model, described in the next section, to understand and systematise the elements involved in simulation-based medical education in obstetric simulation [39-41].

\section{What is transfer and what influences it?}

Viewed as a complex, dynamic process, transfer is a concept dating back more than 100 years [40]. Originally defined as the extent to which learning of a response in one task or situation influences responses in another task or situation [40], transfer is conceptualised in this thesis as learning through simulation and how this influences clinical work. A more recent definition of positive transfer is the degree to which trainees effectively apply the knowledge, skills and attitudes obtained in a training context to the job [39]. More recent literature argues that transfer is difficult and reports a $10-30 \%$ success rate in applying solutions to clinical problems in accordance with what was previously practised [41,42]. It is argued that in the effort to improve the transfer of learning, more focus should be put on the ability to behave intelligently and to acquire knowledge [43].

We apply Baldwin and Ford's recognised transfer model to describe and discuss the various elements of simulation-based obstetric simulation (figure 1.2A) [39,40].

Training input: The transfer model describes training input variables as having an effect on the following three factors: 1) Trainee characteristics, 2) training design and 3) work environment. The first factor, trainee characteristics, involves aspects such as age, sex, cognitive ability, self-efficacy, skills, motivation, personality and experience, but is described poorly in the literature $[40,41]$. Next, training design or intervention design includes needs analysis, training objectives and methods, as well as the incorporation of learning principles such as multiple training techniques and opportunities for practice $[40,41]$. Finally, the third factor, work environment, includes transfer climate, social support from supervisors and peers, and the constraints on or opportunities for e.g. performing learned skills on the job $[39,40]$.

Training output and conditions of transfer: For transfer to have occurred the learned behaviour must ultimately be transferred to the job context and maintained over a period of time [39]. As simulation-based medical education is a complex intervention, surrogate outcomes or proxy parameters are often applied to report results. Cook et al. [44] argue for the necessity of having a proper balance between learner-centred and patient-centred assessment, especially when it comes to the evaluation of programme implementation and theory-building research [44]. 


\section{Training inputs}

Training outputs

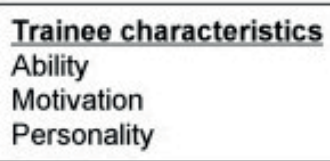

Trainee characteristics

Ability

Motivation

Personality

Training design

Principles of learning

Sequencing

Training content

Work environment

Support

Opportunity to use

\section{Conditions of transfer}




\section{Application of the transfer model}

Using the transfer model to systematise the outcome variables involved in simulationbased medical education research, this thesis describes how these variables can potentially interfere with each other. First we focus on outcome variables related to training design, such as simulation fidelity, followed by an introduction to the context and setting. We then present the research question (RQ) and subsequently describe how the training design and other training input variables (such as trainee characteristics and work environment), training output and transfer conditions interfere with each other. We also describe which outcome variables are independent and which ones are dependent or moderating variables.

\section{What do we know about fidelity?}

Training design in simulation-based medical education may be influenced by the level of fidelity, which is classically understood as the degree of faithfulness or authenticity that exists between two entities. Fidelity in simulation-based medical education is of importance and may improve the effectiveness of a simulation, thereby preparing participants to perform clinically [45]. The term fidelity was introduced in the medical education literature based on experiences from flight simulation [46]. In the 1990s flight simulation research described fidelity as a vague term with many different definitions and a more multidimensional concept was introduced [47]. Fidelity was later adapted to the medical educational literature and described as consisting of two aspects. First, physical or engineering fidelity is the degree to which the simulators duplicates the appearance and feel of the real system and this also covers environmental fidelity, which is the extent to which the simulator duplicates practical and sensory information from the task environment. The second aspect is psychological fidelity, also called functional fidelity, which is the degree to which the trainee perceives the simulation as an authentic surrogate for the task being trained $[46,48,49]$. These aspects of fidelity are interrelated and different genres of simulation can be combined to increase both physical and psychological fidelity. Because fidelity is a complex term this thesis operationalises it by focusing on the simulation context [50] and setting of simulation.

\section{What elements in the working context are important?}

The work setting can be viewed as the working context. Context, however, can be expanded to include physical, semantic and commitment aspects [50].In medical education the physical context can comprise the physical setting or surroundings $[50,51]$. and appears to be parallel to the aspect of fidelity described as physical, i.e. the degree to which the simulation resembles the appearance and perception of the real system $[46,48]$. There is also the semantic context, which reflects how well the context contributes to the learning task, and the commitment context, which reflects motivation and sense of responsibility [50,52]. This expanded perception of the term context is important to understanding the setting in simulation-based medical education. 


\section{The simulation setting: Off site or in situ}

Simulation-based medical education has traditionally been conducted off site in settings or contexts such as simulation centres, but some hospitals also provide in-house training in rooms specifically allocated to training [35]. This thesis defines off site simulation (OSS) as simulation-based medical education where the setting is either a simulation centre or in-house training facilities consisting of hospital rooms set up for simulation training and that resemble simulation centre facilities to some extent. Introduced over the past decade, in situ simulation (ISS), as defined by Riley et al., is "a team-based simulation strategy that occurs on patient care units involving actual healthcare team members within their own working environment" [53]. Rosen et al. describe in a review ISS as a blend of simulation and real working environments providing training where people actually work [49]. ISS can be conducted as either announced or unannounced, the latter of which is called a drill $[49,54]$.

In summary, we use the following four terms for simulation settings in this thesis: 1) OSS in simulation centres; 2) OSS in-house in training rooms in hospitals; 3 ) announced ISS; and 4) unannounced ISS.

The number of original publications on ISS is growing. A search for literature on ISS and related terms resulted in approximately 120 hits for original research papers, several of which are on the reference list in this thesis [53,55-102]. No reviews have to my best knowledge been published since Rosen's in 2012 review [49], which pointed out issues such as small sample sizes, weak study designs and inadequate evaluations of the effectiveness of in situ programmes. Several studies have been written since 2012, but to the best of our knowledge no randomised studies have addressed a comparison between ISS versus OSS settings. Two recent studies used randomisation to compare ISS to OSS, but focused on frequency of training and did not include a relevant control group $[59,61]$.

Because ISS takes place in the real working environment, it is argued that ISS can be used to identify organisational or system weaknesses $[55,62,63,81,83,101]$. ISS is also used to test how new processes function in clinical facilities $[64,85,87]$. Some argue that ISS is more feasible and cost saving than simulation centres $[60,67,88,94,96]$. The potential disadvantages of unannounced ISS, however, have also been pointed out, including its time-consuming nature and how participants may experience it as intimidating, though this has been poorly explored in the literature [54]. ISS is in descriptive studies argued to improve patient safety culture and quality $[93,95]$, various procedures $[90,98,102]$ team functions $[89,92,100]$ and participants confidence $[82,84,91]$. In addition, literature on whether ISS is useful for individual learning or whether it solely provides an organisational system perspective is also scarce [49]. The assumption is that ISS, compared to OSS, is more realistic because it is conducted in a real context and thus is believed to have a positive impact on learning $[49,53,56,58,62,101]$. 


\section{Research questions}

Overall this thesis addresses how various aspects of obstetric simulation-based medical education interfere and impact outcomes. More specifically it examines the following four overarching research questions which are descriptive, explanatory and exploratory:

I. Is there interaction between training design interventions (in situ and off site simulation) and healthcare professionals' reactions and work environment?

II. Do training design interventions (in situ and off site simulation) affect learning and organisation?

III. What does the literature reveal about knowledge testing in a simulated multidisciplinary training programme and how can a multiple choice test be developed and validated?

IV. What are the characteristics of simulation that healthcare professionals perceive to be influential for learning and the transfer of learned skills and knowledge to a clinical setting?

\section{Transfer model and trainee characteristics, training design and work environment}

We used the transfer model to define variables and outcomes during our studies, which will be outlined later. The transfer model was used to operationalise variables such as the training input (trainee characteristics, training design and work environment), training outputs and conditions of transfer (figure 1.2B).

The training design is the independent variable [103] and we aim to study how variations in the training design, i.e. setting or context, for simulation-based medical education will affect other aspects of the model, i.e. changes in announced and unannounced ISS or OSS in-house training.

We study various aspects of trainee characteristics, which are understood in this thesis as the characteristics of healthcare professionals. We view aspects of the trainee (healthcare professionals') characteristics and work environment as dependent variables influenced by the independent variable, i.e. the training design (ISS and OSS), but we do not see them as static. They are changeable, which is why we also define them as moderating variables. As a result our model contains the addition of two sets of dotted arrows [39]. Moderating variables are a special type of independent variable as they affect or modify the relationship between the primary independent variable (training design) and aspects of the trainee characteristics and work environment [103]. 


\section{Training inputs}

\section{Trainee characteristics'}

Demographic data

Self-perceived confidence

Perceptions of simulation

Stress and anxiety

Motivation

DEPENDENT VARIABLE

MODERATING VARIABLE

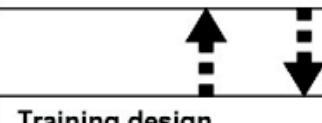

Training design

Simulation-based medical education in obstetric

emergency training

Changes in setting (context):

off site and and in situ simulation

INDEPENDENT VARIABLE

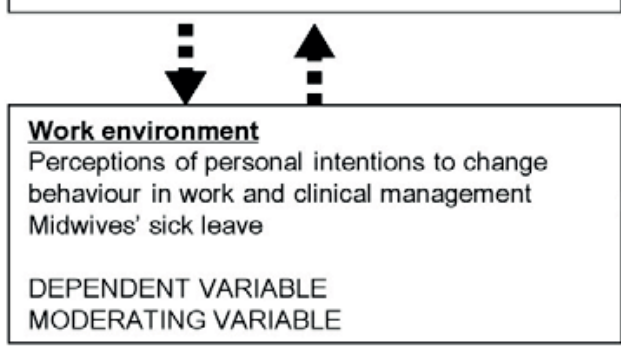

Training outputs Conditions of transfer

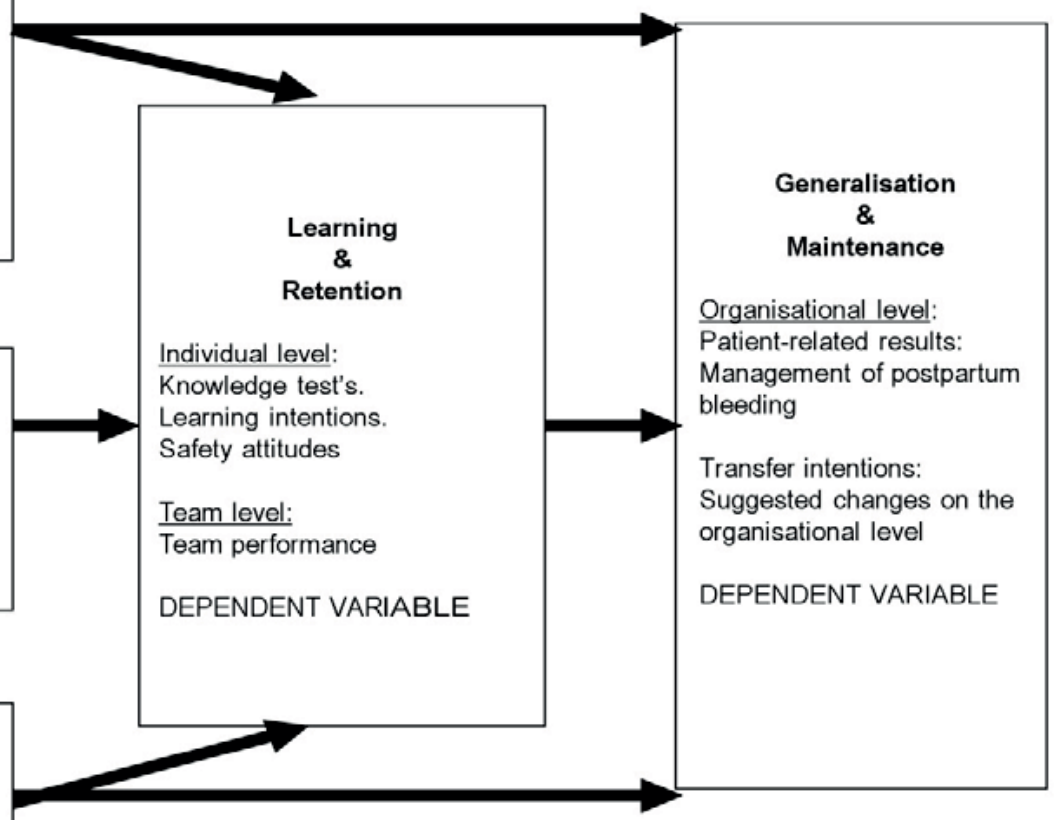

Source: Modification of Baldwin and Ford's 1988 transfer model 


\section{Training design and trainee characteristics}

As stated earlier, the training design is the independent variable [103] and our aim is also to study how variations in the training design, i.e. setting or context, for ISS and OSS simulation will affect and be moderated by trainee characteristics. This thesis operationalises the characteristics of trainees (healthcare professionals) for various outcomes, such as demographic data, self-perceived confidence, perceptions of simulation, stress, anxiety and motivation (figure 1.2B).

\section{Training design and work environment}

We also aim to study how variations in the training design, i.e. setting or context, for ISS and OSS simulation will affect and be moderated by aspects of the work environment. This thesis operationalises work environment as perceptions of personal intentions to change clinical management behaviour at work and in measuring the sick leave of midwives (figure 1.2B).

\section{Training design and training output and transfer conditions}

The training design, i.e. setting or context, for ISS and OSS simulation can be expected to affect training outcomes such as learning and retention, and transfer conditions such as generalisation and maintenance. The training output is operationalised on the individual level as knowledge gain, learning intentions and safety attitudes, and on the team level as team performance. For transfer conditions, such as retention and maintenance, the outcomes are selected patient outcomes from patient databases and records and transfer intentions such as suggested changes on the organisational level (figure 1.2B).

\section{Overview of the studies}

The first study (The implementation and evaluation of a mandatory multi-professional obstetric skills training programme), presented in chapter $\mathbf{2}$, is an observational study based on the OSS setting and addresses research questions I and II. The study implemented and evaluated a simulation-based, multi-professional mandatory training programme for obstetric teams consisting of midwives, obstetric nurses, auxiliary nurses, obstetric trainees and specialist doctors. Outcome variables were on trainee characteristics, i.e. the characteristics of healthcare professionals as perceptions of simulation, self-perceived confidence and stress. Outcome variables on work environment were conceptualised in perceptions of personal intentions to change behaviour in work and clinical management and the frequency of sick leave among midwives. Learning and retention were measured with a knowledge test that included retention of knowledge. On the level of generalisation and maintenance, we integrated data on changes in work routines and integrated data from the Danish Medical Birth Registry for information on the diagnosis and management of postpartum bleeding. We used specifically in this study the Kirkpatrick's four levels of evaluation to organise, interpret and discuss the 
data obtained from the study [104,105]: (1) reaction level, which measures the participants' satisfaction with the training programme; (2) learning level, which is the extent to which a training programme changed the participants' attitudes, affected their knowledge and/or improved their skills; (3) behaviour level, which is the transfer of learning from an educational setting to real life; and (4) the results level, which examines the impact on the organisation and patient outcomes as a consequence of the training programme $[104,105]$.

The second study (Evaluation of multi-professional obstetric skills training for postpartum haemorrhage), presented in chapter 3, is a data-base audit using data obtained through linkage of the Danish Medical Birth Registry and the local transfusion database, as well as from a subsequent audit of medical records. This study addressed research questions II and provided information on generalisation and maintenance in the transfer model [39]. This study aimed to evaluate the effect of a multi-professional obstetric skills training programme on the incidence of postpartum bleeding, indicated by red blood cell transfusion and time delay in surgical interventions before (2003), during (2005) and after (2007) implementation of the obstetric simulation training described in chapter 2.

The third study (Unannounced in situ simulation of obstetric emergencies: Staff perceptions and organisational Impact), presented in Chapter 4, was an observational study that focused on the unannounced ISS setting. It mainly addressed research questions I and provided inspiration for the studies in chapters 6 and 7. Some of the data from the study presented in chapter 2 were also used here, but they were obtained before implementation of unannounced ISS and provided information on healthcare professionals' perceptions of unannounced ISS and its likely usefulness and impact in terms of perceived stress. We compiled these historical data (from chapter 2) with data from the perceptions of healthcare professionals after implementation of unannounced ISS. We investigated both healthcare professionals actively involved in the unannounced ISS and other healthcare professionals in the organisation (controls). This study was designed to provide information on the effect of unannounced ISS on trainee (healthcare professionals) characteristics, including subjective stress, anxiety, learning and retention, and generalisation and maintenance of learning intentions and transfer intentions triggered by the implementation of an unannounced ISS.

The study described in chapter 2 used a non-validated knowledge test to measure learning and retention. Guidance on how to develop written tests for a post-graduate multi-disciplinary setting is sparse. The principles for developing written tests are universal, but the post-graduate, multi-disciplinary context should be taken into account during test development. We identified a need for developing a knowledge test for future use in training programmes involving simulation-based medical education. The fourth study presented in chapter 5 (Development of knowledge tests for multidisciplinary emergency training: A review and an example) addressed research ques- 
tions III and introduced a template for developing a knowledge test, in addition to providing a detailed description of the process for developing and evaluating this knowledge test for use in a multi-disciplinary training programme in obstetricanaesthesia emergencies.

The study in chapter 5 was a prerequisite for the primary outcome in the study presented in chapter 6, Parts I and II (Part I: In situ simulation versus off site simulation in obstetric emergencies and their effect on knowledge, safety attitudes, team performance, stress and motivation: Study protocol for a randomised controlled trial; and Part II: Simulation-based multi-professional obstetric anaesthesia training conducted in situ versus off site leads to similar individual and team outcomes: A randomised educational trial). In our studies presented in chapters 2 and 4 the simulation setting is either OSS or ISS. Research questions I and II are addressed again using an explanatory approach, while a randomised trial compared the training design for OSS and ISS. Based on the results from the data-base audit used in the study in chapter 3 , we decided to involve the anaesthesia operation team together with the obstetric team, which was involved in all previous simulations, hence expanding from a multi-professional to a multidisciplinary approach [22]. As a result we decided to carry out an experimental study with a randomised design to investigate the effect ISS versus OSS on various outcomes. For the randomised trial we initially wrote a protocol article. The intervention comprised two multi-professional simulations to be conducted in teams in either the ISS or the OSS setting. Reflecting on our previous choice of non-validated outcomes, we used a knowledge test as described in chapter 5 . We decided to use previously validated scales for measuring stress and motivation [106-114], safety attitudes [115-118,119]. perceptions of the simulation and for team performance video assessment $[120,121]$. We collected input from participants on suggested organisational changes. We hypothesised that the physical ISS setting would influence fidelity and hence that ISS could be more effective for educational purposes. We also anticipated that the participants would experience ISS as more demanding and as creating higher levels of stress and motivation, and that this might enhance their learning. Furthermore, we hypothesised that ISS might provide the researchers with more information on changes needed in the organisation to improve patient safety and the quality of care.

Part I of this chapter contains a protocol article that details the design and outcome of the original research, which is presented in part II.

Chapter 7 contains a qualitative study (Clarifying the learning experiences of healthcare professionals with in situ and off site simulation-based medical education: A qualitative study) that explored how the ISS and OSS setting in simulation-based medical education affects the perceptions and learning experience of healthcare professionals. This study addressed Research question IV. Healthcare professionals participating in the randomised trial presented in chapter 6 were recruited to explore the assumption that ISS is believed to increase learning because it takes place in the clinical setting, where the 
learning context is more similar to the context of practice. This qualitative study attempts to shed light on the general assumption that context and fidelity are determinants for how different kinds of simulation-based medical education are experienced and it endeavours to determine the veracity of the common assumption that ISS is a more effective learning tool than OSS.

Chapter 8 contains a review (Twelve tips for designing simulation-based medical education and choosing the simulation setting) of the existing evidence on designing simulation-based medical education and the choice of simulation setting, in addition to discussing concepts such as setting, context and fidelity. We provide twelve practical tips on how to design and determine which setting is the best choice for simulation-based medical education.

Chapter 9 contains a general discussion which summarises and discusses the key findings of the studies in the light of the present research in the field. The strengths and limitations are discussed and implications for practice in design of simulation-based medical education and the choice of simulation are discussed and ideas future research are proposed. The discussion chapter is followed by a summary in English, Dutch and Danish.

This dissertation comprises papers written for peer-reviewed scientific journals; hence the repetition of some information is unavoidable. 


\section{References}

1. Veltman LL. Getting to havarti: moving toward patient safety in obstetrics. Obstet Gynecol 2007;110:1146-50.

2. Drife J. Reducing risk in obstetrics. Qual Health Care 1995;4:108-14.

3. Johannsson H, Ayida G, Sadler C. Faking it? Simulation in the training of obstetricians and gynaecologists. Curr Opin Obstet Gynecol 2005;17:557-61.

4. Guise JM. Anticipating and responding to obstetric emergencies. Best Pract Res Clin Obstet Gynaecol 2007;21:625-38.

5. Merien AE, Van der Ven J, Mol BW, Houterman S, Oei SG. Multidisciplinary team training in a simulation setting for acute obstetric emergencies: a systematic review. Obstet Gynecol 2010;115:1021-31.

6. Draycott TJ, Collins KJ, Crofts JF, Siassakos D, Winter C, Weiner CP, Donald F. Myths and realities of training in obstetric emergencies. Best Pract Res Clin Obstet Gynaecol 2015;29:1067-76.

7. Bergh AM, Baloyi S, Pattinson RC. What is the impact of multi-professional emergency obstetric and neonatal care training? Best Pract Res Clin Obstet Gynaecol 2015;29:1028-43.

8. Issenberg SB, McGaghie WC, Petrusa ER, Lee GD, Scalese RJ. Features and uses of high-fidelity medical simulations that lead to effective learning: a BEME systematic review. Med Teach 2005;27:10-28.

9. McGaghie WC, Issenberg SB, Petrusa ER, Scalese RJ. A critical review of simulation-based medical education research: 2003-2009. Med Educ 2010;44:50-63.

10. Motola I, Devine LA, Chung HS, Sullivan JE, Issenberg SB. Simulation in healthcare education: a best evidence practical guide. AMEE Guide No. 82. Med Teach 2013;35:e1511-e1530.

11. Kneebone R. Simulation in surgical training: educational issues and practical implications. Med Educ 2003;37:267-77.

12. Bradley P, Postlethwaite K. Setting up a clinical skills learning facility. Med Educ 2003;37 Suppl 1:613.

13. Bradley $P$, Postlethwaite K. Simulation in clinical learning. Med Educ 2003;37 Suppl 1:1-5.

14. Bradley P, Bligh J. Clinical skills centres: where are we going? Med Educ 2005;39:649-50.

15. Salas E, DiazGranados D, Weaver SJ, King H. Does team training work? Principles for health care. Acad Emerg Med 2008;15:1002-9.

16. Cornthwaite K, Edwards S, Siassakos D. Reducing risk in maternity by optimising teamwork and leadership: an evidence-based approach to save mothers and babies. Best Pract Res Clin Obstet Gynaecol 2013;27:571-81.

17. Hove LD, Bock J, Christoffersen JK, Hedegaard M. Analysis of 127 peripartum hypoxic brain injuries from closed claims registered by the Danish Patient Insurance Association. Acta Obstet Gynecol Scand 2008;87:72-5.

18. Teteris E, Fraser K, Wright B, McLaughlin K. Does training learners on simulators benefit real patients? Adv Health Sci Educ Theory Pract 2012;17:137-44.

19. Lingard L. Rethinking Competence in the Context of teamwork. In: Hodges B, Lingard L, editors. The Question of Competence. Reconsidering Medical Education in the Twenty-First Century. First ed. New York: ILR Press an imprent of Cornell University Press; 2012. p. 42-69.

20. World Health Organization. Framework for Action on Interprofessional Education \& Collaborative Practice. 2010. Ref Type: Internet Communication

21. Hammick M. Interprofessional education: evidence from the past to guide the future. Med Teach 2000;22:461-7.

22. Nancarrow SA, Booth A, Ariss S, Smith T, Enderby P, Roots A. Ten principles of good interdisciplinary team work. Hum Resour Health 2013;11:19.

23. Oneha MF, Yoshimoto $\mathrm{CM}$, Bell S, Enos RN. Educating health professionals in a community setting: what students value. Educ Health (Abingdon ) 2001;14:256-66.

24. Cook DA, Hatala R, Brydges R, Zendejas B, Szostek JH, Wang AT, Erwin PJ, Hamstra SJ. Technologyenhanced simulation for health professions education: a systematic review and meta-analysis. JAMA 2011;306:978-88.

25. Zendejas B, Brydges R, Hamstra SJ, Cook DA. State of the evidence on simulation-based training for laparoscopic surgery: a systematic review. Ann Surg 2013;257:586-93. 
26. Ahlberg G, Enochsson L, Gallagher AG, Hedman L, Hogman C, McClusky DA, III, Ramel S, Smith CD, Arvidsson D. Proficiency-based virtual reality training significantly reduces the error rate for residents during their first 10 laparoscopic cholecystectomies. Am J Surg 2007;193:797-804.

27. Larsen CR, Soerensen JL, Grantcharov TP, Dalsgaard T, Schouenborg L, Ottosen C, Schroeder TV, Ottesen BS. Effect of virtual reality training on laparoscopic surgery: randomised controlled trial. BMJ 2009;338:b1802.

28. Barsuk JH, Cohen ER, Feinglass J, McGaghie WC, Wayne DB. Use of simulation-based education to reduce catheter-related bloodstream infections. Arch Intern Med 2009;169:1420-3.

29. Draycott T, Sibanda T, Owen L, Akande V, Winter C, Reading S, Whitelaw A. Does training in obstetric emergencies improve neonatal outcome? BJOG 2006;113:177-82.

30. Seymour NE. VR to OR: a review of the evidence that virtual reality simulation improves operating room performance. World J Surg 2008;32:182-8.

31. Brydges R, Hatala R, Zendejas B, Erwin PJ, Cook DA. Linking simulation-based educational assessments and patient-related outcomes: a systematic review and meta-analysis. Acad Med 2015;90:246-56.

32. Crofts J, Lenguerrand E, Bentham G, Tawfik S, Claireaux H, Odd D, Fox R, Draycott T. Prevention of brachial plexus injury-12 years of shoulder dystocia training: an interrupted time-series study. BJOG 2015.

33. McGaghie WC, Issenberg SB, Barsuk JH, Wayne DB. A critical review of simulation-based mastery learning with translational outcomes. Med Educ 2014;48:375-85.

34. Cook DA, Hamstra SJ, Brydges R, Zendejas B, Szostek JH, Wang AT, Erwin PJ, Hatala R. Comparative effectiveness of instructional design features in simulation-based education: systematic review and meta-analysis. Med Teach 2013;35:e867-e898.

35. Ellis D, Crofts JF, Hunt LP, Read M, Fox R, James M. Hospital, simulation center, and teamwork training for eclampsia management: a randomized controlled trial. Obstet Gynecol 2008;111:72331.

36. Crofts JF, Ellis D, Draycott TJ, Winter C, Hunt LP, Akande VA. Change in knowledge of midwives and obstetricians following obstetric emergency training: a randomised controlled trial of local hospital, simulation centre and teamwork training. BJOG 2007;114:1534-41.

37. Fransen AF, Van der Ven J, Merien A, de Wit-Zuurendonk L, Houterman S, Mol B, Oei S. Effect of obstetric team training on team performance and medical technical skills: a randomised controlled trial. BJOG 2012;119:1387-93.

38. Van der Ven J, Houterman S, Steinweg RA, Scherpbier AJ, Wijers W, Mol BW, Oei SG. Reducing errors in health care: cost-effectiveness of multidisciplinary team training in obstetric emergencies (TOSTI study); a randomised controlled trial. BMC Pregnancy Childbirth 2010;10:59.

39. Baldwin TT, Ford JK. Transfer of training: A review and directions for future research. Personnel Psychology 1988;41:63-105.

40. Blume BD, Ford K, Baldwin TT, Huang JL. Transfer and Training: A Meta-Analytic Review. Journal of Management 2010;36:1065.

41. Burke LA, Hutchins HM. Training Transfer: An Integrative Literature Review. Human Resource Developement review 2007;6:263-96.

42. Norman G. Teaching basic science to optimize transfer. Med Teach 2009;31:807-11.

43. Mylopoulos M. Exploring Construction of Knowledge. In: Hodges B, Lingard L, editors. The Question of Competence. 1 ed. New York: Cornell University Press; 2015. p. 97-112.

44. Cook DA, West CP. Perspective: Reconsidering the focus on "outcomes research" in medical education: a cautionary note. Acad Med 2013;88:162-7.

45. Grierson LE. Information processing, specificity of practice, and the transfer of learning: considerations for reconsidering fidelity. Adv Health Sci Educ Theory Pract 2014;19:281-9.

46. Beaubien JM, Baker DP. The use of simulation for training teamwork skills in health care: how low can you go? Qual Saf Health Care 2004;13 Suppl 1:i51-i56.

47. Rehmann A, Mitman RD, Reynolds MC. A Handbook of Flight Simulation Fidelity Requirements for Human Factors Research. Atlantic City Airport, NJ 08405: U.S. Department ofTransportation Federal Aviation Administration; 1995. Report No.: DOT/FAA/CT-TN95/46.

48. Norman G, Dore K, Grierson L. The minimal relationship between simulation fidelity and transfer of learning. Med Educ 2012;46:636-47. 
49. Rosen MA, Hunt EA, Pronovost PJ, Federowicz MA, Weaver SJ. In situ simulation in continuing education for the health care professions: a systematic review. J Contin Educ Health Prof 2012;32:243-54.

50. Koens F, Mann KV, Custers EJ, Ten Cate OT. Analysing the concept of context in medical education. Med Educ 2005;39:1243-9.

51. Teunissen PW, Wilkinson TJ. Learning and teaching in workplaces. In: Dornan T, Mann K, Scherpbier A., Spencer J, editors. Medical Education: Theory and Practice.Edinburgh, London, New York, Oxford, Philadelphia, St Louis, Sydney, Toronto: Churchill Livingstone Elsevier; 2011. p. 193209.

52. Koens F, Ten Cate OT, Custers EJ. Context-dependent memory in a meaningful environment for medical education: in the classroom and at the bedside. Adv Health Sci Educ Theory Pract 2003;8:155-65.

53. Riley W, Davis S, Miller KM, Hansen H, Sweet RM. Detecting breaches in defensive barriers using in situ simulation for obstetric emergencies. Qual Saf Health Care 2010;19 Suppl 3:i53-i56.

54. Anderson E, Black R, Brocklehurst P. Acute obstetric emergency drill in England and Wales: a survey of practice. BJOG 2005;112:372-5.

55. Riley W, Hansen H, Gurses AP, Davis S, Miller K, Priester R. The Nature, Characteristics and Patterns of Perinatal Critical Events Teams. In: Henriksen K, Battles JB, Keyes MA, Grady ML, editors. Advances in Patient Safety: New Directions and Alternative Approaches. Vol 3 ed. Rockville (MD): Agency for Healthcare Research and Quality (US); 2008.

56. Walker ST, Sevdalis N, McKay A, Lambden S, Gautama S, Aggarwal R, Vincent C. Unannounced in situ simulations: integrating training and clinical practice. BMJ Qual Saf 2013;22:453-8.

57. Patterson MD, Geis GL, Lemaster T, Wears RL. Impact of multidisciplinary simulation-based training on patient safety in a paediatric emergency department. BMJ Qual Saf 2013;22:383-93.

58. Patterson MD, Geis GL, Falcone RA, Lemaster T, Wears RL. In situ simulation: detection of safety threats and teamwork training in a high risk emergency department. BMJ Qual Saf 2013;22:46877.

59. Sullivan NJ, Duval-Arnould J, Twilley M, Smith SP, Aksamit D, Boone-Guercio P, Jeffries PR, Hunt EA. Simulation Exercise to Improve Retention of Cardiopulmonary Resuscitation Priorities for InHospital Cardiac Arrests: A Randomized Controlled Trial. Resuscitation 2014;86C:6-13.

60. van Schaik SM, Plant J, Diane S, Tsang L, O'Sullivan P. Interprofessional team training in pediatric resuscitation: a low-cost, in situ simulation program that enhances self-efficacy among participants. Clin Pediatr (Phila) 2011;50:807-15.

61. Rubio-Gurung S, Putet G, Touzet S, Gauthier-Moulinier H, Jordan I, Beissel A, Labaune JM, Blanc S, Amamra N, Balandras C, Rudigoz RC, Colin C, Picaud JC. In situ simulation training for neonatal resuscitation: an RCT. Pediatrics 2014;134:e790-e797.

62. Guise JM, Lowe NK, Deering S, Lewis PO, O'Haire C, Irwin LK, Blaser M, Wood LS, Kanki BG. Mobile in situ obstetric emergency simulation and teamwork training to improve maternal-fetal safety in hospitals. Jt Comm J Qual Patient Saf 2010;36:443-53.

63. Hamman WR, Beaudin-Seiler BM, Beaubien JM, Gullickson AM, Gross AC, Orizondo-Korotko K, Fuqua W, Lammers R. Using in situ simulation to identify and resolve latent environmental threats to patient safety: case study involving a labor and delivery ward. J Patient Saf 2009;5:184-7.

64. Bender GJ. In situ simulation for systems testing in newly constructed perinatal facilities. Semin Perinatol 2011;35:80-3.

65. Auerbach M, Kessler D, Foltin JC. Repetitive pediatric simulation resuscitation training. Pediatr Emerg Care 2011;27:29-31.

66. Brooks-Buza H, Fernandez R, Stenger JP. The use of in situ simulation to evaluate teamwork and system organization during a pediatric dental clinic emergency. Simul Healthc 2011;6:101-8.

67. Calhoun AW, Boone MC, Peterson EB, Boland KA, Montgomery VL. Integrated in-situ simulation using redirected faculty educational time to minimize costs: a feasibility study. Simul Healthc 2011;6:337-44.

68. Chan SY, Figueroa M, Spentzas T, Powell A, Holloway R, Shah S. Prospective Assessment of Novice Learners in a Simulation-Based Extracorporeal Membrane Oxygenation (ECMO) Education Program. Pediatr Cardiol 2012.

69. Edler AA, Chen M, Honkanen A, Hackel A, Golianu B. Affordable simulation for small-scale training and assessment. Simul Healthc 2010;5:112-5. 
70. Garden AL, Mills SA, Wilson R, Watts P, Griffin JM, Gannon S, Kapoor I. In situ simulation training for paediatric cardiorespiratory arrest: initial observations and identification of latent errors. Anaesth Intensive Care 2010;38:1038-42.

71. Kobayashi L, Dunbar-Viveiros JA, Devine J, Jones MS, Overly FL, Gosbee JW, Jay GD. Pilot-Phase Findings From High-fidelity In Situ Medical Simulation Investigation of Emergency Department Procedural Sedation. Simul Healthc 2012;7:81-94.

72. Kobayashi L, Parchuri R, Gardiner FG, Paolucci GA, Tomaselli NM, Al-Rasheed RS, Bertsch KS, Devine J, Boss RM, Gibbs FJ, Goldlust E, Monti JE, O'Hearn B, Portelli DC, Siegel NA, Hemendinger $D$, Jay GD. Use of in situ simulation and human factors engineering to assess and improve emergency department clinical systems for timely telemetry-based detection of life-threatening arrhythmias. BMJ Qual Saf 2013;22:72-83.

73. Kobayashi L, Dunbar-Viveiros JA, Sheahan BA, Rezendes MH, Devine J, Cooper MR, Martin PB, Jay GD. In situ simulation comparing in-hospital first responder sudden cardiac arrest resuscitation using semiautomated defibrillators and automated external defibrillators. Simul Healthc 2010;5:82-90.

74. Kobayashi L, Shapiro MJ, Sucov A, Woolard R, Boss RM, III, Dunbar J, Sciamacco R, Karpik K, Jay G. Portable advanced medical simulation for new emergency department testing and orientation. Acad Emerg Med 2006;13:691-5.

75. Lighthall GK, Poon T, Harrison TK. Using in situ simulation to improve in-hospital cardiopulmonary resuscitation. Jt Comm J Qual Patient Saf 2010;36:209-16.

76. Mondrup F, Brabrand M, Folkestad L, Oxlund J, Wiborg KR, Sand NP, Knudsen T. In-hospital resuscitation evaluated by in situ simulation: a prospective simulation study. Scand J Trauma Resusc Emerg Med 2011;19:55.

77. Nunnink L, Welsh AM, Abbey M, Buschel C. In situ simulation-based team training for post-cardiac surgical emergency chest reopen in the intensive care unit. Anaesth Intensive Care 2009;37:74-8.

78. Preston $\mathrm{P}$, Lopez $\mathrm{C}$, Corbett $\mathrm{N}$. How to integrate findings from simulation exercises to improve obstetrics care in the institution. Semin Perinatol 2011;35:84-8.

79. Theilen U, Leonard P, Jones P, Ardill R, Weitz J, Agrawal D, Simpson D. Regular in situ simulation training of paediatric medical emergency team improves hospital response to deteriorating patients. Resuscitation 2013;84:218-22.

80. Hunt EA, Heine M, Hohenhaus SM, Luo X, Frush KS. Simulated pediatric trauma team management: assessment of an educational intervention. Pediatr Emerg Care 2007;23:796-804.

81. Barbeito A, Bonifacio A, Holtschneider M, Segall N, Schroeder R, Mark J. In situ simulated cardiac arrest exercises to detect system vulnerabilities. Simul Healthc 2015;10:154-62.

82. Surcouf JW, Chauvin SW, Ferry J, Yang T, Barkemeyer B. Enhancing residents' neonatal resuscitation competency through unannounced simulation-based training. Med Educ Online 2013;18:1-7.

83. Wetzel EA, Lang TR, Pendergrass TL, Taylor RG, Geis GL. Identification of latent safety threats using high-fidelity simulation-based training with multidisciplinary neonatology teams. Jt Comm J Qual Patient Saf 2013;39:268-73.

84. Dowson A, Russ S, Sevdalis N, Cooper M, De MC. How in situ simulation affects paediatric nurses' clinical confidence. Br J Nurs 2013;22:610-7.

85. Gardner AK, Ahmed RA, George RL, Frey JA. In situ simulation to assess workplace attitudes and effectiveness in a new facility. Simul Healthc 2013;8:351-8.

86. Atamanyuk I, Ghez O, Saeed I, Lane M, Hall J, Jackson T, Desai A, Burmester M. Impact of an openchest extracorporeal membrane oxygenation model for in situ simulated team training: a pilot study. Interact Cardiovasc Thorac Surg 2014;18:17-20.

87. Ventre KM, Barry JS, Davis D, Baiamonte VL, Wentworth AC, Pietras M, Coughlin L, Barley G. Using in situ simulation to evaluate operational readiness of a children's hospital-based obstetrics unit. Simul Healthc 2014;9:102-11.

88. Shapiro FE, Pawlowski JB, Rosenberg NM, Liu X, Feinstein DM, Urman RD. The use of in-situ simulation to improve safety in the plastic surgery office: a feasibility study. Eplasty 2014;14:e2.

89. Klipfel JM, Carolan BJ, Brytowski N, Mitchell CA, Gettman MT, Jacobson TM. Patient safety improvement through in situ simulation interdisciplinary team training. Urol Nurs 2014;34:39-46. 
90. Marshall NE, Vanderhoeven J, Eden KB, Segel SY, Guise JM. Impact of simulation and team training on postpartum hemorrhage management in non-academic centers. J Matern Fetal Neonatal Med 2015;28:495-9.

91. Katznelson JH, Mills WA, Forsythe CS, Shaikh S, Tolleson-Rinehart S. Project CAPE: a high-fidelity, in situ simulation program to increase Critical Access Hospital Emergency Department provider comfort with seriously ill pediatric patients. Pediatr Emerg Care 2014;30:397-402.

92. Gundrosen S, Solligard E, Aadahl P. Team competence among nurses in an intensive care unit: the feasibility of in situ simulation and assessing non-technical skills. Intensive Crit Care Nurs 2014;30:312-7.

93. Calhoun AW, Boone MC, Dauer AK, Campbell DR, Montgomery VL. Using simulation to investigate the impact of hours worked on task performance in an intensive care unit. Am J Crit Care 2014;23:387-95.

94. Lois FJ, Pospiech AL, Van Dyck MJ, Kahn DA, De Kock MF. Is the "in situ" simulation for teaching anesthesia residents a lower cost, feasible and satisfying alternative to simulation center ? A 24 months prospective observational study in a university hospital. Acta Anaesthesiol Belg 2014;65:61-71.

95. Braddock CH, III, Szaflarski N, Forsey L, Abel L, Hernandez-Boussard T, Morton J. The TRANSFORM Patient Safety Project: a microsystem approach to improving outcomes on inpatient units. J Gen Intern Med 2015;30:425-33.

96. Sweeney J, Maietta R, Olson K. An analysis comparing "Sim Huddles" to traditional simulation for obstetric emergency preparedness. Nurs Womens Health 2015;19:16-25.

97. Couto TB, Kerrey BT, Taylor RG, FitzGerald M, Geis GL. Teamwork Skills in Actual, In Situ, and InCenter Pediatric Emergencies: Performance Levels Across Settings and Perceptions of Comparative Educational Impact. Simul Healthc 2015;10:76-84.

98. Siegel NA, Kobayashi L, Dunbar-Viveiros JA, Devine J, Al-Rasheed RS, Gardiner FG, Olsson K, Lai S, Jones MS, Dannecker M, Overly FL, Gosbee JW, Portelli DC, Jay GD. In situ medical simulation investigation of emergency department procedural sedation with randomized trial of experimental bedside clinical process guidance intervention. Simul Healthc 2015;10:146-53.

99. Kessler DO, Walsh B, Whitfill T, Gangadharan S, Gawel M, Brown L, Auerbach M. Disparities in Adherence to Pediatric Sepsis Guidelines across a Spectrum of Emergency Departments: A Multicenter, Cross-sectional Observational In Situ Simulation Study. J Emerg Med 2015;doi: 10.1016/j.jemermed.2015.08.004. [Epub ahead of print].

100. Amiel I, Simon D, Merin O, Ziv A. Mobile in Situ Simulation as a Tool for Evaluation and Improvement of Trauma Treatment in the Emergency Department. J Surg Educ 2015;doi: 10.1016/j.jsurg.2015.08.013. [Epub ahead of print].

101. Guise JM, Mladenovic J. In situ simulation: identification of systems issues. Semin Perinatol 2013;37:161-5.

102. Minai F, Shafiq F, UI Haq MI. Value of real life (in situ) simulation training for tracheal intubation skills in medical undergraduates during short duration anesthesia rotation. J Anaesthesiol Clin Pharmacol 2014;30:484-7.

103. Fraenkal JR, Wallen NE, Hyun H.H. Variable and Hypothesis. In: Fraenkal JR, Wallen NE, Hyun H.H, editors. How to Design and Evaluate Research in Education. Eight ed. New York: McGraw-Hill; 2012. p. 75-89.

104. Kirkpatrick DL., kirkpatrick JD. Evaluating Training Programs: The Four Levels. 3rd ed. San Francisco, CA: Berrett-Koehler Publishers; 2006.

105. Morrison J. ABC of learning and teaching in medicine: Evaluation. BMJ 2003;326:385-7.

106. LeBlanc VR. The effects of acute stress on performance: implications for health professions education. Acad Med 2009;84:S25-S33.

107. LeBlanc VR, Manser T, Weinger MB, Musson D, Kutzin J, Howard SK. The study of factors affecting human and systems performance in healthcare using simulation. Simul Healthc 2011;6 Suppl:S24S29.

108. Arora S, Sevdalis N, Aggarwal R, Sirimanna P, Darzi A, Kneebone R. Stress impairs psychomotor performance in novice laparoscopic surgeons. Surg Endosc 2010;24:2588-93.

109. Harvey A, Nathens AB, Bandiera G, LeBlanc VR. Threat and challenge: cognitive appraisal and stress responses in simulated trauma resuscitations. Med Educ 2010;44:587-94. 
110. Harvey A, Bandiera G, Nathens AB, LeBlanc VR. Impact of stress on resident performance in simulated trauma scenarios. J Trauma Acute Care Surg 2012;72:497-503.

111. Finan E, Bismilla Z, Whyte HE, Leblanc V, McNamara PJ. High-fidelity simulator technology may not be superior to traditional low-fidelity equipment for neonatal resuscitation training. J Perinatol 2012;32:287-92.

112. Kusurkar RA, Ten Cate TJ, van AM, Croiset G. Motivation as an independent and a dependent variable in medical education: a review of the literature. Med Teach 2011;33:e242-e262.

113. Ten Cate TJ, Kusurkar RA, Williams GC. How self-determination theory can assist our understanding of the teaching and learning processes in medical education. AMEE guide No. 59. Med Teach 2011;33:961-73.

114. Ryan RM, Deci EL. Intrinsic and Extrinsic Motivations: Classic Definitions and New Directions. Contemp Educ Psychol 2000;25:54-67.

115. Schwendimann R, Zimmermann N, Kung K, Ausserhofer D, Sexton B. Variation in safety culture dimensions within and between US and Swiss Hospital Units: an exploratory study. BMJ Qual Saf 2013;22:32-41.

116. Sexton JB, Helmreich RL, Neilands TB, Rowan K, Vella K, Boyden J, Roberts PR, Thomas EJ. The Safety Attitudes Questionnaire: psychometric properties, benchmarking data, and emerging research. BMC Health Serv Res 2006;6:44.

117. Sexton JB, Berenholtz SM, Goeschel CA, Watson SR, Holzmueller CG, Thompson DA, Hyzy RC, Marsteller JA, Schumacher K, Pronovost PJ. Assessing and improving safety climate in a large cohort of intensive care units. Crit Care Med 2011;39:934-9.

118. Deilkas ET, Hofoss D. Psychometric properties of the Norwegian version of the Safety Attitudes Questionnaire (SAQ), Generic version (Short Form 2006). BMC Health Serv Res 2008;8:191.

119. Kristensen S, Sabroe S, Bartels P, Mainz J, Christensen KB. Adaption and validation of the Safety Attitudes Questionnaire for the Danish hospital setting. Clin Epidemiol 2015;7:149-60.

120. Cooper S, Cant R, Porter J, Sellick K, Somers G, Kinsman L, Nestel D. Rating medical emergency teamwork performance: development of the Team Emergency Assessment Measure (TEAM). Resuscitation 2010;81:446-52.

121. McKay A, Walker ST, Brett SJ, Vincent C, Sevdalis N. Team performance in resuscitation teams: comparison and critique of two recently developed scoring tools. Resuscitation 2012;83:1478-83. 


\section{CHAPTER 2}

\section{The implementation and evaluation of a mandatory multi-professional obstetric skills training program}

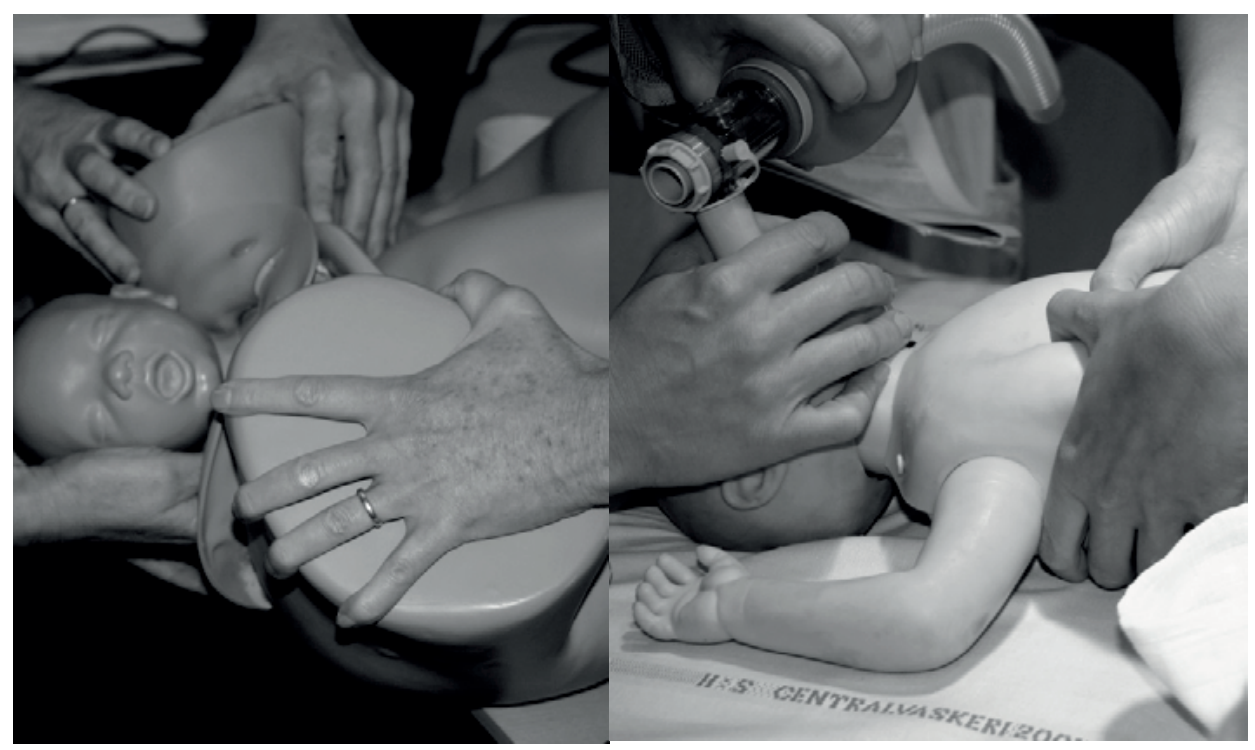

Jette Led Sørensen, Ellen Løkkegaard, Marianne Johansen, Charlotte Ringsted, Svend Kreiner, Sean McAleer.

Published in Acta Obstet Gynecol Scand 2009;88:1107-17. 


\begin{abstract}
Objective: To implement and evaluate a simulation-based training program.

Design: Descriptive. Study period: June 2003 - June 2006. Setting: Obstetric Department, Copenhagen University Hospital, Rigshospitalet, Copenhagen, Denmark. Population: Two training sessions were provided for all health professionals including doctors, midwives, auxiliary nurses, and 147 out 156 participants (94\%) took part in the first training session and 192 out possible 201 (96\%) took part in the second session.

Methods: An intervention study of the impact of simulation-based training in management of postpartum bleeding, shoulder dystocia, basic neonatal resuscitation, and severe preeclampsia.

Main outcome measures: Before, just after and 9-15 months following the training, data were collected on the confidence and stress levels relating to the carrying out of certain procedures. In addition, a written objective test on basic neonatal resuscitation was administered. Data on any changes in work-routines experienced by the participants were obtained by open-ended questions. Registry data from the Danish Medical Birth Registry and from the hospital administration were included in the analysis.

Results: Ninety-two percent of all respondents had a positive attitude toward the training program. They considered management of shoulder dystocia, preeclampsia, and neonatal resuscitation less stressful and less unpleasant to perform after training. Confidence scores for all the trained skills improved significantly. A significant association was found between confidence in neonatal resuscitation and numbers of correct answers in the objective test. More than $90 \%$ found the training to have had a positive influence on their work. The need for organizational changes in the department became evident and necessary changes were implemented. Sick leave amongst midwives diminished significantly during the study period.

Conclusions: A comprehensive evaluation of a mandatory simulation-based program, implemented in a obstetric department, demonstrated a positive impact at individual and organizational levels.
\end{abstract}

Key words: Patient simulation, clinical competence, performance assessment, skills training, education, obstetrics, labor. 


\section{Introduction}

Labor wards have a dual function in creating a relaxed atmosphere for normal childbirth and dealing with life-threatening emergencies. This makes them a challenging work place. It is a prerequisite that labor ward staff has knowledge, skills, and competence in clinical problem solving, communication, and cooperation with both the delivering women, their relatives, and all the different health professionals involved [1-4].

The working conditions in the labor ward may have an influence on the staff's wellbeing and competencies. As a profession, midwives are described to be likely to suffer from burn out [5], and they have limited access to training and knowledge updating [6]. The frequency of sick leave among midwives was for several years antedating the present study among the highest compared to other staff group in the Copenhagen University Hospital, Rigshospitalet.

Previous research on obstetric training has been sparse. A review [7] concluded that 'few programs have been described and even fewer have been evaluated. Training methods need to be developed, described, and evaluated; further well-conducted research for this important intervention is urgently required'. It has been stressed that other specialties are ahead of obstetrics in the use of simulation [2,8]. It is argued [2] that 'those of us involved in training must think creatively' and that there is a need for new training methods with more emphasis on team training. In a British study, a mandatory annual course for all labor ward staff was shown to be associated with clinical importance and sustained improvement in perinatal outcome [9]. That observational study from 2006 was followed by a randomized study in obstetric simulation [10,11], where no additional benefit from training in a simulation center compared with training in local hospitals was found. Thus, it is important to address the questions about training in simulation centers versus training in local hospitals in obstetrics [12].

The present study describes the implementation and evaluation of a mandatory multiprofessional simulation-based training program in a local hospital.

\section{Material and methods}

The evaluation in this study design was based on Kirkpatricks four levels of evaluation $[13,14]$ : (1) Reaction-level which measures the participants' satisfaction with the training program, (2) Learning-level comprising of the extent to which a training program has changed the participants' attitudes, affected their knowledge, and/or increased their skills, (3) Behavior-level which indicates the transfer of learning from an educational setting to real life, and (4) Results-level which looks at the impact on the organization and patient outcome as a consequence of the training program.

The study was undertaken at an obstetric department that had between 3,285 and 3,686 deliveries during the years 2003-2006, with approximately one-third being highrisk referrals. The study period was June 2003-June 2006. A total of 220 staff members 
(49 doctors, 105 midwives, 24 auxiliary nurses, and 42 nurses) were employed in the department during the training period.

Two training periods were undertaken consecutively. Details for the organization and the structure of the obstetric skills training program is shown in Figure 1. Each training session had 12 participants and was scheduled for two-and-a-half hours. It included a lecture followed by multi-professional training workshops with six participants in each workshop. Training material was developed by the local steering committee. A hierarchical task analysis was used, i.e. a task is broken down into a series of subtasks, as it is well suited to the development of training material and can be used to identify training needs, specify training objectives and elaborating training contents. It provides a logical rather than a psychological analysis of a task $[15,16]$.

All the obstetric training scenarios were conducted in various rooms near the labor ward and not in a skills center. The training scenarios included simulated environments such as a delivery or a baby mannequin combined with relevant equipment, such as drips, medicines, catheters, and suction devices.

The training program was mandatory for all staff and was planned either during normal working hours or if outside normal working hours, the participants were paid extra per hour. All costs were covered by the departmental budget.

The main outcome measures were related to Kirkpatricks four level approach, and data for the analysis was collected before, immediately after and 9-15 months following the training. Most of the questionnaires used closed questions, with responses marked on a 5-point Likert scale as follows:

Kirkpatricks level 1 (Reaction): Measurement of the reaction of the participants toward the training program was obtained by questionnaires focusing on issues such as participants' opinion and percep- tion of relevance of the training program.

Kirkpatricks level 2 (Learning): The value of participants learning was measured by participants self-assessed confidence (rated on a 5-point Likert scale from not confident=1 to fully confident $=5$ ) in performing specified procedures and self-assessed statements on whether clinical events were considered stressful and unpleasant (rated on a 5-point Likert scale from strongly disagree $=1$ to strongly agree $=5$ ). In addition, a written test of knowledge of skills (KOS) regarding basic neonatal resuscitation was undertaken. The KOS-test was composed of 7-8 short cases based on clinical scenarios (2-4 lines) followed by 3-6 questions with a yes/no/do not know response format. The test was administered pre- and twice post-training. The KOS test was chosen over an objective skills tests, as it could test many participants in a relatively short time and at low costs [17] and furthermore because it is reported to predict results in performance-based tests [17]. The KOS-test was not developed as an instrument for individual testing, but was chosen to test variations in different staff groups over a period of time [18]. 
Kirkpatricks level 3 (Behavior): Data on behavior were collected by a questionnaire with semi-structured, open-ended questions to obtain information on how work routines were influenced by the training on the individual level.

Kirkpatricks level 4 (Results): Data were collected following each training session about the need for changes in working procedures at the organizational level. Data from the Danish Medical Birth Registry were obtained to give information on changes in the diagnosis. Data were obtained from Hospital Administration about midwives' sick leave. Sick leave was measured as number of hours sick leave over hours of work per year.

An application for approval was filed to the Danish National Committee on Biomedical Research Ethics (number 16752). However, since the study did not involve patients, no approval was needed.

Each participant was given a project number, which was only known to the main author. The participants were ensured that during analysis and reporting, data would be treated as non-traceable information.

\section{Statistical analysis}

Quantitative data were analyzed using the Statistical Package for Social Sciences and SCD/DIGRAM [19]. Log-linear chain graph models were used to analyze the correlations among responses to the questions. Most of the responses were measured on an ordinal 5-point rating scale, a Likert-like scale, by partial gamma coefficients, or partial rank correlations. The questions on whether or not attitudes and experiences in relation to the work had been influenced by training were tested by marginal and conditional homogeneity. The significance of the $p$-values was assessed, taking the association between the repeated measurements into account. The objective test by 'knowledge of skills tests' was analyzed by pairwise t-tests. Data from the Danish Medical Birth Registry were analyzed with odds ratios and 95\% confidence intervals. Data from hospital statistics were analyzed with a chi-squared test for trend. The qualitative data consisted of open-ended questions, which were analyzed by two investigators, i.e. the first author (JLS) and a person with no connection to the course and study. The two investigators together developed categories in order to quantify and condense the results for analysis. 
Figure 2.1 Flowchart of the obstetric skills training program over two training periods.
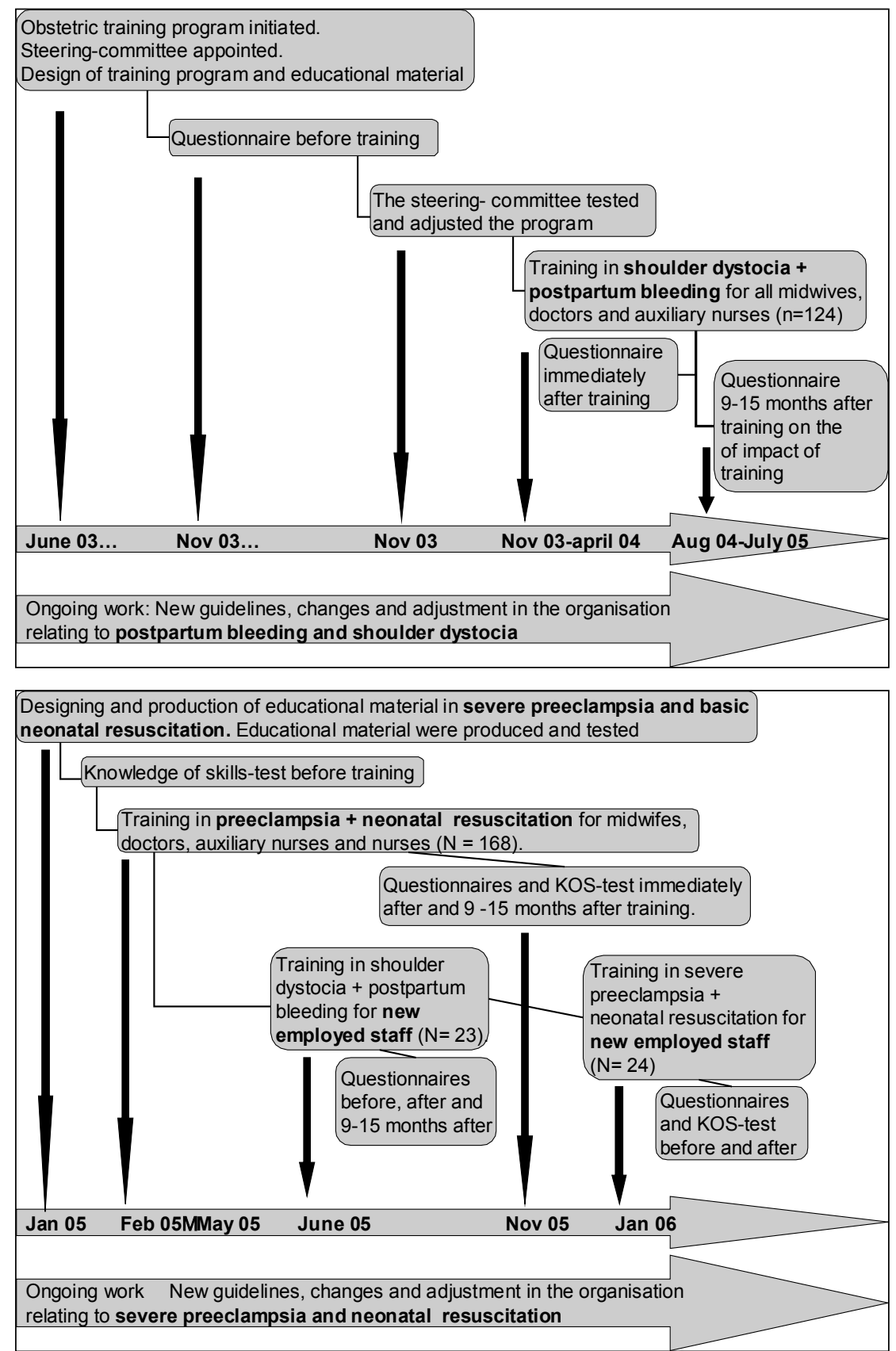


\section{Results}

As regards management of shoulder dystocia and postpartum bleeding, 94\% (147/156) of eligible staff participated and in training on the management of preeclampsia and neonatal resuscitation, 96\% (192/201) participated (Tables 2.1 and 2.2). Thirty training sessions were conducted.

Response rates (Tables 2.1 and 2.2) to the questionnaires before training varied from 88 to $98 \%$ between the different health professional groups. Immediately after training, the questionnaire response rate within the different health professional groups was 89$100 \%$ and $70-100 \%$ for the questionnaires delivered 9-15 months after training.

Response rates to the KOS-test in neonatal resuscitation before and immediately after training were $98 \%$ (190/192). For late testing, only 168 staff members were eligible (24 staff members were included too late for the late post-testing to occur). The late response rate was $76 \%(128 / 168)$.

The participants who were eligible for training, but did not manage to attend the training, did not differ from the participants involved in the training. Non-responders of the questionnaires did not differ concerning years of obstetric work experiences, selfassessed confidence, and numbers of correct answers in the first KOS-test.

\section{Kirkpatrick level 1: reaction}

Of the participants, 92-98\% agreed or strongly agreed that each of the four training programs were good, and more than $80-92 \%$ agreed or strongly agreed that they considered the training relevant for their clinical work. The majority (85-95\%) of all staff considered the multi-professional organization of the training program to be good or very good.

\section{Kirkpatrick level 2: learning}

Confidence scores for all the trained skills improved significantly when measured 9-15 months following training (Table 2.1). Scores for confidence in management of postpartum bleeding did not improve immediately after training, but significantly when measured 9-15 months following training. An analysis of how confidence was retained revealed that for management of shoulder dystocia and severe preeclampsia, no significant reduction in the level of confidence was found when early post-testing was compared with late post-testing 9-15 months following training. However, for neonatal resuscitation, there was a significant reduction in confidence $(p<0.001)$ from early post-testing compared with late post-testing. A greater increase in the score for high self-assessment in confidence amongst the trainee doctors, auxiliary nurses, midwives, and nurses was found and less so amongst specialized doctors and specialized midwives (data not shown). Self-assessment of confidence (scores 4 and 5) in management of shoulder dystocia was significantly increased for trainee doctors with a rise from 15 to $50 \%$, for specialized midwives from 89 to $100 \%$ and for midwives from 22 to $56 \%$. Self- 
assessment of confidence (score $4+5$ ) with clinical management of postpartum bleeding increased significantly for trainee doctors from 48 to $100 \%$ and for auxiliary nurses from 22 to $50 \%$. In the management of severe preeclampsia, the increase was significant for trainee doctors from 33 to $43 \%$. For management of basic neonatal resuscitation, the increase was significant for trainee doctors from 20 to $36 \%$, for midwives from 24 to $53 \%$, and for nurses from 13 to $21 \%$.

Management of shoulder dystocia, severe preeclampsia, and neonatal resuscitation was considered stressful and unpleasent to perform before training, but the level of discomfort was significantly less following training for all health professional groups (Table 2.2). In comparison, no difference was found for management of postpartum bleeding. Data on how the different health professional groups experienced the different skills in terms of being stressful and unpleasant showed for the auxiliary nurses, the trainee doctors, the midwives, and the nurses, a reduction in how stressful and unpleasant a skill was perceived. Less or no reductions were found for the specialized doctors and the specialized midwifes (data not shown).

For midwives, all trained skills except for management of postpartum bleeding were scored significantly less stressful and less unpleasent to perform 9-15 months following training.

Nurses were only trained in management of severe preclampsia and basic neonatal resuscitation. For both skills the nurses 9-15 months following training scored significantly lower in how stressful and unpleasant they considered performance of the skills.

KOS-test

The number of correct answers in the KOS-test in basic neonatal resuscitation increased significantly $(p<0.001)$ from $65 \%$ before training to $94 \%$ at early post-testing. There was a significant reduction $(p<0.001)$ in numbers of correct answers at the time of early post-testing compared with the late post-test results. However, at the time of late post-testing, it was still significantly higher $(p<0.001)$ than at the time of pretesting. 
Table 2.1 Self assessment of confidence before, just after and 9-15 months following training in the management of four obstetric emergency skills. The replies were rated on a five point Likert scale from not confident $=1$ to fully confident $=5$

\begin{tabular}{|c|c|c|c|c|c|c|c|c|c|c|c|c|c|c|c|c|c|c|c|c|c|c|c|c|}
\hline $\begin{array}{l}\text { Trained obstetric } \\
\text { emergency }\end{array}$ & \multicolumn{6}{|c|}{ Management of shoulder dystocia } & \multicolumn{6}{|c|}{ Management of postpartum bleeding } & \multicolumn{6}{|c|}{ Management of severe preeclampsia } & \multicolumn{6}{|c|}{ Basic neonatal resuscitation } \\
\hline $\begin{array}{l}\text { Eligible for } \\
\text { training }\end{array}$ & \multicolumn{6}{|c|}{$156^{a}$} & \multicolumn{6}{|c|}{$1566^{a}$} & \multicolumn{6}{|c|}{$201 \mathrm{a}$} & \multicolumn{6}{|c|}{201 a } \\
\hline Participated & \multicolumn{6}{|c|}{147} & \multicolumn{6}{|c|}{147} & \multicolumn{6}{|c|}{192} & \multicolumn{6}{|c|}{192} \\
\hline Questionnaires & \multicolumn{2}{|c|}{$\begin{array}{l}\text { Before } \\
\text { training }\end{array}$} & \multicolumn{2}{|c|}{$\begin{array}{l}\text { After } \\
\text { training }\end{array}$} & \multicolumn{2}{|c|}{$\begin{array}{l}9-15 \\
\text { months } \\
\text { after }\end{array}$} & \multicolumn{2}{|c|}{$\begin{array}{l}\text { Before } \\
\text { training }\end{array}$} & \multicolumn{2}{|c|}{$\begin{array}{l}\text { After } \\
\text { training }\end{array}$} & \multicolumn{2}{|c|}{$\begin{array}{l}9-15 \\
\text { months } \\
\text { after }\end{array}$} & \multicolumn{2}{|c|}{$\begin{array}{l}\text { Before } \\
\text { training }\end{array}$} & \multicolumn{2}{|c|}{$\begin{array}{l}\text { After } \\
\text { training }\end{array}$} & \multicolumn{2}{|c|}{$\begin{array}{l}9-15 \\
\text { months } \\
\text { after }\end{array}$} & \multicolumn{2}{|c|}{$\begin{array}{l}\text { Before } \\
\text { training }\end{array}$} & \multicolumn{2}{|c|}{$\begin{array}{l}\text { After } \\
\text { training }\end{array}$} & \multicolumn{2}{|c|}{$\begin{array}{l}9-15 \\
\text { months } \\
\text { after }\end{array}$} \\
\hline $\begin{array}{l}\text { Total } \\
\text { respondents }\end{array}$ & $158^{b}$ & $100 \%$ & 139 & $100 \%$ & 127 & $100 \%$ & $165^{b}$ & $100 \%$ & 139 & $100 \%$ & 129 & $100 \%$ & $199^{b}$ & $100 \%$ & 187 & $100 \%$ & 141 & $100 \%$ & $201^{b}$ & $100 \%$ & 188 & $100 \%$ & 140 & $100 \%$ \\
\hline Not confident 1 & 20 & 13 & 1 & 1 & 2 & 2 & 6 & 4 & 1 & 1 & 0 & 0 & 19 & 10 & 2 & 1 & 4 & 3 & 46 & 23 & 0 & 0 & 2 & 3 \\
\hline Confidence 2 & 30 & 19 & 7 & 5 & 6 & 5 & 9 & 6 & 6 & 4 & 0 & 0 & 38 & 19 & 8 & 4 & 12 & 9 & 35 & 17 & 4 & 2 & 15 & 11 \\
\hline Confidence 3 & 50 & 32 & 35 & 25 & 34 & 29 & 46 & 28 & 30 & 22 & 24 & 19 & 63 & 32 & 66 & 35 & 47 & 33 & 66 & 33 & 40 & 21 & 53 & 38 \\
\hline Confidence 4 & 48 & 30 & 86 & 62 & 75 & 59 & 66 & 40 & 78 & 56 & 78 & 60 & 55 & 28 & 99 & 52 & 64 & 45 & 34 & 17 & 123 & 65 & 60 & 43 \\
\hline Fully confident 5 & 10 & 6 & 10 & 7 & 10 & 8 & 38 & 23 & 24 & 17 & 27 & 21 & 24 & 12 & 12 & 6 & 14 & 10 & 20 & 10 & 21 & 11 & 8 & 6 \\
\hline Not eligible $^{\mathrm{c}}$ & & & & & & & & & & & & & & & & & 24 & & & & & & 24 & \\
\hline $\begin{array}{l}\text { No answer or } \\
\text { don't know }\end{array}$ & & & 8 & & 20 & & & & 8 & & 18 & & & & 5 & & 27 & & & & 5 & & 27 & \\
\hline$p_{\text {-value }}{ }^{d}$ & & & $<0$ & $001^{d}$ & & & & & & $07^{d}$ & & & & & $<0$. & $001^{d}$ & & & & & 0.0 & $01^{d}$ & & \\
\hline Gamma $\gamma^{\mathrm{e}}$ & & & & $35^{\mathrm{e}}$ & & & & & & $75^{e}$ & & & & & & $19 \mathrm{e}$ & & & & & & $51 \mathrm{e}$ & & \\
\hline
\end{tabular}

Nurses: only training in management of preeclampsia and basic neonatal resuscitation

Not all staff that answered the first questionnaire was eligible for the training as they left the department.

Some were included late in the training period and not eligible for 9-15 month questionnaire and test.

d. Paired test for conditional and marginal homogeneity. Data before training are compared with data 9-15 month following training.

e. Partial gamma coefficients are calculated in different strata of a multidimensional contingency table. A high gamma $(\gamma>0.30)$ indicates high correlation between variables, and a low $(\gamma<0.15)$ little or no correlation. 
Table 2.2 Questionnaire to whether management of obstetric emergencies were considered stressful and unpleasant before and 9-15 months following training. The replies were rated on a 5 point Likert scale from strongly disagree $=1$ to strongly agree $=5$.

\begin{tabular}{|c|c|c|c|c|c|c|c|c|c|c|c|c|c|c|c|c|}
\hline $\begin{array}{l}\text { Trained obstetric emer- } \\
\text { gency }\end{array}$ & \multicolumn{4}{|c|}{ Management of shoulder dystocia } & \multicolumn{4}{|c|}{ Management of postpartum bleeding } & \multicolumn{4}{|c|}{$\begin{array}{c}\text { Management of severe preeclampsia and } \\
\text { eclampsia }\end{array}$} & \multicolumn{4}{|c|}{ Basic neonatal resuscitation } \\
\hline Eligible in training & \multicolumn{2}{|c|}{$156^{\mathrm{a}}$} & & & \multicolumn{4}{|c|}{$156^{\mathrm{a}}$} & \multicolumn{4}{|c|}{$201^{a}$} & \multicolumn{4}{|c|}{$201^{a}$} \\
\hline Participated & \multicolumn{2}{|c|}{147} & & & \multicolumn{2}{|c|}{147} & & & \multicolumn{2}{|c|}{192} & & & \multicolumn{2}{|c|}{192} & & \\
\hline Questionnaires & \multicolumn{2}{|c|}{ Before training } & \multicolumn{2}{|c|}{$\begin{array}{l}9-15 \text { months after } \\
\text { training }\end{array}$} & \multicolumn{2}{|c|}{ Before training } & \multicolumn{2}{|c|}{$\begin{array}{l}9-15 \text { months after } \\
\text { training }\end{array}$} & \multicolumn{2}{|c|}{ Before training } & \multicolumn{2}{|c|}{$\begin{array}{l}9-15 \text { months after } \\
\text { training }\end{array}$} & \multicolumn{2}{|c|}{$\begin{array}{l}\text { Before } \\
\text { training }\end{array}$} & \multicolumn{2}{|c|}{$\begin{array}{l}9-15 \text { months after } \\
\text { training }\end{array}$} \\
\hline Total respondents (\%) & $155^{b}$ & $100 \%$ & 126 & $100 \%$ & $161^{\mathrm{b}}$ & $100 \%$ & 128 & $100 \%$ & $194^{b}$ & 100 & 141 & $100 \%$ & 192 & 100 & 139 & $100 \%$ \\
\hline Strongly disagree & 12 & 8 & 14 & 11 & 23 & 14 & 22 & 17 & 16 & 8 & 21 & 15 & 16 & 8 & 6 & 4 \\
\hline Disagree & 49 & 32 & 50 & 40 & 87 & 54 & 71 & 56 & 71 & 37 & 73 & 52 & 71 & 37 & 49 & 35 \\
\hline Uncertainty & 29 & 19 & 27 & 21 & 23 & 14 & 18 & 14 & 49 & 25 & 27 & 19 & 49 & 25 & 44 & 31 \\
\hline Agree & 50 & 33 & 30 & 24 & 24 & 15 & 14 & 11 & 45 & 23 & 16 & 11 & 45 & 23 & 34 & 24 \\
\hline Strongly agree & 15 & 10 & 5 & 4 & 4 & 2 & 3 & 2 & 13 & 7 & 4 & 3 & 13 & 7 & 7 & 5 \\
\hline Not eligible $^{b}$ & & & & & & & & & & & 24 & & & & 24 & \\
\hline No answer or don't know & & & 21 & & & & 21 & & & & 23 & & & & 23 & \\
\hline Don't know & & & 0 & & & & 0 & & & & 4 & & & & 5 & \\
\hline$p^{c}$ & & & $.003^{c}$ & & & & $24^{c}$ & & & & $01^{c}$ & & & & $0.001^{c}$ & \\
\hline Gamma $\gamma^{d}$ & & & $.52^{d}$ & & & & $29^{d}$ & & & & & & & & $0.41^{d}$ & \\
\hline
\end{tabular}

a. Nurses: only training in management of preeclampsia and basic neonatal resuscitation

b. Not all staff that answered the first questionnaire was eligible for the training as they left the department.

c. Some were included late in the training period and not eligible for 9-15 month questionnaire and test.

d. Paired test for conditional and marginal homogeneity. Data before training are compared with data 9-15 month following training.

e. Partial gamma coefficients are calculated in different strata of a multidimensional contingency table. A high gamma $(\gamma>0.30)$ indicates high correlation between variables, and a low $\gamma<0.15)$ little or no correlation. Nurses: only training in management of preeclampsia and basic neonatal resuscitation 
The lowest average numbers of correct answers before training were found among auxiliary nurses (50\%) and nurses (52\%), whereas the average of correct answers before training were $70 \%$ for midwives, $75 \%$ for specialized midwives, $68 \%$ for trainee doctors, and $72 \%$ for specialized doctors. At the time of early post-testing, numbers of correct answers were 88-96\%, with lowest numbers for auxiliary nurses and highest score among trainee doctors. Figure 2.2 shows a significant association between high confidence score before training and increasing numbers of correct answers in the KOStest. The association between years of clinical work in obstetrics and the numbers of correct answers in the KOS-test can be seen in Figure 2.3. The partial gamma coefficient was 0.04 , which indicated no correlation.

Kirkpatrick level 3: behaviour

The open-ended questions 9-15 months following the obstetric skills training in shoulder dystocia and postpartum bleeding showed that $89 \%$ of midwives (74/83), $94 \%$ $(15 / 16)$ of auxiliary nurses, and $70 \%(23 / 33)$ of the doctors reported that training had a positive influence on their work.

Work-influence category results were as follows: 'feeling of confidence, safety and security'=36-40\%, 'coordination of management, better multi-professional effort, staff taking responsibility'=26-27\%, and 'changes in clinical management' $=23-24 \%$.

Kirkpatrick level 4: results

Table 2.3 shows information obtained from the steering committee after every training session on the need for changes at the organizational level. These suggestions, along with considerations on implementation, were discussed in the steering committee and with the management team of the Obstetric Department and actions were taken.

\section{Prevalence of obstetric emergencies}

During the study period a significant increase $(p<0.001)$ of $42 \%$ in frequency of the ICD-code for postpartum bleeding was found. In 2002-2003, the ICD-code for postpartum bleeding was used in $3.4 \%(215 / 6.356)$ of the deliveries compared with $4.7 \%$ $(309 / 6.506)$ of the deliveries in 2004-2005 (OR=1.42; 95\% confidence interval 1.191.70). Nationally, a significant increase in the use of this ICD code also was observed (OR=1.07; 95\% confidence interval 1.03-1.12).

The administration of uterotonics was significantly increased at $24 \%$ during the study period and was given to $4.5 \%$ (287/6.356) in $2002 / 2003$ compared to $5.6 \%(365 / 6.506)$ in $2004 / 2005$ (OR=1.24; $95 \%$ confidence interval $1.07-1.42)$. Nationally this prevalence was unaltered with an $\mathrm{OR}=0.9 ; 95 \%$ confidence interval 0.87-0.92. 
Figure 2.2 The association between self assessed confidence and numbers of correct answers in KOS-test in basic neonatal resuscitation according to health professional group.

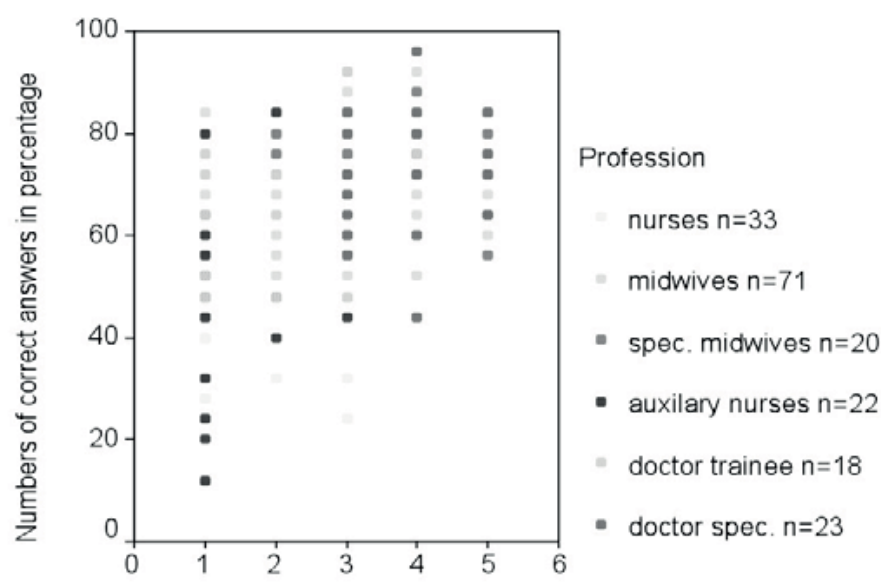

Self assessed confidence $1=$ not confident; 5 = fully confident

Statistical analysis: Partial gamma coefficients showed association between self-assessment score in confidence and number of correct answers in the KOS-test in neonatal resuscitation $(\gamma=0.44)$.

A significant association was seen between self-assessment and the numbers of correct answers in the KOS-test in neonatal resuscitation ( $p<0.001$, Test of marginal and conditional homogeneity).

Figure 2.3 The association between years of obstetrical work experience and correct answers in the KOS-test in neonatal resuscitation according to health professional group. .

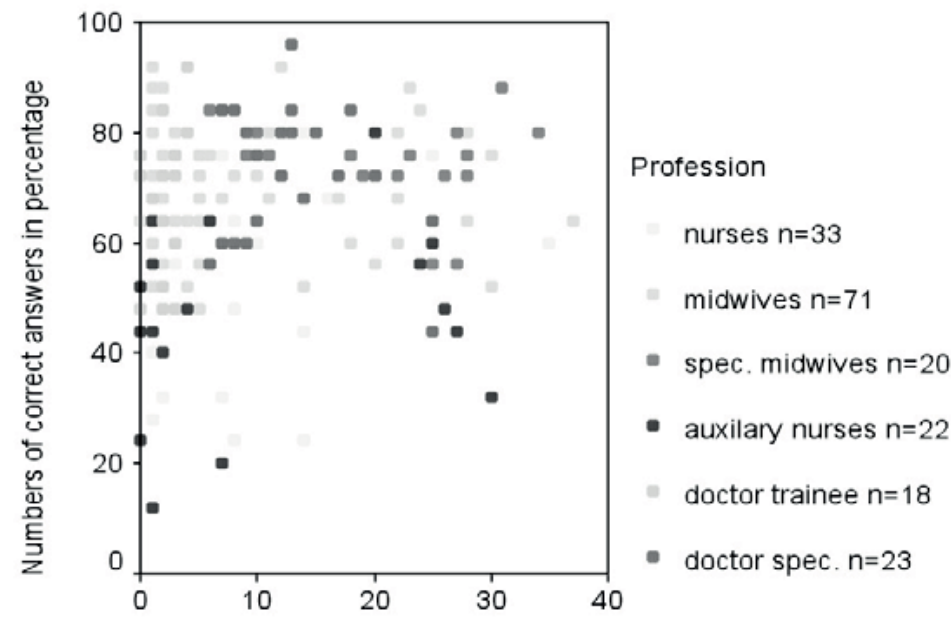

Years with obstetric work experience

Statistical analysis: Partial gamma coefficients showed no association between self-assessment score and number of correct answers in the KOS-test in neonatal resuscitation $(\gamma=0.04$ and no statistical significance $p=0.286)$. No further statistical analysis was performed. 


\section{Sick leave among midwives}

Midwives sick leave dropped significantly $(p=0.002)$ from $8 \%(7.017 / 87.712)$ in 2000 to $2.9 \%(2.449 / 85.500)$ in 2006 .

Table 2.3 Changes after implementation of the obstetric training program.

- Clinical guidelines in postpartum bleeding, shoulder dystocia and preeclampsia were composed or updated.

- An algorithm for basic neonatal resuscitation was designed in accordance with international guidelines. This was done in cooperation with the Department of Anesthesia and the Department of Neonatology.

- Highlights were extracted from guidelines and laminated action cards were designed and placed on open shelves in every labor ward suite.

- $\quad$ Filled in forms to order blood tests were made in a laminated form with information on which blood tests to order in emergency cases. These forms were placed on open shelves in every labor ward suite.

- A new observation form chart form was designed. It was developed in an attempt to achieve the loss of observations that seemed to happen on transfer between the labor ward and the postnatal ward.

- 'Bleeding boxes' and 'Preeclampsia boxes' with the most important medications were made. These boxes were placed in the labor ward, operating theatre and the postnatal ward.

- For neonatal resuscitation new self-expanding bags and masks were introduced. They were considered to be safer and more applicable for staff members who rarely use it.

- New clocks were placed over the delivery bed in every labor suite to ensure and make time taking easier.

- A condensed version of the teaching materials used during the training sessions were laminated and placed in folders in the labor ward easily accessible to all labor ward staff members.

- The cupboards in all the labor ward suites were organized according to the same standard.

\section{Discussion}

An evaluation of the present mandatory simulation-based training program in a large obstetric department demonstrated a positive impact on the participant's satisfaction with the program, aspects of gaining in learning, and changes in work routines. At the same time an impact on the organizational level was found with changes in guidelines and equipment in the labor ward, reduced sick leave among midwives, and data on the prevalence of some obstetric emergencies, that seems to suggest that the identification and management of postpartum bleeding was given more focus following training.

Implementation of a training program in a clinical setting on a large scale is complex [20]. The involvement of staff at all hierarchical levels, as well as support from the management team, was considered to be prerequisites for a successful implementation. The implementation of a mandatory training program was proven feasible as 94$96 \%$ of the eligible staff members participated. For a training program like this, it is essential to have a continuously updated database on staff members. The organization 
including the management team needs to be able to cope with designing and implementing such a multi-professional training program $[9,21]$.

The data revealed that the participants had a positive attitude of the training program and considered it to be relevant. No major differences were obtained between the different health professional groups (Kirkpatrick level 1, reaction). Looking at the scores of confidence, the participating staff scored higher at the time of early post-testing compared with pre-testing and confidence seemed to be retained over a period of 9-15 months, except for management of basic neonatal resuscitation. This may be explained by that the skill in managing neonatal resuscitation is less frequently needed compared with any other skills trained. Self-assessed confidence in each skill among midwives, trainee doctors, auxiliary nurses, and nurses improved more than it did among specialized doctors and specialized midwives, presumably due to less potential capacity for improvement existing in these two groups, as these scored higher before training (Kirkpatrick level 2, learning).

Validity of self-assessment is disputable and there is a difference between confidence and competence $[22,23]$. Improvement in confidence is not necessarily translated into better competence and better outcome. In the present study a significant association was found between levels of confidence in the management of basic neonatal resuscitation and in the numbers of correct answers in the KOS-test. This result may indicate that the participants were capable of assessing their own competence in basic neonatal resuscitation skills. Whether this can be generalized to other areas remains to be investigated. In the present study a tendency towards participants' un- derestimation of own skills was seen. It has been hypothesized that people who underestimate their own competences are at risk of burning out. Some argue that guided self-assessment should be incorporated as an essential professional skill in continuous professional development [22].

No association was found between a high number of correct answers in the KOS-test and many years of work experience. Due to this lack of association, the skills that are required in basic neonatal resuscitation do not seem to be learnt and/or retained with years of work experience. This is in accordance with a previous review [24], where it was concluded that in half of previous studies there was an inverse relation between years of work experience and the quality of care that doctors provided.

Staff members reported the management of shoulder dystocia, severe preeclampsia, and basic neonatal resuscitation to be less stressful and less unpleasant following training. No difference was observed with regard to management of postpartum bleeding. One possible explanation for this may be that postpartum bleeding was scored less stressful before training, probably because it is a more frequently experienced clinical event than any of the other three skills trained. 
Looking at the different health professional groups, significant improvements in general were observed for nurses and midwives. Less or no improvements were found for specialist doctors. However, they still approved the training program.

Relatively, little research has been carried out on stress levels among labor ward staff [25]. In future studies, whether randomized or before-after studies, validated scales for burn-out scores or work-related stress could be applied. The KOS-test of neonatal resuscitation showed a significant increase in the numbers of correct answers after training. Although a drop back was observed 9-15 months following training, the score was still significantly higher than the pre-test score. Whether the KOS-test only reflects the performance in the simulated setting and not real clinical life remains to be investigated. An important question to address is when to reassess knowledge and skills, as immediate post-testing has been reported to be insufficient [26]. The literature about retention of skills is sparse, but maybe retention is low already after 3-10 months posttraining $[27,28]$.

Behavior or transfer of learning (Kirkpatrick, level 3) is generally considered a difficult issue to address $[13,14]$. In this study we concluded that the training did have a positive influence on work performance. The need for organizational changes became obvious during the training period and the motivation to implement these changes was clearly present at all hierarchical levels of the organization (Kirkpatrick level 4). There was a significant increase in the prevalence of postpartum bleeding during the study period and no such increase was observed at a national level. It can be argued that the training resulted in a greater attention to cases with postpartum bleeding and that the staff, for this reason, more often used the diagnosis. The use of uterotonics also increased significantly during the training period.

The reduction in sick leave among midwives cannot be assigned causality in the present study. However the management team of the obstetric department considered the implementation of the training program to have played an important role on the observed reduction in sick leave.

A limitation of the present study was the lack of randomization and control groups. The present study design can be viewed as a 'compromise design', which is often seen in educational research [29]. It can be argued that the changes observed following the training program may have happened even without the training program. The project was only carried out in one hospital setting, which gave local possibilities for measuring effects, but at the same time raised the questions about external validity of the study and on whether the project would be applicable in other settings. In future studies on multi-professional simulation-based training in labor wards, a multicenter approach could be relevant.

The outcome measures fall short of direct observation of management in real emergencies, as the trained events occur rarely. The prevalence figures for maternal and 
fetal morbidity and mortality are so low that any significant changes may only be revealed in large multicenter studies. In obstetric research very high numbers of deliveries are required to measure direct outcomes [30].

Anderson et al. [21] suggested that methods to assess and optimize obstetric training are urgently required in order for women and their babies to benefit from these expensive and complex interventions. Evaluation should be integrated as an important part of all training activities, but evaluations are often inconsistent, or even lacking $[13,14]$. In the present study we chose a broad range of evaluation tools and found these to complement each other. The study gave a good basis for changes at a local organizational level.

There are advantages in courses run on local basis, as they reduce costs and increase the access to training, compared to courses run on a national or international level, while the disadvantages could be problems with organization and quality of content, which suggests that locally organized training programs might be overseen at a national level to ensure quality [7]. We found it was an advantage to develop and implement the present training program on a local basis, and that a skills center not was pre- requisite for implementation. We agree as others [12] that skill centers and simulators are only of value within the context of a program or a total educational curriculum.

This mandatory obstetric training program thus had an impact on both the individual and on the organizational level. Implementation of the training program was feasible without a skills center. A vital resource behind the success described in this study was the development and implementation of a training program that involved representatives of all health professionals, staff with educational and obstetric competencies, plus a supportive management team. 


\section{Acknowledgements}

Professor emeritus Knut Aspegren gave guidance on qualitative data analysis. Steen Rasmussen, National Board of Health, Denmark and Jens Langhoff-Ross, Copenhagen University Hospital, Rigshospitalet contributed with data from the Danish Medical Birth Registry. Statistical supervision was organized through the Advisory Service in Clinical Research Methodology and Medical Statistics, Department of Biostatistics, Faculty of Health Sciences, University of Copenhagen, Denmark.

\section{Declaration of interest}

The authors report no conflicts of interest. The authors alone are responsible for the content and writing of the paper.

The article is based on a Master Thesis in Medical Education: Jette Led Sørensen. Obstetric skills training development, implementaion and evaluation of a training program. Centre for Medical Education, University of Dundee, Scotland, United Kingdom, 2007. 


\section{References}

1. Drife J. Reducing risk in obstetrics. Qual Health Care 1995;4:108-14.

2. Johannsson H, Ayida G, Sadler C. Faking it? Simulation in the training of obstetricians and gynaecologists. Curr Opin Obstet Gynecol 2005;17:557-61.

3. Veltman LL. Getting to havarti: moving toward patient safety in obstetrics. Obstet Gynecol 2007;110:1146-50.

4. Guise JM. Anticipating and responding to obstetric emergencies. Best Pract Res Clin Obstet Gynaecol 2007;21:625-38.

5. Kristensen TS, Hannerz H, Hogh A, Borg V. The Copenhagen Psychosocial Questionnaire--a tool for the assessment and improvement of the psychosocial work environment. Scand J Work Environ Health 2005;31:438-49.

6. Ashcroft B, Elstein M, Boreham N, Holm S. Prospective semistructured observational study to identify risk attributable to staff deployment, training, and updating opportunities for midwives. BMJ 2003;327:584.

7. Black RS, Brocklehurst P. A systematic review of training in acute obstetric emergencies. BJOG 2003;110:837-41.

8. Macedonia CR, Gherman RB, Satin AJ. Simulation laboratories for training in obstetrics and gynecology. Obstet Gynecol 2003;102:388-92.

9. Draycott T, Sibanda T, Owen L, Akande V, Winter C, Reading S, Whitelaw A. Does training in obstetric emergencies improve neonatal outcome? BJOG 2006;113:177-82.

10. Crofts JF, Ellis D, Draycott TJ, Winter C, Hunt LP, Akande VA. Change in knowledge of midwives and obstetricians following obstetric emergency training: a randomised controlled trial of local hospital, simulation centre and teamwork training. BJOG 2007;114:1534-41.

11. Ellis D, Crofts JF, Hunt LP, Read M, Fox R, James M. Hospital, simulation center, and teamwork training for eclampsia management: a randomized controlled trial. Obstet Gynecol 2008;111:723-31.

12. Issenberg SB, McGaghie WC, Petrusa ER, Lee GD, Scalese RJ. Features and uses of high-fidelity medical simulations that lead to effective learning: a BEME systematic review. Med Teach 2005;27:1028.

13. Kirkpatrick DL., kirkpatrick JD. Evaluating Training Programs: The Four Levels. 3rd ed. San Francisco, CA: Berrett-Koehler Publishers; 2006.

14. Morrison J. ABC of learning and teaching in medicine: Evaluation. BMJ 2003;326:385-7.

15. McLeod PJ, Steinert Y, Trudel J, Gottesman R. Seven principles for teaching procedural and technical skills. Acad Med 2001;76:1080.

16. Stewart A. Instructional design. In: Dent JA, Harden RM., editors. A Practical Guide for Medical Teachers. Third edition ed. Edinburgh, London, New York, Oxford, Philadelphia, St Louis, Sydney, Toronto: Curchill Livingstone Elsevier; 2009. p. 205-10.

17. Remmen R, Scherpbier A, Denekens J, Derese A, Hermann I, Hoogenboom R, van d, V, van RP, Bossaert L. Correlation of a written test of skills and a performance based test: a study in two traditional medical schools. Med Teach 2001;23:29-32.

18. Kramer AW, Jansen JJ, Zuithoff P, Dusman H, Tan LH, Grol RP, van der Vleuten C. Predictive validity of a written knowledge test of skills for an OSCE in postgraduate training for general practice. Med Educ 2002;36:812-9.

19. Kreiner S. Introduction to DIGRAM. Department of Biostatistics, Faculty of Health Sciences, University of Copenhagen, Denmark.; 2003 Oct 3.

20. Campbell M, Fitzpatrick R, Haines A, Kinmonth AL, Sandercock P, Spiegelhalter D, Tyrer P. Framework for design and evaluation of complex interventions to improve health. BMJ 2000;321:694-6.

21. Anderson E, Black R, Brocklehurst P. Acute obstetric emergency drill in England and Wales: a survey of practice. BJOG 2005;112:372-5.

22. Duffy FD, Holmboe ES. Self-assessment in lifelong learning and improving performance in practice: physician know thyself. JAMA 2006;296:1137-9.

23. Ward M, Gruppen L, Regehr G. Measuring self-assessment: current state of the art. Adv Health Sci Educ Theory Pract 2002; 7:63-80.

24. Choudhry NK, Fletcher RH, Soumerai SB. Systematic review: the relationship between clinical experience and quality of health care. Ann Intern Med 2005;142:260-73. 
25. Engelbrecht S. Motivation and burnout in human service work. The case of midwifery in Denmark. National Institute of Occupational Health, Copenhagen and Roskilde University, Faculty of Psycology, Plilosophy and Science Studies; 2006.

26. Arthur W, Benneth W, Stanush PL, Mc Nelly TL. Factors that influence skill decay and retention: a quantitative review and analysis. Human Performance 1998;11:57-101.

27. Hamilton R. Nurses' knowledge and skill retention following cardiopulmonary resuscitation training: a review of the literature. J Adv Nurs 2005;51:288-97.

28. Trevisanuto D, Ferrarese $P$, Cavicchioli $P$, Fasson A, Zanardo V, Zacchello F. Knowledge gained by pediatric residents after neonatal resuscitation program courses. Paediatr Anaesth 2005;15:944-7.

29. Cohen L, Manion I, Morrison K. Research Methods in Education. London and New York: Routhledgefalmer; 2003.

30. Mongelli M, Chung TK, Chang AM. Obstetric intervention and benefit in conditions of very low prevalence. Br J Obstet Gynaecol 1997;104:771-4. 



\section{CHAPTER 3 \\ Evaluation of multi-professional obstetric skills training for postpartum haemorrhage}

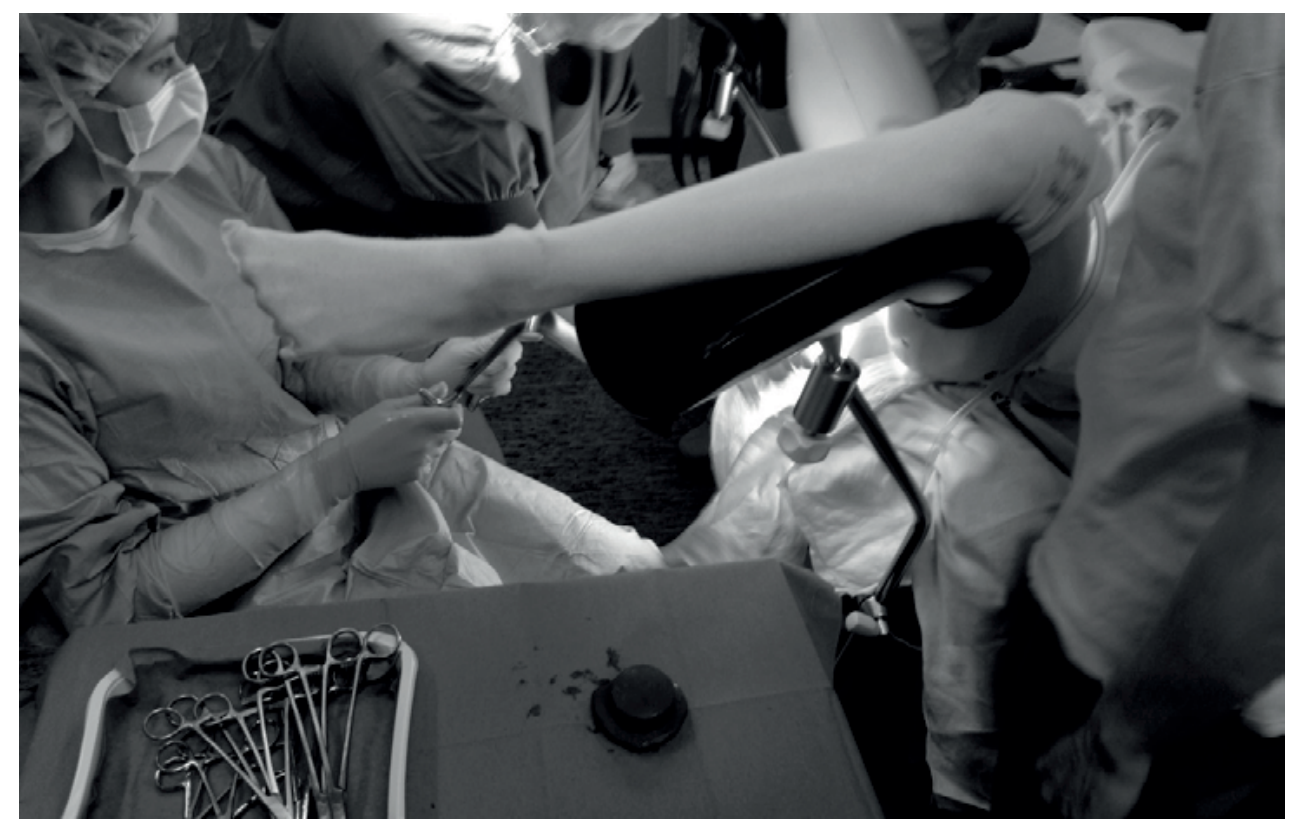

Veronika Markova, Jette Led Sørensen, Charlotte Holm, Astrid Norgaard, Jens LanghoffRoos.

Published in Acta Obstet Gynecol Scand 2012; 91:346-52. 


\begin{abstract}
Objective: To evaluate the effect of multi-professional obstetric skills training on the incidence of postpartum hemorrhage (PPH) indicated by red blood cell (RBC) transfusion and time delay in surgical interventions before, during, and after implementation of the training. Design. A database audit. Setting. University hospital, Rigshospitalet, Copenhagen, Denmark. Population. Women receiving red blood cell (RBC) transfusion up to seven days postpartum before (2003), during (2005), and after (2007) the introduction of training. Methods. Linkage of the Danish Medical Birth Registry and the local transfusion database, followed by audit of medical records. We identified 148 women with RBC transfusion for PPH in 10.461 deliveries and assessed the cause of PPH, surgical interventions and transfusion data.
\end{abstract}

Main outcome measures: RBC transfusion. Delay to surgical intervention. Results. RBC transfusion rates for PPH were 1.5\% (2003), 1.6\% (2005), and 1.2\% (2007) (not statistically significant). The transfusion rates did not change after vaginal delivery but decreased after cesarean section [2.4, 2.1 and $0.7 \%(p<0.01)]$. Transfusion requirements and pre-transfusion hemoglobin values did not change. The median time from delivery to manual removal of the placenta increased non-significantly (64, 70 and 75 minutes). The median time from decision to manual removal of the placenta remained unchanged (30 minutes).

Conclusion: There was no effect of multi-professional obstetric skills training on the rate of RBC transfusion for PPH. The unchanged long delay in handling a retained placenta indicates a need for multi-disciplinary training in collaboration with staff from anesthesiology and the operation theater.

Abbreviations: $\mathrm{PPH}$, postpartum hemorrhage; RBC, red blood cell; $\mathrm{CS}$, cesarean section; $\mathrm{Hb}$, hemoglobin, mmol/L (conversion algorithm: $1 \mathrm{mmol} / \mathrm{L}=16 \mathrm{~g} / \mathrm{L}$ ).

Key words: Blood transfusion, high-risk pregnancy, maternal morbidity, obstetric training, patient simulation, postpartum hemorrhage, retained placenta, uterine atony. 


\section{Introduction}

In December 2003 the obstetric department at Copenhagen University Hospital (Rigshospitalet), introduced multi-professional obstetric skills training in the management of emergency obstetric situations which may occur in conjunction with vaginal delivery, e.g. management of postpartum hemorrhage (PPH), shoulder dystocia, basic neonatal resuscitation, and severe preeclampsia. Midwives, nurses, auxiliary nurses and doctors on call participated. The training was highly appreciated by the staff and there was a general impression that the training improved collaboration and handling of obstetric emergencies. The evaluation of this intervention showed a significant increase in self-assessed confidence among auxiliary nurses and trainee doctors in management of PPH, a significant increase in the administration of uterotonics and the use of the ICD-code for PPH, as well as a facilitation of staff-directed infrastructural changes in the delivery room, such as emergency boxes with relevant medicines and equipment for the management of PPH [1].

In the present study we evaluated the effects that this form of multi-professional obstetric skills training had on the incidence and causes of severe PPH. To estimate this, we performed an audit of medical records and used transfusion rates and the individual requirements for red blood cell (RBC) unit transfusions as indicators in three groups of patients with PPH representing the period before, during and after implementation of the multi-professional obstetric skills training. We also evaluated the pre- and posttransfusion hemoglobin levels to estimate any change in transfusion decision practice, and the compliance with national and hospital transfusion guidelines. Both vaginal deliveries and cesarean sections (CS) were evaluated.

We hypothesized that multi-professional obstetric skills training could reduce the number of women who suffered excessive bleeding and therefore received RBC transfusions, and that this would be reflected in transfusion rates and requirements.

\section{Material and methods}

The introduction of simulation-based multi-professional obstetric skills training for PPH started with a focus on basic skills in managing PPH at and after vaginal delivery. The training sessions were mandatory for midwives, nurses, auxiliary nurses and on-call doctors in the obstetric department [1].

Each 2.5-hour training session included: 1. a theoretical lecture for 12 participants from different staff groups, 2. a multi-professional workshop for groups of six participants where scenario-based skills training was provided, and 3. discussion and feed-back for the whole group. The scenarios were based on vaginal deliveries only. Techniques were taught on mannequins. The training focused on prophylaxis, identification of PPH and estimation of blood loss, administration of uterotonics, fluid replacement and compression of the uterus, but did not focus on how and when to give RBC transfusions [1]. 
The training sessions were (and still are) held regularly to include all staff, and members are invited to repeat the course every two to three years. The first session with a small minority $(n=12)$ of the staff $(n=156)$ was provided 9 December 2003 - the only session in 2003. In 2004 an increasing number of staff participated, and in 2005 a total of about 95\% of staff had participated in the obstetric skills training. In 2007 almost all staff had participated once or twice in the training sessions. For simplicity, we have chosen to use the terms 'before' (hardly anyone had training), 'during' (almost all staff had recent training) and 'after' (the training was a routine and had been repeated) the introduction of the obstetric skills training.

We performed a retrospective descriptive database audit. Information on 10461 women who gave birth at the university hospital in 2003, 2005 and 2007 was retrieved from the Danish Medical Birth Register (http://www.sst.dk). The dataset, which included information on time of delivery, was merged with that of the local blood bank's ITsystem to create an individualized dataset containing information on trans- fused patients within the postpartum period, defined as seven days postpartum for the purpose of this study. Based on the national register and the local blood bank's IT-system a total of 201 transfusion episodes were identified (Figure 3.1).

Figure 3.1 Flowchart for selection of 148 mothers with red blood cell transfusions for postpartum hemorrhage for non-medical reasons by mode of delivery.

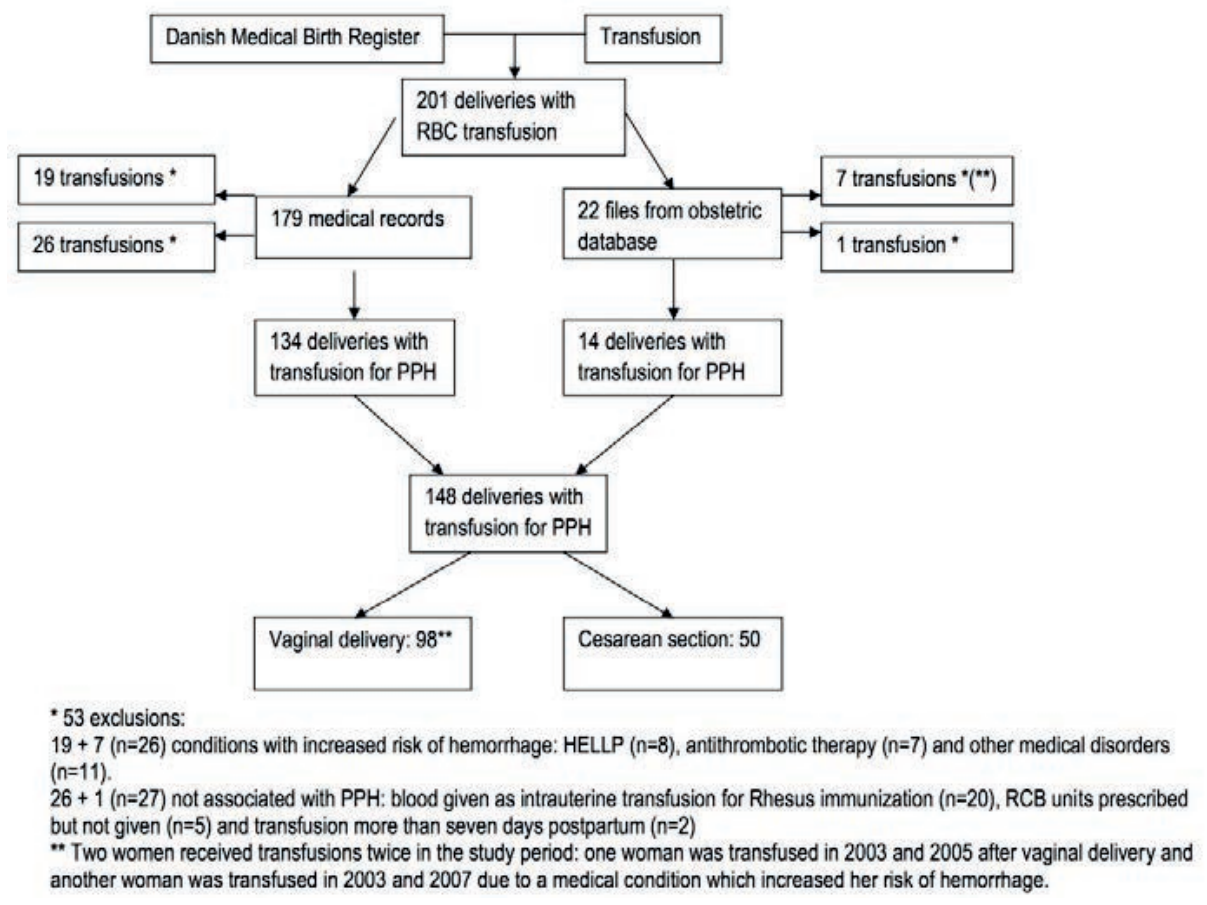


Of the 201 transfusion episodes we were able to obtain 179 medical records from the hospital archives and searched for the following variables: time of delivery, twin deliveries, polyhydramnios, macrosomia, mode of delivery, number of RBC units per transfusion episode, time of started transfusion, the last hemoglobin $(\mathrm{Hb})$ value before and the first after transfusion, and time from delivery to manual removal of a retained placenta. The time delay from decision to commencement of surgical intervention was noted for the 134 deliveries followed by PPH. We categorized the interventions performed in the operation theater $(n=60)$ into two types: (1) manual removal of the placenta, exploration of the uterine cavity and uterine massage or compression $(n=46)$ and (2) repair of complicated lacerations or paravaginal hematomas $(n=14)$. In 22 of the 201 transfusion episodes, patient records could not be retrieved. Some information on these 22 transfusion episodes, such as time of delivery, birth weight, and surgical and medical diagnoses was obtained by a search of the local obstetric database. The number of RBC units transfused was obtained from the hospital blood bank's transfusion database. In 14 of these 22 cases the transfusion was associated with PPH.

An audit was performed on the 179 available medical records and 22 patient files from obstetric database by two senior consultants (J.L.R., J.L.S.). The patients with PPH were grouped by the main cause of bleeding (Figure 3.2). When PPH was associated with both a placental complication and atonic bleeding or laceration, the placental complication was considered to be more likely to cause excessive bleeding and was selected as the dominant cause. Otherwise, the assessment was done based on the clinical information. Uterine atony was considered the cause of bleeding if this.

Figure 3.2 Postpartum hemorrhage by mode of delivery and major cause $(n=148)$. Diagnosis was stated in the medical record or in the absence of other obvious causes.

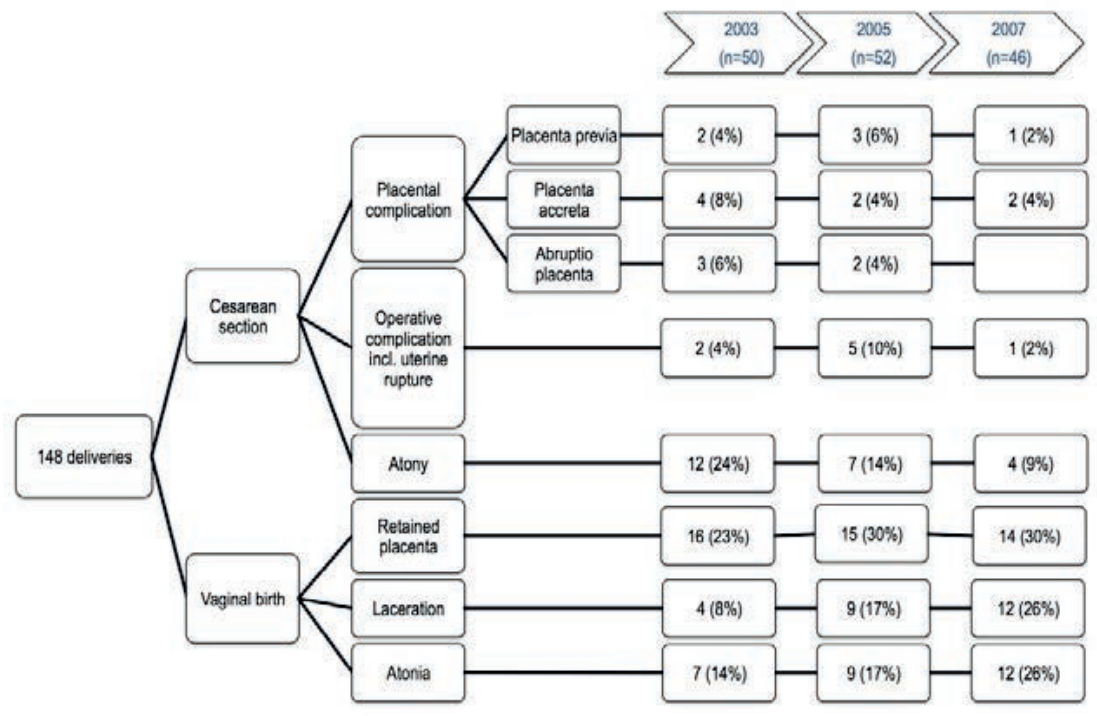


Through the audit, 53 cases were excluded (Figure 1); in 26 the transfusion was not associated with PPH and in 27 the bleeding was considered due to medical conditions or anticoagulant treatment.

RBC transfusion was measured by the following clinical transfusion indicators [2]: transfusion rate, transfusion rate by patient category, transfusion requirement and pre- and post-transfusion $\mathrm{Hb}$ levels. We defined RBC transfusions as immediate when given within 24 hours postpartum and delayed when given 24 hours to seven days postpartum. All RBC transfusions (both immediate and delayed) were included in the transfusion rate and transfusion requirement analyses. We analyzed $\mathrm{Hb}$ levels before and after transfusion in cases of delayed transfusion only. Use of plasma and platelets was not analyzed.

The study was approved by the Danish Data Protection Agency and the Danish Bioethics Committees for the Capital Region.

Statistical analysis

We used chi-squared tests to test whether changes in rates between the three periods were significant for a $p$-value $<0.05$. A trend-test was used to compare the amount of RBC units over time. Comparison of the non-categorical variables was done using ANOVA supplemented by Kruskal-Wallis tests for variables that were not normally distributed. Data was analyzed with statistical software package SAS version 9.2.

\section{Results}

There were 3284,3272 and 3905 deliveries at the hospital in the three study periods $(2003,2005$ and 2007$)$ in which the proportion of vaginal deliveries (71.2-72.4\%) and CS (27.6-28.8\%) remained stable. Figure 2 shows the distribution of causes for PPH.

Overall transfusion rates were 1.5, 1.6 and $1.2 \%$ for each of the three periods (no significant difference). Transfusion rates at or after vaginal delivery remained unchanged as $1.2,1.4$ and $1.4 \%$ of all vaginal deliveries (not significant), whereas the transfusion rates for CS decreased from 2.4 to 2.1 and $0.7 \%$ ( $p<0.01$ ). In the three periods a total of 162 $(n=50), 172(n=52)$ and $135(n=46)$ RBC units were given, with an overall median transfusion requirement of two units in each period (no significant difference). The distribution of transfusion requirement is shown in Table 3.1.

The distribution of women by pre-transfusion $\mathrm{Hb}$ value is shown in Table 3.2. Pretransfusion mean (median; range) $\mathrm{Hb}$ values in the three periods were $4.3(4.4$; $3.5-$ $5.3), 4.4(4.5 ; 3.7-5,0)$ and $4.3(4.3 ; 3.5-5.3) \mathrm{mmol} / \mathrm{L}$ (no significant difference). Mean $\mathrm{Hb}$ values after completed transfusion were $5.7,6.1$ and $5.6 \mathrm{mmol} / \mathrm{L}$, respectively. There were 26, 29 and 21 immediate and 22, 17 and 19 delayed transfusions in the three periods, resulting in an immediate/delayed-ratio of 1.2, 1.7 and 1.1 (no significant change). 
Table 3.1 The distribution of the number of red blood cell units transfused per transfused patient in each period.

\begin{tabular}{ccccccc}
\hline & \multicolumn{2}{c}{2003} & \multicolumn{2}{c}{2005} & \multicolumn{2}{c}{2007} \\
\hline \multirow{2}{*}{ units } & \multicolumn{2}{c}{ Recipients (50) } & \multicolumn{2}{c}{ Recipients (52) } & \multicolumn{2}{c}{ Recipients (46) } \\
& $\mathbf{n}$ & $\%$ & $\mathbf{n}$ & $\%$ & $\mathbf{N}$ & $\%$ \\
\hline 1 & 3 & 6 & 2 & 3.8 & 5 & 10.9 \\
2 & 32 & 64 & 27 & 51.9 & 26 & 56.5 \\
3 & 3 & 6 & 7 & 13.5 & 8 & 17.4 \\
4 & 4 & 8 & 9 & 17.3 & 5 & 10.9 \\
5 & 3 & 6 & 3 & 5.8 & 0 & 0 \\
$>5$ & 5 & 10 & 4 & 7.7 & 2 & 4.3 \\
\hline
\end{tabular}

Table 3.2 Pre-transfusion hemoglobin values before, during and after implementation of multiprofessional obstetric skills training.

\begin{tabular}{lcccccc}
\hline Hemoglobin mmol/L & \multicolumn{2}{c}{ Recipients in 2003 } & \multicolumn{2}{c}{ Recipients in 2005 } & \multicolumn{2}{c}{ Recipients in 2007 } \\
\hline Before transfusion & $\mathbf{N}$ & $\mathbf{\%}$ & $\mathbf{N}$ & $\mathbf{\%}$ & $\mathbf{N}$ & $\mathbf{\%}$ \\
\hline$\leq 4.5^{*}$ & 18 & 81.8 & 11 & 64.7 & 12 & 63.2 \\
$\geq 4.6$ & 4 & 18.2 & 6 & 35.3 & 7 & 36.8 \\
\hline
\end{tabular}

*Hemoglobin trigger for transfusion according to Rigshospitalet's recommendation for transfusion policy.

The median time from delivery to manual removal of the placenta (excluding cases where placental tissue was retained for more than eight hours) was 64 minutes $(n=11$, range 33-131 minutes), 70 minutes ( $n=13$, range $23-497$ minutes) and 75 minutes ( $n=13$, range 35-397 minutes) in each study period (no significant difference). The number of women who needed anesthetic support for PPH was 18, 28 and 24 in the three periods and information on time delay from decision on intervention to start of procedure at the operating theater was available for 17, 23 and 20 women. Median time from decision to perform surgery to commencement of the intervention was recorded for manual removal of the placenta, exploration of the uterine cavity, and uterine massage or compression where the average delay was 30 minutes ( $n=15$, range 0 60 minutes), 30 minutes ( $n=17$, range $0-80$ minutes) and 30 minutes ( $n=14$, range 15155 minutes) in the three periods (not significant). For repair of lacerations or paravaginal hematomas the median delay was 53.5 minutes ( $n=2$, range 42-65 minutes), 60 minutes ( $n=6$, range 15-185 minutes) and 22.5 minutes ( $n=6$, range 15-405 minutes) in each study period (not significant).

\section{Discussion}

The rates and requirements for RBC transfusions among women with severe PPH after vaginal delivery did not decrease significantly following introduction of multi- 
professional obstetric skills training. There was no decrease in RBC unit requirements. There was a non-significant increase in delay from delivery to manual removal of a retained placenta. No significant changes were observed in median delay from decision on surgical intervention to commencement. A significant decrease in transfusion use after CS was observed.

Most previous studies on the effect of obstetric training have focused on easily available proxy variables and not on outcome variables relevant for patients $[3,4]$. In one British study the effect of obstetric training was investigated, focusing on asphyxia. A reduction of asphyxiated infants following training was found [5]. One French study investigated the effect of an intervention protocol on the rate of PPH. No significant effect was shown [6]. Another French study showed a significant effect of routine clinical audits on PPH [7]. The present study is the first that investigated the effect of multiprofessional obstetric skills training on $\mathrm{PPH}$.

Estimates of blood loss are quite subjective [8-10] and the diagnosis of PPH reflects inherently both an unreliable estimate and varying attention to the condition. Thus, the ICD-code diagnoses of PPH at the hospital in the three periods increased both by number and in percent. This might be due to an increased focus on PPH during the obstetric skills training [1], and the fact that staff during training were encouraged to measure the blood loss by weighing. Several studies have also shown an increase in PPH incidence over time [11-14]. Therefore we chose RBC transfusions as an outcome measure for severe PPH instead of estimating blood loss.

It is commonly accepted that uterine atony is the main reason for PPH. The specific rates differ between studies [8,15-19]. The proportions of atony in three different American and one Norwegian register-based study, which included all deliveries, were $50 \%$ [18], 59\% [17], 79\% [16] and 30\% [8]. The Norwegian study [8] with the lowest proportion of atony used criteria indicating severe PPH. Thus, it seems that atony is less common as a cause of PPH when the bleeding is severe. Two of the studies were Nigerian audits that focused on vaginal deliveries and found atony in $11 \%$ [15] and 54\% [19]. The criteria used for PPH in these two studies also indicate that PPH was more severe in the first study with a lower rate of atony. Otherwise, the reasons for different proportions of atony may be due to heterogeneity of the population of parturients, design of study (register-based or audit), differences in definitions of PPH $[9,19,20]$, estimation of blood loss (a reliable method has yet to be identified[8-10]); as well as prophylactic use of uterotonics and routines for removal of a retained placenta. Also in the present study, including only severe PPH as indicated by need of blood transfusion, we found that PPH was caused by atony in a relatively small proportion of vaginal deliveries (14$26 \%$ ). This may be explained by early administration of uterotonics in atony, which may result in less severe PPH that does not require transfusion. When severe hemorrhage, which necessitates transfusion, is considered, placental complications will be the prom- 
inent cause. This might explain our large proportion of cases with placental complications and a rather low proportion of atony.

It is paradoxical that although the rate of RBC transfusions in conjunction with CS decreased, this was not the case after vaginal deliveries. The local routine standard procedure for administration of uterotonics changed gradually from a relatively large dose of oxytocin $10 \mathrm{IU}$ i.v. bolus $+10 \mathrm{IU}$ injected into the uterine muscle during the operation to only $10 \mathrm{IU}$ to the uterine muscle. The decrease in PPH after CS might be a result of this change, although other studies report an increase in PPH for CS [11,13]. Another hypothesis for a significant decrease in RBC transfusions after CS would be the increased focus on surgical training, and avoiding independent and unsupervised CS by junior doctors too early in their training. Studies show an increased risk of bleeding when trainees are performing CS and special attention should be given to the first 2040 CS [21-23]. Factors of significance for avoiding PPH in CS might be increased focus on surgical training and evaluation. The lack of reduction in transfusion rates for severe PPH after vaginal delivery might possibly be related to a narrow focus in the multiprofessional obstetric skills training evaluated here and partly to the increasing rates of CSs in high-resource countries such as Denmark, which may predispose to PPH at a subsequent vaginal delivery $[11,14]$.

The median number of two units per woman did not change throughout the three periods (Table 1). This is not surprising, as it is a widespread practice to transfuse RBC units by the pair. Each RBC unit increases $\mathrm{Hb}$ by approximately $0.5 \mathrm{mmol} / \mathrm{L}$. The posttransfusion $\mathrm{Hb}$ levels are rather high compared with the lower normal reference value $(5.9 \mathrm{mmol} / \mathrm{L})[24,25]$, indicating that use of transfusion could be restricted by adhering strictly to the guideline trigger and to transfusing only one unit at a time for $\mathrm{Hb}$ $>3.9 \mathrm{mmol} / \mathrm{L}$.

We evaluated only the $\mathrm{Hb}$ values for delayed transfusions because of the questionable reliability of $\mathrm{Hb}$ values during active bleeding episodes, as redistribution of extravascular fluids takes time. With ongoing bleeding the $\mathrm{Hb}$ values may be high relative to the actual physiological condition. There was no change in pre-transfusion $\mathrm{Hb}$ values or in the number of cases where the guidelines for transfusion at a $\mathrm{Hb}$ value of $4.5 \mathrm{mmol} / \mathrm{L}$ were met (www.sst.dk). There was no significant change in the immediate/delayed transfusion ratio. One can assume that multi-professional obstetric skills training should enable the staff to stop excessive bleeding and thus prevent immediate transfusion. Our results show that multi-professional obstetric skills training did not have an influence on when the transfusion was given.

Before, during and after implementation of the obstetric training there was an unchanged delay from delivery to manual removal of the placenta or manual exploration and repair of lacerations. This might be regarded as a direct outcome of the multiprofessional obstetric skills training, as initial medical treatment such as giving utero- 
tonics and massaging the uterus is inevitably associated with a delay of moving the woman from the delivery room to the operating theater while effects are awaited. Nevertheless, this observation indicates a need for a change in the focus of multiprofessional obstetric skills training to include improved collaboration with anesthesiology and operating theater staff. In a French study such an approach showed a significant decrease in PPH incidence by introducing multi-disciplinary clinical audits every three months to review and critically analyze the care given [7]. Furthermore, clinical observations show that bleeding can intermittently stop and then recur after some time. This indicates a need for increased attention to retained placenta management in the training given. This can perhaps be carried out by using routine ultrasound after delivery to identify remaining placental tissue [26,27], although this option must be explored in a future study.

The lack of substantial effect of the multi-professional obstetric skills training seen in this study could be due to several reasons. The lack of a reduction in RBC transfusions may in practice be due to not following the standard procedures as instructed in the training program, but if this was the case, then it could be concluded that training should have focused on different aspects. A general tendency of unnecessary doublet transfusions (two, four, six, etc.) could also have added to the lack of effect. The multiprofessional obstetric skills training programs could be improved by including evidencebased instructions on transfusion practice and guidelines for transfusion policy, which also should mention the number of units to be used.

To optimize management of PPH, there should also be a focus on when to request surgery in order to minimize delay from delivery to manual placenta removal. This challenges the decision-making process and must involve all health professionals and disciplines that take part in managing the PPH situation. The multi-professional obstetric skills training for PPH should be changed to achieve earlier identification of a retained placenta or other reasons for bleeding. A future strategy could be a combination of a revised obstetric skills training involving not only all staff in the labor ward, but also staff from the operation theaters and anesthesiology department, plus repeated systematic multi-disciplinary clinical audits with feedback to improve the content and educational strategy of the training.

It is currently being discussed how to consider the active components in effective training of obstetric emergencies [4]. Both the aim and purpose of training and the principles of educational strategy seem to be of significant importance, and these will probably change over both time and place. The literature on the effect of obstetric training is complex, but there seem to be noteworthy components for focusing on institutionlevel incentives to train all staff in a unit, i.e. teamwork training integrated with clinical teaching and the possible use of high-fidelity simulation models. Local training also appeared to facilitate staff-directed structural changes at the labor ward. 
The present study has helped us to evaluate an outcome that provides guidance on the organization of how future training should be planned. Outcome measures such as satisfaction and self-assessment among staff are not enough to measure the effect of an intervention. 


\section{Acknowledgments}

Research nurse Susanne Schiang ${ }^{\dagger}$, Department of Anesthesia, Rigshospitalet, University of Copenhagen, initiated the collection of data. Birgitte Diness, Department of Clinical Genetics, Copenhagen University Hospital, Rigshospitalet, helped with data analyses and Steen Rasmussen, National Board of Health, Denmark, helped to retrieve data from databases. Karl Bang Christensen, Department of Biostatistics, Faculty of Health Sciences, University of Copenhagen, helped with the statistical analyses.

\section{Funding}

There was no private or public funding. All resources were financed by the authors. 


\section{References}

1. Sorensen JL, Lokkegaard E, Johansen M, Ringsted C, Kreiner S, McAleer S. The implementation and evaluation of a mandatory multi-professional obstetric skills training program. Acta Obstet Gynecol Scand 2009;88:1107-17.

2. Hardy JF. Endpoints in clinical trials on transfusion requirements: the need for a structured approach. Transfusion 2005;45(1 Suppl):9S-13S.

3. Birch L, Jones N, Doyle PM, Green P, McLaughlin A, Champney C, Williams D, Gibbon K, Taylor K. Obstetric skills drills: evaluation of teaching methods. Nurse Educ Today 2007 Nov;27(8):915-22.

4. Siassakos D, Crofts JF, Winter C, Weiner CP, Draycott TJ. The active components of effective training in obstetric emergencies. BJOG 2009;116:1028-32.

5. Draycott T, Sibanda T, Owen L, Akande V, Winter C, Reading S, Whitelaw A. Does training in obstetric emergencies improve neonatal outcome? BJOG 2006;113:177-82.

6. Deneux-Tharaux C, Dupont C, Colin C, Rabilloud M, Touzet S, Lansac J, Harvey T, Tessier V, Chauleur C, Pennehouat G, et al. Multifaceted intervention to decrease the rate of severe postpartum haemorrhage: the PITHAGORE6 cluster-randomised controlled trial. BJOG 2010;117:1278-87.

7. Dupont C, Deneux-Tharaux C, Touzet S, Colin C, Bouvier-Colle MH, Lansac J, Thevenet S, BoberieMoyrand C, Piccin G, Fernandez MP, et al. Clinical audit: a useful tool for reducing severe postpartum haemorrhages? Int J Qual Health Care 2011;23:583-9.

8. Al-Zirqi I, Vangen S, Forsen L, Stray-Pedersen B. Prevalence and risk factors of severe obstetric haemorrhage. BJOG 2008;115:1265-72.

9. Oyelese $\mathrm{Y}$, Ananth CV. Postpartum hemorrhage: epidemiology, risk factors, and causes. Clin Obstet Gynecol 2010;53:147-56.

10. Rath WH. Postpartum hemorrhage--update on problems of definitions and diagnosis. Acta Obstet Gynecol Scand 2011;90:421-8.

11. Al-Zirqi I, Vangen S, Forsen L, Stray-Pedersen B. Effects of onset of labor and mode of delivery on severe postpartum hemorrhage. Am J Obstet Gynecol 2009;201:273-9.

12. Ford JB, Roberts CL, Simpson JM, Vaughan J, Cameron CA. Increased postpartum hemorrhage rates in Australia. Int J Gynaecol Obstet 2007;98:237-43.

13. Rossen J, Okland I, Nilsen OB, Eggebo TM. Is there an increase of postpartum hemorrhage, and is severe hemorrhage associated with more frequent use of obstetric interventions? Acta Obstet Gynecol Scand 2010;89:1248-55.

14. Sakse A, Weber T, Nickelsen C, Secher NJ. Peripartum hysterectomy in Denmark 1995-2004. Acta Obstet Gynecol Scand 2007;861472-5.

15. Ajenifuja KO, Adepiti CA, Ogunniyi SO. Post partum haemorrhage in a teaching hospital in Nigeria: a 5-year experience. Afr Health Sci 2010;10:71-4.

16. Bateman BT, Berman MF, Riley LE, Leffert LR. The epidemiology of postpartum hemorrhage in a large, nationwide sample of deliveries. Anesth Analg 2010;110:1368-73.

17. Callaghan WM, Kuklina EV, Berg CJ. Trends in postpartum hemorrhage: United States, 1994-2006. Am J Obstet Gynecol 2010;202:353-6.

18. Grotegut CA, Paglia MJ, Johnson LN, Thames B, James AH. Oxytocin exposure during labor among women with postpartum hemorrhage secondary to uterine atony. Am J Obstet Gynecol 2011 ;204:56.

19. Ijaiya MA, Aboyeji AP, Abubakar D. Analysis of 348 consecutive cases of primary postpartum haemorrhage at a tertiary hospital in Nigeria. J Obstet Gynaecol 2003;23:374-7.

20. Knight M, Callaghan WM, Berg C, Alexander S, Bouvier-Colle MH, Ford JB, Joseph KS, Lewis G, Liston $\mathrm{RM}$, Roberts $\mathrm{CL}$, et al. Trends in postpartum hemorrhage in high resource countries: a review and recommendations from the International Postpartum Hemorrhage Collaborative Group. BMC Pregnancy Childbirth 2009;9:55.

21. Fok WY, Chan LY, Chung TK. The effect of learning curve on the outcome of caesarean section. BJOG 2006;113:1259-63.

22. Muller I, Zimmermann R. [The learning curve in the context of the cesarean section]. Gynakol Geburtshilfliche Rundsch 2003;43:238-44.

23. Sheehan SR, Montgomery AA, Carey M, McAuliffe FM, Eogan M, Gleeson R, Geary M, Murphy DJ. Oxytocin bolus versus oxytocin bolus and infusion for control of blood loss at elective caesarean section: double blind, placebo controlled, randomised trial. BMJ 2011;343:d4661. 
24. Larsson A, Palm M, Hansson LO, Axelsson O. Reference values for clinical chemistry tests during normal pregnancy. BJOG 2008;115:874-81.

25. Klajnbard A, Szecsi PB, Colov NP, Andersen MR, Jorgensen M, Bjorngaard B, Barfoed A, Haahr K, Stender S. Laboratory reference intervals during pregnancy, delivery and the early postpartum period. Clin Chem Lab Med 2010;48:237-48.

26. Brown DL. Pelvic ultrasound in the postabortion and postpartum patient. Ultrasound $Q$ 2005;21:27-37.

27. Hertzberg BS, Bowie JD. Ultrasound of the postpartum uterus. Prediction of retained placental tissue. J Ultrasound Med 1991;10:451-6. 


\section{CHAPTER 4}

\section{Unannounced in situ simulation of obstetric emergencies: staff perceptions and organisational impact}

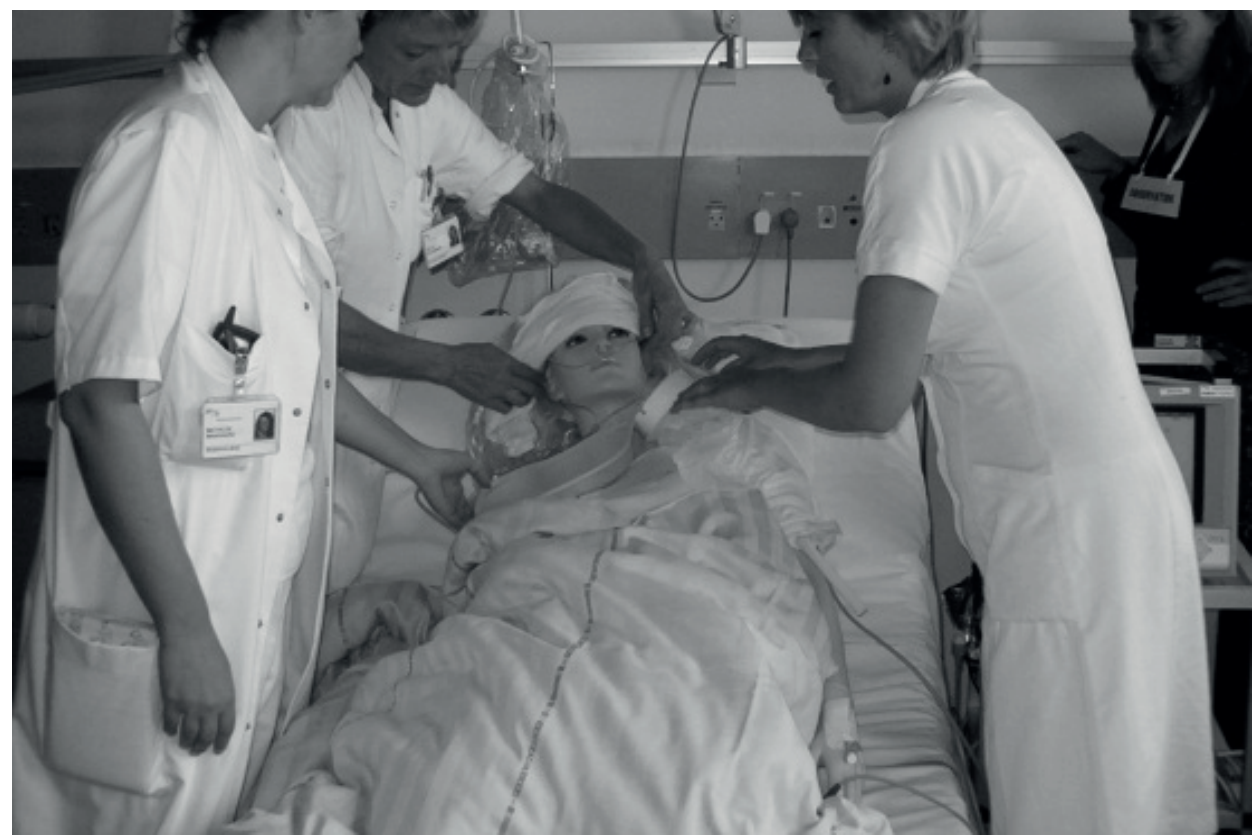

Jette Led Sørensen, Pernille Lottrup, Cees van der Vleuten, Kristine Sylvan Andersen, Mette Simonsen, Pernille Emmersen, Bent Ottesen.

Published in Postgrad Med J 2014;90:622-9. 


\begin{abstract}
Aim: To describe how unannounced in situ simulation (ISS) was perceived by healthcare professionals before and after its implementation, and to describe the organisational impact of ISS.

Study design: Ten unannounced ISS involving all staff were scheduled March-August 2007. Questionnaire surveys on staff perceptions were conducted before (2003-2006) and after (2007-2008) implementation of unannounced ISS. Information from the debriefing sessions following each ISS constituted a proxy measure of the organisational impact of the ISS.

Results: Five out of ten of the unannounced ISS scheduled were conducted. Twentythree members of the staff at work on a scheduled day for ISS were randomly selected to participate. Questionnaires before implementation revealed that $137 / 196$ (70\%) of staff members agreed or strongly agreed that ISS was a good idea and 52/199 (26\%) thought it likely to be stressful and unpleasant. Questionnaires completed after implementation showed significantly more staff members, 135/153 (89\%), thought ISS was a good idea. A significantly higher amount of staff members 50/153 (33\%) found it to be stressful and unpleasant, and among midwives, 15/59 (25\%) were anxious about ISS, whereas none of the obstetricians reported this. Information obtained through debriefing sessions generated learning points.

Conclusions: The number of staff members with a positive perception of multiprofessional unannounced ISS increased after implementation; however, one-third considered ISS to be stressful and unpleasant and midwives more frequently so. The specific perception of ISS by each healthcare profession should be taken into account when planning ISS. The information from the debriefing sessions showed that implementation of ISS had an impact as it provided information required for organisational changes.
\end{abstract}




\section{Introduction}

Labour wards have the dual function of creating a relaxed atmosphere for normal childbirth and of simultaneously having to be constantly prepared to deal with lifethreatening emergencies [1]. As a result, labour wards are challenging workplaces, where patient safety and medical litigation are high on the agenda [2,3]. Labour ward staff must be prepared to deal with unexpected emergencies. Clinical management of obstetric emergencies is difficult to learn in real life due to the rarity of emergency events, which is why simulation-based training is essential [4-9]. In recent years, many wards have implemented simulation-based medical training. Health authorities such as the National Board of Health in Denmark and the Clinical Negligence Scheme for Trusts in Britain currently require all labour ward staff to participate in annual skill drills $[3,10]$. Little is published on optimal training content, preferred educational and learning strategies or the optimal physical setting for simulation-based training $[7,11]$.

Simulation-based training has traditionally been conducted off site in simulation centres and some hospital departments also provide in-house training at the hospital in rooms specifically allocated to training [5]. In situ simulation (ISS), introduced over the past decade, is defined by Riley et al [12] as "a team-based simulation strategy that occurs on patient care units involving actual healthcare team members within their own working environment". Conduction of ISS can be either announced or unannounced $[13,14]$. The term drill is sometimes used for unannounced ISS $[13,14]$. An advantage of ISS is that it is conducted in the real workplace, thus making it possible to train staff and also identify systemic weaknesses, which in turn forms the basis for required organisational changes [15-18]. Some have argued that ISS is more feasible and cost saving compared with traditional simulation conducted in simulation centres $[19,20]$. Some studies concluded that ISS is met with widespread acceptance among participants and has resulted in a collaborative approach to patient safety $[14,19,21,22]$.

Emergency drills are described by Anderson et al as "as scenario-based training in obstetric emergencies conducted in 'real time' in the normal working environment, without the prior knowledge of the staff involved. This type of training is sometimes called 'fire drill'. The aim of such drill is to test local systems and protocols for responding to emergencies, as well as to test professional teamwork and individual skills and knowledge [13]." Inspired by this approach, we decided to focus on unannounced ISS. Anderson et al [13] indicated that emergency drills can be perceived as intimidating by participants, but so far this has been poorly explored in the literature.

This is an observational study with the primary aim of describing how healthcare professionals perceive unannounced ISS in obstetric emergencies before and after its implementation and, secondarily, to analyse the organisational impact of ISS. The more specific objectives were to describe staff members' perceptions of ISS and its likely use- 
fulness and impact in terms of anxiety, stress and other perceptions and to describe any changes in these views once staff members had become familiar with ISS.

\section{Materials and methods}

See box 4.1 for the setting.

Box 4.1 Setting.

$>$ The study took place at the Department of Obstetrics, Juliane Marie Centre for Children, Women and Reproduction, Rigshospitalet, University of Copenhagen, Copenhagen, Denmark.

$>$ During the study period, the department had approximately 3,300 deliveries per year, approximately two thirds of which came from a local catchment area in Copenhagen, while the remaining third comprised high-risk referrals from Eastern Denmark and a small number of special cases categorised as nationwide referrals.

> Participants were recruited from the following staff groups: specialised obstetricians, trainee obstetricians, midwives, specialised midwives, auxiliary nurses, and nurses in ante- and postnatal wards. With turnover in staff accounted for, the department employed an estimated 160-170 staff at any given time during the study period.

\section{Research group}

The research group consisted of one obstetrician (JLS), three midwives (PL, MS, KSA) and one nurse (PE). MS and PE were a part of the departmental management team, and KSA was the quality coordinator in the department and cooperated with the risk managers at the hospital. Everyone in the research group was ISS instructors. Obstetrician JLS and a midwife KSA were responsible for the debriefing. Two psychologists from the hospital's Development and Quality Improvement Department helped to design the structure of the debriefing session.

\section{Intervention}

The research group laid down the prerequisites for the intervention, which was unannounced ISS before its implementation (box 4.2). Since 2003, the department has regularly conducted planned in-house mandatory multiprofessional obstetric training at the hospital in dedicated training rooms. Hence, the staff was used to and had participated in planned mandatory training, which was part of a research project that involved the entire staff completing questionnaires from 2003 to 2006 [23].

Unannounced ISS included the following emergencies: (1) shoulder dystocia (a complication of vaginal delivery, where the baby's shoulders are impacted behind the pubic bone after delivery of the foetal head), (2) postpartum bleeding and (3) severe preeclampsia with eclamptic convulsions. 
Before implementation of the unannounced ISS, all staff members were informed at staff meetings by email and on notice boards that one would take place within a 6month period (March-August 2007). Internet links to the relevant clinical guidelines for the three emergencies in focus were made easily available.

The research group planned the unannounced ISS in detail, wrote scripts for the ISS and selected manikins. The setting either a labour ward delivery room (shoulder dystocia and postpartum bleeding) or an in-patient room on postnatal ward (severe preeclampsia). Online supplementary table 4.S1 presents examples of ISS planning. Ten unannounced ISS were scheduled.

Each of the unannounced ISS was expected to involve an authentic team of 4-5 different healthcare professionals. The ISS participants were randomly selected among the staff at work on the day scheduled for the unannounced ISS. The ISS participants had to be replaced by other staff members during the ISS and subsequent debriefing sessions to ensure that the ISS did not interfere with regular patient care.

Box 4. 2 Prerequisites for unannounced ISS established by the research group before planning and implementing the unannounced ISS.

$>\quad$ Before participating in an unannounced ISS, staff are required to attend the department's mandatory obstetric training programme, which was established in 2003 and is currently conducted quarterly or bimonthly [23].

$>\quad$ Staff must be informed in advance of planned unannounced ISS.

$>$ Instructors must be prepared to cancel scheduled unannounced ISS in the event of heavy patient loads, staff shortage, or recent severe obstetric emergencies.

$>\quad$ The unannounced ISS must not pose any risk to real-life patient care, which means extra staff must be available to replace staff participating in the unannounced ISS.

$>\quad$ The planning of the unannounced ISS and the debriefing must be systematic and focus on the identification of systemic errors, quality improvement initiatives and the need for future training.

$>\quad$ Immediately after taking part in an unannounced ISS, participants must be given the opportunity to retrain on manikins and/or be provided with written guidelines.

$>$ Facilitators of the debriefing must write a report based on the information that emerges. This report must be approved by ISS participants and subsequently distributed to all department staff.

$>\quad$ If suggested changes are relevant, management and the department's quality coordinator must assist with problem solving and work to implement the recommended changes.

\section{Debriefing}

Scheduled to take place immediately after each unannounced ISS, all debriefing sessions were facilitated by an obstetrician (JLS) and a midwife (KSA). The debriefing sessions explored the participant's views on organisational learning, the individual and team learning, and proposals for organisational changes in practices could also be put forward. The debriefing sessions were oral, and the facilitators took notes. The debriefing sessions lasted 30-60 min and comprised three phases: description, analysis and application [24]. 
Figure 4.1 Healthcare professional groups eligible to complete questionnaires administered before (Pre-Q) and within three to nine months after (Post-Q) implementation of unannounced in situ simulation (ISS), and healthcare professional groups eligible for recruitment to unannounced ISS.

QUESTIONONAIRE (PRE-Q): BEFORE IMPLEMENTATION OF ISS: June 2003-June 2006

Questionnaire for all healthcare professional groups when mandatory planned obstetric training was implemented, but before unannounced ISS was implemented.

Eligible for questionnaire: $\mathrm{N}=220$

- Obstetricians: 28

- Trainee obstetricians: 21

- $\quad$ Specialised midwives: 21

- Midwives: 84

- Auxiliary nurses: 24

- Nurses: 42

IMPLEMENTATION OF UNANNOUNCED ISS: March-August 2007

Healthcare professional groups eligible for recruitment to ISS:

- Obstetricians

- Trainee obstetricians

- $\quad$ Specialised midwives

- Midwives

- Auxiliary nurses

- Nurses

QUESTIONAIRE (Post-Q): 3-9 MONTHS AFTER IMPLEMENTATION OF UNANNOUNCED ISS: November 2007-January 2008

Questionnaire for all participating and non-participating healthcare professionals after implementation of unannounced ISS.

Eligible for questionnaire: $\mathrm{N}=178$

- $\quad$ Obstetricians: 21

- Trainee obstetricians: 14

- $\quad$ Specialised midwives: 14

- Midwives 64

- Auxiliary nurses: 30

- Nurses: 35

The facilitators in the debriefing session (JLS, KSA) wrote a report that had to be approved by all the ISS participants. Upon approval, the report was distributed in the department by email, website and on notice boards. The department's managerial team.

Participants eligible for questionnaires and as ISS participants

Eligible participants comprised staff from all healthcare professional groups working on the labour ward (figure 4.1) and they were all invited to complete questionnaires before 
(pre-Q) and after implementation (post-Q) of ISS. Staff members eligible for taking part in the unannounced ISS were recruited randomly on the day designated for the ISS from among the healthcare professional groups at work.

\section{Questionnaires}

Pre- $Q$ and post- $Q$ questionnaires, administered as presented in figure 4.1, comprised items using a five-point Likert scale, ranging from $1=$ strongly disagree to $5=$ strongly agree or from $1=$ never to $5=$ very often.

The paper questionnaires were distributed via the internal mail system, and after filling them out by hand, staff members were asked to return them in either closed boxes placed in the wards or to two research group members (JLS or PL).

The pre- $Q$ addressed issues like whether planned and mandatory obstetric training was perceived as a good idea and whether unannounced ISS was perceived as potentially stressful and unpleasant and/or as instructive and educational (table 4.1). The post- $Q$ was given to all staff, that was, both ISS participants and staff members who did not participate in the ISS. Some questions addressed to all staff in the pre-Q were repeated after implementation. Hence, the post- $Q$ asked all of the healthcare professionals whether ISS was a good idea and whether they perceived it to be stressful and unpleasant (table 4.2). Furthermore, after implementation (post-Q) they were also asked whether they knew about the ISS, were anxious about them or hoped more of them would follow. They were also asked about their view on the impact of ISS on future interprofessional collaboration, its perceived helpfulness in preparing healthcare professionals for real emergencies and whether the unannounced ISS encouraged staff to study the literature and guidelines, and finally on whether it would impact the level of individual practice (table 4.3). Tables 4.1-4.3 present a translated, condensed version of the original questionnaire items in Danish.

\section{Data analysis}

Questionnaire data were transferred in coded form from the paper version to a 2003 Excel spreadsheet by JLS and PL and prepared for statistical analysis performed by SR.

After the debriefing session, the facilitators (JLS and KSA) documented the findings in five reports, which, based on the debriefing session, were then reanalysed using content analysis to condense the acquired information [25].

\section{Statistical analysis}

The questionnaire responses based on a Likert scale were treated as ordinal data. For questions answered twice by the same participants (pre-Q and post-Q), the proportion of participants giving the same responses on the two occasions, reflecting marginal homogeneity of ordinal tables of agreement, was quantified by weighted $\mathrm{k}$ statistics. Marginal homogeneity was also formally tested by a generalisation of the McNemar test for paired proportions appropriate to multicategory ordinal rating data [26]. A value of $\mathrm{k}$ close to zero means the paired proportions differed between the two measurement 
occasions, and close to one means agreement between the two measurement occasions. The Cochran-Armitage test for trend was used to determine whether there was an association between responses to ordinal questionnaire items and participation in unannounced ISS (yes/no)[26]. The Kruskal-Wallis test was used to determine whether responses to the questionnaire differed by healthcare professional groups. Our analyses have not been adjusted for multiple statistical testing, and due to the large number of tests, no conclusions were drawn on associations of borderline significance. SAS V.9.2 and R V.3.0.2 were used for the statistical analysis.

Table 4.1 Pre-Q-1 (2003-2006): Healthcare professionals' perceptions of planned obstetric training and of unannounced in situ simulation (ISS) (referred to as 'unannounced drill' in the questionnaires') before implementation of ISS.

\begin{tabular}{|c|c|c|c|c|c|}
\hline & $\begin{array}{l}\text { Planned multi- } \\
\text { professional } \\
\text { obstetric train- } \\
\text { ing is a good } \\
\text { idea. }\end{array}$ & $\begin{array}{l}\text { Mandatory } \\
\text { planned multi- } \\
\text { professional } \\
\text { obstetric training } \\
\text { is a good idea }\end{array}$ & $\begin{array}{l}\text { Unannounced } \\
\text { drills in ob- } \\
\text { stetric emer- } \\
\text { gencies are a } \\
\text { good idea }\end{array}$ & $\begin{array}{l}\text { Unannounced } \\
\text { drills in ob- } \\
\text { stetric emer- } \\
\text { gencies are } \\
\text { stressful and } \\
\text { unpleasant }\end{array}$ & $\begin{array}{l}\text { Unannounced } \\
\text { drills in ob- } \\
\text { stetric emer- } \\
\text { gencies are } \\
\text { instructive and } \\
\text { educational }\end{array}$ \\
\hline $\begin{array}{l}\text { Strongly } \\
\text { diagree }\end{array}$ & $1(1 \%)$ & $1(1 \%)$ & $1(1 \%)$ & 27 (14\%) & $1(1 \%)$ \\
\hline Disagree & $3(1 \%)$ & $3(1 \%)$ & $16(8 \%)$ & 75 (38\%) & $10(5 \%)$ \\
\hline Uncertain & 0 & $2(1 \%)$ & $42(21 \%)$ & $45(23 \%)$ & $34(17 \%)$ \\
\hline Agree & 31 (15\%) & $36(18 \%)$ & $55(28 \%)$ & 41 (21\%) & $69(35 \%)$ \\
\hline $\begin{array}{l}\text { Strongly } \\
\text { agree }\end{array}$ & $167(83 \%)$ & 159 (79\%) & $82(42 \%)$ & $11(6 \%)$ & 84 (42\%) \\
\hline Total (\%) & 202 (100\%) & 201 (100\%) & $196(100 \%)$ & 199 (101\%) & $198(100 \%)$ \\
\hline $\begin{array}{l}\text { Non res- } \\
\text { ponders }\end{array}$ & $18 / 220(8 \%)$ & $19 / 220(9 \%)$ & $24 / 220$ (11\%) & $21 / 220(10 \%)$ & $22 / 220(10 \%)$ \\
\hline
\end{tabular}

\section{Ethical permission}

Since the study did not involve patients, no approval was required under Danish regulations. Questionnaire respondents were assigned identification numbers known only to JLS and PL. During the analysis and reporting phase, all data were treated as nontraceable information.

\section{Results}

\section{Response rates to questionnaires}

The response rate to the pre-Q for all staff members was 196-207/220 (89-94\%), which varied for different questions. For the individual staff groups, the highest response rate was obstetricians: 27/28; trainee obstetricians: $21 / 21$; specialised midwives: $18 / 21$; midwives: $80 / 84$; auxiliary nurses: $21 / 24$; and nurses: $40 / 42$. The response rate to the post-Q for all staff members was $84-86 \%$ (149-155/178). For the individual staff groups, 
the highest response rate was obstetricians: $21 / 21$; trainee obstetrician: $14 / 14$; specialised midwives: 13/14; midwives 59/64; auxiliary nurses: 19/30; and nurses: 28/35.

\section{Number of ISS conducted and ISS participants}

Five out of ten of the scheduled ISS were conducted and analysed, while the other five were cancelled due to the heavy workload on the labour ward, a shortage of labour ward delivery rooms and/or shortage of staff. Altogether, 23 healthcare professionals out of a possible 178 eligible staff members participated in an ISS and distribution among the staff was as follows: three obstetricians, four trainee obstetricians, three specialised midwives (one participated twice), five midwives, four auxiliary nurses and four obstetric nurses. The response rate after implementation of ISS was 18/23 (79\%) among ISS participants and 131-135/155 (85-88\%) among non-participants.

\section{Perceptions of ISS before and after implementation}

Table 4.1 shows staff perceptions of planned and mandatory training and unannounced ISS before implementation of ISS. Table 4.2 shows a comparison of staff perceptions before and after implementation of ISS. Before implementation, 137/196 (70\%) of all participants 'agreed' or 'strongly agreed' that unannounced ISS was a good idea and this increased to $135 / 153$ (89\%) after implementation ( $p<0.0001$ ). In summary, 52/199 (26\%) 'agreed' or 'strongly agreed' that unannounced ISS was stressful or unpleasant before implementation compared with an increase of 50/153 (33\%) afterwards ( $p=0.0001)$.

\section{Perception of ISS among non-participants and ISS participants}

Table 4.3 summarises the perceptions of ISS among participating and non-participating staff. Questions on information and discussion about ISS showed that staff participating in ISS had heard about ISS and discussed ISS significantly more often. Participating staff also expected ISS to prepare them for real emergencies significantly more often, while both participating and non-participating staff found ISS to be important for future cooperation and for identifying changes in work processes to the same extent. Responses did not differ between staff participating in ISS and non-participating staff concerning anxiety about ISS and whether ISS was perceived to be stressful or unpleasant. Participant responses differed, however, depending on their profession. The question rating whether ISS was stressful or unpleasant was rated as 'agree' or 'strongly agree' by $1 / 13$ (8\%) specialised midwives; $2 / 21$ (10\%) obstetricians; $3 / 14$ (21\%) trainee obstetricians; $8 / 27$ (30\%) nurses; $7 / 19$ (37\%) auxiliary nurses; and 29/59 (50\%) midwives ( $p=0.0082$ using the Kruskal-Wallis test for the full set of ordinal responses). Responses to the question on perceived anxiety towards ISS also differed by profession. Midwives rated 'agree' or 'strongly agree' to feeling anxiety about ISS, 15/59 (25\%) compared with 0/21 (00\%) for obstetricians $(p=0.0023)$. Participating and nonparticipating staff reported studying guidelines and reading the literature to the same degree. This was not the case for this question, however, with regards to profession, where 4/13 (31\%) trainee obstetricians and 5/14 (36\%) specialised midwives 'agreed' or 'strongly agreed' that they read educa- 
tional material to prepare for ISS, which represents a higher proportion than the other professions ( $p=0.0019)$.

\section{Organisational impact}

Analysis of the reports from the debriefing sessions resulted in several learning points at individual, team and organisational levels. Online supplementary table 4.52 presents a comprehensive list concerning organisational impact. Several of the practical changes recommended after ISS were implemented, for example, improvements in operating the telephone system, checking stopwatches in labour rooms, checking content of delivery room cabinets and the setup of blood pressure monitoring systems in the postnatal ward. 
Table 4. 2 Data from the pre-Q and post-Q questionnaires: Perceptions of healthcare professionals before (2003-2006) and after (2007-2008) the implementation of unannounced in situ simulation (ISS) (referred to as 'unannounced drill' in the questionnaires). Responses were rated on a five-point Likert scale from strongly disagree to strongly agree. The questionnaire statements are shown in italics.

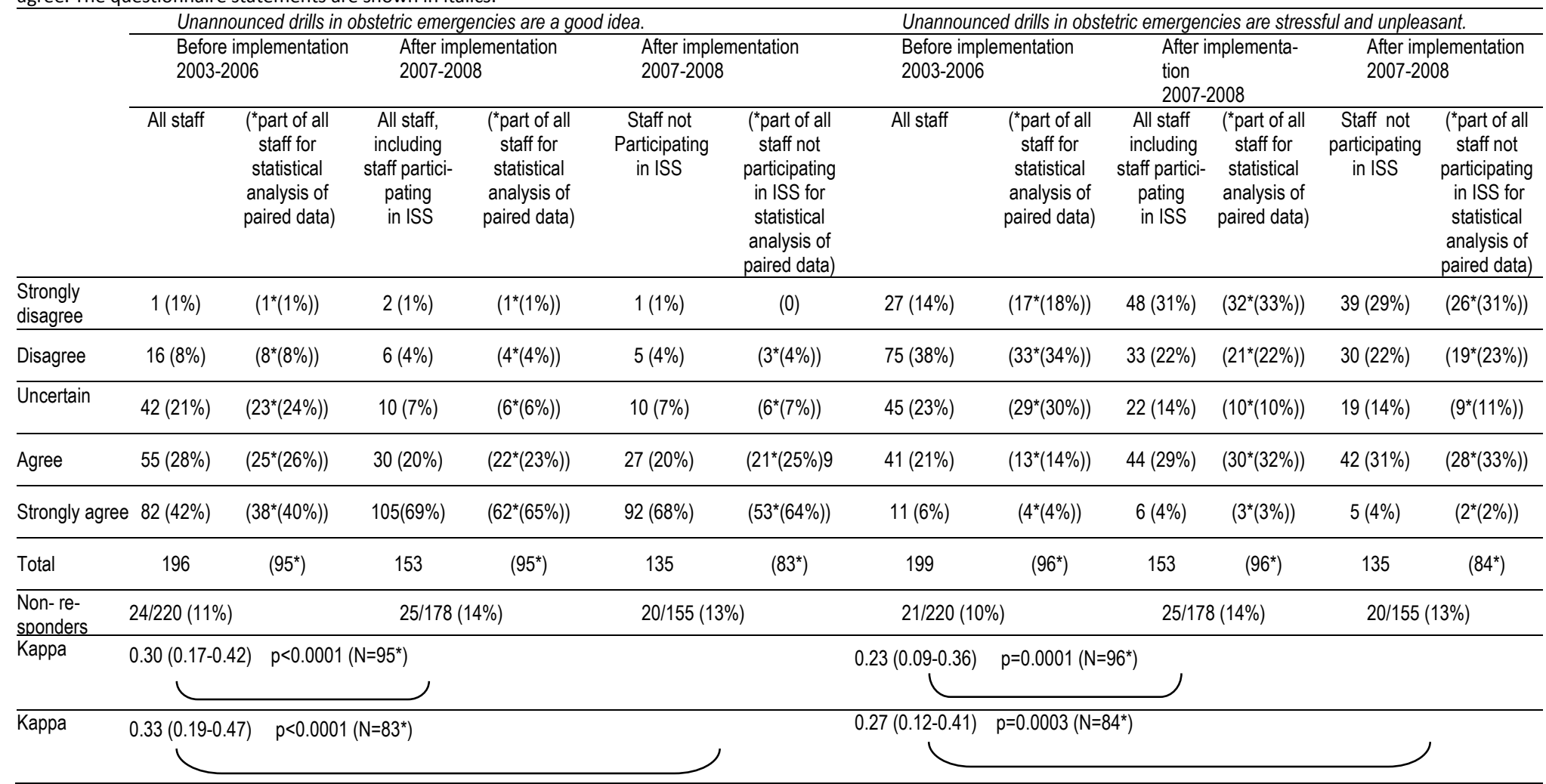

* ( ) represents the number of respondents included in the statistical test, as the test is based on paired data and only respondents who completed both pre-Q and post-Q questionnaires were part of the statistical analysis. Annual staff turnover due to, e.g. maternity leave and job changes reduced staff able to responds twice to both pre- $Q$ and post- $Q$ questionnaires 
Table 4.3 Data from post-Q questionnaire: Healthcare professionals' perceptions after implementation of unannounced in situ simulation (ISS) (referred to as "unannounced drills" in the questionnaires).

\begin{tabular}{|c|c|c|c|c|c|c|c|c|c|c|c|c|c|c|c|c|c|c|c|c|c|c|c|c|c|c|}
\hline \multirow{3}{*}{$\begin{array}{l}\text { Question } \\
\text { items } \\
\text { Staff +/- } \\
\text { ISS } \\
\text { Strongly } \\
\text { disagree }\end{array}$} & \multicolumn{2}{|c|}{$\begin{array}{l}\text { Did you hear } \\
\text { about the } \\
\text { unannounced } \\
\text { drills? }\end{array}$} & \multicolumn{2}{|c|}{$\begin{array}{l}\text { Did you talk } \\
\text { about the } \\
\text { clinical } \\
\text { content of } \\
\text { unannounced } \\
\text { drills? }\end{array}$} & \multicolumn{2}{|c|}{$\begin{array}{l}\text { Did you talk } \\
\text { about } \\
\text { participating } \\
\text { in unan- } \\
\text { nounced } \\
\text { drills? }\end{array}$} & \multicolumn{2}{|c|}{$\begin{array}{l}\text { Were you } \\
\text { anxious } \\
\text { about the } \\
\text { unannounced } \\
\text { drills? }\end{array}$} & \multicolumn{2}{|c|}{$\begin{array}{l}\text { Did you look } \\
\text { forward to } \\
\text { the unan- } \\
\text { nounced } \\
\text { drills? }\end{array}$} & \multicolumn{2}{|c|}{$\begin{array}{l}\text { Do you think } \\
\text { that unan- } \\
\text { nounced drills } \\
\text { are important } \\
\text { for future } \\
\text { cooperation? }\end{array}$} & \multicolumn{2}{|c|}{$\begin{array}{l}\text { Do you think } \\
\text { that unan- } \\
\text { nounced drills } \\
\text { are important } \\
\text { to identify } \\
\text { necessary } \\
\text { changes in } \\
\text { work pro- } \\
\text { cesses? }\end{array}$} & \multicolumn{2}{|c|}{$\begin{array}{l}\text { Do you think } \\
\text { that unan- } \\
\text { nounced drills } \\
\text { are helpful in } \\
\text { preparing for } \\
\text { real-life } \\
\text { emergencies? }\end{array}$} & \multicolumn{2}{|c|}{$\begin{array}{l}\text { Do you think } \\
\text { planned } \\
\text { obstetric } \\
\text { training is a } \\
\text { prerequisite } \\
\text { for unan- } \\
\text { nounced } \\
\text { drills? }\end{array}$} & \multicolumn{2}{|c|}{$\begin{array}{l}\text { Did you study } \\
\text { the written } \\
\text { reports on the } \\
\text { unannounced } \\
\text { drills? }\end{array}$} & \multicolumn{2}{|c|}{$\begin{array}{l}\text { Did you study } \\
\text { clinical } \\
\text { guidelines } \\
\text { because of } \\
\text { the unan- } \\
\text { nounced } \\
\text { drills? }\end{array}$} & \multicolumn{2}{|c|}{$\begin{array}{l}\text { Did you study } \\
\text { other written } \\
\text { materials or } \\
\text { literature } \\
\text { because of } \\
\text { the unan- } \\
\text { nounced } \\
\text { drills? }\end{array}$} & \multicolumn{2}{|c|}{$\begin{array}{l}\text { Did you train } \\
\text { on a delivery } \\
\text { manikin } \\
\text { because of } \\
\text { the unan- } \\
\text { nounced } \\
\text { drills? }\end{array}$} \\
\hline & -ISS & +ISS & -ISS & +ISS & -ISS & +ISS & -ISS & +ISS & -ISS & +ISS & -ISS & +ISS & -ISS & +ISS & -ISS & +ISS & -ISS & +ISS & -ISS & +ISS & -ISS & +ISS & -ISS & +ISS & $-I S S$ & +ISS \\
\hline & $\begin{array}{l}4 \\
(3 \%)\end{array}$ & 0 & $\begin{array}{l}38 \\
(28 \%)\end{array}$ & $\begin{array}{l}1 \\
(6 \%)\end{array}$ & $\begin{array}{l}44 \\
(33 \%)\end{array}$ & $\begin{array}{l}1 \\
(6 \%)\end{array}$ & $\begin{array}{l}56 \\
(41 \%)\end{array}$ & $\begin{array}{l}11 \\
(61 \%)\end{array}$ & $\begin{array}{l}11 \\
(8 \%)\end{array}$ & $\begin{array}{l}1 \\
(6 \%)\end{array}$ & $\begin{array}{l}1 \\
(1 \%)\end{array}$ & $\begin{array}{l}1 \\
(6 \%)\end{array}$ & $\begin{array}{l}12 \\
(9 \%)\end{array}$ & $\begin{array}{l}1 \\
(6 \%)\end{array}$ & $\begin{array}{l}22 \\
(16 \%)\end{array}$ & 0 & $\begin{array}{l}12 \\
(9 \%)\end{array}$ & $\begin{array}{l}2 \\
(11 \%)\end{array}$ & $\begin{array}{l}35 \\
(26 \%)\end{array}$ & $\begin{array}{l}1 \\
(6 \%)\end{array}$ & $\begin{array}{l}36 \\
(27 \%)\end{array}$ & $\begin{array}{l}5 \\
(28 \%)\end{array}$ & $\begin{array}{l}41 \\
(31 \%)\end{array}$ & $\begin{array}{l}6 \\
(33 \%)\end{array}$ & $\begin{array}{l}57 \\
(44 \%)\end{array}$ & $\begin{array}{l}7 \\
(39 \%)\end{array}$ \\
\hline Disagree & $\begin{array}{l}12 \\
(9 \%)\end{array}$ & 0 & $\begin{array}{l}53 \\
(39 \%)\end{array}$ & $\begin{array}{l}5 \\
(27 \%)\end{array}$ & $\begin{array}{l}48 \\
(35 \%)\end{array}$ & $\begin{array}{l}4 \\
(22 \%)\end{array}$ & $\begin{array}{l}34 \\
(25 \%)\end{array}$ & $\begin{array}{l}5 \\
(28 \%)\end{array}$ & $\begin{array}{l}15 \\
(11 \%)\end{array}$ & $\begin{array}{l}1 \\
(6 \%)\end{array}$ & $\begin{array}{l}4 \\
(3 \%)\end{array}$ & $\begin{array}{l}1 \\
(6 \%)\end{array}$ & $\begin{array}{l}11 \\
(8 \%)\end{array}$ & $\begin{array}{l}1 \\
(6 \%)\end{array}$ & $\begin{array}{l}15 \\
(11 \%)\end{array}$ & $\begin{array}{l}1 \\
(6 \%)\end{array}$ & $\begin{array}{l}7 \\
(5 \%)\end{array}$ & $\begin{array}{l}1 \\
(6 \%)\end{array}$ & $\begin{array}{l}22 \\
(16 \%)\end{array}$ & $\begin{array}{l}1 \\
(6 \%)\end{array}$ & $\begin{array}{l}39 \\
(29 \%)\end{array}$ & $\begin{array}{l}6 \\
(33 \%)\end{array}$ & $\begin{array}{l}42 \\
(32 \%)\end{array}$ & $\begin{array}{l}6 \\
(33 \%)\end{array}$ & $\begin{array}{l}21 \\
(16 \%)\end{array}$ & $\begin{array}{l}3 \\
(17 \%)\end{array}$ \\
\hline Uncertain & 0 & 0 & $\begin{array}{l}9 \\
(7 \%)\end{array}$ & $\begin{array}{l}1 \\
(6 \%)\end{array}$ & $\begin{array}{l}5 \\
(4 \%)\end{array}$ & 0 & $\begin{array}{l}21 \\
(16 \%)\end{array}$ & 0 & $\begin{array}{l}38 \\
(28 \%)\end{array}$ & $\begin{array}{l}4 \\
(22 \%)\end{array}$ & $\begin{array}{l}12 \\
(9 \%)\end{array}$ & 0 & $\begin{array}{l}57 \\
(42 \%)\end{array}$ & $\begin{array}{l}2 \\
(11 \%)\end{array}$ & $\begin{array}{l}47 \\
(35 \%)\end{array}$ & $\begin{array}{l}4 \\
(22 \%)\end{array}$ & $\begin{array}{l}15 \\
(11 \%)\end{array}$ & $\begin{array}{l}2 \\
(11 \%)^{\prime}\end{array}$ & $\begin{array}{l}7 \\
(5 \%)\end{array}$ & $\begin{array}{l}2 \\
(11 \%)\end{array}$ & $\begin{array}{l}12 \\
(9 \%)\end{array}$ & $\begin{array}{l}2 \\
(11 \%)\end{array}$ & $\begin{array}{l}23 \\
(17 \%)\end{array}$ & $\begin{array}{l}3 \\
(17 \%)\end{array}$ & $\begin{array}{l}26 \\
(20 \%)^{\prime}\end{array}$ & $\begin{array}{l}1 \\
(6 \%)\end{array}$ \\
\hline Agree & $\begin{array}{l}51 \\
(38 \%)\end{array}$ & $\begin{array}{l}2 \\
(11 \%)\end{array}$ & $\begin{array}{l}31 \\
(23 \%)\end{array}$ & $\begin{array}{l}10 \\
(55 \%)\end{array}$ & $\begin{array}{l}35 \\
(26 \%)\end{array}$ & $\begin{array}{l}13 \\
(72 \%)\end{array}$ & $\begin{array}{l}19 \\
(14 \%)\end{array}$ & $\begin{array}{l}1 \\
(6 \%)\end{array}$ & $\begin{array}{l}40 \\
(30 \%)\end{array}$ & $\begin{array}{l}5 \\
(27 \%)\end{array}$ & $\begin{array}{l}19 \\
(14 \%)\end{array}$ & $\begin{array}{l}3 \\
(17 \%)\end{array}$ & $\begin{array}{l}26 \\
(19 \%)\end{array}$ & $\begin{array}{l}8 \\
(44 \%)\end{array}$ & $\begin{array}{l}36 \\
(27 \%)\end{array}$ & $\begin{array}{l}9 \\
(50 \%)\end{array}$ & $\begin{array}{l}46 \\
(34 \%)\end{array}$ & $\begin{array}{l}8 \\
(44 \%)\end{array}$ & $\begin{array}{l}46 \\
(34 \%)\end{array}$ & $\begin{array}{l}9 \\
(50 \%)\end{array}$ & $\begin{array}{l}44 \\
(32 \%)\end{array}$ & $\begin{array}{l}4 \\
(22 \%)\end{array}$ & $\begin{array}{l}23 \\
(17 \%)\end{array}$ & $\begin{array}{l}3 \\
(17 \%)\end{array}$ & $\begin{array}{l}20 \\
(15 \%)\end{array}$ & $\begin{array}{l}4 \\
(22 \%)\end{array}$ \\
\hline $\begin{array}{l}\text { Strongly } \\
\text { agree }\end{array}$ & $\begin{array}{l}68 \\
(50 \%)\end{array}$ & $\begin{array}{l}16 \\
(89 \%)\end{array}$ & $\begin{array}{l}4 \\
(3 \%)\end{array}$ & $1(6 \%)$ & $\begin{array}{l}3 \\
(2 \%)\end{array}$ & 0 & $\begin{array}{l}5 \\
(4 \%)\end{array}$ & $\begin{array}{l}1 \\
(6 \%)\end{array}$ & $\begin{array}{l}31 \\
(23 \%)\end{array}$ & $\begin{array}{l}7 \\
(38 \%)\end{array}$ & $\begin{array}{l}98 \\
(73 \%)\end{array}$ & $\begin{array}{l}13 \\
(72 \%)\end{array}$ & $\begin{array}{l}28 \\
(21 \%)\end{array}$ & $\begin{array}{l}6 \\
(33 \%)\end{array}$ & $\begin{array}{l}15 \\
(11 \%)\end{array}$ & $\begin{array}{l}4 \\
(22 \%)\end{array}$ & $\begin{array}{l}55 \\
(41 \%)\end{array}$ & $\begin{array}{l}5 \\
(28 \%)\end{array}$ & $\begin{array}{l}25 \\
(19 \%)\end{array}$ & $\begin{array}{l}5 \\
(28 \%)\end{array}$ & $\begin{array}{l}4 \\
(3 \%)\end{array}$ & $\begin{array}{l}1 \\
(6 \%)\end{array}$ & $\begin{array}{l}4 \\
(3 \%)\end{array}$ & 0 & $\begin{array}{l}7 \\
(5 \%)\end{array}$ & $\begin{array}{l}3 \\
(17 \%)\end{array}$ \\
\hline Total (\%) & 135 & 18 & 135 & 18 & 135 & 18 & 135 & 18 & 135 & 18 & 134 & 18 & 134 & 18 & 135 & 18 & 135 & 18 & 135 & 18 & 135 & 18 & 133 & 18 & 131 & 18 \\
\hline $\begin{array}{l}\text { Non- } \\
\text { responders }\end{array}$ & $\begin{array}{l}20 / 155 \\
(13 \%)\end{array}$ & $\begin{array}{l}5 / 23 \\
(21 \%)\end{array}$ & $\begin{array}{l}20 / 155 \\
(13 \%)\end{array}$ & $\begin{array}{l}5 / 23 \\
(21 \%)\end{array}$ & $\begin{array}{l}20 / 155 \\
(13 \%)\end{array}$ & $\begin{array}{l}5 / 23 \\
(21 \%)\end{array}$ & $\begin{array}{l}20 / 155 \\
(13 \%)\end{array}$ & $\begin{array}{l}5 / 23 \\
(21 \%)\end{array}$ & $\begin{array}{l}20 / 155 \\
(13 \%)\end{array}$ & $\begin{array}{l}5 / 23 \\
(21 \%)\end{array}$ & $\begin{array}{l}21 / 155 \\
(14 \%)\end{array}$ & $\begin{array}{l}5 / 23 \\
(21 \%)\end{array}$ & $\begin{array}{l}21 / 155 \\
(14 \%)\end{array}$ & $\begin{array}{l}5 / 23 \\
(21 \%)\end{array}$ & $\begin{array}{l}20 / 155 \\
(13 \%)\end{array}$ & $\begin{array}{l}5 / 23 \\
(21 \%)\end{array}$ & $\begin{array}{l}20 / 155 \\
(13 \%)\end{array}$ & $\begin{array}{l}5 / 23 \\
(21 \%)\end{array}$ & $\begin{array}{l}20 / 155 \\
(13 \%)\end{array}$ & $\begin{array}{l}5 / 23 \\
(21 \%)\end{array}$ & $\begin{array}{l}20 / 155 \\
(13 \%)\end{array}$ & $\begin{array}{l}5 / 23 \\
(21 \%)\end{array}$ & $\begin{array}{l}22 / 155 \\
(14 \%)\end{array}$ & $\begin{array}{l}5 / 23 \\
(21 \%)\end{array}$ & $\begin{array}{l}24 / 155 \\
(15 \%)\end{array}$ & $\begin{array}{l}5 / 23 \\
(21 \%)\end{array}$ \\
\hline $\begin{array}{l}\text { Cochrane- } \\
\text { Armitage } \\
\text { trend test }\end{array}$ & 0.009 & & 0.00 & & 0.0 & 005 & 0.1 & 218 & 0.1 & 739 & & 5987 & & 4427 & & 056 & & 5111 & & 215 & & 095 & 0.64 & 433 & 0.25 & 550 \\
\hline
\end{tabular}

Responses are presented separately for staff who participated in the ISS (+ ISS) and who did not participate in the unannounced ISS (- ISS). Responses to questionnaire items were given on a fivepoint Likert scale from strongly disagree to strongly agree. The questionnaire statements are shown in bold 


\section{Discussion}

The unannounced ISS implemented over a 6-month period were considered to be a good idea by the majority of staff members, and acceptance increased after implementation. Nevertheless, approximately one-third of all staff members found unannounced ISS to be potentially stressful and unpleasant, and this number increased after implementation of ISS. In particular, midwives perceived unannounced ISS as unpleasant and stressful and reported related anxiety, whereas obstetricians reported no anxiety at all. When planning multiprofessional educational interventions, like unannounced ISS, it is therefore important to consider these differences in perceptions between groups of healthcare professionals.

Almost all staff members, and both ISS participants and nonparticipating staff, thought that unannounced ISS was important for future collaboration. Three-quarters of the staff participating in ISS indicated a belief that unannounced ISS would enhance their performance in future real emergencies, whereas the corresponding number among nonparticipants was only about one-third. Approximately half of the non-participating staff reported having studied the written reports on the unannounced ISS debriefing sessions. An ongoing question is how does ISS, involving only few staff members, influence all staff members and the organisation as a whole? The findings of the present study suggest that effects of the intervention (ISS) can be extrapolated to the entire staff to some extent, for example, to the non-participants.

Our results support the conclusion that only five unannounced ISS were sufficient to provide the organisation with valuable information on weaknesses in the system, including information that may prove difficult to obtain elsewhere. This is consistent with conclusions in other studies on the impact factor of ISS, thus emphasising the system perspective of ISS $[12,14-19,22]$. Overall, the managerial team considered the organisational value of implementing unannounced ISS in the department to be of major importance. In this study, the research group included members of the department's managerial team and a midwife working as quality coordinator, which we considered useful in the process of evaluating the need for implementation of the proposed changes.

It could be argued that some of the system weaknesses could also have been identified with announced ISS, which is presumably easier to organise and implement. It seems unlikely, however, that problems with, for example, telephones and the calling system would have been exposed quite as noticeably as they were during the unannounced ISS. This may be due to the unpreparedness aspect of unannounced ISS, which potentially allows a more authentic simulation of the stress element experienced in real-life obstetric emergencies. This phenomenon warrants further investigation in future studies comparing announced and unannounced ISS. A potentially powerful contributor to the effects of simulation is the simulation's level of fidelity [27]. The setting in which the simu- 
lation takes place may partially determine the fidelity, but more research is needed to clarify how announced and unannounced ISS influence the level of fidelity and learning.

Implementing unannounced ISS was time consuming and challenging for the research group, which is why strong support from the management team was of paramount importance. A shortage of staff members and delivery rooms meant we could only carry out 5 instead of the 10 unannounced ISS originally planned.

The study has limitations and the design of the study can be characterised as a compromise design, which is not unusual in educational research. A randomised design with control groups would have been preferable. We were unable to identify any randomised studies comparing ISS and simulation training in a simulation centre or in-house training in hospital facilities. We were also unable to identify studies comparing announced and unannounced ISS [14]. Another limitation was the lack of validated questionnaires. Use of validated instruments to measure the level of anxiety, stress and motivation should be considered for future studies [28]. Furthermore, this study did not take an explorative approach and hence was not designed to elaborate upon and explain why problems appeared during the ISS and the debriefing session. The study was small and resulted in the inclusion of only five unannounced ISS, all conducted in the same hospital. This provided the opportunity to measure local effects but also raised the issue as to whether the results can be transferred to other departments. All the unannounced ISS were carried out during daytime hours which means our study does not address whether conducting unannounced ISS during night shifts or on weekends would produce different or new findings.

The five unannounced ISS in this study appear to have had a positive organisational impact by providing information to support organisational changes and changes in the clinical management of the department. To date, the ISS literature has primarily focused on organisational impact, neglecting the perceptions of participating and nonparticipating staff, which was the major focus of our study. Our findings indicate that further studies are warranted to explore the mechanisms at play in relation to the differences in perception of unannounced ISS between various healthcare professional groups that emerged during our study and their implications for learning. 


\section{Main messages}

Midwives perceived unannounced in situ simulation (ISS) as unpleasant and stressful and reported related anxiety, whereas the obstetricians reported no anxiety at all. When planning unannounced ISS in a multiprofessional environment, it is important to consider differences in the perception between healthcare professional groups

$>\quad$ Despite the fact that the number of staff members with an overall positive perception of unannounced ISS increased with its implementation, one-third still indicated unannounced ISS to be stressful and unpleasant

$>\quad$ Planning and implementation of unannounced ISS was time consuming and challenging. Strong support from the managerial team was of paramount importance

$>\quad$ Even after conduction of only five unannounced ISS, we were able to identify important areas for organizational development and improvement.

\section{Current research questions}

$>\quad$ How does the setting, that is, ISS versus off-site simulation of obstetric training, affect the level of learning?

What role do factors like the fidelity of simulation setting, stress and motivation play in relation to the differences between healthcare professionals' perceptions of the simulation setting and what implications do they have on learning?

\section{Postscript}

Based on experiences from the present study, ISS has recently been implemented in the same department but involves also anaesthesia trainee and consultants, anaesthesia nurses and surgical nurses, in addition to the same obstetric staff members. Our recent work on implementing ISS has focused on applying experiences from our previous ISS work. Apart from appointing a working committee with representatives from each healthcare professional group, we have worked closely to involve all of the healthcare professionals and the management. A protocol article describes this new ISS intervention[28]. 


\section{Acknowledgements}

Psychologists Morten Jack and Dorthe Degnegaard, Development and Quality Improvement Department, Rigshospitalet, University of Copenhagen, Denmark, helped to design the structure of the debriefing session after the unannounced ISS and provided feedback to the instructors. The authors would like to thank Mereke Gosira, Department of Educational Development and Research, Faculty of Health, Medicine and Life Sciences, Maastricht University, the Netherlands, and obstetric consultant Marianne Johansen, Department of Obstetrics, Rigshospitalet, University of Copenhagen, for editing the manuscript.

\section{Contributors}

JLS conceived the idea, acquired data for the prequestionnaire, drafted this paper and obtained funding jointly with BO. PL acquired the data for the postquestionnaire. JLS, PL, MS, KSA and PE contributed to the practical design and practical completion of this study. SR performed in cooperation with JLS the statistical analysis. All authors contributed to the discussion and interpretation of the data as well as a critical revision of the manuscript. BO and CV discussed the manuscript in detail, and all authors approved the final manuscript.

\section{Funding}

The Capital Region of Denmark, a non-profit public organisation, provided funding for this project.

\section{Competing interests}

None.

\section{Provenance and peer review}

Not commissioned; externally peer reviewed. 


\section{References}

1. Drife J. Reducing risk in obstetrics. Qual Health Care 1995;4(:108-14.

2. Hove LD, Bock J, Christoffersen JK, Hedegaard M. Analysis of 127 peripartum hypoxic brain injuries from closed claims registered by the Danish Patient Insurance Association. Acta Obstet Gynecol Scand 2008;87:72-5.

3. Cantwell R, Clutton-Brock T, Cooper G, Dawson A, Drife J, Garrod D, Harper A, Hulbert D, Lucas S, McClure J, et al. Saving Mothers' Lives: Reviewing maternal deaths to make motherhood safer: 2006-2008. The Eighth Report of the Confidential Enquiries into Maternal Deaths in the United Kingdom. BJOG 2011;118 Suppl 1:1-203.

4. Johannsson H, Ayida G, Sadler C. Faking it? Simulation in the training of obstetricians and gynaecologists. Curr Opin Obstet Gynecol 2005;17:557-61.

5. Ellis D, Crofts JF, Hunt LP, Read M, Fox R, James M. Hospital, simulation center, and teamwork training for eclampsia management: a randomized controlled trial. Obstet Gynecol 2008;111:72331.

6. Fransen AF, Van der Ven J, Merien A, de Wit-Zuurendonk L, Houterman S, Mol B, Oei S. Effect of obstetric team training on team performance and medical technical skills: a randomised controlled trial. BJOG 2012;119:1387-93.

7. Merien $A E$, Van der Ven J, Mol BW, Houterman S, Oei SG. Multidisciplinary team training in a simulation setting for acute obstetric emergencies: a systematic review. Obstet Gynecol 2010;115:1021-31.

8. Issenberg SB, McGaghie WC, Petrusa ER, Lee GD, Scalese RJ. Features and uses of high-fidelity medical simulations that lead to effective learning: a BEME systematic review. Med Teach 2005;27:10-28.

9. McGaghie WC, Issenberg SB, Petrusa ER, Scalese RJ. A critical review of simulation-based medical education research: 2003-2009. Med Educ 2010;44:50-63.

10. Maagaard $M$, Johansen $M$, Lottrup $P$, Sorensen JL. Clinical skills training in obstetrics - a descriptive survey of current practice in Denmark. Acta Obstet Gynecol Scand 2012 Jan;91(1):143-6.

11. Siassakos D, Draycott TJ, Crofts JF, Hunt LP, Winter C, Fox R. More to teamwork than knowledge, skill and attitude. BJOG 2010;117:1262-9.

12. Riley W, Davis S, Miller KM, Hansen H, Sweet RM. Detecting breaches in defensive barriers using in situ simulation for obstetric emergencies. Qual Saf Health Care 2010 Oct;19 Suppl 3:i53-i56.

13. Anderson $E$, Black R, Brocklehurst $P$. Acute obstetric emergency drill in England and Wales: a survey of practice. BJOG 2005;112:372-5.

14. Rosen MA, Hunt EA, Pronovost PJ, Federowicz MA, Weaver SJ. In situ simulation in continuing education for the health care professions: a systematic review. J Contin Educ Health Prof 2012;32:243-54.

15. Guise JM, Lowe NK, Deering S, Lewis PO, O'Haire C, Irwin LK, Blaser M, Wood LS, Kanki BG. Mobile in situ obstetric emergency simulation and teamwork training to improve maternal-fetal safety in hospitals. Jt Comm J Qual Patient Saf 2010;36:443-53.

16. Hamman WR, Beaudin-Seiler BM, Beaubien JM, Gullickson AM, Orizondo-Korotko K, Gross AC, Fuqua W, Lammers R. Using in situ simulation to identify and resolve latent environmental threats to patient safety: case study involving operational changes in a labor and delivery ward. Qual Manag Health Care 2010;19:226-30.

17. Bender GJ. In situ simulation for systems testing in newly constructed perinatal facilities. Semin Perinatol 2011;35:80-3.

18. Maslovitz S, Barkai G, Lessing JB, Ziv A, Many A. Recurrent obstetric management mistakes identified by simulation. Obstet Gynecol 2007;109:1295-300.

19. Walker ST, Sevdalis N, McKay A, Lambden S, Gautama S, Aggarwal R, Vincent C. Unannounced in situ simulations: integrating training and clinical practice. BMJ Qual Saf 2013 Jun;22(6):453-8.

20. Calhoun AW, Boone MC, Peterson EB, Boland KA, Montgomery VL. Integrated in-situ simulation using redirected faculty educational time to minimize costs: a feasibility study. Simul Healthc 2011;6:337-44.

21. van Schaik SM, Plant J, Diane S, Tsang L, O'Sullivan P. Interprofessional team training in pediatric resuscitation: a low-cost, in situ simulation program that enhances self-efficacy among participants. Clin Pediatr (Phila) 2011;50:807-15. 
22. Patterson MD, Geis GL, Falcone RA, Lemaster T, Wears RL. In situ simulation: detection of safety threats and teamwork training in a high risk emergency department. BMJ Qual Saf 2013;22:468-77.

23. Sorensen JL, Lokkegaard E, Johansen M, Ringsted C, Kreiner S, McAleer S. The implementation and evaluation of a mandatory multi-professional obstetric skills training program. Acta Obstet Gynecol Scand 2009;88:1107-17.

24. Rudolph JW, Simon R, Dufresne RL, Raemer DB. There's no such thing as "nonjudgmental" debriefing: a theory and method for debriefing with good judgment. Simul Healthc 2006;1:49-55.

25. Hsieh HF, Shannon SE. Three approaches to qualitative content analysis. Qual Health Res 2005;15:1277-88.

26. Agresti A. Categorical Data Analysis. 3rd Edition ed. Wiley; 2013.

27. Norman G, Dore K, Grierson L. The minimal relationship between simulation fidelity and transfer of learning. Med Educ 2012;46:636-47.

28. Sørensen JL, Van der Vleuten C, Lindschou J, Gluud C, Ostergaard D, Leblanc V, Johansen M, Ekelund K, Albrechtsen CK, Pedersen BW, et al. 'In situ simulation' versus 'off site simulation' in obstetric emergencies and their effect on knowledge, safety attitudes, team performance, stress, and motivation: study protocol for a randomized controlled trial. Trials 2013;14:220. 
Table 4.S1.A. Example execution of unannounced in situ simulation (ISS) involving a shoulder dystocia scenario in the labour ward

- $\quad$ The research team, i.e. the ISS instructors, contacted the specialised midwife in charge of the labour ward to inform her that an unannounced ISS would take place. A labour room was selected and the instructors prepared the ISS there unbeknownst to the staff.

- $\quad$ At a conference with all the midwives, the specialised midwife in charge of the labour ward explained that "a patient', i.e. the ISS case, had arrived recently and that she did not know any details.

- When a call arrived from the dedicated labour room, the specialised midwife asked one of the midwives to go to the room. All the midwives on call were eligible to participate in the ISS with, as determined in advance, the exception of midwives who had, for example, recently returned to work after a long sick leave or maternity leave or who had recently been involved in a severe obstetric disaster, such as intrapartum foetal death or maternal death.

- Instructor 1 stood just inside the door and said the following to the midwife selected: 'This is a drill and you should act exactly as you normally would in a real situation. Call for help, ask for and use equipment just as you would in a real situation. There is a healthy 30 -year-old woman in the birting labour bed who is pushing and just about to deliver. Will you please help her?'

- $\quad$ The PRactical $\underline{\text { Obstetric }}$ Multi-Professional Iraining (PROMPT) birthing simulator, provided by Limbs \& Things, was used in this ISS. Instructor 2 held the PROMPT birthing simulator between her legs and controlled the baby mannequin, pushing it out while simultaneously pretending to be a woman in labour.

- The midwife was expected to call an auxiliary nurse and prepare the equipment for a normal delivery.

- Instructor 2 pushed the head of the baby mannequin out and ready for the delivery, but its shoulders could not be delivered because they were impacted behind the symphysis.

- $\quad$ The midwife and auxiliary nurse involved were expected to diagnose shoulder dystocia, call for help and then continue with the delivery, performing relevant obstetric manoeuvres. The midwives and obstetricians who arrived were expected to assist or to take over the manoeuvres, as well as take notes and keep time. The baby mannequin was considered to be born when a midwife or trainee or consultant obstetrician delivered its posterior arm. The team was expected to call the neonatologist. The scenario ceased as soon as the baby mannequin was born and the neonatologist had arrived.

- Instructor 3 observed the proceedings and took notes. 
Table 4.S1.B. Example execution of an unannounced in situ simulation (ISS) involving postpartum bleeding in the labour ward

- The research team, i.e. the ISS instructors, contacted the specialised midwife in charge of the labour ward to inform her that an unannounced ISS would take place. A labour room was selected and the instructors prepared the ISS there unbeknownst to the staff.

- At a conference with all the midwives, the specialised midwife in charge of labour ward explained that "a patient', i.e. the ISS case, had given birth and that a midwife needed to go to the labour room.

- All the midwives on call were eligible to participate in the ISS with, as determined in advance, the exception of midwives who had, for example, recently returned to work after a long sick leave or maternity leave or who had recently been involved in a severe obstetric disaster, such as intrapartum foetal death or maternal death.

- Instructor 1 stood just inside the door and said the following to the midwife selected: 'This is a drill and you should act exactly as you normally would in a real situation. Call for help, ask for and use equipment just as you would in a real situation. There is a healthy 30 -year-old woman in the labour bed who has just given birth a few minutes ago and the placenta has not been delivered. The baby is fine. Will you please help her?'

- A low-tech obstetrical mannequin, provided by Educational + Scientific Products Ltd, was placed on the birthing bed. The obstetrical mannequin contained a foam rubber uterus and a real placenta with umbilical cord hanging out of the vagina. The bleeding was simulated using $1000 \mathrm{ml}$ of artificial blood in a catheter bag with the catheter tube hanging out the vagina. Large nappies were prepared in advance with $250 \mathrm{ml}$ of artificial blood and placed under the obstetrical mannequin as the bleeding proceeded. The upper body of a female mannequin (purchased at a second-hand clothing store) was placed in extension of the obstetrical mannequin.

- Instructor 2, sitting next to the birthing bed, gave the patient's history, showed papers with the patient's pulse and blood pressure and controlled the amount of artificial bleeding.

- The midwife was expected to call an auxiliary nurse and to begin delivering the placenta. Instructor 2 administered the ongoing bleeding and placed nappies with artificial blood under the delivery mannequin. The midwife was expected to call for more help and another midwife, a trainee and a consultant obstetrician. The team was expected to manage the postpartum bleeding in accordance with guidelines. When the team estimated a blood loss greater than $1000 \mathrm{ml}$, they were expected to refer the patient to surgery. When this occurred, the scenario ceased.

- Instructor 3 observed the proceedings and took notes. 
Table 4.S1.C. Example execution of an unannounced in situ simulation (ISS) involving severe preeclampsia with eclamptic convulsions in the postnatal ward

- The research team, i.e. the ISS instructors, contacted the nurse in charge of the postnatal ward to inform her that an unannounced ISS would take place. A ward room was selected and the instructors prepared the ISS there unbeknownst to the staff.

- $\quad$ At a conference with all nurses, the nurse in charge of the ward explained that "a patient', i.e. the ISS case, had arrived and then she asked a nurse to go to the ward room.

- $\quad$ All the nurses on call were eligible to participate in the ISS with, as determined in advance, the exception of nurses who had, for example, recently returned to work after a long sick leave or maternity leave or who had recently been involved in a severe obstetric disaster, such as maternal death.

- Instructor 1 stood just inside the door and said the following to the nurse selected: 'This is a drill and you should act exactly as you normally would in a real situation. Call for help, ask for and use equipment just as you would in a real situation. There is a healthy 30 -year-old woman in the bed who just gave birth four hours ago. Her blood pressure went up during delivery and she had an epidural. Her blood pressure settled and the patient is now complaining of severe headache and pain in the upper abdomen. Will you please help her?'

- $\quad$ The upper body of a female mannequin (purchased at a second-hand clothing store) was placed in the hospital bed.

- Instructor 2 sat next to the bed and pretended to be the patient's voice by constantly complaining about having a very severe headache. Instructor 2 also showed papers with the patient's pulse and blood pressure. Instructor 2 shook the mannequin for 60 seconds when the patient had an eclamptic convulsion.

- $\quad$ The nurse was expected to organise measurement of blood pressure and pulse and to call for more help, another nurse and an obstetrician. The team was expected to manage the severe preeclampsia in accordance with guidelines. When the patient had convulsions and the correct medicine was administered, the scenario ceased.

- Instructor 3 observed the proceedings and took notes. 
Table 4.S2. Individual, team and organisational learning points based on the reports from the debriefing sessions after five unannounced in situ simulations (ISS) on the labour ward.

The two facilitators involved in the debriefing wrote a report on the day of the 'in situ simulation' (ISS).

All five reports were structured in the same way: 1) Heading with date and content of the ISS. 2) Participants' names and healthcare professional group' s. 3) Instructors' names and healthcare professional groups. 4) Short description of the ISS scenario. 5) Participants' conclusions based on their perceptions of the scenario. 6) Ideas on how participants are likely to respond in the future to situations that are similar to the ISS. 7) Ideas on changes that are needed in the organisation. The following text is a summary across all five reports.

\section{Learning points for the organisation and suggestions for practical changes:}

- The emergency boxes (haemorrhage box and preeclampsia box), and the related guidelines worked well; however some staff members were unfamiliar with the boxes and the guidelines. It was recommended that all staff should spend time studying the content of the haemorrhage and preeclampsia boxes. This recommendation was included in the introduction for new staff members and in mandatory training.

- $\quad$ Demands for more haemorrhage boxes in the labour ward were granted.

- It was decided to take measures to ensure that intravenous saline was available in all the delivery rooms.

- $\quad$ The ISS gave rise to many discussions about the dysfunctional telephone system; staff members in the delivery rooms were expected to use the patient telephone to call for help. This was problematic because the system often did not work and it was inconvenient to make phone calls in close proximity to the patient. The decision to switch to portable telephones was implemented and such phones have been placed in all the delivery rooms.

- $\quad$ Lists of all relevant phone numbers to call in emergencies were positioned more visibly in the delivery rooms.

- $\quad$ Stopwatches on the walls in the delivery rooms did not work. Arrangements were made for regular check-ups of the electric system in all the delivery rooms.

- $\quad$ There was a lack or shortage of footstools in the delivery room, on which staff members stand to be able to perform suprapubic pressure in shoulder dystocia. Footstools were placed in all the delivery rooms.

- $\quad$ After the ISS, it was decided to ensure that more medicines were present in the delivery rooms, because it was found that due to a lack of medicines, the auxiliary nurses often had to leave the room to find them.

- $\quad$ Several items were not present in the cabinets of a recently opened new delivery room. This was remedied. 
- There was a lack of equipment in the patient rooms on the postnatal ward, and too much time was wasted looking for blood pressure monitors. It was arranged for blood pressure monitors to be present in all the patient rooms.

- Individual and team learning points:

- $\quad$ Even the auxiliary nurses felt doing routine work; as other staff members were not familiar with her work, it was important for the auxiliary nurses to say aloud what they were doing.

- It was considered important for obstetricians or specialised midwives to help the auxiliary nurse to prioritise her work. If the auxiliary nurse was asked to do too many things at the same time, it was important for her to say so aloud in order to alert the other staff members.

- $\quad$ An electronic blood pressure monitor could be useful if the auxiliary nurse had many tasks.

- $\quad$ The auxiliary nurses could be more proactive. For instance, after they have called for help in shoulder dystocia they could ask if they should apply suprapubic pressure.

- If staff members were called to events as postpartum bleeding or preeclampsia, they should ask on the telephone if they should bring the haemorrhage box or the preeclampsia box.

- When midwives called trainee and consultant obstetricians, they should, if possible, state the diagnosis or the key symptoms. This would enable called staff to consider what to do when they were on their way to the labour room.

- When trainee doctors had been called and the situation deteriorated after they had arrived, it was important for the trainee doctor to remember to call a consultant obstetrician. For instance, in postpartum bleeding a trainee doctor should be called when blood loss was estimated at $500 \mathrm{ml}$, and a consultant obstetrician should be called when blood loss was estimated at 750 $\mathrm{ml}$.

- $\quad$ After being called, almost all staff members were very quick to arrive, but there were some situations where this was not the case. If a staff member was a long distance away from the labour or postnatal ward, they should give an estimate of how long it would take them to get there. They might suggest somebody else who could be called instead.

- When a staff member identified a problem or made a diagnosis, they should say this aloud. For instance:' This is severe preeclampsia', 'This is a shoulder dystocia', 'This is a postpartum bleeding with XXX ml of blood loss'. This was helpful in creating a common understanding in the room.

- $\quad$ Summarising findings was very important and helpful in creating shared understanding. In cases of postpartum bleeding and preeclampsia it was very important to give regular and repetitive summaries of medications, IV-saline etc. which had been administered.

- It was emphasised that it was important to summarise when a new staff member arrived. If the team was busy, the team leader could say that they would summarise shortly.

- It was stressed that it was important to remember to keep time and start the stopwatch in the delivery room. 
- It was important to coordinate who made calls if additional staff was needed to avoid that staff members were called twice. In most cases it was the task of the midwife to coordinate this.

- It was a good idea to say aloud who was the team leader, if this was not self-evident. The person who summarised most often was most likely to be identified as the team leader.

- It was highlighted that it was important for all staff members to indicate by say it aloud when they had finished a task, placed a drip etc., so-called'closed loop'.

- If staff members were asked to do a task for which they not had the appropriate level of proficiency, it was important to respond aloud (i.e. an auxiliary nurse confused suprapubic pressure with fundal pressure).

- $\quad$ Even after the arrival of a consultant obstetrician; the nurse or midwife should not leave the room. They should call for more help if someone had to leave the room temporarily to get equipment.

- If there were not enough staff members present in the room, it should be considered to use the alarm. During the unannounced ISS it turned out that staff members had to spend too much time getting the telephone system to work (the telephone system was changed as a result of the ISS).

- It was considered important for staff members to state aloud what was going on. In shoulder dystocia, for example, arriving staff members could not see which obstetric manoeuvres the midwife was performing. It was discussed that in shoulder dystocia it was often impossible to perform the obstetric manoeuvres and give a summary at the same time. The arriving obstetric consultant or specialised midwife could ask: Have you done suprapubic pressure, taken the legs up, rotated the foetus etc. And the midwife could answer yes or no, to ensure that the obstetrician and midwives who were taking over knew which manoeuvres had to be performed.

- Information about blood loss should be estimated clinically by the midwife near the patient and then confirmed by weighing. This estimation should be announced aloud in the room and confirmed by the team leader. The amount of bleeding is essential for guiding the decision-making in postpartum bleeding.

- $\quad$ Observation sheets were often initiated too late, and not fully completed.

- If a situation was being handled well by the midwife and the trainee doctor, it was not necessary for the specialised midwife and obstetric consultant to take over, and it would be sufficient for them to support the more junior staff.

- In the ward: it was a good idea to move surveillance equipment from the recovery room to the patient room. It was stressed that patients in poor condition must never be moved, the equipment had to moved instead. 


\section{Learning points for the research group:}

- Staff indicated that they appreciated a calm atmosphere and pleasant tone of voice, during both the scenario and the debriefing. The instructors and facilitators were asked to encourage that.

- The participants requested that during the scenario the instructors would carry name badges indicating they were instructors. Instructors should avoid standing too close to the labour bed, as they could be mistaken for staff members who were expected to provide care.

- It was considered crucial that arriving staff members should be briefed, i.e. be given information by the instructor, but arriving staff members tended to rush into the room. The instructor should ask arriving staff members to stop and listen to the briefing.

- Instructors should encourage participants to perform the simulation as realistically as possible and to perform tasks in real time, .i.e., instructors should stop participants if they said I have given this medicine, but omitted getting the box with the medicine, taking the medicine out, preparing it, and simulating the administration. 



\section{CHAPTER 5 \\ Development of knowledge tests for multi-disciplinary emergency training: a review and an example}

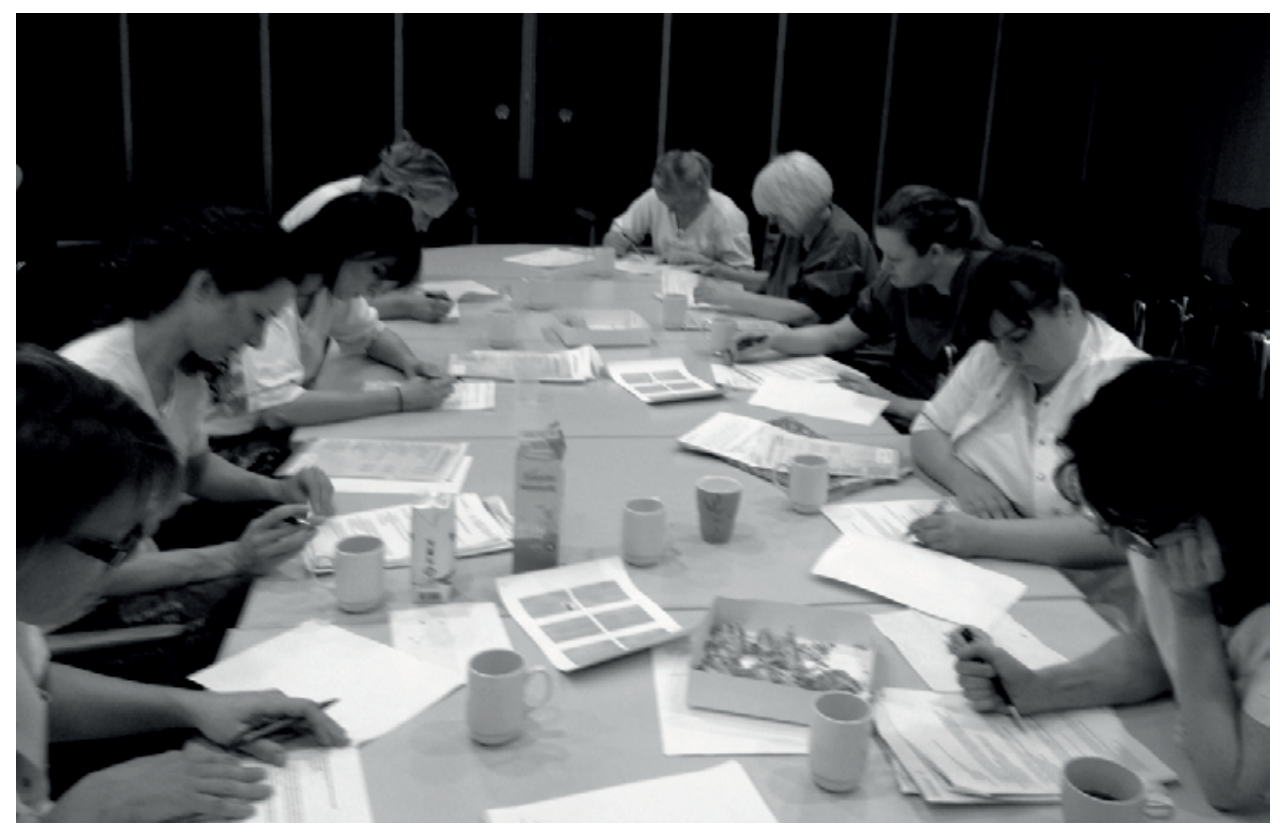

Jette Led Sørensen, Line Thellensen, Jeanett Strandbygaard, Kira D. Svendsen, Karl Bang Christensen, Marianne Johansen, Pernille Langhoff-Roos, Kim Ekelund, Bent Ottesen, Cees van der Vleuten.

Published in Acta Anaesthesiol Scand 2015;59:123-33. 


\section{Abstract}

Background: The literature is sparse on written test development in a post-graduate multi-disciplinary setting. Developing and evaluating knowledge tests for use in multidisciplinary post-graduate training is challenging. The objective of this study was to describe the process of developing and evaluating a multiple-choice question (MCQ) test for use in a multi-disciplinary training program in obstetric-anesthesia emergencies.

Methods: A multi-disciplinary working committee with 12 members representing six professional healthcare groups and another 28 participants were involved. Recurrent revisions of the MCQ items were undertaken followed by a statistical analysis. The MCQ items were developed stepwise, including decisions on aims and content, followed by testing for face and content validity, construct validity, item-total correlation, and reliability.

Results: To obtain acceptable content validity, 40 out of originally 50 items were included in the final MCQ test. The MCQ test was able to distinguish between levels of competence, and good construct validity was indicated by a significant difference in the mean score between consultants and first-year trainees, as well as between first-year trainees and medical and midwifery students. Evaluation of the item-total correlation analysis in the 40 items set revealed that 11 items needed re-evaluation, four of which addressed content issues in local clinical guidelines. A Cronbach's alpha of 0.83 for reliability was found, which is acceptable.

Conclusion: Content and construct validity and reliability were acceptable. The presented template for the development of this MCQ test could be useful to others when developing knowledge tests and may enhance the overall quality of test development. 


\section{Introduction}

Multi-professional training is expected to lead to better patient care and is increasingly recomended as essential in the context of continuous professional development $[1,2]$. Evidence on its effectiveness is nevertheless limited [3-6] and only few studies on multidisciplinary and multiprofessional education present any kind of outcomes [5]. Guidance on how to develop written tests for a post-graduate multi-disciplinary setting is sparse, but principles for written test development are universal. The post-graduate multidisciplinary context, however, must be taken into account in the process of test development.

This paper presents the developmental process of a written knowledge test applied in a postgraduate multi-disciplinary training program to determine the training effect on knowledge [7]. Other outcomes studied in the same training program[7] are attitudes toward patient safety, team performance, level of stress, and motivation. The training program was conducted in a randomized controlled trial comparing in situ simulation with off-site simulation, but this article, however, does not describe these outcome data. The knowledge test target group comprised auxiliary nurses, midwives, nurse anesthetists, operating room nurses, trainees, and consultants in obstetrics and anesthesiology [7].

The optimal approach to assessing clinical competences in a post-graduate setting is disputable[1]. Performance-based tests are currently the most preferred type of test for assessing clinical competences, but they are expensive and less practical than written tests, which is why written knowledge testing may be preferred. Previous research on assessment suggests that knowledge-based written assessments can predict the results of performance-based tests applied to the same test group [8-10]. Several types of written assessment tests exist, including multiple-choice question (MCQ) tests, which have been found to be effective for cognitive assessment [11-15]. Development of a MCQ test requires testing for validity and reliability. The validity of a test is the extent to which the test measures what it intends to measure, and reliability pertains to the accuracy with which a score on a test is determined [11].

Many anesthesiologists and nurse anesthetists participate in internationally developed courses such as Advanced Life Support [16], European Paediatric Life Support and Advanced Trauma Life Support, whereas obstetricians and midwifes participate in courses like Advanced Life Support in Obstetrics. In these courses, knowledge-based tests such as MCQ tests are applied as pre- and post-tests. The literature argues that a cautious approach must be taken when describing MCQ tests as comparable with one another because tests can have varying degrees of difficulty [17]. Many articles on these international courses refer to $\mathrm{MCQ}$ tests when describing course results, but articles describing how these tests were developed or validated are sparse $[16,18]$. 
The aim of this study was to present a short review of the literature and a template for developing an MCQ test and to describe the process of developing and evaluating it for use in a multi-disciplinary training program in obstetric-anesthesia emergencies.

\section{Material and methods}

\section{Setting}

The Departments of Obstetrics and Anesthesiology, Juliane Marie Centre for Children, Women and Reproduction, Rigshospitalet, University of Copenhagen, Denmark, with approximately 6000 deliveries per year.

The management teams at the Departments of Obstetrics and Anesthesiology appointed a multidisciplinary working committee to do the overall planning of the training program [7] and the development of the MCQ test. The committee consisted of 12 members: a chair (author JLS), two consultant obstetricians (which include author MJ), two consultant anesthesiologists (which include author KE), two midwives (which include author PLR), two nurse anesthetists, two operating room nurses, and one obstetric nurse.

\section{Study participants}

Twelve representatives from the working committee were involved in designing and reviewing the test. An additional 28 participants were involved in pilot testing and validation and comprised four consultant obstetricians and four consultant anesthesiologists from four university hospitals in Denmark; six first-year obstetric trainees from two university hospitals in Denmark; nine medical students in their sixth and final year of medical school at the University of Copenhagen who had completed 2 out of 4 weeks of clinics at the Departments of Obstetrics and 2 weeks at the Department of Anesthesiology; and five midwifery students in their final year of a 3.5-year program at Metropolitan University College, Copenhagen.

\section{Stepwise test development}

Anchored in the current test development literature, the test development method was based on the following stepwise protocol (Table 5.1)[12,13,19] (g).

A. Aims and objectives: The working committee defined aims and objectives for the multidisciplinary training program [7], which constituted the content to be included in the MCQ test. The departmental management teams in the Departments of Obstetrics and Anesthesiology approved the aims and objectives. 
Table 5.1 Item writing template. Basic principles for writing 'one-best-answer' items for a MCQ-test $[12,13,19](\mathrm{g})$.

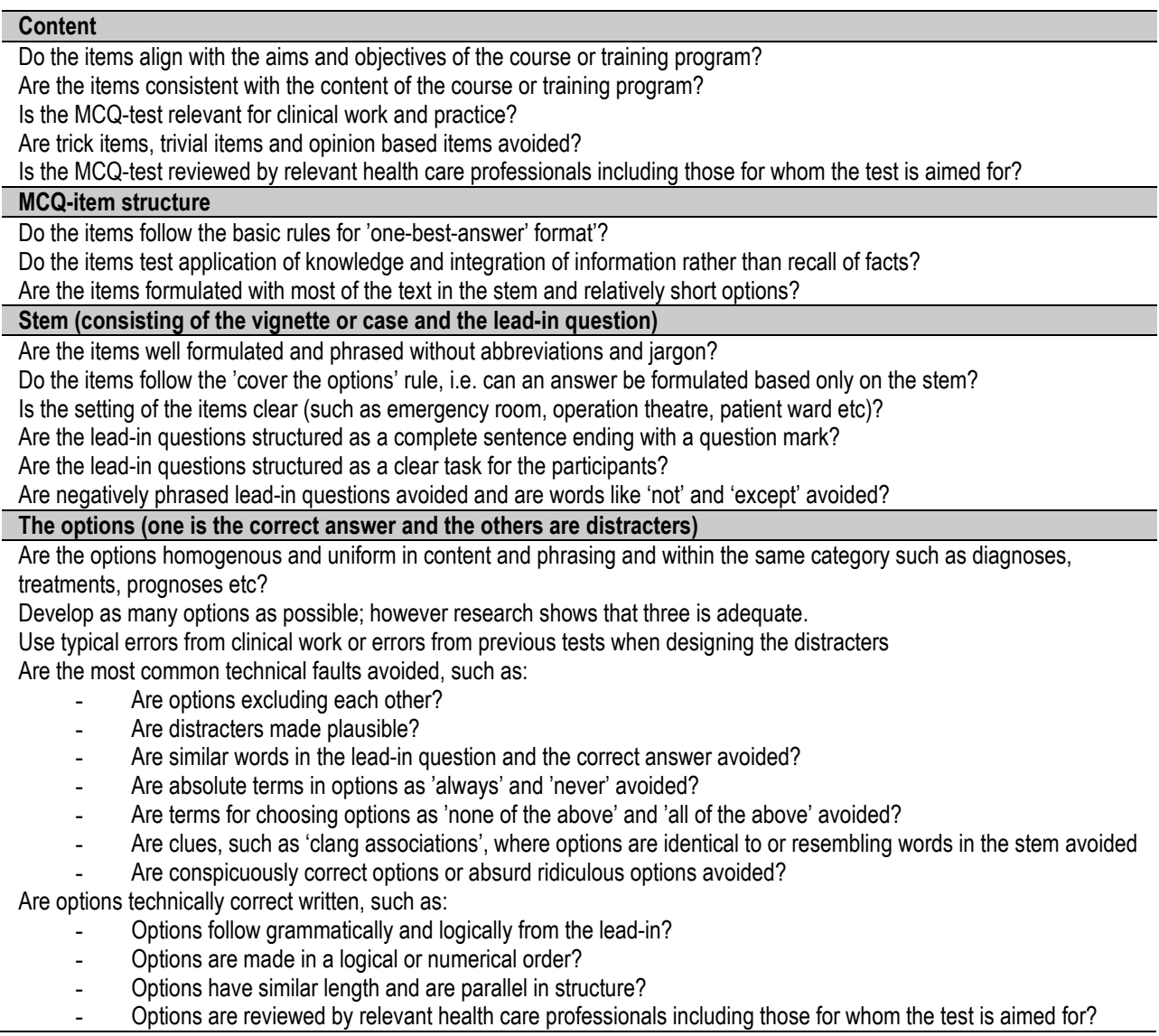

B. Blueprint and content of the MCQ test: The term blueprint describes subcategories and subclassifications of content in the MCQ test, precisely specifying the proportion of test questions in each category [20]. The working committee determined the blueprintconfiguration, which was based on the occurrence of various obstetric-anesthesia emergencies and the aims and objectives from step A. The blueprint was divided into four topics and the items within each topic were distributed according to importance: management of postpartum bleeding: approximately 35\%; preeclampsia: approximately 35\%; Cesarean section: approximately 15\%; emergency obstetrics, including resuscitation of the pregnant woman: approximately $15 \%$. The content was in accordance with national guidelines $(a, b, c)$. The Danish Society of Obstetrics and Gynecology in cooperation with representatives from the Danish Society of Anesthesiology and Intensive Care Medicine have appointed groups to develop the national guide- 
lines based on a comprehensive review of the international literature and the British guidelines. The national guidelines were then adjusted and made into local guidelines reviewed by the Departments of Obstetrics and Anesthesiology, Juliane Marie Centre, Rigshospitalet (d,e,f).

C. Items in the MCQ test: The one-best-answer principle was applied in designing each test items included in the MCQ test and is a method acknowledged by the American National Board of Medical Examiners (g) [19] and in the test literature [11-15]. Based on the literature, we developed an item-writing template (Table $5.1)[12,13,19](\mathrm{g})$, which was used to create items in our MCQ test. Each item consists of a stem, e.g. a clinical case or vignette and a lead-in question. The vignette or case represents a relevant clinical problem and the setting (e.g. an emergency room, operating room, patient ward) for the clinical problem must be clear. The 'cover-your-options' rule helps to control the text in the stem, which means that it must be possible to answer appropriately based solely on the stem (vignette and lead-in question). The stem is followed by a variety of options comprising only one correct answer and various distracters, the latter of which must be homogenous and uniform regarding content and phrasing and withinthe same category, such as diagnosis, treatment, or prognosis etc. The principle is that the correct answer is the most likelyanswer [19]. See Table 5.1 for more details. Previous obstetric knowledge tests were used for inspiration in designing our MCQ test [21,22]. Table 5.2 presents four examples of MCQ test items. The entire MCQ test has not been published, because future studies and training that involve the use of the MCQ test are planned. A copy of the entire test can be obtained from the corresponding author (JLS) by request from departments or organizations that would like to use the MCQ test. The first author (JLS) wrote the first 50 items, and the third author (JS), who also has experience in test development, was responsible for editing them [23].

D. Face and content validity I: Validity can be differentiated into face and content validity, representing the acceptance by experts that the test actually tests what it intends to test, whereas construct validity represents a tests ability to discriminate between participants with various levels of competence[11,13,24]. To ensure that the items were in accordance with the aims, objectives, and content of the multi- disciplinary training program [7], a midwife also trained as a nurse (PLR), an obstetrician (MJ), and an anesthesiologist (KE) from the working committee performed and reviewed the MCQ test by providing feedback and discussing each item with JLS before she revised the MCQ test.

E. Face and content validity II: Twelve healthcare professionals from six healthcare professionals group on the working committee took the MCQ test and added written comments on each item to ensure the relevance of the entire MCQ test for the training program participants [7]. JLS then designed a revised version of 
the 50 -item test.

F. Face and content validity III: To test the accuracy and generalizability of the content and the clinical relevance of the test inside and outside local settings, four consultant obstetricians and four consultant anesthesiologists from four university hospitals were asked to: (1) take the test; (2) rate the relevance of each item on a 3-point scale [(1): not relevant; (2): relevant; (3): very relevant]; (3) provide written feedback on each item; and (4) suggest new items. Based on this feedback, JLS created a new version of the MCQ test.

G. Construct validity $[12,13,24]$ : This was tested by comparing the test results from groups with expected differentiated level of knowledge and clinical competences comprising: (1) consultant obstetricians and anesthesiologists (from step F); (2) first-year obstetric trainees; (3) medical and midwifery students.

H. Test-time registration: The amount of time it took to take the entire MCQ test was only registered for the first-year obstetric trainees, the medical students, and the midwifery students. In addition to taking the test, the other participants spent time providing feedback, which means that recording how long it took them to take the test was not useful.

\section{INTERNET LINKS}

a http://www.dsog.dk/files/postpartum_bloedning.pdf (19.10.2014)

b http://www.dsog.dk/sandbjerg/120403\%20PIH\%202012\%20final

c http://www.dsog.dk/sandbjerg/090405\%20Guideline\%20Akut \%20sectio\%20-

\%20klassifikation\%20\%20Sandbjerg\%202009.pdf (19.10.2014)

d http://vip.regionh.dk/VIP/Admin/GUI.nsf/Desktop.html?open\& open-

link=http://vip.regionh.dk/VIP/Slutbruger/Portal.nsf/Main

.html?open\&unid=X2A39F5D1F8F5992CC125795000421E19\&dbpath=/VIP/Redaktoer/1301XJ.nsf/\&windowwi $\mathrm{dth}=1100 \&$ windowheight $=600 \&$ windowtitle=S\%F8g (19.10.2014)

e http://vip.regionh.dk/VIP/Admin/GUI.nsf/Desktop.html?open\& open-

link=http://vip.regionh.dk/VIP/Slutbruger/Portal.nsf/Main.html?

open\&unid=X5143CF11C0E062A9C125791500780413\&dbpath $=/$

VIP/Redaktoer/1301XJ.nsf/\&windowwidth=1100\&windowheight

$=600 \&$ windowtitle=S\%F8g (19.10.2014)

f http://vip.regionh.dk/VIP/Admin/GUI.nsf/Desktop.html?open\&

openlink=http://vip.regionh.dk/VIP/Slutbruger/Portal.nsf/Main.html?

open\&unid=X324B22542088F6A4C125791500786CBC\&dbpath=/

VIP/Redaktoer/1301XJ.nsf/\&windowwidth=1100\&windowheight

$=600 \&$ windowtitle=S\%F8g (19.10.2014)

g http://www.nbme.org/pdf/itemwriting_2003/2003iwgwhole .pdf(20.6.2014) 
Table 5. 2 Four examples of MCQ-items. These items were constructed in accordance with the template in table 5.1 .

\begin{tabular}{|c|c|c|c|}
\hline \multirow[t]{6}{*}{$\begin{array}{l}\text { Blueprint: } \\
\text { Postpartum } \\
\text { bleeding } \\
\text { (N16) }\end{array}$} & STEM & VIGNETTE or CASE & $\begin{array}{l}\text { A previous healthy woman delivered assisted by a } \\
\text { vacuum extractor two hours ago. She has acceptable } \\
\text { vaginal bleeding. She complaints of severe pain in } \\
\text { lower abdomen and vagina. She has normal pulse and } \\
\text { blood pressure. A midwife asks if she can give morphine } \\
\text { injection for pain relief. }\end{array}$ \\
\hline & & LEAD-IN QUESTION & $\begin{array}{l}\text { What is the most likely explanation for the severe } \\
\text { pain? }\end{array}$ \\
\hline & & OPTIONS & Rupture of uterus \\
\hline & & & Retained part of placenta in the uterus \\
\hline & & & Thrombosis in the pelvic veins \\
\hline & & & Vaginal haematoma \\
\hline \multirow[t]{6}{*}{$\begin{array}{l}\text { Blueprint: } \\
\text { Preeclampsia } \\
\text { (N37) }\end{array}$} & STEM & VIGNETTE or CASE & $\begin{array}{l}\text { A pregnant woman in labour ward with severe } \\
\text { preeclampsia receives infusion with Magnesium Sul- } \\
\text { phate. She is transferred to operation theatre for } \\
\text { Caserean section. When she arrives in theatre she feels } \\
\text { very uncomfortable. Staff in theatre discuss whether it } \\
\text { is due to side effects to the Magnesium infusion }\end{array}$ \\
\hline & & LEAD-IN QUESTION & $\begin{array}{l}\text { What is the most common side effect to Magnesium } \\
\text { Sulphate, pregnant women complains about? }\end{array}$ \\
\hline & & OPTIONS & Tingling in lips and tongue \\
\hline & & & Cutaneous flushing \\
\hline & & & Ringing in the ears \\
\hline & & & Metallic taste \\
\hline \multirow{6}{*}{$\begin{array}{l}\text { Blueprint: } \\
\text { Emergency } \\
\text { cesarean } \\
\text { section } \\
\text { (N1) }\end{array}$} & STEM & VIGNETTE or CASE & $\begin{array}{l}\text { There is planned an emergency caesarean section. The } \\
\text { pregnant woman arrives to the operation room and } \\
\text { need to be placed on the operating table. }\end{array}$ \\
\hline & & LEAD-IN QUESTION & $\begin{array}{l}\text { Which position is the most likely for the pregnant } \\
\text { women during caesarean section }\end{array}$ \\
\hline & & OPTIONS & Trendelenburg position \\
\hline & & & Flat on the back \\
\hline & & & 15-20 degree in left lateral position \\
\hline & & & $15-20$ degree in right lateral position \\
\hline \multirow{6}{*}{$\begin{array}{l}\text { Blueprint: } \\
\text { Resuscitation } \\
\text { in obstetrics } \\
\text { (N40) }\end{array}$} & STEM & VIGNETTE or CASE & $\begin{array}{l}\text { The ECG shows ventricular fibrillation, and there is } \\
\text { indication for defibrillation }\end{array}$ \\
\hline & & LEAD-IN QUESTION & $\begin{array}{l}\text { How will you manage defibrillation in a pregnant } \\
\text { patient? }\end{array}$ \\
\hline & & OPTIONS & As in non-pregnant patients \\
\hline & & & Shall not be used \\
\hline & & & Is a risk for the fetus \\
\hline & & & Shall be used with increased current flow \\
\hline
\end{tabular}




\section{Ethics}

The study did not involve patients, which means no approval was required under Danish regulations. Responses from medical students and midwifery students were non-traceable data, but responses from the other participants were not anonymized as they were both written and oral. Participants were informed that during the analyses and reporting of the data, all information would be treated as non-traceable.

\section{Data analyses}

Data were processed using Microsoft Office Excel 2007 [Microsoft (2007), Microsoft Excel (computer software), Redmond, WA, USA], SAS 9.2 (SAS Institute Inc, Cary, NC, USA), and $R$ version 3.0.1 ( $R$ Core Team, Vienna, Austria). Appendix 5.S1 provides supplementary material on the statistical analysis undertaken.

An initial aspect of the analysis process involved a qualitative assessment of the content of the 50 items that entailed revising and excluding items based on feedback, ultimately providing information on face and content validity $[11,13,24]$. The second part involved statistical analyses of the remaining 40 items. A Wilcoxon rank sum test was used to analyze the construct validity by comparing the test scores of the three groups of participants (consultants, trainee, and students) [12]. This was done to examine the MCQ test's ability to discriminate between participants with various levels of competence.

The statistical validation of the MCQ test investigated the correlation between the MCQ items. To address the function of the individual items, we computed item-total correlations. For each item within the blueprint, Spearman's rank correlation was used to evaluate the total score, while Loevinger $\mathrm{H}$ coefficients using nonarametric item response theory, also known as Mokken scale analysis, were used to further examine item quality [25-28]. Mokken scale analysis is particularly convenient if the number of items in a scale is low, as is the case for our MCQ test[27,28]. The latter analysis was done iteratively by removing items until the requirement of values larger than 0.30 was met[28]. A correlation level above 0.30 is generally considered acceptable.

Cronbach'salphawasused to examinethereliability of the MCQ test [29] and was applied by iteratively removing items leading to an acceptable value. A Cronbach's alpha of 0.70 or higher is acceptable in a test that does not have any consequences for the participants [29]. If the test involves certification or is a genuine examination, the reliability requirements are higher, which means that Cronbach's alpha should exceed 0.90. [12,29].

We computed the proportion of correct answers for each of the 40 items to evaluate floor and ceiling effects: The floor effect is when a test is too difficult and only a minor number of participants can answer the test questions correctly, whereas the ceiling effect is when a test has a maximum score that can be attained too easily without an outstanding performance. 


\section{Results}

The study period for developing and testing MCQ items was December 2012 to April 2013.

Fifty items were developed in accordance with the template in Table 5.1. According to feedback from the eight consultants, five items were excluded, three of them because three to six of the consultants answered them incorrectly. Of the two remaining items, five out of eight consultants considered one to be irrelevant and the other had more than one correct option, thus reducing the number of MCQ test items from 50 to 45 .

Only one of the consultants suggested new ideas for obstetric resuscitation items and one sentence was added to two of the existing items. No new items were constructed. When two medical students pointed out that the correct answer for one item was available in the stem of another item, it was revised.

Table 5.3 Criterion related construct validity: Mean test scores in the 40-item MCQ-test for consultant obstetricians and anesthesiologists, obstetric first-year trainee, medical students and midwifery students. In comparisons between either consultants or first-year trainees and medical/midwifery students, the two latter groups were merged.

\begin{tabular}{|c|c|c|c|c|}
\hline & $\begin{array}{l}\text { Consultant obstetricians } \\
\text { and consultant } \\
\text { anesthesiologists } \\
(n=8)\end{array}$ & $\begin{array}{l}\text { Obstetric first- year } \\
\text { trainee }(n=6)\end{array}$ & $\begin{array}{l}\text { Medical } \\
\text { students } \\
(n=9)\end{array}$ & $\begin{array}{l}\text { Midwifery } \\
\text { students } \\
(n=5)\end{array}$ \\
\hline \multirow[t]{4}{*}{$\begin{array}{l}\text { Mean score } \\
\text { (Standard deviation } \\
=\text { SD) } \\
\text { Mean test score in } \\
\text { percentage (range) }\end{array}$} & $\begin{array}{l}35.3(\mathrm{SD}=2.9) \\
89 \%(78-98 \%)\end{array}$ & $\begin{array}{l}28.8(S D=2.7) \\
72 \%(60-78 \%)\end{array}$ & $\begin{array}{l}24.8(S D=3.5) \\
62 \%(43-70 \%)\end{array}$ & $\begin{array}{l}20.4(\mathrm{SD}=4.5) \\
50 \%(38-63 \%)\end{array}$ \\
\hline & & $p=0.007$ & & \\
\hline & & & & $p=0.001$ \\
\hline & & & & $p=0.02$ \\
\hline
\end{tabular}

*Wilcoxon rank sum test.

On average, medical students, midwifery students, and first-year obstetric trainees spent $34 \mathrm{~min}$ (28-45 $\mathrm{min}$ ) on the 45 -item test. We wanted to minimize testing time to make the test applicable for a multi-disciplinary training program [7], which is why an additional five items were excluded, reducing the final total to 40 items. The eight specialists considered the last five items left out as relevant but not very relevant.

After this qualitative analysis, the MCQ test consisted of 40 items distributed in accordance with the blueprint: management of post-partum bleeding: 14 items (35\%); preeclampsia: 14 items (35\%); Cesarean section: 6 items (15\%); and emergency obstetrics, including resuscitation: 6 items (15\%). 
Table 5.3 presents information on construct validity. The mean test scores for consultant obstetricians and anesthesiologist, first-year obstetric trainees, medical students, and midwifery students are presented and a significant difference the mean score between the groups was detected, indicating acceptable construct validity.

Table 5.4 shows the items within each blueprint, the proportion of correct answers, the item-total Spearman's rank correlation, and the $\mathrm{H}$ coefficients. Values for the remaining items after omission of those with values below 0.3 are also shown. The item-total correlations indicated that 7 of the 40 items were needed to be reevaluated. The $\mathrm{H}$ coefficients also indicated a misfit of the same seven items and an additional four. Thus, 11 of the 40 items were needed to be re-evaluated. Hence, the criteria based on Spearman's rank correlation and the Mokken scale analysis coincided. The content in 4 of the 11 problematic items was based on local guidelines on management of post-partum bleeding (N12, 26, 29) and preeclampsia (N31). For example, an MCQ item on local guidelines specified when to call for help when managing post-partum bleeding and another item on expected time to wait for blood transfusion in emergency situations.

The computed proportion of correct answers for each of the 40 items revealed no floor effect and a minor and acceptable ceiling effect.

When analyzing all 40 items, the MCQ test revealed a Cronbach's alpha of 0.83 . The Cronbach's alpha in each of the four blueprint topics resulted in lower values. In postpartum bleeding, Cronbach's alpha could be improved from 0.45 to 0.65 when removing 4 (N8, N12, N14, and N26) of the 14 items. The Cronbach's alpha for the 14 items in preeclampsia was 0.75 , and there was no notable increase when items were removed. Cronbach's alpha for the six items in cesarean section and obstetric resuscitation were 0.60 and 0.54 , respectively.

\section{Discussion}

The final version of the MCQ test had acceptable reliability, content, and construct validity.

The initial part of the development process consisted of qualitative analyses involving relevant healthcare professionals and representatives from anesthesiology and obstetrics. Feedback from consultant and trainee obstetricians and anesthesiologists, midwives, nurse anesthetists, operating room nurses, medical students, and midwifery students ensured that the content and diction were understandable for a broad group of healthcare professionals.

The statistical analyses provided information on the quality of each item in the MCQ test and indicated which items needed further discussion and perhaps re-evaluation. 
Table 5.4 Proportion of correct answers, item-total correlation and H-coefficient in the MCQ-test.

\begin{tabular}{|c|c|c|c|c|c|}
\hline $\begin{array}{l}\text { Blueprint } \\
\text { topic }\end{array}$ & $\begin{array}{l}\text { MCQ- } \\
\text { item }\end{array}$ & $\begin{array}{l}\text { Proportion } \\
\text { of correct } \\
\text { answers } \\
(\%)\end{array}$ & $\begin{array}{l}\text { Item-total correla- } \\
\text { tion } \\
\text { (Spearman rank } \\
\text { correlation) }\end{array}$ & $\mathrm{H}$-coefficient & $\begin{array}{l}\text { MCQ-items that need to be re- } \\
\text { evaluated }\end{array}$ \\
\hline \multirow{14}{*}{$\begin{array}{l}\text { Postpartum } \\
\text { bleeding }\end{array}$} & N8 & 86 & & & To be re-evaluated \\
\hline & N11 & 71 & 0.33 & 0.30 & \\
\hline & $\mathrm{N} 12$ & 75 & & & To be re-evaluated (locally relevant) \\
\hline & $\mathrm{N} 13$ & 46 & 0.74 & 0.57 & \\
\hline & $\mathrm{N} 14$ & 57 & & & To be re-evaluated \\
\hline & N15 & 25 & 0.44 & 0.40 & \\
\hline & N16 & 93 & 0.32 & 0.36 & \\
\hline & $\mathrm{N} 18$ & 79 & 0.43 & 0.32 & \\
\hline & $\mathrm{N} 25$ & 50 & 0.6 & 0.36 & \\
\hline & $\overline{\mathrm{N}} 26$ & 57 & & & To be re-evaluated (locally relevant) \\
\hline & $\mathrm{N} 27$ & 46 & 0.56 & 0.35 & \\
\hline & N29 & 64 & & & To be re-evaluated (locally relevant) \\
\hline & $\mathrm{N} 30$ & 75 & 0.51 & 0.39 & \\
\hline & $\overline{\mathrm{N}} 32$ & 75 & & & To be re-evaluated \\
\hline \multirow{14}{*}{$\begin{array}{l}\text { Preeclampsia } \\
\& \text { eclampsia }\end{array}$} & N5 & 71 & 0.54 & 0.34 & \\
\hline & N6 & 79 & 0.51 & 0.30 & \\
\hline & N7 & 86 & 0.42 & 0.37 & \\
\hline & $\overline{\mathrm{N} 9}$ & 57 & 0.51 & 0.27 & \\
\hline & $\mathrm{N} 10$ & 54 & 0.75 & 0.46 & \\
\hline & $\overline{\mathrm{N} 23}$ & 68 & 0.42 & 0.27 & \\
\hline & $\mathrm{N} 24$ & 57 & 0.51 & 0.34 & \\
\hline & $\mathrm{N} 28$ & 79 & 0.47 & 0.24 & \\
\hline & N31 & 75 & 0.33 & & To be re-evaluated (locally relevant) \\
\hline & N33 & 43 & 0.31 & & To be re-evaluated \\
\hline & N34 & 64 & 0.43 & & To be re-evaluated \\
\hline & N36 & 93 & 0.4 & 0.56 & \\
\hline & N37 & 54 & 0.63 & 0.39 & \\
\hline & N38 & 75 & 0.51 & 0.33 & \\
\hline \multirow{6}{*}{$\begin{array}{l}\text { Emergency } \\
\text { cesarean } \\
\text { section }\end{array}$} & $\mathrm{N} 1$ & 71 & 0.65 & 0.33 & \\
\hline & $\mathrm{N} 17$ & 61 & 0.71 & 0.42 & \\
\hline & N19 & 82 & 0.54 & 0.40 & \\
\hline & $\mathrm{N} 20$ & 71 & 0.58 & 0.27 & \\
\hline & $\overline{\mathrm{N}} 21$ & 64 & 0.59 & 0.28 & \\
\hline & N35 & 89 & & & To be re-evaluated \\
\hline \multirow{6}{*}{$\begin{array}{l}\text { Resuscitation } \\
\text { in obstetrics }\end{array}$} & N2 & 79 & 0.47 & & To be re-evaluated \\
\hline & N3 & 96 & 0.33 & 0.69 & \\
\hline & N4 & 79 & 0.63 & 0.41 & \\
\hline & $\mathrm{N} 22$ & 64 & 0.67 & 0.44 & \\
\hline & N 39 & 89 & 0.44 & 0.23 & \\
\hline & $\overline{\mathrm{N} 40}$ & 86 & 0.57 & 0.34 & \\
\hline
\end{tabular}

The Mokken scale analysis identified 11 misfit items, seven of which were also identified by the Spearman's rank correlation. This means that an expected correct answer to one of these 11 problematic items did not necessarily correlate with the probability of answering other items on the MCQ test correctly. The content in 4 of the 11 problematic items was based on local guidelines, and this might explain why these items turned 
out to be problematic in the statistical analysis when testing participants who were from other hospitals. These four items can be considered relevant for our MCQ test when applied to the local setting. If the test is to be used at other hospitals, these four items will need to be revised or excluded. The remaining seven items need to be either excluded or reanalyzed in a larger population that fully matches the participants for whom the MCQ test targets [7]. Information on the floor and ceiling effect revealed an acceptable balance between easy and difficult items.

Cronbach's alpha provides information on the reliability of a test. If a test is reliable, it indicates that retest results will be similar. The present test generated a high Cronbach's alpha (0.83) when using all 40 items. When analyzing data from each blueprint separately, the Cronbach's alpha values were lower, which could be due to the small number of items. We considered the Cronbach's alpha values of the present test to be acceptable. To measure the effect of a training program, ideally we would measure direct clinical outcomes such as neonatal and maternal morbidity and mortality. This, however, is normally not feasible as a high number of deliveries are required to measure patient-relevant outcomes in the wide clinical spectrum covered by our MCQ test[31]. Moreover, some educational studies indicate that performance in a written knowledge test can relate to a clinical performance-based test [8-10,32].

Studies show that participants that were tested on a specific topic retain knowledge better than if they were not tested: the so-called testing effect $[33,34]$. Relevant testing has even been shown to lead to more knowledge gain than teaching without testing [34]. Well-designed written tests combined with other assessment tools may therefore be used as an integrated learning strategy in a training program. In specialist training in anesthesiology in Denmark, several knowledge tests that are used as formative testing, i.e. tests given for feedback purposes, such as the MCQ test, are currently being implemented. Presently, whether to integrate knowledge testing as a part of several postgraduate training programs in gynecology and obstetrics, e.g. basic laparoscopy training [23] in Denmark and Norway and cardiotocography training programs in Sweden and Denmark, is being discussed [35]. In these post-graduate training programs, a specific test is integrated into the training program, and testing is not isolated from training, e.g. learning and testing are applied as part of a program integrated in the clinical context.

Test development is often considered a simple task; however, designing a valid and reliable test is a complex process. In the process of test development for a multidisciplinary setting, involving representatives from all the relevant healthcare professional groups and from all the relevant medical specialties is essential. Enhancing the generalizability of our MCQ test to other institutions required incorporating feedback on the content of the test from consultants from other hospitals. Substantial insight in test development literature from textbooks and original scientific work is a necessary prerequisite when embarking on test development [11-15,19,20,29,30]. Developing valid 
and reliable items requires competences within both test development and test statistics combined with in-depth knowledge on the content of the test. The template presented for item writing and the examples of MCQ items may prove useful for others who would like to develop a test and can potentially enhance the quality of tests by improving validity, correlation, and reliability. 


\section{Acknowledgements}

We would like to thank everyone who participated in taking and providing feedback on the MCQ test: consultant anesthesiologists: Helle Thy Østergaard and Lone Fuhrmann, Department of Anesthesiology, Herlev Hospital; Mette Gøttge Madsen, Department of Anesthesiology, North Zealand Hospital; Søren Heltbo, Department of Anesthesiology, Odense University Hospital. Consultant obstetricians: Nina Colov Palmgren, Department of Obstetrics, Rigshospitalet; Lone Krebs, Department of Obstetrics and Gynecology, Holbæk Hospital; Birgit Bødker, Department of Obstetrics and Gynecology, North Zealand Hospital; Morten Beck Sørensen, Department of Obstetrics and Gynecology, Odense University Hospital. We would also like to thank these first-year obstetrics trainees: Flemming Bjerrum, Tanja Roien Jacobsen, Astrid Kolte, Mette Petri, and Camilla Wullf. We are also grateful to the Rigshospital working committee: consultant anesthesiologist Charlotte Krebs Albrechtsen, consultant obstetrician Berit Woetman Pedersen, midwife Kristine Sylvan Andersen, nurse anesthetists Charlotte Glob Frandsen and Marianne Sand Flindt, operating room nurses Pernille Baagøe Schou and Birgitte Otzen, and obstetric nurse Vibeke Ladefoged. We also extend our thanks to the medical and midwifery students who took the MCQ test and provided feedback.

\section{Author contributions}

JLS created the idea for this article with support from CVdV and BO. JLS was responsible for acquiring funding in cooperation with BO. JLS, LT, JS, MJ, KE, and PL-R made substantial contributions to the practical issues involved in developing the MCQ test. KDS and KBC jointly performed the statistical analysis with JLS. JLS wrote the draft manuscript. All of the authors provided critical review of this paper and approved the final manuscript.

\section{Conflicts of interest}

The authors confirm that there are no conflicts of interest.

\section{Funding}

Development of the MCQ test was part of a trial [7] based on departmental funding and on non-profit funding from the Danish Regions Development and Research Fund, and a minor amount of non-profit funding from the Laerdal Foundation for Acute Medicine and the Aase and Ejnar Danielsens Foundation. None of the foundations played a role in the design or conduct of the study. 


\section{References}

1. Norman GR, Shannon SI, Marrin ML. The need for needs assessment in continuing medical education. BMJ 2004;328:999-1001.

2. Choudhry NK, Fletcher RH, Soumerai SB. Systematic review: the relationship between clinical experience and quality of health care. Ann Intern Med 2005;142:260-73.

3. Reeves S, Zwarenstein M, Goldman J, Barr H, Freeth D, Koppel I, Hammick M. The effectiveness of interprofessional education: key findings from a new systematic review. J Interprof Care 2010;24:230-41.

4. Zwarenstein M, Goldman J, Reeves S. Interprofessional collaboration: effects of practice-based interventions on professional practice and healthcare outcomes. Cochrane Database Syst Rev 2009;(3):CD000072.

5. Headrick LA, Wilcock PM, Batalden PB. Interprofessional working and continuing medical education. BMJ 1998;316:771-4.

6. Nancarrow SA, Booth A, Ariss S, Smith T, Enderby P, Roots A. Ten principles of good interdisciplinary team work. Hum Resour Health 2013;11:19

7. Sørensen JL, Van der Vleuten C, Lindschou J, Gluud C, Ostergaard D, Leblanc V, Johansen M, Ekelund K, Albrechtsen CK, Pedersen BW, et al. 'In situ simulation' versus 'off site simulation' in obstetric emergencies and their effect on knowledge, safety attitudes, team performance, stress, and motivation: study protocol for a randomized controlled trial. Trials 2013;14:220.

8. Remmen R, Scherpbier A, Denekens J, Derese A, Hermann I, Hoogenboom R, van d, V, van RP, Bossaert L. Correlation of a written test of skills and a performance based test: a study in two traditional medical schools. Med Teach 2001;23:29-32.

9. Kramer AW, Jansen JJ, Zuithoff P, Dusman H, Tan LH, Grol RP, van der Vleuten C. Predictive validity of a written knowledge test of skills for an OSCE in postgraduate training for general practice. Med Educ 2002;36:812-9.

10. van der Vleuten C, Van Luyk SJ, Beckers HJ. A written test as an alternative to performance testing. Med Educ 1989;23:97-107.

11. Schuwirth LW, van der Vleuten C. ABC of learning and teaching in medicine: Written assessment. BMJ 2003;326:643-5.

12. Downing SM. Written tests. Constructed-Response and Selected-Response Formats. In: Downing SM, Yudkowsky R, editors. Assessment in Health Professions Education. First ed. New York, Oxon: Routhledge; 2009. p. 149-84.

13. Downing SM. Twelve Steps for Effective Test Development. In: Downing SM, Haladyna TM, editors. Handbook of Test Development.Mahwah, New Jersey: Lawrence Erlbaum Associates, Inc.Publishers; 2011. p. 3-25.

14. Schuwirth LW, van der Vleuten C. Different written assessment methods: what can be said about their strengths and weaknesses? Med Educ 2004;38:974-9.

15. Schuwirth LW, van der Vleuten C. Written assessments. In: Dent JA, Harden RM., editors. A Practical Guide for Medical Teachers.Edinburgh, London, New York, Oxford, Philadelphia, St Louis, Sydney, Toronto: Churchill Livingstone Elsevier; 2009. p. 325-32.

16. Yang CW, Yen ZS, McGowan JE, Chen HC, Chiang WC, Mancini ME, Soar J, Lai MS, Ma MH. A systematic review of retention of adult advanced life support knowledge and skills in healthcare providers. Resuscitation 2012;83:1055-60.

17. Ringsted C, Lippert F, Hesselfeldt R, Rasmussen MB, Mogensen SS, Frost T, Jensen ML, Jensen MK, Van d, V. Assessment of Advanced Life Support competence when combining different test methods-reliability and validity. Resuscitation 2007;75:153-60.

18. Lorello GR, Cook DA, Johnson RL, Brydges R. Simulation-based training in anaesthesiology: a systematic review and meta-analysis. Br J Anaesth 2014;112:231-45.

19. Case SM, Swanson DB. Constructing Written Test Questions For the Basic and Clinical Sciences. 3rd edition ed. National Board of Medical Examiners; 2002.

20. Downing SM, Haladyna TM. Validity and its threats. In: Downing SM, Yudkowsky R, editors. Assessment in Health Professions Education. First ed. New York, Oxon: Routledge; 2009. p. 21-53.

21. Sorensen JL, Lokkegaard E, Johansen M, Ringsted C, Kreiner S, McAleer S. The implementation and evaluation of a mandatory multi-professional obstetric skills training program. Acta Obstet Gynecol Scand 2009;88:1107-17. 
22. Crofts JF, Ellis D, Draycott TJ, Winter C, Hunt LP, Akande VA. Change in knowledge of midwives and obstetricians following obstetric emergency training: a randomised controlled trial of local hospital, simulation centre and teamwork training. BJOG 2007;114:1534-41.

23. Strandbygaard J, Maagaard M, Larsen CR, Schouenborg L, Ottosen C, Ringsted C, Grantcharov T, Ottesen B, Sorensen JL. Development and validation of a theoretical test in basic laparoscopy. Surg Endosc 2013;27:1353-9.

24. Wisborg T, Ringsted C. Tools for the assessment of practical skills and performance. Acta Anaesthesiol Scand 2011;55:633-4.

25. Streiner L, Norman.GR. Item response theory. In: Streiner L, Norman.GR, editors. Health measurement scales. Fourth ed. Oxford: Oxford University Press; 2008. p. 299-330.

26. Streiner LD, Norman GR. Selecting the items. Health measurement scales. Fourth ed. Oxford: Oxford University Press; 2008. p. 77-102.

27. Sijtsma K, Molenaar IW. Introduction to nonparametric item response theory. California, London, New Delphi: Sage Publication; 2002.

28. Mokken R.J., Lewis J.R. A Nonparametric Approach to the Analysis of Dichotomous Item Responses. Applied Psychological Measurement 1982;6:417-30.

29. Axelson R.D, Kreiter C.D. Reliability. In: Downing SM, Yudkowsky R, editors. Assessment in Health Professions Education. First ed. New York, Oxon: Routhledge; 2009. p. 57-73.

30. Naeem N, van der Vleuten C, Alfaris EA. Faculty development on item writing substantially improves item quality. Adv Health Sci Educ Theory Pract 2012;17:369-76.

31. Mongelli M, Chung TK, Chang AM. Obstetric intervention and benefit in conditions of very low prevalence. Br J Obstet Gynaecol 1997;104:771-4.

32. Ram P, van der Vleuten C, Rethans JJ, Schouten B, Hobma S, Grol R. Assessment in general practice: the predictive value of written-knowledge tests and a multiple-station examination for actual medical performance in daily practice. Med Educ 1999;33:197-203.

33. Larsen DP, Butler AC, Roediger HL, III. Test-enhanced learning in medical education. Med Educ 2008;42:959-66.

34. Kromann C, Koefoed M, Jensen M, Ringsted C. Test af viden og færdigheder $\emptyset$ ger indlæring [Test of knowledge and skills enhances learning]. Ugeskr Laeger 2012;174:716-9.

35. Millde-Luthander C, Hogberg U, Nystrom ME, Pettersson H, Wiklund I, Grunewald C. The impact of a computer assisted learning programme on the ability to interpret cardiotochography. A before and after study. Sex Reprod Healthc 2012;3:37-41. 


\section{Supplementary material on line}

This appendix outlines the statistical methodology used in the validation of the present MCQ test.

Item-total correlation: Ideally an item in a test should be correlated to the underlying construct to evaluate the item quality. In the item-total correlation reported, the total is used as a proxy for the underlying construct, thus yielding an estimate of the association between the item and the underlying construct. We would expect a monotonous relationship between any item score and the construct that the item measures and so in these analyses low correlations are a point of concern. This can be done using Spearman rank correlation

Loevinger $\mathrm{H}$ coefficients: The correlation coefficients study if respondent that answer one item correctly are more likely to answer a second question correctly. The Loevinger $[1,2]$ scalability coefficients takes this a step further and considers the relative difficulty of the items since a respondent that answer a complicated item correctly should certainly be able to give a correct answer on an easier item. To exemplify: a school pupil answering the math item " $\sqrt{9}=$ _ should also give a correct response to the easier item " $2+2=\ldots$ " [3]. This is addressed by the Loevinger $\mathrm{H}$ coefficients. These coefficients are applied in the framework of Item Response Theory (IRT) [4,5] also known as Mokken scale analysis [6]. Mokken scale analysis is particularly useful if the number of items in a scale is low, as it was in the present MCQ-test

Cronbach coefficient alpha: Beyond validity (i.e. the issue of whether a tests measures what it purports to measure) the issue of reliability should also be addressed. Ideally tests should be retested to test whether the first and subsequently responses are compatible. However this is complicated with a written test like a MCQ-test, as the items will be recognizable and therefore easier to answer the subsequent time. A statistical approach for analysis for a fictitious retest was done by analysis with Cronbach's coefficient alpha [7]. Hence reliability was assessed using alpha and this measure was applied by iteratively removing items leading to an acceptable value.

The number of items is related to a higher Cronbach's alpha and a test with many items will therefore automatically generate a higher reliability. 


\section{References - supplementary}

1. Loevinger JA. A systematic approach to the construction and evaluation of tests of ability. Psychological Monographs. 1947.

2. Loevinger JA. The technique of homogeneous tests compared with some aspects of scale analysis and factor analysis. Psycological Bulletin 45, 503-530. 1948.

3. Guttman L. The basis for scalogram analysis. In: Stoufer, Guttman, Suchman, Lazarsfeld, Star, Clausen, editors. Studies in social psychology in World War II.Princeton, NJ: Princeton University Press; 1950. p. 60-90.

4. Mokken R.J., Lewis J.R. A Nonparametric Approach to the Analysis of Dichotomous Item Responses. Applied Psychological Measurement 1982;6:417-30.

5. Sijtsma K, Molenaar IW. Introduction to nonparametric item response theory. California, London, New Delphi: Sage Publication; 2002.

6. Mokken R.J. A theory and procedure of scale analysis with applications in political research. The Hague, the Netherlands: Mouton; 1971.

7. Cronbach LJ. Coefficient alpha and the internal structure of tests. Psycometrika 16, 297-334. 1951. 



\section{CHAPTER 6 Part I}

\section{'In situ simulation' versus 'off site simulation' in obstetric emergencies and their effect on knowledge, safety attitudes, team performance, stress, and motivation: study protocol for a randomized controlled trial}

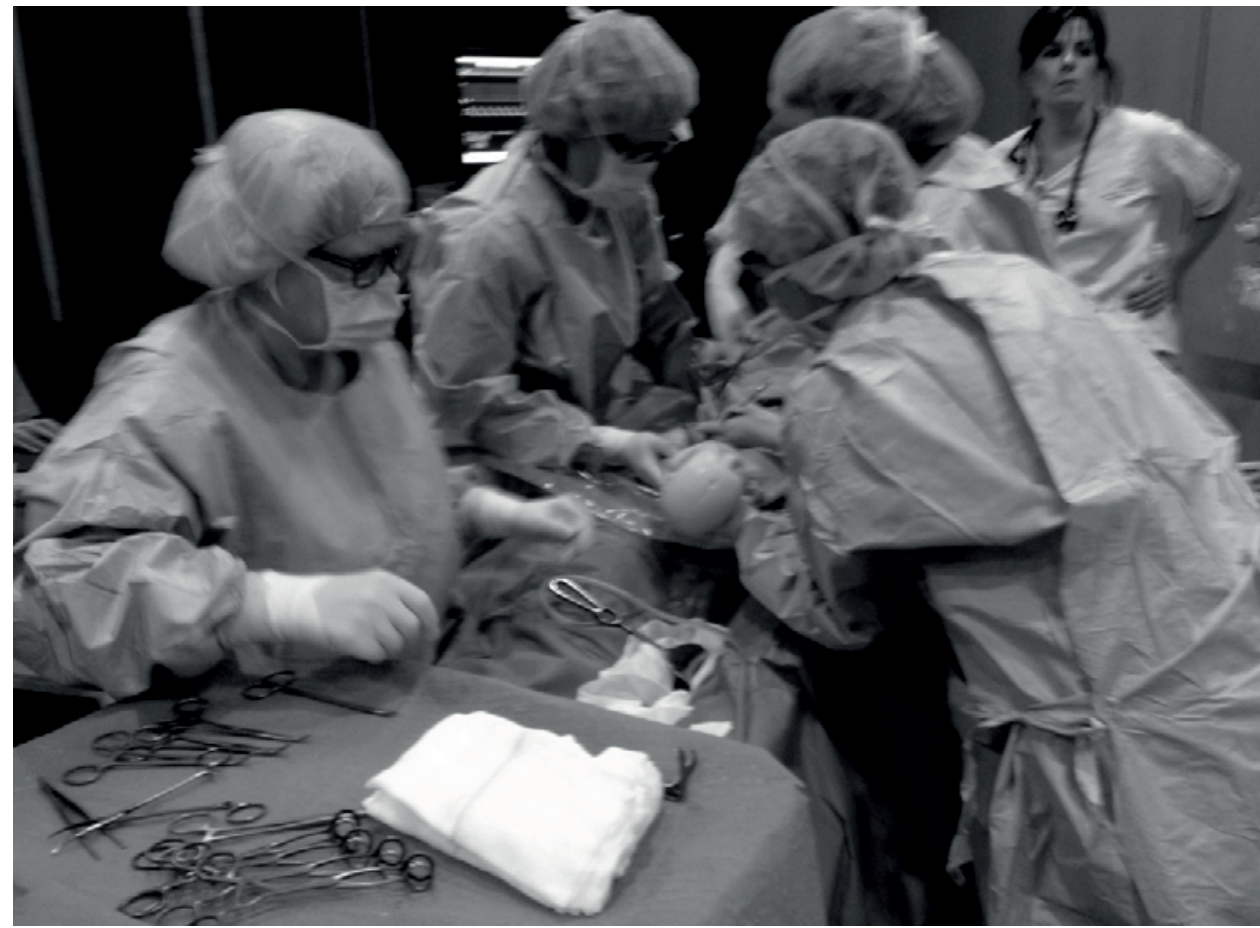

Jette Led Sørensen, Cees van der Vleuten, Jane Lindschou, Christian Gluud, Doris $\emptyset$ stergaard, Vicki Leblanc, Marianne Johansen, Kim Ekelund, Charlotte Krebs Albrechtsen, Berit Woetmann Pedersen, Hanne Kjærgaard, Pia Weikop and Bent Ottesen. Published in Trials 2013;14:220. 


\section{Abstract}

Background: Unexpected obstetric emergencies threaten the safety of pregnant women. As emergencies are rare, they are difficult to learn. Therefore, simulation-based medical education (SBME) seems relevant. In non-systematic reviews on SBME, medical simulation has been suggested to be associated with improved learner outcomes. However, many questions on how SBME can be optimized remain unanswered. One unresolved issue is how 'in situ simulation' (ISS) versus 'off site simulation' (OSS) impact learning. ISS means simulation-based training in the actual patient care unit (in other words, the labor room and operating room). OSS means training in facilities away from the actual patient care unit, either at a simulation centre or in hospital rooms that have been set up for this purpose.

Methods and design: The objective of this randomized trial is to study the effect of ISS versus OSS on individual learning outcome, safety attitude, motivation, stress, and team performance amongst multi-professional obstetric-anesthesia teams.

The trial is a single-centre randomized superiority trial including 100 participants. The inclusion criteria were health-care professionals employed at the department of obstetrics or anesthesia at Rigshospitalet, Copenhagen, who were working on shifts and gave written informed consent. Exclusion criteria were managers with staff responsibilities, and staff who were actively taking part in preparation of the trial. The same obstetric multi-professional training was conducted in the two simulation settings. The experimental group was exposed to training in the ISS setting, and the control group in the OSS setting. The primary outcome is the individual score on a knowledge test. Exploratory outcomes are individual scores on a safety attitudes questionnaire, a stress inventory, salivary cortisol levels, an intrinsic motivation inventory, results from a questionnaire evaluating perceptions of the simulation and suggested changes needed in the organization, a team-based score on video-assessed team performance and on selected clinical performance.

Discussion: The perspective is to provide new knowledge on contextual effects of different simulation settings.

Trial registration: ClincialTrials.gov NCT01792674.

Keywords: Simulation, In situ simulation, Randomized trial, Obstetric emergencies, Multi-professional education, Stress. 


\section{Background}

Care for pregnant and parturient women is a field where unexpected emergencies occur; for example, emergency Caesarean section, postpartum bleeding or severe preeclampsia, that may potentially harm both mother and baby [1-4]. Since obstetric emergencies are rare and hence by nature difficult to learn in real life, simulation-based medical education (SBME) is argued to be an essential remedy [5]. SBME is defined as "a person, device, or set of conditions which attempts to present education and evaluation problems authentically. The student or trainee is required to respond to the problems as he or she would under natural circumstances" [6].

Labor wards have a dual function in creating a relaxed atmosphere for normal childbirth and at the same time showing readiness to deal with life-threatening emergencies [7]. Labor wards are challenging work places and patient safety and medical litigation are high on the agenda [8-11]. In certain situations, clinical management of pregnant and parturient women may require the involvement of a variety of health-care professionals and medical specialties. The primary care team in a delivery room consists of a midwife assisted by an auxiliary nurse. In cases of emergencies, more experienced midwives and obstetricians will be called for assistance. If the clinical situation progresses further to an emergency, an anesthesiologist, a nurse anesthetist and the operating room personnel may become involved. Occasionally, involvement of other specialties may also be required, when a rather common clinical event has evolved into a potentially life-threatening situation calling for multi-professional and multi-disciplinary clinical management.

Such rare and complex clinical situations require complex skills, which cannot be trained and learned in clinical practice. Thus, there is a need for SBME in obstetric emergencies. In a systematic review of training in acute obstetric emergencies [12] the authors applied the quality assessment of diagnostic accuracy studies criteria. Out of 97 arti- cles, only eight articles - four randomized trials and four cohort studies - assessing the effect of teamwork training in a simulation setting were identified. Based on these trials, it was concluded that teamwork training in a simulation-based setting resulted in improvements in knowledge, practical skills, communication, and team performance in acute obstetric situations. No difference in outcomes was found when comparing SBME in a dedicated simulation centre with SBME in a local hospital setting [13,14].

From the non-systematic reviews on SBME $[6,15]$ and the obstetric systematic review [12] we can conclude that SBME in labor wards is worthwhile, and that multi- professional and multi-disciplinary team training are important approaches due to the complexities of the trained skills and the rarity of the high-risk obstetric emergencies. However, we need to further study key elements of SBME in order to fully understand how we can best improve SBME in obstetric emergencies. One potential element influencing the effect of simulation might be the level of authenticity of the simulation or, in other 
words, the fidelity of the simulation. Fidelity is described as a multi- dimensional concept consisting of different parts: 1) physical/functional or engineering fidelity, which mean the degree to which the simulator duplicates the appearance and perception of the real system; 2) psychological fidelity is the degree to which the trainee perceives the simulation to be an authentic surrogate for the trained task. The literature states that psychological fidelity is considered to be the most essential requirement when conducting team training $[16,17]$. The simulation setting has traditionally been 'off site simulation' (OSS), either at a simulation centre or in local facilities in the hospital set up for the single purpose of simulation training. However, more recently, a new simulation modality, the 'in situ simulation' (ISS), has been introduced. ISS is described by Riley and colleagues [18] as "a team-based simulation strategy that occurs on the actual patient care units involving actual healthcare team members within their own working environment". An unanswered question is whether ISS is superior compared with OSS with regards to simulation-based learning in obstetric emergencies? We hypothesized that the psychological fidelity is influenced by the setting in which the simulation training is conducted, and that ISS can add to the level of fidelity and therefore be more effective.

Apart from a few larger observational studies within different medical specialties [1820], most of the studies conducted on ISS describe a local educational intervention with a local ISS program. Methodologically, the studies are descriptive and few include a control group or pre- and post-tests, and we have not been able to identify any randomized trials [21]. It is argued that ISS can identify system weaknesses because ISS takes place in the real working environment and, therefore, potentially has more psychological fidelity as opposed to OSS [18-22], and ISS can be used to test how new processes are functioning in clinical facilities [23]. Some argue that ISS overcomes feasibility issues and is cost saving compared to OSS in simulation centers [24,25]. ISS can consist of either an announced training event or an unannounced event. Anderson and colleagues [26] focused on unannounced ISS and its potential disadvantages, and argued how unannounced ISS is time consuming and may intimidate participants.

Human factors such as stress and motivation impact learning [27-31]. Studies show that simulation can be a stressor. High stress responsiveness has been associated with both enhanced and impaired performance, but with enhanced learning [29]. As such, further exploration of these issues is needed. Experimental studies have used unspecific measurements of stress level [32], and different stress inventories as well as measurements of salivary cortisol levels [20,33-36]. Motivational processes are central to learning $[27,30,37]$, and as part of this trial we will investigate phenomena such as intrinsic motivation, and how this is moderated by the two different training settings (ISS versus OSS). We hypothesize that, in simulation-based training in obstetric emergencies, ISS is more effective than OSS regarding learning. We anticipate that the participants will experience ISS as more demanding, and that ISS will create higher levels of stress and motivation, which may yet again enhance learning. Further, we hypothesize that ISS 
training may provide the investigators with more information on changes needed in the organization than OSS training will. Randomized trials are needed to obtain knowledge on the effect of ISS versus OSS on participants and its advantages and disadvantages.

\section{Methods and design}

The design is a single-center, investigator-initiated randomized superiority trial.

The setting

The trial was undertaken at Rigshospitalet, Copenhagen University Hospital, in an obstetric and anesthesia highrisk department with approximately 6.600 deliveries per year. The intervention period was scheduled to run through April to June 2013, and follow-up by questionnaires until August 2013.

\section{Participants}

All health-care professionals from the department of obstetrics and anesthesia, Juliane Marie Centre for Children, Women and Reproduction, Rigshospitalet, working on or in relation to the labor ward, were eligible for inclusion in the trial. These health-care professional groups, who were working on shift, encompassed: specialized obstetricians; trainee obstetricians; midwives; specialized midwives; auxiliary nurses; specialized anesthesiologists; trainee anesthesiologists; nurse anesthetists; and surgical nurses. Participants gave informed consent. Exclusion criteria were lack of informed consent, employees with managerial and staff responsibilities, staff members involved in the design or conduction of the trial, and finally employees who did not work in shifts.

\section{Randomization}

Randomization was done by the Copenhagen Trial Unit, using a computer-generated allocation sequence concealed to the investigators. The randomization was conducted in two steps. The participants were individually randomized into the experimental group (ISS) or the control group (OSS). The allocation sequence was stratified according to health-care professional groups in order to resemble authentic teams and according to the days they were available for training. After individual randomization, the participants in either group (ISS and OSS) were randomized into five teams each.

\section{Trial interventions}

This trial included an experimental educational intervention ISS [18,21], which means training in the actual patient care unit (in other words, the labor room and operating theatre). The experimental intervention in the present trial was pre-announced ISS. We planned to conduct announced ISS training, as the complexity of conducting unannounced ISS sessions with the involvement of health-care professionals on a larger scale is unrealistic taking into consideration work schedules and the daily clinical work activities. Training of the control group (OSS) took place in training rooms that were set up for the occasion in the hospital, but away from the actual patient care unit. 
The simulated scenarios applied in the trial were contained in a full training day. The development of the curriculum for the training day was based on an instructional design approach $[38,39]$ and was developed and pilot tested by a local multi-professional working committee. In January 2012 this working committee was appointed by the managerial groups of the departments of anesthesia and obstetrics and consisted of representatives from all the health-care professionals who will participate in the trial. This working committee developed aims and objectives based on the principles of Blooms taxonomy [40], and the aims and objectives were approved by the management groups. The simulated scenarios in ISS and OSS were designed in a way that involved both the labor room setting and the operating theatre, to specifically focus on the patient journey and the communication amongst healthcare professionals during patient transfers, where many different health-care professionals and different medical disciplines are involved. This approach to training was chosen based upon previous experience with obstetric simulation-based training conducted in the obstetric department $[32,41]$ and was designed in accordance with the overall plan of strategy of the obstetric department and the anesthesia department, Juliane Marie Centre for Children, Women and Reproduction, Rigshospitalet [42].

In the labor room, a simulated patient acted as the patient. In the operating room, a full body interactive birthing simulator, a SimMom, was the patient [43]. The SimMom simulator offers the functionality required for training in a wide range of midwifery, obstetric and anesthesia skills, and the anatomy and functionality of the SimMom allows for multi-professional training of labor and delivery management. Standardized clinical simulated scenarios were designed and, combined with preprogrammed scenarios on the SimMom, this allowed for standardized training. The educators were recruited from the local working committee, and all educators were trained to run the scenarios in a standardized way and in facilitating the simulation scenarios and debriefing the participants.

In addition, the training day also included some videobased, case-based and lecturebased teaching sessions. Also, on the simulation days, data related to the trial were collected in the form of written multiple choice questions (MCQ), questionnaires on subjective stress and salivary cortisol samples (Table 6.I.1). Training days were scheduled into the individual employee's working plan. Figure 6.I.1 gives an overview of the randomization and intervention procedure as well as outcomes. 
Table 6.I.1 Time schedule of measurements.

\begin{tabular}{|c|c|c|c|c|c|c|c|c|}
\hline \multicolumn{7}{|c|}{ Individual measurements } & \multicolumn{2}{|c|}{ Team measurements } \\
\hline $\begin{array}{l}\text { Multiple } \\
\text { choice ques- } \\
\text { tionnaire }\end{array}$ & $\begin{array}{l}\text { Safety atti- } \\
\text { tudes ques- } \\
\text { tionnaire }\end{array}$ & $\begin{array}{l}\text { Stress- } \\
\text { trait } \\
\text { anxiety } \\
\text { inventory }\end{array}$ & $\begin{array}{l}\text { Cognitive } \\
\text { appraisal }\end{array}$ & $\begin{array}{l}\text { Test for } \\
\text { salivary } \\
\text { cortisol }\end{array}$ & $\begin{array}{l}\text { Intrinsic } \\
\text { motivation } \\
\text { inventory }\end{array}$ & $\begin{array}{l}\text { Evaluation } \\
\text { questionnaire }\end{array}$ & $\begin{array}{l}\text { Team } \\
\text { emergency } \\
\text { assessment } \\
\text { measure }\end{array}$ & $\begin{array}{l}\text { Selected } \\
\text { clinical } \\
\text { measures }\end{array}$ \\
\hline $\begin{array}{l}\text { Training } \\
\text { day } \\
\text { start of day }\end{array}$ & $\begin{array}{l}4 \text { weeks } \\
\text { before } \\
\text { training day }\end{array}$ & $\begin{array}{l}\text { Training } \\
\text { day } \\
\text { before } \\
\text { 1. simula- } \\
\text { tion } \\
\text { and twice } \\
\text { after }\end{array}$ & $\begin{array}{l}\text { Training } \\
\text { day } \\
\text { before } \\
\text { 1. simula- } \\
\text { tion } \\
\text { and twice } \\
\text { after }\end{array}$ & $\begin{array}{l}\text { Training } \\
\text { day } \\
\text { before } \\
\text { 1.simulation } \\
\text { and three } \\
\text { times after }\end{array}$ & $\begin{array}{l}1 \text { week } \\
\text { after } \\
\text { training day }\end{array}$ & $\begin{array}{l}1 \text { week } \\
\text { after } \\
\text { training day }\end{array}$ & $\begin{array}{l}\text { 1. simulation: } \\
\text { Video } \\
\text { recordings. } \\
\text { Video as- } \\
\text { sessment } \\
\text { by independ- } \\
\text { ent asses- } \\
\text { sors. }\end{array}$ & $\begin{array}{l}\text { 1.simulation: } \\
\text { video } \\
\text { recordings. } \\
\text { Video } \\
\text { assessment } \\
\text { by inde- } \\
\text { pendent } \\
\text { assessors. }\end{array}$ \\
\hline $\begin{array}{l}\text { Training } \\
\text { day } \\
\text { end of day }\end{array}$ & $\begin{array}{l}4 \text { weeks } \\
\text { after } \\
\text { training day }\end{array}$ & $\begin{array}{l}\text { Training } \\
\text { day } \\
\text { before } \\
\text { 2. simula- } \\
\text { tion and } \\
\text { twice after }\end{array}$ & $\begin{array}{l}\text { Training } \\
\text { day } \\
\text { before } \\
\text { 2. simula- } \\
\text { tion and } \\
\text { twice after }\end{array}$ & $\begin{array}{l}\text { Training } \\
\text { day } \\
\text { before } \\
\text { 2. simula- } \\
\text { tion and } \\
\text { three times } \\
\text { after }\end{array}$ & & & $\begin{array}{l}\text { Training day } \\
\\
\text { 2. simulation: } \\
\text { video } \\
\text { recordings. } \\
\text { Video as- } \\
\text { sessment by } \\
\text { independent } \\
\text { assessors }\end{array}$ & $\begin{array}{l}\text { 2. simulation: } \\
\text { video } \\
\text { recordings. } \\
\text { Video } \\
\text { assessment } \\
\text { by inde- } \\
\text { pendent } \\
\text { assessors }\end{array}$ \\
\hline
\end{tabular}

\section{Blinding}

The participants and the educators providing the educational intervention, and the assessors observing and assessing videos, were not blinded to the intervention. The data managers, statisticians and investigators drawing conclusions will be blinded to the allocated intervention groups.

\section{Measurements and assessment of outcomes}

Table 6.I.2 provides an overview of the variables, outcomes and accompanying statistical analyses. Table 6.I.2 is inspired by the SPIRIT 2013: Explanation and elaboration: guidance for protocols of clinical trials [44]. See Table 6.I.1 for the time schedule for obtaining measurements.

\section{Primary outcome}

The primary outcome is knowledge test results from MCQs. The mean values of results of the MCQs of the experimental and control group were tested at the end of the training day and will be compared.

Previous research on knowledge testing has found that written tests are able to predict results in performancebased testing $[45,46]$. The argument for applying the MCQ is that it is feasible to test many participants in a relatively short time and at low costs [46]. Previously used MCQ tests and 'knowledge of skills test' $[13,32]$ were used for inspiration, when constructing this new MCQ. 
The MCQs were created as a 'one-best-answer' item format with three to five options, which requires the participants to select the single best response $[47,48]$. The content of the MCQs were based on aims and objectives developed by the multi-professional working group appointed by the management and has been tested amongst all healthcare professional in this local working group. The content validity was further tested among specialized obstetricians and specialized obstetric anesthesiologists. Subsequently, the MCQs were tested among midwifery students, medical students, trainee doctors and specialized obstetricians and specialized obstetric anesthesiologists from other hospitals and were found to be construct valid. During the statistical analysis, some items in the MCQ needed to be deleted. The description of development and results of the MCQs used in this trial will be reported in another publication.

Figure 6.I.1 Randomized trial of 'in situ simulation' (ISS) versus 'off site simulation' (OSS): randomization, intervention and outcome measurements.

Information to all eligible staff members: Obstetric and anesthesia doctors, anesthesia and scrub nurses, auxiliary nurses, midwifes from obstetric department, anesthesia and operative department

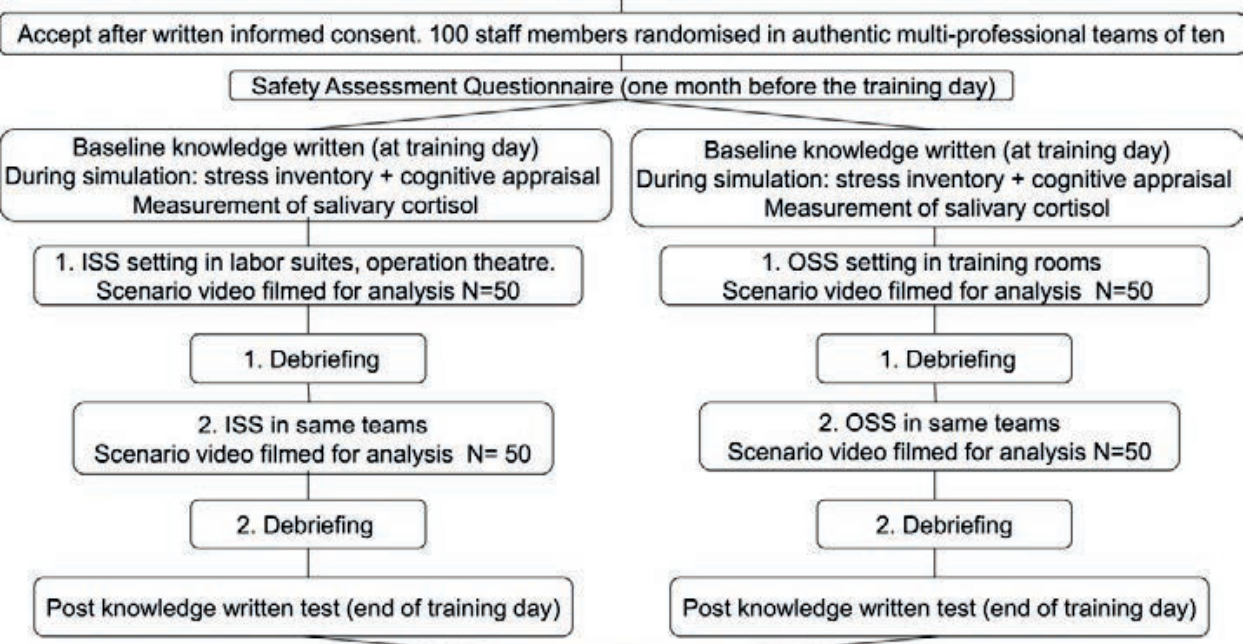

Questionnaire about perceptions of simulations, debriefing and ideas about organisational changes. Intrinsic Motivation Inventory (one week after the training day)

Safety Assessment Questionnaire (one month after the training day) 
Table 6.I.2 Variables, research hypothesis, outcome measures and methods of statistical analysis.

The table is inspired by SPIRIT 2013: Explanation and elaboration: guidance for protocols of clinical trials [44]. ANOVA, analysis of variance

\begin{tabular}{|c|c|c|c|c|}
\hline $\begin{array}{l}\text { Variable/outcome on individual level } \\
(\mathrm{N}=100)\end{array}$ & $\begin{array}{l}\text { Research hypothesis: experimental group } \\
\text { versus control group }\end{array}$ & Outcome measure & Type of variable & $\begin{array}{l}\text { Methods of statistical } \\
\text { analysis }\end{array}$ \\
\hline \multicolumn{5}{|l|}{ Primary outcome } \\
\hline Multiple choice questions & Improvement occurs in the experimental group & Percentage correct in 40 multiple choice questions & $\begin{array}{l}\text { Will be analyzed as interval data, a Gaussian } \\
\text { distribution is expected }\end{array}$ & $\begin{array}{l}\text { Parametric techniques } \\
\text { ANOVA }\end{array}$ \\
\hline \multicolumn{5}{|l|}{ Exploratory outcome } \\
\hline \multirow[t]{2}{*}{ Safety Attitudes Questionnaire } & Increased score in the experimental group & $\begin{array}{l}33 \text { items on a 5-point scale. } \\
\text { Divided into } 6 \text { dimensions }\end{array}$ & $\begin{array}{l}\text { Will be analyzed as interval data, a Gaussian } \\
\text { distribution is expected }\end{array}$ & $\begin{array}{l}\text { Parametric techniques } \\
\text { ANOVA }\end{array}$ \\
\hline & & Data are converted to the 100 -point scale & & Chi-square tests \\
\hline $\begin{array}{l}\text { Stress-Trait Anxiety Inventory } \\
\text { Baseline }\end{array}$ & $\begin{array}{l}\text { Increased peak score in } \\
\text { the experimental group }\end{array}$ & Inventory 20 item (interval 20 to 80 ). & $\begin{array}{l}\text { Will be analyzed as interval data, a Gaussian } \\
\text { distribution is expected }\end{array}$ & Parametric techniques \\
\hline
\end{tabular}

Baseline the experimental group

Data are converted to the 100-point scale

ANOVA

Stress-Trait Anxiety Inventory 1

Stress-Trait Anxiety Inventory 2

Cognitive appraisal A Baseline

Cognitive appraisal 1

Increased peak score in

Likert scale 1 (10 point)/Likert scale 2

Ordinal data

Non-parametric techniques

Cognitive appraisal 2

Test for salivary cortisol Baseline

(10 point) (interval 1/10 to 10 )

Test for salivary cortisol 1

Increased salivary cortisol

Cortisol level in nmol/l

Interval data

Parametric techniques

group

ANOVA

Test for salivary cortisol 2

Test for salivary cortisol 3

Evaluation questionnaire

\begin{tabular}{llll}
\hline Evaluation questionnaire & $\begin{array}{l}\text { Increased positive evaluation } \\
\text { in the experimental group }\end{array}$ & 20 questions on a 5-point Likert scale & $\begin{array}{l}\text { Non-parametric techniques } \\
\text { Treated as ordinal data at the } \\
\text { item level }\end{array}$ \\
\hline Intrinsic Motivation Inventory & Increased score in the experimental group & $\begin{array}{l}\text { Task evaluation inventory 22 items on } \\
\text { a 7-point scale. Divided into 4 dimensions }\end{array}$ & $\begin{array}{l}\text { Non-parametric techniques } \\
\text { Mann Whitney U test }\end{array}$ \\
\hline
\end{tabular}

Variables on team-level $(\mathrm{N}=10$

teams)

Team Emergency Assessment

Measure

Improved outcome in the experimental group

Video assessment on a 5-point scale ( 0 to 5 ) of 11 questions ( 0 to 44$) 10$ points Ordinal data

Non-parametric techniques

Selected clinical measures

Improved outcome in the experimental group Video assessment on a 5 point scale Mann Whitney U tes

Minutes before decision making about operation, minutes before operation

Interval data

Parametric techniques

initiated. Medication given yes/no 


\section{Exploratory outcomes}

The "Safety Attitudes Questionnaire" (SAQ) consists of 33 items on a five-point scale that is divided into six dimensions. SAQ was applied approximately 1 month prior to and approximately 1 month after the training day. The mean values on six different dimensions of the SAQ results from the experimental and control group will be compared 1 month after the training day. SAQ is an inventory used in several countries and also applied and validated in a Scandinavian context, and previously tested in Denmark [49-51].

Salivary cortisol (reflecting the hypothalamic-pituitary-adrenal axis activity) was used as a biological marker of stress levels. The Sarstedt Cortisol Salivette Device, provided by Neogen corporation 944 Nandino Blvd, Lexint KY 40511- 1205 USA Product no. 402710, was used The analysis will be a duplicate analysis based on the Elisa Technique $405 \mathrm{~nm}$, where $100 \mathrm{ul}$ sample will be extracted and $50 \mathrm{ul}$ in duplication will be used in the ELISA kit. Eight standards in ranges from $0.04 \mathrm{ng} / \mathrm{ml}$ up to $10 \mathrm{ng} / \mathrm{ml}$ will be used in the assay together with a blanc control. The microtitterplate will be read in a dual wavelength set at $450 \mathrm{~nm}$ and $650 \mathrm{~nm}$. In calculation of the data, the blanc background will be subtracted from all absorbance values before a non linear fit to the standard curve will be calculated.

The salivary cortisol sample was obtained before the simulation (baseline) and three times in relation to the simulations. The cortisol response will be measured as increased salivary cortisol from individual baseline to peak, and mean response values in the experimental and control group will be compared.

State-Trait Anxiety Inventory (STAI-1) was administered before the simulations started (baseline) and twice following the simulations [52,53]. It will reflect the subjective stress response. The peak level of subjective stress response will be used and mean values in the experimental and control group will be compared.

Cognitive appraisal $[31,36,54]$ was assessed before and after each scenario, using the method described by Tomaka [54]; in other words, primary appraisal was examined by asking the participants to answer the question "how stressful do you expect the upcoming task to be?" Secondary appraisal was measured by asking the participants "how able were you to cope with this task?" The participants indicated their answers on an anchored ten-point Likert scale. An index of cognitive appraisal will be calculated as the ratio of the primary appraisal (task) to the secondary appraisal (resource). If the resources are assessed as being greater than the task demands, the situation is appraised as a 'challenge'. If the task demands were appraised as being greater than the resources, the situation is appraised as a 'threat' [54].

"Intrinsic Motivation Inventory" consists of 22 items on a seven-point scale that is divided into four dimensions. It was administered as a questionnaire approximately 1 
week after the training day [27]. The median values in the experimental and control group will be compared.

A questionnaire was administered to evaluate participant perceptions of the simulations and the debriefing approximately 1 week after the training day. This questionnaire included questions on a Likert scale about personal perceptions of the scenario (that is, learning, realism, cooperation between health-care professionals, own role in the team, et cetera) and whether the simulation training scenarios inspired the participants to suggest organizational change proposals (that is, changes in guidelines, practical things, et cetera). The data will be treated as ordinal data at the item level. The median values in the experimental and control group will be compared.

Team performance score will be assessed by independent observers through reviewing video recordings of the scenarios. A validated rating scale "Team Emergency Assessment Measure" developed by Cooper and colleagues $[55,56]$ will be used. The median scores of the performance in the experimental and control group will be compared.

Clinical performance in the simulated setting will be assessed by the independent assessors through the reviewing of video recordings of the scenarios. The assessment score is based on data such as minutes passed from the scenario starts till decision was made about operation, minutes from decision making before operation was initiated, and whether medications such as uterotonics were administered or not. The mean score of the performance in the experimental and control group will be compared.

\section{Sample size calculation}

There are no data on training effectiveness of ISS upon which to base sample size calculations. We chose to calculate the required sample size based on experience with knowledge tests from data in previous studies [13,32]. We were planning a trial of a continuous response variable from independent control and experimental participants with one control per experimental participant. We assumed the response within the experimental and the control group to be normally distributed with a standard deviation of $24 \%$. If the true difference in the experimental and control means was $17 \%$, we needed to study 32 experimental participants and 32 control participants (a total of 64 ) to be able to reject the null hypothesis; that is, that there was no difference in population means of the experimental and control groups with a probability of (power) $80 \%$. The two-sided type I error probability associated to test this null hypothesis was $5 \%$.

\section{Sample size estimation adjusted for clustering}

As the intervention was delivered in teams (clusters), observations on participants in the same team were likely to be correlated. Hence the effective sample size was less than that suggested by the actual number of individual participants. The reduction in effective sample size depends on the intra-class or cluster correlation coefficient (ICC) $[57,58]$. In order to adjust the sample size for this, the crude sample size calculated above needed to be multiplied by the design effect. The cluster size was ten, as there were ten partici- 
pants in each team, and we assumed the ICC to be 0.05 [58]. Design effect $=1+$ (cluster size -1$) \times$ ICC $\rightarrow$ design effect $=1.45$. Accordingly, the sample size was then $64 \times 1.45=$ 92.8 participants. We therefore planned to include 100 participants in the experimental and control groups (50 in each group) each of which consists of five teams of 10 participants in each arm. Statistical methods for the primary and exploratory outcome of the hypotheses are laid out in Table 6.I.2, and also the statistical methods are described. The intervention was delivered in teams, which means that participants were clustered within teams. Since observations from individuals in the same team are potentially correlated we will use generalized estimating equations (GEE) [59] in the parametric analyses to take this cluster effect into account. The statistical analysis will be adjusted for healthcare professional groups. The experimental group (participants or teams in ISS) will be compared against the control group (participants or teams in OSS) for all analyses. The results will be expressed by means with standard deviations and confidence intervals, as well as by medians with percentiles. Associated P-values and effect sizes will be reported.

For the interval scale data, linear regression will be used to analyze changes between the experimental and the control group from baseline to peak. GEE will be used to take the clustered nature of the data into account. Non-parametric statistical analyses will be used for the ordinal scale data. Medians and percentiles will be reported and the MannWhitney $U$ test will be used. Individual responses to the evaluation questionnaire are measured on a Likert scale and will be treated as ordinal data and analyzed at the item level.

To take missing data into account, all analyses will be performed as intention-to-treat analyses. Missing data will be handled by multiple imputation techniques. For all tests, we will use 2 -sided P-values with alpha $<0.05$ being the level of significance. We will use the Benjamin-Hochberg method to adjust for multiple testing [60].

\section{Ethical consideration}

Participants are health-care professionals and neither patients nor patient data are used in the trial. The trial complies with the current version of the Declaration of Helsinki on biomedical research and with the Act on Processing of Personal Data. Relevant approval from The Regional Ethics Committee (protocol number H-2-2012-155) and the Danish Data Protection Agency (Number 2007-58-0015) are obtained. The trial is registered at www.clinicaltrials.gov with number NCT01792674.

The training program was planned to take place during normal working hours and participants were paid full salary for their attendance. No further compensation was given to participants. Participation was voluntary and the participants could withdraw from the trial at any time.

Participants were assured that their personal data, data on questionnaires, salivary cortisol samples and videorecordings will remain anonymous during analyses and reporting. 
The participants were asked to respect the confidentiality of their observations about colleagues' performance in the simulated setting.Recruitment of participants

The eligible participants were informed at conferences, meetings, on a web page [61], by written notice on notice boards, and by a personal letter administered by the hospital local post distribution, which gave the participants the opportunity to make an informed decision about their participation in the trial. The eligible participants could obtain more written information from our web page [61] and by contacting the principal investigator or another contact person directly. After receiving written and verbal information, eligible participants were asked to sign a consent form before being enrolled in the trial.

\section{Discussion}

This is the first randomized trial investigating the effect of ISS versus OSS for SBME. An advantage of the trial is that it includes authentic teams of health-care professionals also involved in these clinical scenarios in real life. Several simulation-based studies are not performed on authentic teams and students have often been enrolled as they are more flexible and easier to include in trials. However, applicability of these data is questionable as results based upon undergraduate students may not necessarily apply to postgraduate employed health-care workers. Including authentic teams will probably be advantageous when interpreting the results and drawing conclusions.

However, the fact that authentic obstetric-anesthesia teams are trial participants - that is, fully employed healthcare professionals - may carry feasibility problems. There will be a risk that situations arise in which real emergencies combined with lack of staff necessitate that some of the randomized health-care professionals will need to discontinue the trial participation. Further, there is a minor risk that a full team randomized to ISS needs to discontinue if a real life emergency situation necessitates the use of the rooms in the labor ward and operating theatre that were allocated to the trial for the day. Through our careful planning and cooperation with the managerial teams of the involved departments, this risk will be minimized.

A potential weakness is the fact that the trial is a single site trial, including only a moderate number of participants. There will also be a risk of contamination amongst teams, as the health-care professionals in the experimental team (ISS) intermingle with staff members allocated to the control group (OSS) and may share information. This may affect the generalizability of this study. Moreover, this trial only assesses surrogate outcomes for the relevant clinical outcome, that is, whether neonatal and maternal health fares better with ISS compared with OSS. However, being the first randomized trial comparing ISS with OSS, the trial has the potential to add some new insight with regards to the effect of authenticity in the setting for SBME and to inform future research in this field. 
The sample size estimation has been based on data from other knowledge tests [13,32], as there are no current data on knowledge testing, and on the effect of training effectiveness of ISS versus OSS. The sample size calculation is adjusted for clustering. However, we have no prior information about the ICC, and therefore this estimation is based on general recommendations $[57,58]$. The primary outcome is a knowledge test. As alluded to above, it would have been more optimal to have neo-natal and maternal health as clinical outcomes. However, this is not possible in the present trial, as a very high number of deliveries will be required to directly measure patient-relevant outcomes in obstetrics [62]. However, there are educational studies indicating that a performance in a written knowledge test can relate to clinical performance in practice [63].

Given the nature of the trial, it will not be possible to blind the participants, the educators providing the educational intervention, or the assessors observing and assessing videos. This will give a risk of overestimating the beneficial effects of the experimental intervention $[64,65]$. However, the allocated intervention group will be blinded for the data managers, statisticians and investigators drawing conclusions, and we will consider the risks of bias when drawing conclusions.

This trial can bring new information on SBME. The simulation setting has traditionally been OSS; however, an unanswered question is which advantages, if any, ISS can add to learning. Randomized trials are needed to obtain knowledge of advantages and disadvantages of ISS versus OSS. The study can potentially also inform the theory of fidelity of simulation [16]. The results of this trial may also add knowledge to inform the political planning and decision making process during rebuilding and building of hospitals and simulation centers. It is important to know whether high-fidelity simulation centers should be prioritized as opposed to designing/building simulation rooms 'in situ' for future simulation-based education. 


\title{
Trial status
}

Planning of the trial was initiated in January 2012. Enrolment of participants was initiated in January 2013. The intervention is scheduled to start in April 2013 and will stop in June 2013. Follow-up by questionnaires will continue until August 2013.

\begin{abstract}
Abbreviations
GEE: Generalized estimating equations; ICC: Intra-class or cluster correlation coefficient; ISS: In situ simulation; MCQ: Multiple choice questions; OSS: Off site simulation; SAQ: Safety Attitudes Questionnaire; SBME: Simulation-based medical education.
\end{abstract}

\section{Competing interests}

The authors declare they have no financial or academic competing interests.

\section{Authors' contributions}

JLS created the idea of the trial. All authors made contributions to the design of this trial. BO and CVdV are supervisors of the trial. Acquisition of funding was done by JLS, supported by BO and HK. JLS, JL and CG have contributed to the sample size estimation and detailed designing of and execution of the randomization process. JLS, MJ, CKA, KE, BWP, D $\varnothing$ and VL made substantial contributions to the practical issues and logistics of the trial. PW contributed to the discussion, practical issues and logistics about testing salivary cortisol. JLS wrote the draft manuscript. All authors provided critical review of this paper and approved the final manuscript.

\section{Acknowledgements}

The trial is mainly funded by a non-profit fund, the Danish Regions Development and Research Fund, and another non-profit fund, the Laerdal Foundation for Acute Medicine, has funded a minor part of the study. None of the funds have a role in the design or conduct of the study. The authors would like to thank the doctors, midwives and nurses taking part in the working committee planning the intervention, specifically midwife Pernille Langhoff-Roos for her contributions to detailed planning and recruitment of participants. The authors would like to thank Jørn Wetterslev for advice on potential impact of clustering effect. The authors would also like to thank Susanne Rosthøj and Karl Bang Christensen (Department of Biostatistics, Faculty of Health Sciences, University of Copenhagen) for advice on the statistical plan, Solvejg Kristensen (Danish National Clinical Quality Improvement Programme) for advice on the Safety Attitudes Questionnaire, and Per Bech (Psychiatric Research Unit, Mental Health Centre North Zealand, Denmark) for advice and a Danish edition of the State-Trait Anxiety Inventory. 


\section{References}

1. Hove LD, Bock J, Christoffersen JK, Hedegaard M. Analysis of 127 peripartum hypoxic brain injuries from closed claims registered by the Danish Patient Insurance Association. Acta Obstet Gynecol Scand 2008;87:72-5.

2. Berglund S, Grunewald C, Pettersson H, Cnattingius S. Severe asphyxia due to delivery-related malpractice in Sweden 1990-2005. BJOG 2008;115:316-23.

3. Cantwell R, Clutton-Brock T, Cooper G, Dawson A, Drife J, Garrod D, Harper A, Hulbert D, Lucas S, McClure J, et al. Saving Mothers' Lives: Reviewing maternal deaths to make motherhood safer: 2006-2008. The Eighth Report of the Confidential Enquiries into Maternal Deaths in the United Kingdom. BJOG 2011;118 Suppl 1:1-203.

4. Bodker B, Hvidman L, Weber T, Moller M, Aarre A, Nielsen KM, Sorensen JL. Maternal deaths in Denmark 2002-2006. Acta Obstet Gynecol Scand 2009;88:556-62.

5. Johannsson H, Ayida G, Sadler C. Faking it? Simulation in the training of obstetricians and gynaecologists. Curr Opin Obstet Gynecol 2005;17:557-61.

6. Issenberg SB, McGaghie WC, Petrusa ER, Lee GD, Scalese RJ. Features and uses of high-fidelity medical simulations that lead to effective learning: a BEME systematic review. Med Teach 2005;27:10-28.

7. Drife J. Reducing risk in obstetrics. Qual Health Care 1995;4:108-14.

8. Gold KJ, Kuznia AL, Hayward RA. How physicians cope with stillbirth or neonatal death: a national survey of obstetricians. Obstet Gynecol 2008;112:29-34.

9. Committee opinion no. 497: Coping with the stress of medical professional liability litigation. Obstet Gynecol 2011;118(2 Pt 1):389-91.

10. Veltman LL. Getting to havarti: moving toward patient safety in obstetrics. Obstet Gynecol 2007;110:1146-50.

11. Pronovost PJ, Holzmueller CG, Ennen CS, Fox HE. Overview of progress in patient safety. Am J Obstet Gynecol 2011;204:5-10

12. Merien AE, Van der Ven J, Mol BW, Houterman S, Oei SG. Multidisciplinary team training in a simulation setting for acute obstetric emergencies: a systematic review. Obstet Gynecol 2010;115:1021-31.

13. Crofts JF, Ellis D, Draycott TJ, Winter C, Hunt LP, Akande VA. Change in knowledge of midwives and obstetricians following obstetric emergency training: a randomised controlled trial of local hospital, simulation centre and teamwork training. BJOG 2007;114:1534-41.

14. Ellis D, Crofts JF, Hunt LP, Read M, Fox R, James M. Hospital, simulation center, and teamwork training for eclampsia management: a randomized controlled trial. Obstet Gynecol 2008;111:72331.

15. McGaghie WC, Issenberg SB, Petrusa ER, Scalese RJ. A critical review of simulation-based medical education research: 2003-2009. Med Educ 2010;44:50-63.

16. Norman G, Dore K, Grierson L. The minimal relationship between simulation fidelity and transfer of learning. Med Educ 2012;46:636-47.

17. Beaubien JM, Baker DP. The use of simulation for training teamwork skills in health care: how low can you go? Qual Saf Health Care 2004;13 Suppl 1:i51-i56.

18. Riley W, Davis S, Miller KM, Hansen H, Sweet RM. Detecting breaches in defensive barriers using in situ simulation for obstetric emergencies. Qual Saf Health Care 2010;19 Suppl 3:i53-i56.

19. Walker ST, Sevdalis N, McKay A, Lambden S, Gautama S, Aggarwal R, Vincent C. Unannounced in situ simulations: integrating training and clinical practice. BMJ Qual Saf 2013;22:453-8.

20. Patterson MD, Geis GL, Falcone RA, Lemaster T, Wears RL. In situ simulation: detection of safety threats and teamwork training in a high risk emergency department. BMJ Qual Saf 2013;22:46877.

21. Rosen MA, Hunt EA, Pronovost PJ, Federowicz MA, Weaver SJ. In situ simulation in continuing education for the health care professions: a systematic review. J Contin Educ Health Prof 2012;32:243-54.

22. Guise JM, Lowe NK, Deering S, Lewis PO, O'Haire C, Irwin LK, Blaser M, Wood LS, Kanki BG. Mobile in situ obstetric emergency simulation and teamwork training to improve maternal-fetal safety in hospitals. Jt Comm J Qual Patient Saf 2010;36:443-53.

23. Bender GJ. In situ simulation for systems testing in newly constructed perinatal facilities. Semin Perinatol 2011;35:80-3. 
24. Calhoun AW, Boone MC, Peterson EB, Boland KA, Montgomery VL. Integrated in-situ simulation using redirected faculty educational time to minimize costs: a feasibility study. Simul Healthc 2011;6:337-44.

25. van Schaik SM, Plant J, Diane S, Tsang L, O'Sullivan P. Interprofessional team training in pediatric resuscitation: a low-cost, in situ simulation program that enhances self-efficacy among participants. Clin Pediatr (Phila) 2011;50:807-15.

26. Anderson E, Black R, Brocklehurst P. Acute obstetric emergency drill in England and Wales: a survey of practice. BJOG 2005;112:372-5.

27. Kusurkar RA, Ten Cate TJ, van AM, Croiset G. Motivation as an independent and a dependent variable in medical education: a review of the literature. Med Teach 2011;33:e242-e262.

28. LeBlanc VR, Manser T, Weinger MB, Musson D, Kutzin J, Howard SK. The study of factors affecting human and systems performance in healthcare using simulation. Simul Healthc 2011;6 Suppl:S24S29.

29. LeBlanc VR. The effects of acute stress on performance: implications for health professions education. Acad Med 2009;84(10 Suppl):S25-S33.

30. Ten Cate TJ, Kusurkar RA, Williams GC. How self-determination theory can assist our understanding of the teaching and learning processes in medical education. AMEE guide No. 59. Med Teach 2011;33:961-73.

31. Harvey A, Nathens AB, Bandiera G, LeBlanc VR. Threat and challenge: cognitive appraisal and stress responses in simulated trauma resuscitations. Med Educ 2010;44:587-94.

32. Sorensen JL, Lokkegaard E, Johansen M, Ringsted C, Kreiner S, McAleer S. The implementation and evaluation of a mandatory multi-professional obstetric skills training program. Acta Obstet Gynecol Scand 2009;88:1107-17.

33. Arora S, Sevdalis N, Aggarwal R, Sirimanna P, Darzi A, Kneebone R. Stress impairs psychomotor performance in novice laparoscopic surgeons. Surg Endosc 2010;24:2588-93.

34. Harvey A, Bandiera G, Nathens AB, LeBlanc VR. Impact of stress on resident performance in simulated trauma scenarios. J Trauma Acute Care Surg 2012;72:497-503.

35. Keitel A, Ringleb M, Schwartges I, Weik U, Picker O, Stockhorst U, Deinzer R. Endocrine and psychological stress responses in a simulated emergency situation. Psychoneuroendocrinology 2011;36:98-108.

36. Finan E, Bismilla Z, Whyte HE, Leblanc V, McNamara PJ. High-fidelity simulator technology may not be superior to traditional low-fidelity equipment for neonatal resuscitation training. J Perinatol 2012;32:287-92.

37. Ryan RM, Deci EL. Intrinsic and Extrinsic Motivations: Classic Definitions and New Directions. Contemp Educ Psychol 2000;25:54-67.

38. Stewart A. Instructional design. In: Dent JA, Harden RM., editors. A Practical Guide for Medical Teachers. Third edition ed. Edinburgh, London, New York, Oxford, Philadelphia, St Louis, Sydney, Toronto: Curchill Livingstone Elsevier; 2009. p. 205-10.

39. Cannon-Bowers JA. Recent advances in scenario-based training for medical education. Curr Opin Anaesthesiol 2008;21:784-9.

40. Anderson LW, Krathwohl DR, Airasan PW, Cruikshank KA, Mayer RE, PIntrinch PR, et al. A Taxonomy for Learning, Teaching, and Assessing. A Revision of Bloom's Taxonomy of Educational Objectives. Abridged Edition ed. New York, San Francisco, Boston, London, Toronto, Sydney, Tokoy, Singapore, Madrid, Mexico City, Munich, Paris, Cape Town, Hong Kong, Montreal: Addison Wesley Longman, Inc.; 2001.

41. Markova V, Sorensen JL, Holm C, Norgaard A, Langhoff-Roos J. Evaluation of multi-professional obstetric skills training for postpartum hemorrhage. Acta Obstet Gynecol Scand 2012;91:346-52.

42. Plan of Strategy Juliane Marie Centre, Rigshospitalet, Copenhagen University Hospital. http://www.rigshospitalet.dk/menu/AFDELINGER/Juliane+Marie+Centret/Organisering/Om+Julian e+Marie+Centret.htm . 2013.

43. SimMom Mannequin. http://www.laerdal.com/dk/SimMom. 2013.

44. Chan AW, Tetzlaff JM, Gotzsche PC, Altman DG, Mann H, Berlin JA, Dickersin K, Hrobjartsson A, Schulz KF, Parulekar WR, et al. SPIRIT 2013 explanation and elaboration: guidance for protocols of clinical trials. BMJ 2013;346:e7586. 
45. Remmen R, Scherpbier A, Denekens J, Derese A, Hermann I, Hoogenboom R, van d, V, van RP, Bossaert L. Correlation of a written test of skills and a performance based test: a study in two traditional medical schools. Med Teach 2001;23:29-32.

46. Kramer AW, Jansen JJ, Zuithoff P, Dusman H, Tan LH, Grol RP, van der Vleuten C. Predictive validity of a written knowledge test of skills for an OSCE in postgraduate training for general practice. Med Educ 2002;36:812-9.

47. Case SM, Swanson DB. Constructing Written Test Questions For the Basic and Clinical Sciences. 3rd edition ed. National Board of Medical Examiners; 2002.

48. Schuwirth LW, van der Vleuten $C$. ABC of learning and teaching in medicine: Written assessment. BMJ 2003;326:643-5.

49. Sexton JB, Helmreich RL, Neilands TB, Rowan K, Vella K, Boyden J, Roberts PR, Thomas EJ. The Safety Attitudes Questionnaire: psychometric properties, benchmarking data, and emerging research. BMC Health Serv Res 2006;6:44.

50. Deilkas E, Hofoss D. Patient safety culture lives in departments and wards: multilevel partitioning of variance in patient safety culture. BMC Health Serv Res 2010;10:85.

51. Deilkas ET, Hofoss D. Psychometric properties of the Norwegian version of the Safety Attitudes Questionnaire (SAQ), Generic version (Short Form 2006). BMC Health Serv Res 2008;8:191.

52. Spielberger CD, Gorsuch RL, Lushene RE. Manual for the State-Trait Anxiety Inventory. Palo Alto, Calif.: Consulting Psychologists Press; 1970.

53. Bech P. [Klinisk psykometri]. 1.udgave, 2 oplag ed. Munksgaard Danmark; 2011.

54. Tomaka J, Blascovich J, Kibler J, Ernst JM. Cognitive and physiological antecedents of threat and challenge appraisal. J Pers Soc Psychol 1997;73:63-72.

55. Cooper S, Cant R, Porter J, Sellick K, Somers G, Kinsman L, Nestel D. Rating medical emergency teamwork performance: development of the Team Emergency Assessment Measure (TEAM). Resuscitation 2010;81:446-52.

56. McKay A, Walker ST, Brett SJ, Vincent C, Sevdalis N. Team performance in resuscitation teams: comparison and critique of two recently developed scoring tools. Resuscitation 2012;83:1478-83.

57. Ukoumunne OC, Gulliford MC, Chinn S, Sterne JA, Burney PG. Methods for evaluating area-wide and organisation-based interventions in health and health care: a systematic review. Health Technol Assess 1999;3(5):iii-92.

58. Campbell MK, Piaggio G, Elbourne DR, Altman DG. Consort 2010 statement: extension to cluster randomised trials. BMJ 2012;345:e5661.

59. Liang KY, Zeger SL. Longitudinal data analysis using generalized linear models. Biometrika 1986;73:13-22.

60. Benjamin Y, Hochberg Y. Controlling the False Discovery Rate: A Practical and Powerful Approach to Multiple Testing. Journal of the Royal Statistical Society Series B (Methodological) 1995;57:289300.

61. Randomised trial of 'in situ simulation' versus 'off site simulation'. http://www.rh.dk/simulationimc. 2013.

62. Mongelli M, Chung TK, Chang AM. Obstetric intervention and benefit in conditions of very low prevalence. Br J Obstet Gynaecol 1997;104:771-4.

63. Ram P, van der Vleuten C, Rethans JJ, Schouten B, Hobma S, Grol R. Assessment in general practice: the predictive value of written-knowledge tests and a multiple-station examination for actual medical performance in daily practice. Med Educ 1999;33:197-203.

64. Wood L, Egger M, Gluud LL, Schulz KF, Juni P, Altman DG, Gluud C, Martin RM, Wood AJ, Sterne JA. Empirical evidence of bias in treatment effect estimates in controlled trials with different interventions and outcomes: meta-epidemiological study. BMJ 2008 Mar 15;336:601-5.

65. Savovic J, Jones HE, Altman DG, Harris RJ, Juni P, Pildal J, Is-Nielsen B, Balk EM, Gluud C, Gluud LL, et al. Influence of reported study design characteristics on intervention effect estimates from randomized, controlled trials. Ann Intern Med 2012;157:429-38. 


\section{CHAPTER 6 Part II \\ Simulation based multi-professional obstetric anaesthesia training conducted in situ versus off site leads to similar individual and team outcomes - a randomised educational trial}

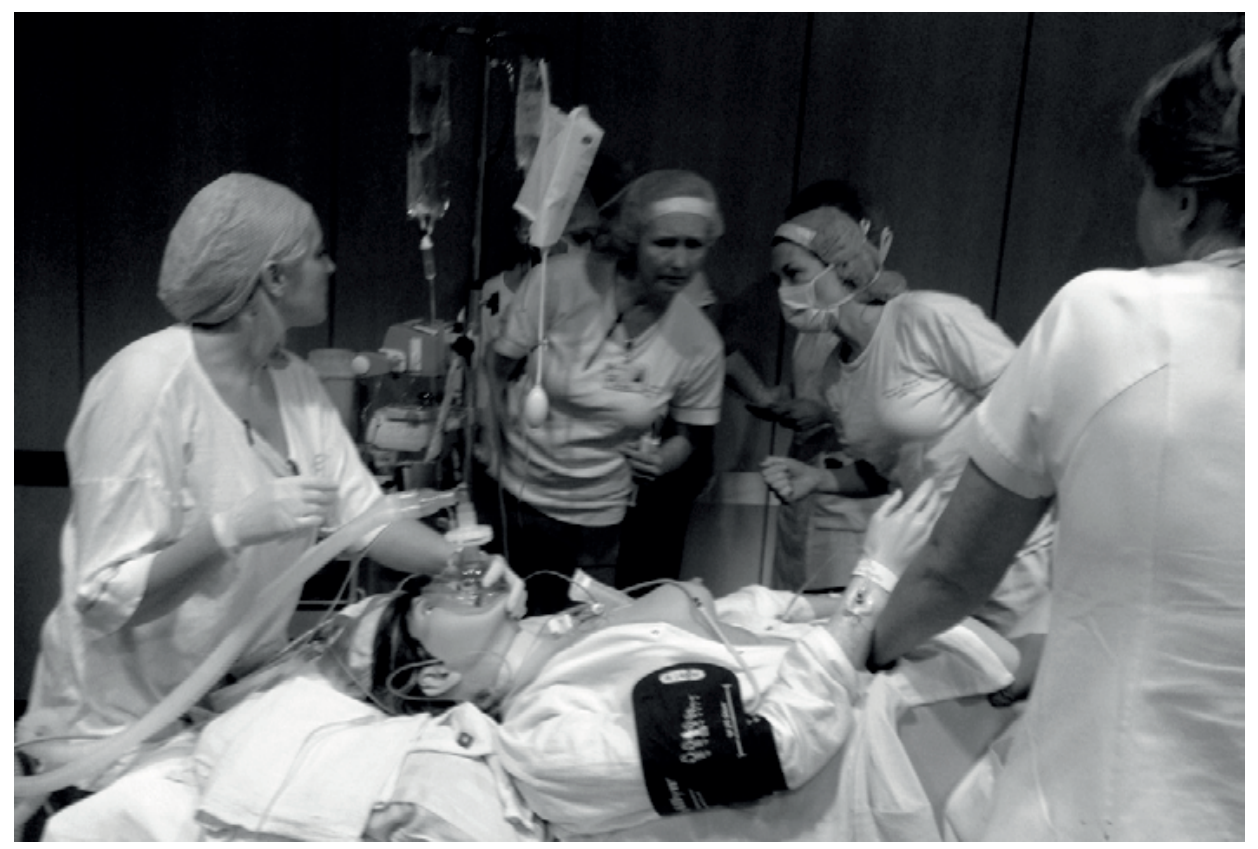

Jette Led Sørensen, Cees van der Vleuten, Susanne Rosthoj, Doris $\emptyset$ stergaard, Vicki Leblanc, Marianne Johansen, Kim Ekelund, Liis Starkopf, Jane Lindschou, Christian Gluud, Bent Ottesen.

Published in BMJ Open 2015;5:e008344. 


\begin{abstract}
Objective: To investigate the effect of in situ simulation (ISS) versus off-site simulation (OSS) on knowledge, patient safety attitude, stress, motivation, perceptions of simulation, team performance and organisational impact.

Design: Investigator-initiated single-centre randomised superiority educational trial.

Setting: Obstetrics and anaesthesiology departments, Rigshospitalet, University of Copenhagen, Denmark. Participants: 100 participants in teams of 10, comprising midwives, specialised midwives, auxiliary nurses, nurse anaesthetists, operating theatre nurses, and consultant doctors and trainees in obstetrics and anaesthesiology.

Interventions: Two multiprofessional simulations (clinical management of an emergency caesarean section and a postpartum haemorrhage scenario) were conducted in teams of 10 in the ISS versus the OSS setting.
\end{abstract}

Primary outcome: Knowledge assessed by a multiple choice question test.

Exploratory outcomes: Individual outcomes: scores on the Safety Attitudes Questionnaire, stress measurements (State-Trait Anxiety Inventory, cognitive appraisal and salivary cortisol), Intrinsic Motivation Inventory and perceptions of simulations. Team outcome: video assessment of team performance. Organisational impact: suggestions for organisational changes.

Results: The trial was conducted from April to June 2013. No differences between the two groups were found for the multiple choice question test, patient safety attitude, stress measurements, motivation or the evaluation of the simulations. The participants in the ISS group scored the authenticity of the simulation significantly higher than did the participants in the OSS group. Expert video assessment of team performance showed no differences between the ISS versus the OSS group. The ISS group provided more ideas and suggestions for changes at the organisational level.

Conclusions: In this randomised trial, no significant differences were found regarding knowledge, patient safety attitude, motivation or stress measurements when comparing ISS versus OSS. Although participant perception of the authenticity of ISS versus OSS differed significantly, there were no differences in other outcomes between the groups except that the ISS group generated more suggestions for organisational changes.

Trial registration number: NCT01792674 


\section{Strengths and limitation of this study}

$>\quad$ To the best of our knowledge, this is the first randomised trial conducted to assess the effects of two different simulation settings, in situ simulation versus off site simulation, on a broad variety of outcomes.

$>$ Previous non-randomised studies have recommended in situ simulation. However, in this randomised trial, no significant differences were found regarding knowledge, patient safety attitude, stress measurements, motivation or team performance when comparing in situ simulation versus off site simulation. The participants in the in situ group scored the authenticity of the simulation significantly higher than the participants in the off site simulation group. However, this perception did not influence the individual and team outcomes. On the outcome on organisational level, the in situ group generated more suggestions for organisational changes.

$>$ A strength of this trial is the involvement of authentic teams that mirrored teams in real life that resembles the real clinical setting in every possible way. This seem to be important for the socalled sociological fidelity.

$>\quad$ A limitation of the trial is the fact that the outcomes were based only on immediate measurements of knowledge level and of team performance. Only perceptions of simulation were measured after one week (evaluation and motivation) and safety attitudes after 1 month. No clinical outcome was measured. 


\section{Introduction}

Frequently recommended as a learning modality [1-5], simulation-based medical education is described as "devices, trained persons, lifelike virtual environments and contrived social situations that mimic problems, events, or conditions that arise in professional encounters"[5]. However, its key elements remain to be studied in depth in order to improve simulation-based medical education. One potential aspect that may influence the effect of this kind of education is the level of fidelity, or authenticity in more layman's terms. Fidelity is traditionally described to be assessed on two levels: (1) engineering or physical fidelity, that is, does the simulation look realistic? (2) psychological fidelity, that is, does the simulator contain the critical elements to accurately simulate the behaviours required to complete a task $[6,7]$ ?

Simulation-based medical education has traditionally been conducted as an off-site simulation (OSS), either at a simulation centre or in facilities in the hospital set up for the purpose of simulation. Recently, in situ simulation (ISS) has been introduced and described as "a team based simulation strategy that occurs on the actual patient care units involving actual healthcare team members within their own working environment"[812]. An unanswered question is whether ISS is superior to OSS. It has been argued that ISS has more fidelity and can lead to better teaching and greater organisational impact compared with OSS [8-14].

We hypothesised that the physical setting could influence fidelity, and hence ISS could be more effective for educational purposes. To the best of our knowledge, no randomised educational trials have been conducted comparing the ISS versus the OSS setting. Two articles that do use randomisation focused on frequency of training and not setting, and did not include a relevant control group $[15,16]$. Previous studies have been criticised for having small sample sizes, weak study designs and a lack of meaningful evaluations of the effectiveness of the programmes [8]. A recent retrospective video-based study showed that the performance was similar in all the tested simulation settings, but the participants favoured ISS and the authors argued that prospective studies are needed [17].

Human factors such as stress and motivation impact learning [18-26], which is why we set out to investigate how stress and motivation were affected by ISS versus OSS. We anticipated that the participants would experience ISS as more demanding and as creating higher levels of stress and motivation, which might enhance their learning. Furthermore, we hypothesised that ISS might provide investigators with more information on changes needed in the organisation to improve quality of care.

In this trial, we wanted to apply simulation-based medical education in the field of obstetrics, as delivery wards are challenging workplaces, where patient safety is high on the agenda and unexpected emergencies occur [27-34]. Simulation-based medical education is thus argued to be an essential learning strategy for labour wards $[4,35]$. The 
objective of this randomised educational trial was to investigate the effect of ISS versus OSS on knowledge, patient safety attitude, stress, motivation, perception of the simulation, team performance and organisational impact among multiprofessional obstetric anaesthesia teams.

\section{Methods}

\section{Design}

An investigator-initiated, single-centre randomised superiority educational trial was previously described in a design article [36].

\section{Setting and participants}

The setting was the Department of Obstetrics and the Department of Anaesthesiology, Juliane Marie Centre for Children, Women and Reproduction, Rigshospitalet, University of Copenhagen, which has approximately 6300 deliveries per year. Participants were healthcare professionals who worked in shifts on the labour ward: consultant and trainee doctors in obstetrics and anaesthesiology, midwives, specialised midwives, auxiliary nurses, nurse anaesthetists and operating theatre nurses. Participants gave written informed consent. Exclusion criteria were lack of informed consent, employees with managerial and staff responsibilities, staff members involved in the design of the trial and employees who did not work in shifts [36].

Recruitment of participants

Eligible participants were provided with information via meetings, a website and personal letters, but additional verbal and written information could also be obtained from the principal investigator (JLS). Informed written consent was obtained if people decided to participate in the trial [36].

\section{Interventions}

The experimental intervention was a preannounced ISS [8,9], that is, simulation-based medical education in the delivery room and operating theatre. The control intervention was an OSS, which took place in hospital rooms set up for the occasion but away from the patient care unit.

An appointed working committee consisting of representatives from all the healthcare professionals participating in the trial developed its aims and objectives, and they designed simulated scenarios for ISS and OSS [36]. The two simulation scenarios were: (1) management of an emergency caesarean section after a cord prolapse; and (2) a postpartum haemorrhage including surgical procedures to evacuate the uterus. Focusing mainly on interprofessional skills and communication, the scen- arios gave each healthcare profession a significant role to play [37].

All participants recruited for a training day were told to arrive at a specific time dressed in work clothes, but had not been told what kind of simulation they were randomised to. The OSS room that was to function as the delivery room was in the doctors' on-call 
room, which was small compared to the usual delivery room. A roller table prepared with the usual labour ward equipment had been placed in the room. The OSS room that was to function as the operating theatre was set up in the corner of a lecture hall. An anaesthetic trolley with the usual equipment was placed in the room and equipment for the operating theatre nurses was placed on a roller table. An introductory presentation was given to all participants on how the simulation was organised and then the participants recruited for OSS were shown the fictitious delivery room and fictitious operating theatre.

In the first part of the simulation in the delivery room, someone who has been instructed in role playing acted as the patient in the ISS and OSS settings. In the real and the fictitious operating theatre, a full-body birthing simulator, a SimMom, was used for parts of the simulation scenario [38]. Recruited from the working committee, the instructors conducting the simulations were trained in facilitating simulations and doing debriefings. The working committee was trained in local organised courses and attended a British National train the trainers course: PROMPT (PRactical Obstetric MultiProfessional Training) [39]. They worked in groups of two comprising either a consultant obstetrician with a nurse anaesthetist or a consultant anaesthetist with a midwife. The debriefings lasted 50-60 min and comprised three phases: description, analysis and application [40]. In addition to the simulation-based medical education, the training day also included video-based, case-based [41] and lecture-based teaching sessions.

\section{Primary outcome}

The primary outcome was the results from a knowledge test based on a 40-item multiple choice question (MCQ) test developed specifically for this trial [42]. The choice of a knowledge test as the primary outcome was mainly a pragmatic choice. MCQ testing is feasible for testing many participants in a relatively short time and at a low cost [43]. Furthermore, previously used knowledge tests could be used for inspiration and for sample size calculation $[44,45]$. The participants completed the MCQ test at the beginning and at the end of the training day. They were asked not to discuss the MCQ test with other participants or instructors during the training day.

\section{Exploratory outcomes}

The Safety Attitudes Questionnaire (SAQ) is validated in a Danish context [46]. It included 33 items covering five dimensions: (1) team work climate; (2) safety climate; (3) job satisfaction; (4) stress recognition; and (5) work conditions $[47,48]$. The participants did the SAQ 1 month prior to and 1 month after participating in the training day.

Stress: Salivary cortisol levels were used as an objective measure of physiological stress [36]. The salivary cortisol samples were obtained as a baseline before the first and the second simulation and at three additional times after the two simulations (figure 6.II.1.). The subjective stress level was measured using the Stress-Trait Anxiety Inventory (STAI) and cognitive appraisal (CA) (figure 6.II.1.) [21,23,49,50]. 
Intrinsic Motivation Inventory (IMI) included 22 items with four dimensions: (1) interest/enjoyment; (2) perceived competence; (3) perceived choice; and (4) pressure or tension (reversed scale) [51].

Figure 6.II.1 Timing of the simulations and measurement of stress: Objective stress was measured by salivary cortisol and subjective stress was measured by State-Trait Anxiety Inventory and cognitive appraisal.

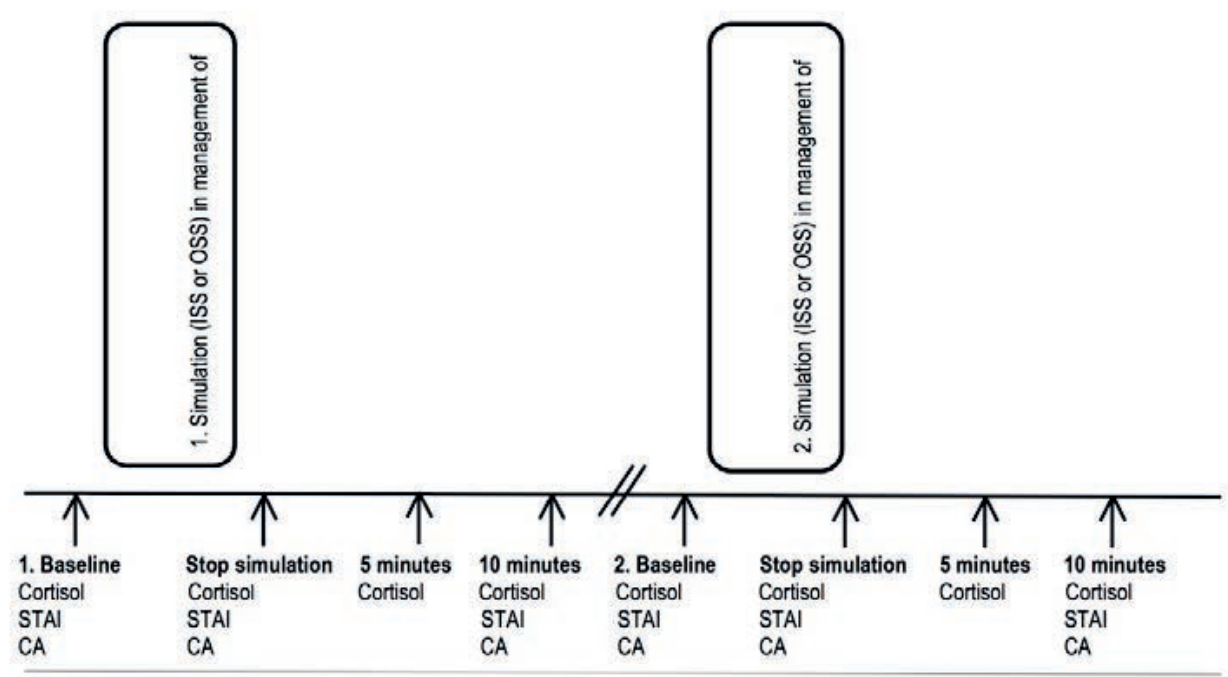

CA: cognitive appraisal ISS: in situ simulation; OSS: off site simulation; STAI: State-Trait Anxiety Inventory.

Evaluation questionnaire: Together with the IMI, each participant received an evaluation questionnaire at the end of the training day and they were asked to return it within a week [36].

Team performance was video recorded and assessed by experts using a Team Emergency Assessment Measure (TEAM) $[36,52,53]$. The TEAM scale was used in the original version in English and supplemented with a translated Danish version. The scoring of team performance was done by two consultant anaesthetists and two consultant obstetricians from outside the trial hospital. All four video assessors jointly attended two times $3 \mathrm{~h}$ training sessions on video rating, but assessment of the trial videos was conducted individually. Each video-assessor received an external hard disc with 20 simulated scenarios in random order of teams and scenarios of management of an emergency caesarean section and a postpartum haemorrhage, respectively.

Organisational outcomes were registered using: (1) two open-ended questions included in the evaluation questionnaire on suggestions for organisational changes; and (2) debriefing and evaluation at the end of the training day, where participants reported ideas for organisational changes. The principal investigator (JLS) took notes during 
these sessions, which were then discussed in the previously mentioned working committee, which included authors MJ and KE.

\section{Sample size calculation}

We chose data from knowledge tests from previous studies to conduct our sample size estimation $[44,45]$. We assumed the distribution of the primary outcome (the percentage of correct MCQ answers) to be normally distributed with an SD of $24 \%$. If a difference in the percentage of correct MCQ answers between the two groups (ISS and OSS) was $17 \%$, then 64 participants had to be included to be able to reject the null hypothesis with a power of $80 \%$. Since the interventions were delivered in teams (clusters), observations from the same team were likely to be correlated [54,54]. The reduction in effective sample size depends on the cluster correlation coefficient, which is why the crude sample size had to be multiplied by a design effect. With a design effect of 0.05 , the minimum sample size was increased to 92.8 participants [55]. We therefore decided to include a total of 100 participants.

\section{Randomisation and blinding}

Randomisation was performed by the Copenhagen Trial Unit using a computergenerated allocation sequence concealed to the investigators. The randomisation was conducted in two steps. First, the participants were individually randomised $1: 1$ to the ISS versus the OSS group. The allocation sequence consisted of nine strata, one for each healthcare professional group. Each stratum was composed of one or two permuted blocks with the size of 10 . Second, the participants in each group were then randomised into one of five teams for the ISS and OSS settings using simple randomisation that took into account the days they were available for training.

Questionnaire data were transferred from the paper versions and coded by independent data managers. The intervention was not blinded for the participants, instructors providing the educational intervention, the video assessors or the investigators drawing the conclusions. The data managers and statisticians were blinded to the allocated intervention groups.

\section{Data analysis and statistical methods}

Owing to the low number of missing values, no missing data techniques were applied. Single missing items in the MCQ test or more than one answer to an MCQ item were treated as incorrect answers. Single missing items in the inventories SAQ, IMI and STAI were excluded from the overall calculation of the summary scores.

Calculation of $95 \% \mathrm{Cl}$ obtained after the simulation intervention (post-MCQ, post-SAQ, stress measurements, IMI) was based on generalised estimating equations (GEE) [56] since observations from individuals on the same team were potentially correlated.

The evaluation data measured on a Likert scale were analysed as comparisons of location of the ordinal responses from items in the evaluation questionnaire performed by 
the Kruskal-Wallis rank sum test, and the $\mathrm{p}$ values were adjusted for multiple testing using the Benjamini-Hochberg method [57].

The mean outcomes obtained after the simulation intervention (postmeasurements) in the two intervention groups were compared by a linear model including framework from the Systems Engineering Initiative for Patient Safety model [58].

SAS V.9.2, R V.3.0.2 and IBM SPSS Statistics V.20 were used for statistical analysis. Twosided $\mathrm{p}$ values $<0.05$ were considered significant.

\section{Results}

Recruitment, basic characteristics and follow-up of participants

Informed written consent for participation in the trial was provided by 116 healthcare professionals. The two randomised intervention groups were comparable (table 6.II.1). The flow of participants is described in figure 6.II.2 and in table 6.II.2.

Intervention delivery

The trial was conducted from April to June 2013. Out of 100 participants included, 97 participated (tables 6.II.1 and 6.II.2 and figure 6.II.2). The 10 simulations were conducted as planned, although one ISS had to be postponed for $15 \mathrm{~min}$ due to an ongoing, real emergency caesarean section. The mean number of minutes spent on the caesarean section simulation in ISS and OSS was 18 and $15 \mathrm{~min}$, respectively $(p=0.70)$, while the mean for the postpartum haemorrhage simulation was 26 and $24 \mathrm{~min}$, respectively, $(p=0.40)$.

\section{Primary outcome}

MCQ test: There was no difference in mean post-MCQ scores between the ISS versus the OSS group adjusted for the pre-MCQ scores (table 6.II.3). Additional analyses based on the MCQ test, including 33 or 29 of the 40 items, gave similar results (data not shown). These additional analyses were performed because validation of the MCQ test revealed that 7-11 of the $40 \mathrm{MCQ}$ items were disputable [42].

Post hoc analysis: The average increase in percentage of correct answers in the MCQ test following training was $13.1 \%(95 \% \mathrm{Cl} 11.0 \%$ to $15.3 \%)$ in the ISS group and $12.7 \%$ $(95 \% \mathrm{Cl} 10.3 \%$ to $15.2 \%)$ in the OSS group (overall tests of no difference between pre and post $\mathrm{MCQ}$ : both $\mathrm{p}<0.0001$ ). 
Table 6.II.1 Baseline Characteristics of participants in the ISS and OSS groups $(n=100)$.

\begin{tabular}{|c|c|c|c|}
\hline & $\begin{array}{l}\text { ISS } \\
\text { group }\end{array}$ & $\begin{array}{l}\text { OSS } \\
\text { group }\end{array}$ & \\
\hline Number of participants & 481 & $49^{2}$ & \\
\hline Number of females/males & $42 / 6$ & $43 / 6$ & \\
\hline Median age (range) & $44.5(26-63)$ & $42(27-65)$ & \\
\hline Median years of obstetric work experiences (range) & $7(0.6-38)$ & $7(0.6-39)$ & \\
\hline \multicolumn{4}{|l|}{ Previous simulation experiences ${ }^{3}$ : } \\
\hline No experience & 8 & 10 & \\
\hline Simple simulation & 25 & 24 & \\
\hline Full-scale simulation & 15 & 15 & \\
\hline Pregnant participants & 2 & 2 & \\
\hline Participants on any kind of medication & 19 & 20 & \\
\hline $\begin{array}{l}\text { Participants on medication with no expected influence on cortisol measure- } \\
\text { ment }^{4}\end{array}$ & 12 & 9 & \\
\hline Participants on medication with potential influence on cortisol measurement & 7 & 11 & \\
\hline $\begin{array}{l}\text { Intranasal and inhaled corticosteroids (mometasone furoate, } \\
\text { budesonide/formoterol, budesonide, fluticasone/salmeterol) }\end{array}$ & 2 & & 3 \\
\hline Levothyroxine & 1 & & 2 \\
\hline Metformin & 1 & & 1 \\
\hline Norethisterone/estradiolacetate & 0 & & 1 \\
\hline Oral contraceptives & 1 & & 3 \\
\hline Beta blockers (metoprolol) & 0 & & 1 \\
\hline Antidepressants (nortriptyline, fluoxetine) & 2 & & 0 \\
\hline $\begin{array}{l}\text { 1) Not included due to illness: A consultant obstetrician and an operating room } \\
\text { 2) Not included due to illness: An auxiliary nurse ( } n=1) \text {. } \\
\text { 3) A simple simulation experience is, for example skills training using a low-tec } \\
\text { of the simulation scenario. Full-scale simulation is done in teams with fully int } \\
\text { scenarios. } \\
\text { 4) Intrauterine contraceptive devices, angiotensin II receptor antagonists, angi } \\
\text { simvastatin, alendronate, pantoprazole, antihistamine and tinzaparine. } \\
\text { ISS: in situ simulation; OSS: off site simulation }\end{array}$ & $\begin{array}{l}\text { urse }(n=2) \text {. } \\
\text { delivery mann } \\
\text { active manneq } \\
\text { ensin-convertin }\end{array}$ & $\begin{array}{l}\text { no video re } \\
\text { video recorde } \\
\text { inhibitors, }\end{array}$ & eording \\
\hline
\end{tabular}

\section{Exploratory outcomes}

$S A Q$ : No differences were found in the ISS versus the OSS group for any of the post-SAQ dimensions (table 6.II.4). Salivary cortisol, STAI and CA: The mean change in baseline to peak was similar for ISS versus OSS for both the first (caesarean section) and the second (post-partum haemorrhage) simulation (table 6.II.5).

Post hoc analysis: The salivary cortisol and STAI levels increased significantly from baseline to peak in the ISS and OSS groups following the first (caesarean section) and the second ( postpartum haemorrhage) simulation (overall tests for no difference between pre and post: all $p<0.0001)$. CA decreased significantly from baseline to peak in the ISS and OSS settings in both the caesarean section and in the postpartum haemorrhage simulations $(p<0.0001)$. 
Figure 6.II.2 Flow diagram for participants in a trial determining the effects of ISS versus OSS on (1) primary outcome: knowledge (MCQ test); and (2) exploratory outcomes: patient safety attitudes (SAQ), stress (salivary cortisol, STAI, CA), motivation (IMI), perceptions of simulation (evaluation questionnaire), video-assssed team performance (TEAM) and organisational impact.

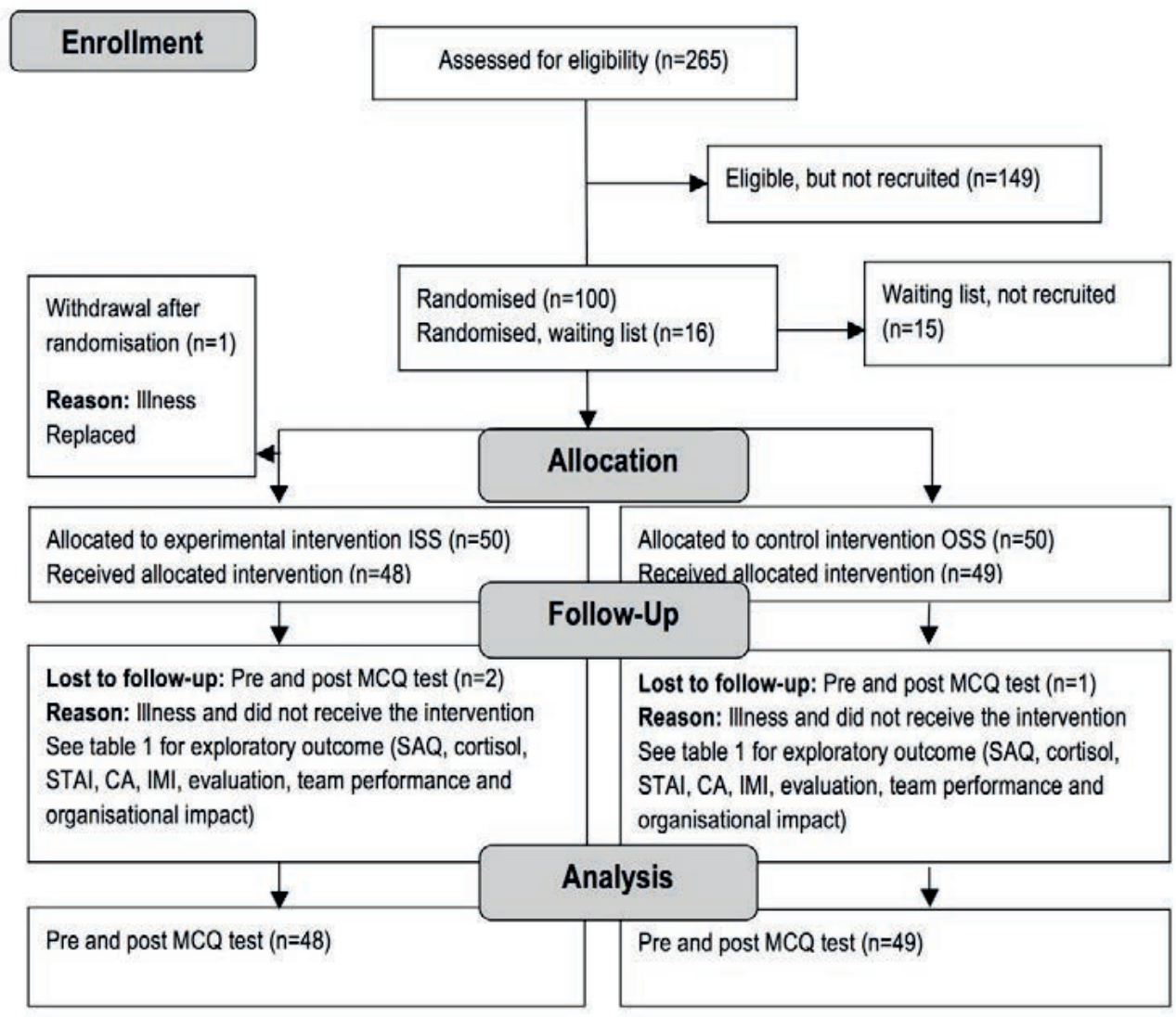

CA: cognitive appraisal; IMI: Intrinsic Motivation Inventory; ISS: in situ simulation; MCQ: multiple choice question; OSS: off site simulation; SAQ: Safety Attitudes Questionnaire; STAI: Stress-Trait Anxiety Inventory; TEAM: Team Emergency Assessment Measure.

IMI: No differences were found in the ISS versus the OSS group for the IMI score (table 6.II.6).

Participant evaluations and perception: For almost all 20 questions in the evaluation questionnaire, the ISS and OSS groups did not differ significantly. However, the two questions addressing the authenticity or fidelity of the simulations were scored significantly higher by the ISS participants compared with the OSS participants (table 6.II.7).

TEAM: No significant differences were found in the team scoring of performance between the ISS versus the OSS group (table 6.II.8). 
TEAM post hoc analysis: A significant increase was found in the team scoring of performance from the first simulation (emergency caesarean section) to the second ( postpartum haemorrhage) (table 6.II.8).

Table 6.II.2 Reasons for lost to follow-up (n/100 randomised participants (\%).

\begin{tabular}{lll}
\hline & ISS group & OSS group \\
\hline Pre MCQ test & $2(2 \%)^{1}$ & $1(1 \%)^{1}$ \\
Post MCQ test & $2(2 \%)^{1}$ & $1(1 \%)^{1}$ \\
Salivary cortisol level at emergency caesarean section simulation & $2(2 \%)^{1}$ & $3(3 \%)^{1,2}$ \\
Salivary cortisol level at postpartum haemorrhage simulation & $2(2 \%)^{1}$ & $2(2 \%)^{1,3}$ \\
STAl at emergency caesarean section simulation & $2(2 \%)^{1}$ & $1(1 \%)^{1}$ \\
STAI at postpartum haemorrhage simulation & $2(2 \%)^{1}$ & $2(2 \%)^{1,3}$ \\
CA at caesarean section simulation & $2(2 \%)^{1}$ & $1(1 \%)^{1}$ \\
CA at postpartum haemorrhage simulation & $2(2 \%)^{1}$ & $2(2 \%)^{1,3}$ \\
Evaluation questionnaire & $3(3 \%)^{1,4}$ & $1(1 \%)^{1}$ \\
IMI & $4(4 \%)^{1,5}$ & $1(1 \%)^{1}$ \\
Pre SAQ & $1(1 \%)^{7}$ & $4(4 \%)^{6}$ \\
Post SAQ & $5(5 \%)^{1,8}$ & $4(4 \%)^{1,8}$ \\
\hline
\end{tabular}

1) Participants ill and did not participate $(n=3)$.

2) Two measurements were clear outliers. A re-evaluation of the data collection indicated that the two samples had most likely been swapped between two participants, which is why these measurements were excluded from all analyses $(n=2)$.

3) Because one participant was temporarily called away for clinical work, the cortisol measurement after the simulation in postpartum haemorrhage is lacking and he was unable to answer parts of the questionnaires $(n=1)$.

4) Questionnaires not returned $(n=1)$.

5) Questionnaires not returned $(n=2)$.

6) For three participants pre SAQ data were excluded because these participants were employed in other departments prior to participating in the training days, hence their responses did not refer to the department in question $(n=3)$.

7) Of the individuals who did not participate due to illness $(n=3)$, one filled out the pre $S A Q$ anyhow.

8) Questionnaires not returned $(n=6)$.

CA: cognitive appraisal; IMI: Intrinsic Motivation Inventory; MCQ: multiple choice question;

SAQ: Safety Attitudes Questionnaire; STAI: Stress-Trait Anxiety Inventory

Organisational changes: A qualitative analysis showed that more ideas for organisational changes were suggested by ISS participants than OSS participants. For details, see online supplementary table S1. The quantitative analysis, however, showed that participants in the ISS and OSS groups scored equally concerning whether the simulations inspired making changes in procedures or guidelines (table 6.II.7., questions 5 and 6). 
Table 6.II.3 Means $(95 \% \mathrm{Cl})$ of percentages of correct answers in the MCQ test before (pre MCQ) and after (post MCQ) in the ISS and OSS groups.

\begin{tabular}{|c|c|c|c|c|}
\hline \multirow[b]{2}{*}{$\begin{array}{l}\text { MCQ test } \\
\text { Per cent } \\
\text { correct }\end{array}$} & \multirow[b]{2}{*}{$\begin{array}{l}\text { Simulation } \\
\text { intervention }\end{array}$} & \multicolumn{2}{|c|}{ Descriptive statistics } & \multirow[b]{2}{*}{ Mean difference 1,2} \\
\hline & & $\begin{array}{l}\text { Pre MCQ mean } 1 \\
\text { (start of training } \\
\text { day) }\end{array}$ & $\begin{array}{l}\text { Post MCQ mean } 1 \\
\text { (end of training } \\
\text { day) }\end{array}$ & \\
\hline & ISS & 69.4 (65.4 to 73.4$)$ & 82.6 (79.3 to 85.8$)$ & \multirow[t]{2}{*}{$\begin{array}{c}-0.02(-2.13 \text { to } 2.09) \\
P=0.98\end{array}$} \\
\hline & OSS & 70.6 (66.0 to 75.2$)$ & 83.3 (80.4 to 86.1 ) & \\
\hline
\end{tabular}

Table 6.II.4 Means (95\% Cl) of SAQ (converted to percentages) for five dimensions one month before (pre $\mathrm{SAQ}$ ) and one month after (post SAQ) the simulation training day with ISS and OSS.

\begin{tabular}{|c|c|c|c|c|}
\hline & \multirow[b]{2}{*}{$\begin{array}{l}\text { Simulation } \\
\text { intervention }\end{array}$} & \multicolumn{3}{|c|}{ Descriptive statistics } \\
\hline & & $\begin{array}{l}\text { Pre SAQ mean } \\
(1 \text { month before ) }\end{array}$ & $\begin{array}{l}\text { Post SAQ mean } 1 \\
\text { (1 month after) }\end{array}$ & Mean difference ${ }^{1,2}$ \\
\hline \multirow{2}{*}{$\begin{array}{l}\text { SAQ Team work } \\
\text { Climate }\end{array}$} & ISS & 80.5 (76.7 to 84.3$)$ & 81.1 (76.7 to 85.5$)$ & \multirow{2}{*}{$-1.4(-5.8$ to 3.1$) P=0.54$} \\
\hline & OSS & 78.4 (74.1 to 82.2$)$ & 81.2 (77.5 to 85.0$)$ & \\
\hline \multirow{2}{*}{$\begin{array}{l}\text { SAQ Safety } \\
\text { Climate }\end{array}$} & ISS & 66.7 (61.8 to 71.6$)$ & 70.6 (65.9 to 75.2$)$ & \multirow{2}{*}{$1.6(-2.0$ to 5.1$) P=0.39$} \\
\hline & OSS & 69.2 (65.4 to 73.0$)$ & 70.8 (66.8 to 74.8$)$ & \\
\hline \multirow{2}{*}{$\begin{array}{l}\text { SAQ Job } \\
\text { Satisfaction }\end{array}$} & ISS & 86.4 (82.9 to 89.8$)$ & 87.5 (83.3 to 91.7$)$ & \multirow{2}{*}{$0.6(-2.9$ to 4.1$) P=0.74$} \\
\hline & OSS & 85.6 (81.6 to 89.6) & 85.7 (81.9 to 89.5$)$ & \\
\hline \multirow{2}{*}{$\begin{array}{l}\text { SAQ Stress } \\
\text { recognition }\end{array}$} & ISS & 69.7 (63.5 to 76.0$)$ & 68.8 (62.4 to 75.1$)$ & \multirow[b]{2}{*}{$-2.6(-9.2$ to 4.0$) P=0.44$} \\
\hline & OSS & 67.3 (61.2 to 73.3$)$ & $69.2(64.0$ to 74.4$)$ & \\
\hline \multirow[b]{2}{*}{ SAQ Work condition } & ISS & 66.4 (60.8 to 72.1$)$ & 64.9 (59.0 to 70.8$)$ & \multirow[b]{2}{*}{$-0.3(-5.7$ to 5.1$) P=0.91$} \\
\hline & oss & 65.9 (59.9 to 71.8$)$ & 64.0 (58.1 to 69.8$)$ & \\
\hline \multicolumn{5}{|c|}{$\begin{array}{l}\text { 1) Based on generalised estimating equations to account for potential correlation within teams. } \\
\text { 2) Adjusted for pre SAQ (ANCOVA). } \\
\text { ANCOVA, analysis of covariance; ISS: in situ simulation; OSS: off site simulation; SAQ: Safety Attitudes Questionnaire (range: 0-100\%) }\end{array}$} \\
\hline
\end{tabular}


Table 6.II.5 Mean $(95 \% \mathrm{Cl}$ ) of salivary cortisol (nmol/L), STAl and CA during simulation in management of an emergency caesarean section and postpartum haemorrhage conducted as ISS and OSS.

\begin{tabular}{|c|c|c|c|c|c|c|c|}
\hline & & Baseline & $\begin{array}{l}\text { Post-simulation } \\
0 \text { min } \\
\text { Mean } 1\end{array}$ & $\begin{array}{l}\text { Post-simulation } \\
5 \text { min } \\
\text { Mean } 1\end{array}$ & $\begin{array}{l}\text { Post-simulation } \\
10 \mathrm{~min} \\
\text { Mean }\end{array}$ & Peak-level mean ${ }^{1,2}$ & $\begin{array}{l}\text { Mean difference of } 1,3 \\
\text { baseline } \\
\text { to peak of } \Delta \text { OSS vs. } \Delta \text { ISS }\end{array}$ \\
\hline \multicolumn{8}{|c|}{ First simulation: Emergency caesarean section } \\
\hline \multirow{2}{*}{ Cortisol } & ISS & 7.0 (6.3 to 7.8$)$ & $8.9(7.2$ to 10.6$)$ & 8.1 (6.6 to 9.6$)$ & 8.1 (6.6 to 9.5$)$ & $9.3(7.6$ to 11.0$)$ & \multirow{2}{*}{$-0.5(-1.6$ to 2.5$) P=0.64$} \\
\hline & oss & 7.3 (5.3 to 9.2$)$ & 8.2 (6.3 to 10.2$)$ & 7.8 (6.1 to 9.6$)$ & $8.0(6.2$ to 9.8$)$ & $9.0(6.9$ to 11.1$)$ & \\
\hline \multirow{2}{*}{ STAI } & ISS & $32.2(30.4$ to 34.0$)$ & 34.8 (32.7 to 37.0$)$ & & $31.3(29.5$ to 33.1$)$ & 36.5 (34.3 to 38.7$)$ & \multirow{2}{*}{$-0.2(-2.1$ to 2.5$) P=0.85$} \\
\hline & oss & 33.1 (31.1 to35.0) & 34.8 (32.2 to 37.3$)$ & & 30.7 (29.0 to 32.4 ) & 37.0 (34.7 to 39.3 ) & \\
\hline \multirow{2}{*}{ CA } & ISS & $1.0(0.9$ to 1.1$)$ & $0.8(0.7$ to 1.0$)$ & & $0.8(0.7$ to 0.9$)$ & $0.8(0.7$ to 1.0.$)$ & \multirow{2}{*}{$0.0(-0.2$ to 0.2$) P=0.93$} \\
\hline & oss & $1.0(1.0$ to 1.1$)$ & $0.8(0.7$ to 0.9$)$ & & 0.8 (0.6 to 0.9$)$ & $0.9(0.7$ to 0.9$)$ & \\
\hline \multicolumn{8}{|c|}{ Second simulation: Postpartum haemorrhage } \\
\hline \multirow{2}{*}{ Cortisol } & ISS & 7.4 (6.5 to 8.3$)$ & $9.2(7.7$ to 10.7$)$ & 7.7 (6.6 to 8.8$)$ & 7.4 (6.3 to 8.5$)$ & $9.4(7.9$ to 10.9$)$ & \multirow{2}{*}{$-1.2(-0.1$ to 0.25$) P=0.07$} \\
\hline & OSS & 6.9 (5.9 to 7.9$)$ & 7.5 (6.6 to 8.4$)$ & 6.7 (5.8 to 7.7$)$ & $6.8(6.0$ to 7.6$)$ & 7.7 (6.7 to 8.7$)$ & \\
\hline \multirow{2}{*}{ STAI } & ISS & $31.8(30.0$ to33.6) & 31.8 (30.1 to 33.6$)$ & & $28.5(27.3$ to 29.7$)$ & $32.2(30.5$ to 33.9$)$ & \multirow{2}{*}{$-0.5(-2.2$ to 1.3$) P=0.61$} \\
\hline & oss & 32.1 (29.9 to34.2) & 32.4 (30.5 to 34.3 ) & & 30.1 (28.5 to 31.8$)$ & 32.8 (31.0 to 34.7$)$ & \\
\hline \multirow[b]{2}{*}{ CA } & ISS & $1.0(0.9$ to 1.1$)$ & $0.8(0.7$ to 0.9$)$ & & $0.8(0.7$ to 0.9$)$ & $0.8(0.7$ to 0.9$)$ & \multirow[b]{2}{*}{$0.1(-0.2$ to 0.1$) P=0.56$} \\
\hline & oss & 1.1 (1.0 to 1.2$)$ & 0.9 (0.7 to 1.0$)$ & & $0.8(0.7$ to 0.9$)$ & 0.9 (0.7 to 1.0.$)$ & \\
\hline
\end{tabular}


Table 6.II.6 Mean $(95 \% \mathrm{Cl})$ motivation after participation in either ISS or OSS. Analysis comprised a comparison of the mean IMI and the mean of the ISS and OSS groups.

Simulation intervention

Interest/Enjoyment

ISS

OSS

Perceived competence

ISS

OSS

Perceived choice

ISS

OSS

Pressure tension (reversed)

ISS

OSS
IMI mean (1 week after ) ${ }^{1}$

$$
\begin{gathered}
5.2(4.9 \text { to } 5.5) \\
5.3(5.1 \text { to } 5.5) \\
P=0.72 \\
5.1(4.8 \text { to } 5.4) \\
4.9(4.7 \text { to } 5.1) \\
P=0.24 \\
5.8(5.6 \text { to } 6.1) \\
5.5(5.2 \text { to } 5.9) \\
P=0.15 \\
2.8(2.5 \text { to } 3.1) \\
2.9(2.6 \text { to } 3.3) \\
P=0.65
\end{gathered}
$$

1) Based on generalised estimating equations to account for potential correlation within teams.

IMI, Intrinsic Motivation Inventory (range:1-7); ISS: in situ simulation;

OSS: off site simulation.

\section{Discussion}

In this randomised trial, we did not find that simulation-based medical education conducted as ISS compared with OSS led to different outcomes assessed on knowledge, patient safety attitude, stress, motivation, perceptions of the simulations and team performance. Participant perception of the authenticity of the ISS and OSS differed significantly, but this had no influence on other individual or team outcomes. We observed that ISS participants provided more ideas for organisational changes than did OSS participants. This is in accordance with several non-randomised studies describing a positive impact of ISS on the organization [8,10,11,13,59-61].

In the evaluation questionnaire (table 6.II.7), participants were asked about their perceptions of the authenticity of the simulations, which can be interpreted as their perception of the simulation's fidelity. The participants scored the authenticity to be significantly higher in ISS compared with OSS; however, there were no differences in any of the other outcomes between the ISS and OSS groups. The results from this randomised 
Table 6.II.7 Participant evaluations after participation in either ISS or OSS in medians with $25 \%$ and $75 \%$ quartiles. Analysis comprised a comparison of the evaluation medians of the ISS versus OSS group.

\begin{tabular}{|c|c|c|c|}
\hline & $\begin{array}{l}\text { ISS Median } \\
\left(1^{\text {st }} Q-3^{\text {rd }} Q\right)\end{array}$ & $\begin{array}{l}\text { OSS Median } \\
\left(1^{\text {st }} Q-3^{\text {rd }} Q\right)\end{array}$ & $\begin{array}{c}\text { P } \\
\text { Value }^{1}\end{array}$ \\
\hline \multicolumn{4}{|l|}{$\begin{array}{l}\text { Evaluation questions (shortened version, original version in } \\
\text { Danish) }\end{array}$} \\
\hline 1. Over all the training day was ( $1=$ very bad to $5=$ very good) & $5(4-5)$ & $5(4-5)$ & 0.70 \\
\hline $\begin{array}{l}\text { 2. Multi-professional approach with all healthcare groups } \\
\text { involved was ( } 1=\text { very bad to } 5=\text { very good) }\end{array}$ & $5(4-5)$ & $5(4-5)$ & 0.70 \\
\hline $\begin{array}{l}\text { 3. I thought the level of education of the training was ( } 1 \text { =very } \\
\text { much over my level to } 5=\text { very much below my level) }\end{array}$ & $3(3-3)$ & $3(3-3)$ & 0.70 \\
\hline $\begin{array}{l}\text { 4. Will recommend others to participate }(1=\text { never to } \\
5=\text { always) }\end{array}$ & $5(5-5)$ & $5(4-5)$ & 0.70 \\
\hline $\begin{array}{l}\text { 5. Did simulations inspire you to change procedures or } \\
\text { practical issues in the labour room or operating theatre ( } 1=\text { no } \\
\text { ideas to } 5=\text { many ideas) (included open-ended questions) }\end{array}$ & $3(2-3)$ & $3(2-4)$ & 0.70 \\
\hline $\begin{array}{l}\text { 6. Did simulations inspire you to change guidelines ( } 1=\text { no } \\
\text { ideas to } 5=\text { many ideas) (included open-ended questions) }\end{array}$ & $2(1-2)$ & $2(1-2)$ & 0.70 \\
\hline \multicolumn{4}{|l|}{ Simulation of an emergency CS } \\
\hline 7. Over all my learning was ( $1=$ very bad to $5=$ very good) & $4(3-4)$ & $4(3-4)$ & 0.90 \\
\hline $\begin{array}{l}\text { 8. The authenticity of the CS simulation was ( } 1=\text { not at all } \\
\text { authentic to } 5=\text { very authentic) }\end{array}$ & $4(3-4)$ & $3(3-4)$ & 0.02 \\
\hline $\begin{array}{l}\text { 9. The authenticity of the CS simulation influenced my } \\
\text { learning ( } 1=\text { not at all important to } 5=\text { very important ) }\end{array}$ & $4(4-4.5)$ & $4(4-4)$ & 0.65 \\
\hline $\begin{array}{l}\text { 10. Collaboration in the CS team was ( } 1=\text { very bad to } 5=\text { very } \\
\text { good) }\end{array}$ & $4(4-4.5)$ & $4(3.8-4)$ & 0.27 \\
\hline $\begin{array}{l}\text { 11. Communication in the CS team was ( } 1=\text { very bad to } 5=\text { very } \\
\text { good) }\end{array}$ & $4(3-4)$ & $4(3-4)$ & 0.23 \\
\hline 12. The CS team leader was ( $1=$ very bad to $5=$ very good) & $4(3-4)$ & $4(3-4)$ & 0.26 \\
\hline $\begin{array}{l}\text { 13. My learning at the debriefing after the CS was ( } 1=\text { very bad } \\
\text { to } 5=\text { very good) }\end{array}$ & $4(4-5)$ & $4(4-4)$ & 0.88 \\
\hline \multicolumn{4}{|l|}{ Simulation in $\mathrm{PPH}$} \\
\hline 14. My learning overall was ( $1=$ very bad to $5=$ very good) & $4(4-4)$ & $4(4-4)$ & 0.70 \\
\hline $\begin{array}{l}\text { 15. The authenticity of the PPH simulation was ( } 1=\text { not a tall } \\
\text { authentic to } 5=\text { very authentic) }\end{array}$ & $4(3-4)$ & $3(3-4)$ & 0.01 \\
\hline $\begin{array}{l}\text { 16. The authenticity of the simulation in } \mathrm{PPH} \text { influenced my } \\
\text { learning ( } 1=\text { not at all important to } 5=\text { very important) }\end{array}$ & $4(4-4.5)$ & $4(4-4)$ & 0.23 \\
\hline $\begin{array}{l}\text { 17. Collaboration in the PPH team was ( } 1=\text { very bad to } 5=\text { very } \\
\text { good) }\end{array}$ & $4(4-4.5)$ & $4(4-4)$ & 0.64 \\
\hline $\begin{array}{l}\text { 18. Communication in the PPH team was ( } 1=\text { very bad to } \\
5=\text { very good) }\end{array}$ & $4(3.5-4)$ & $4(3-4)$ & 0.64 \\
\hline 19. The PPH team leader was ( $1=$ very bad to $5=$ very good) & $4(4-4)$ & $4(3-4)$ & 0.23 \\
\hline $\begin{array}{l}\text { 20. My learning at the debriefing after the PPH was (1=very } \\
\text { bad to } 5=\text { very good) }\end{array}$ & $4(4-4)$ & $4(4-4)$ & 0.57 \\
\hline
\end{tabular}


Table 6.II.8 Mean $(95 \% \mathrm{Cl})$ of video assessment performance scores with the TEAM scale.

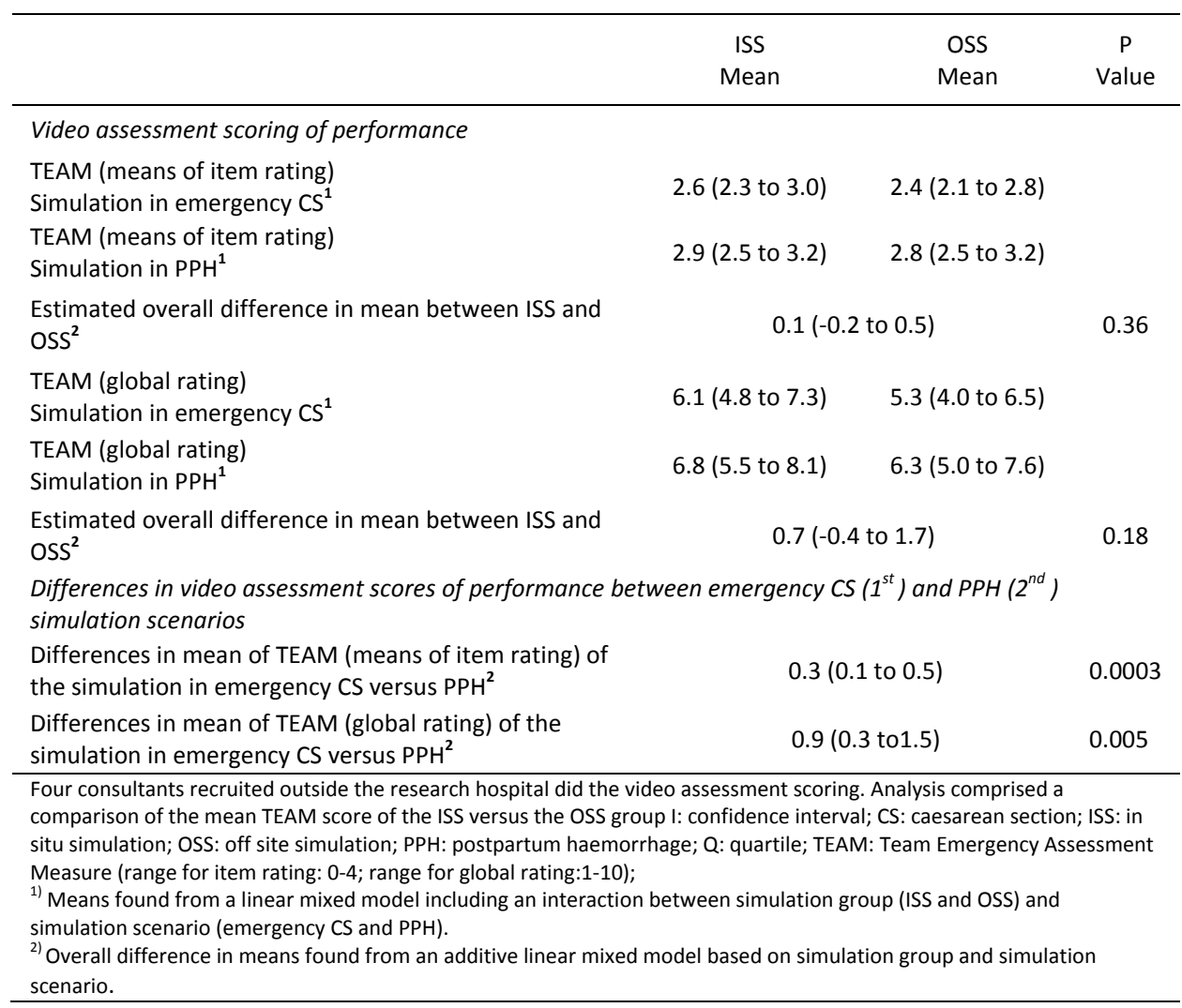

trial are not consistent with traditional situated learning theory, which states that increased fidelity leads to improved learning [62,63]. The conclusions from this trial, however, are in alignment with more recent empirical research and discussions on fidelity and learning [6, 64-66]. Our study indicates that the change in simulation fidelity, that is change in setting for simulation, does not necessarily translate into learning. Another randomised trial, which compared OSS as in-house training at the hospital in rooms specifically allocated for training with OSS in a simulation centre, also showed that the simulation setting was of minor importance and that there was no additional benefit from training OSS in a simulation centre versus OSS in-house $[44,67]$.

The present trial involved simulation-based training with six different healthcare professions. A relevant perspective is the discussion on expanding the traditional concept of fidelity to include the recently introduced term sociological fidelity, which encompasses the relationship between the various healthcare professionals $[37,68]$. After completing the trial, we decided to explore more closely the experiences between the healthcare professionals in a qualitative study [69]. 
Post hoc analyses showed similar educational effects in the ISS and OSS groups with a knowledge gain of approximately $13 \%$ in both groups. It can be argued that this knowledge gain was due to the test effect $[70,71]$. We believe, however, that the test effect was minimised as feedback was not given after the initial testing, which is viewed as crucial to learning from a test, and further- more only one MCQ test was used [71].

No differences were found in the mean SAQ score after simulation-based medical education in the ISS versus the OSS group. Earlier studies have described that high SAQ values mean that SAQ cannot be influenced by an intervention $[72,73]$. The values for

SAQ were generally high in this trial compared with various other studies from nonScandinavian countries [72-75]. There were no differences in the stress level when measured as salivary cortisol levels, STAI and CA in the ISS versus the OSS group. The post hoc analysis showed professionals.

IMI $[24,51]$ revealed no differences between ISS versus OSS. Motivation has not previously been tested in educational simulation studies, and it is argued that a gap appears to exist in the simulation literature on motivational factors and further research has been encouraged [25]. Some argue that simulation in the clinical setting, as with ISS, should increase motivation [14], but this was not confirmed by findings in this trial.

The evaluation data showed no differences between ISS and OSS. Both the ISS and OSS participants gave very high scores on the evaluation. This is in accordance with what is generally seen in interprofessional training [78].

The team performance showed no differences between ISS versus OSS. The post hoc analysis showed that teams performed statistically significantly better in the second compared to the first simulation, which indicates that the simulations were effective. Validated in previous studies, the TEAM scale has been found to be reasonably intuitive to use $[52,53]$, which was also our impression in this study.

According to the participants' own perceptions, they found that ISS and OSS were equally inspirational with regard to suggesting organisational changes in the delivery room and operating theatre and for clinical guidelines. The qualitative analysis, however, revealed that ISS participants provided more ideas for suggested changes, especially concerning technology and tools in the delivery ward and the operating theatre [58]. Previous non-randomised studies have suggested that ISS has an impact on organisations, but this has, to the best of our knowledge, never been confirmed in a randomised trial $[8,11,13,17,59]$.

\section{Strength and limitations}

This trial has several strengths. It was conducted with an adequate generation of allocation sequence; adequate allocation concealment; adequate reporting of all relevant outcomes; had very few dropouts; and was conducted on a not-for-profit basis [79-81]. The trial was also blinded for data managers and statisticians. Generally, ISS pro- 
grammes have been criticised for their lack of meaningful evaluations of the effectiveness of the programmes [8]. A strength of this trial was its use of a broad variety of outcome measures using previously validated scales to assess the effect on the individual, the team and the organisational level.

A limitation of the study is the fact that the outcome was based only on immediate measurements of knowledge level and of team performance. Only perceptions of simulation were measured after 1 week (evaluation and motivation) and safety attitudes after 1 month. No clinical outcomes or patient safety data were measured.

A strength of this trial is the involvement of authentic teams that mirrored teams in real life, which seem to be of importance for the so-called sociological fidelity $[37,68]$. The teams in this trial were authentic in their design and hence resemble the real clinical setting in every possible way $[65,82]$. These kinds of teams are called 'ad hoc' on-call teams and are very difficult to follow and observe in the real clinical setting, and assessment of the clinical performance of ad hoc teams for a long period is almost impossible. The authentic teams may also be a limitation because two-thirds of the participants had some simulation experiences. The findings in this trial therefore need to be confirmed among other kinds of healthcare professionals with less experience in simulation-based education.

Previous research on assessment suggests that knowledge-based written assessments can predict the results of performance-based tests, and hence knowledge-based assessment could be used as a proxy for performance [83-85]. However, a better approach to the assessment could have been performance-based tests of clinical work, but this was considered unfeasible.

In this trial, we did not measure long-term retention. The literature on retention of skills suggests that deterioration of the non-used skills appears to occur about 3-18 months after training. More research within the field of retention and on the effect of short booster courses is necessary [45,86-88].

There is a risk of type II error and the trial is most likely underpowered, as many randomised trials are. On the other hand, it should be discussed whether performing a larger trial to detect a statistically significant effect of ISS is relevant or feasible and appears to have a clinically or educationally relevant effect [89].

The improvements on knowledge and team performance may also be due to the Hawthorne effect, that is, due to individuals changing behaviour as a result of their awareness of being observed [90]. From an educational perspective, a major problem with the Hawthorne effect is an intervention group versus a control group, where the control group is given no intervention [90]. This issue was avoided in this trial as exactly the same intervention was used for both groups, the only difference being the physical setting, thus most likely minimising the Hawthorne effect in our trial [90]. 


\section{Conclusions}

This randomised trial compared ISS versus OSS, where OSS was provided as in-house training at the hospital in rooms specifically allocated for training. From this trial, we concluded that changes in settings from OSS to ISS do not seem to provide key elements for improving simulation-based medical education. Although participant perception of the authenticity or fidelity of ISS versus OSS differed significantly, there were no differences in knowledge, patient safety attitude, stress measurements, motivation and team performance between the groups, except that the ISS group generated more suggestions for organisational changes. This trial indicated that the physical fidelity of the setting seemed to be of less importance for learning; however, more research is necessary to better understand which aspects of simulation to be most important for learning. 


\section{Acknowledgements}

The authors would like to thank the doctors, midwives and nurses who took part in the working committee and in planning the intervention, especially midwife Pernille Langhoff-Roos (Department of Obstetrics, Rigshospitalet, University of Copenhagen) for her contributions to the detailed planning, recruitment of participants and completion of the simulations. They would also like to thank Jørn Wetterslev (Copenhagen Trial Unit) for advice on the potential impact of the clustering effect; Karl Bang Christensen (Section of Biostatistics, Department of Public Health, Faculty of Health and Medical Sciences, University of Copenhagen) for advice on the statistical plan; Solvejg Kristensen (Danish National Clinical Registries) for her advice and for providing a Danish edition of Safety Attitudes Questionnaire; Per Bech (Psychiatric Research Unit, Mental Health Centre North Zealand) for advice and for providing a Danish edition of the State-Trait Anxiety Inventory; Claire Welsh ( Juliane Marie Centre for Children, Women and Reproduction, Rigshospitalet, University of Copenhagen) and Niels Leth Jensen (certified translator) for forwarding the back translation of Intrinsic Motivation Inventory; Jesper Sonne (Department of Clinical Pharmacology, Bispebjerg Hospital) for advice on medicine that can influence cortisol measurements; Anne Lippert and Anne-Mette Hels $\varnothing$ (Danish Institute for Medical Simulation, Herlev Hospital, University of Copenhagen) for training the facilitators in conducting debriefing after simulation; medical student Veronica Markova for undertaking all practical issues on cortisol measurements; Bente Bennike (Laboratory of Neuropsychiatry, Rigshospitalet, University of Copenhagen) for managing the cortisol analyses; medical students Tobias Todsen and Ninna Ebdrup for video recordings of simulations; and Tobias Todsen for editing and preparing videos for assessment. Furthermore, the authors would like to thank Helle Thy $\varnothing$ stergaard and Lone Fuhrmann (Department of Anaesthesiology, Herlev Hospital, University of Copenhagen), Lone Krebs (Department of Obstetrics and Gynecology, Holbæk Hospital) and Morten Beck Sørensen (Department of Obstetrics and Gynecology, Odense University Hospital) for reviewing and assessing all videos. Finally, thank you to Nancy Aaen (copy editor and translator) for revising the manuscript.

\section{Contributors}

JLS conceived of the idea for this trial. BO and CVdV supervised the trial. All authors made contributions to the design of the trial. JLS, assisted by $\mathrm{BO}$, was responsible for acquiring funding. JLS, JL and CG contributed to the sample size estimation and detailed designing of and execution of the randomisation process. JLS, MJ, KE, DOE and VL made substantial contributions to the practical and logistical aspects of the trial, while PW contributed to the discussion and practical and logistical issues concerning testing salivary cortisol. Jointly with JLS, SR and LS performed the statistical analysis. JLS wrote the draft manuscript. All authors provided a critical review of this paper and approved the final manuscript.

\section{Funding}

The trial was funded by non-profit funds, including the Danish Regions Development and Research Foundation, the Laerdal Foundation for Acute Medicine and Aase and Ejnar Danielsen Foundation. None of the foundations had a role in the design or conduct of the study.

\section{Competing interests}

All authors have completed the ICMJE uniform disclosure form at http://www.icmje.org/coi_disclosure.pdf. The principal investigator and lead author (JLS) reports non-profit funding mentioned above. $D \emptyset$ reports board membership of Laerdal Foundation for Acute Medicine. Other authors declare no support from any organisation for the submitted work.

\section{Ethics approval}

Participants were healthcare professionals, and neither patients nor patient data were used in the trial. Approvals from the Regional Ethics Committee ( protocol number H-2-2012-155) and the Danish Data Protection Agency (Number 2007-58-0015) were obtained. Participants were assured that their personal data, data on questionnaires, salivary cortisol samples and video recordings would remain anonymous during analyses and reporting. The participants were asked to respect the confidentiality of their observations about their colleagues' performance in the simulated setting. 
Provenance and peer review Not commissioned; externally peer reviewed.

\section{Data sharing statement}

No consent for data sharing with other parties was obtained, but the corresponding author may be contacted to forward requests for data sharing.

\section{Open Access}

This is an Open Access article distributed in accordance with the Creative Commons Attribution Non Commercial (CC BY-NC 4.0) license, which permits others to distribute, remix, adapt, build upon this work noncommercially, and license their derivative works on different terms, provided the original work is properly cited and the use is non-commercial. See: http://creativecommons.org/licenses/by-nc/4.0/ 


\section{References}

1. Issenberg SB, McGaghie WC, Petrusa ER, Lee GD, Scalese RJ. Features and uses of high-fidelity medical simulations that lead to effective learning: a BEME systematic review. Med Teach 2005;27:10-28.

2. McGaghie WC, Issenberg SB, Petrusa ER, Scalese RJ. A critical review of simulation-based medical education research: 2003-2009. Med Educ 2010;44:50-63.

3. Motola I, Devine LA, Chung HS, Sullivan JE, Issenberg SB. Simulation in healthcare education: a best evidence practical guide. AMEE Guide No. 82. Med Teach 2013;35:e1511-e1530.

4. Merien AE, Van der Ven J, Mol BW, Houterman S, Oei SG. Multidisciplinary team training in a simulation setting for acute obstetric emergencies: a systematic review. Obstet Gynecol 2010;115:1021-31.

5. McGaghie WC, Issenberg SB, Barsuk JH, Wayne DB. A critical review of simulation-based mastery learning with translational outcomes. Med Educ 2014;48:375-85.

6. Norman G, Dore K, Grierson L. The minimal relationship between simulation fidelity and transfer of learning. Med Educ 2012;46:636-47.

7. Beaubien JM, Baker DP. The use of simulation for training teamwork skills in health care: how low can you go? Qual Saf Health Care 2004;13 Suppl 1:i51-i56.

8. Rosen MA, Hunt EA, Pronovost PJ, Federowicz MA, Weaver SJ. In situ simulation in continuing education for the health care professions: a systematic review. J Contin Educ Health Prof 2012;32:243-54.

9. Riley W, Davis S, Miller KM, Hansen H, Sweet RM. Detecting breaches in defensive barriers using in situ simulation for obstetric emergencies. Qual Saf Health Care 2010;19 Suppl 3:i53-i56.

10. Guise JM, Lowe NK, Deering S, Lewis PO, O'Haire C, Irwin LK, Blaser M, Wood LS, Kanki BG. Mobile in situ obstetric emergency simulation and teamwork training to improve maternal-fetal safety in hospitals. Jt Comm J Qual Patient Saf 2010;36:443-53.

11. Walker ST, Sevdalis N, McKay A, Lambden S, Gautama S, Aggarwal R, Vincent C. Unannounced in situ simulations: integrating training and clinical practice. BMJ Qual Saf 2013;22:453-8.

12. Patterson MD, Geis GL, Falcone RA, Lemaster T, Wears RL. In situ simulation: detection of safety threats and teamwork training in a high risk emergency department. BMJ Qual Saf 2013;22:46877.

13. Patterson MD, Geis GL, Lemaster T, Wears RL. Impact of multidisciplinary simulation-based training on patient safety in a paediatric emergency department. BMJ Qual Saf 2013;22:383-93.

14. Stocker M, Burmester M, Allen M. Optimisation of simulated team training through the application of learning theories: a debate for a conceptual framework. BMC Med Educ 2014;14:69.

15. Sullivan NJ, Duval-Arnould J, Twilley M, Smith SP, Aksamit D, Boone-Guercio P, Jeffries PR, Hunt EA. Simulation Exercise to Improve Retention of Cardiopulmonary Resuscitation Priorities for InHospital Cardiac Arrests: A Randomized Controlled Trial. Resuscitation 2014;86C:6-13.

16. Rubio-Gurung S, Putet G, Touzet S, Gauthier-Moulinier H, Jordan I, Beissel A, Labaune JM, Blanc S, Amamra N, Balandras C, Rudigoz RC, Colin C, Picaud JC. In situ simulation training for neonatal resuscitation: an RCT. Pediatrics 2014;134:e790-e797.

17. Couto TB, Kerrey BT, Taylor RG, FitzGerald M, Geis GL. Teamwork Skills in Actual, In Situ, and InCenter Pediatric Emergencies: Performance Levels Across Settings and Perceptions of Comparative Educational Impact. Simul Healthc 2015;10:76-84.

18. LeBlanc VR. The effects of acute stress on performance: implications for health professions education. Acad Med 2009;84:S25-S33.

19. LeBlanc VR, Manser T, Weinger MB, Musson D, Kutzin J, Howard SK. The study of factors affecting human and systems performance in healthcare using simulation. Simul Healthc 2011;6 Suppl:S24S29.

20. Arora S, Sevdalis N, Aggarwal R, Sirimanna P, Darzi A, Kneebone R. Stress impairs psychomotor performance in novice laparoscopic surgeons. Surg Endosc 2010;24:2588-93.

21. Harvey A, Nathens AB, Bandiera G, LeBlanc VR. Threat and challenge: cognitive appraisal and stress responses in simulated trauma resuscitations. Med Educ 2010;44:587-94.

22. Harvey A, Bandiera G, Nathens AB, LeBlanc VR. Impact of stress on resident performance in simulated trauma scenarios. J Trauma Acute Care Surg 2012;72:497-503. 
23. Finan E, Bismilla Z, Whyte HE, Leblanc V, McNamara PJ. High-fidelity simulator technology may not be superior to traditional low-fidelity equipment for neonatal resuscitation training. J Perinatol 2012;32:287-92.

24. Kusurkar RA, Ten Cate TJ, van AM, Croiset G. Motivation as an independent and a dependent variable in medical education: a review of the literature. Med Teach 2011;33:e242-e262.

25. Ten Cate TJ, Kusurkar RA, Williams GC. How self-determination theory can assist our understanding of the teaching and learning processes in medical education. AMEE guide No. 59. Med Teach 2011;33:961-73.

26. Ryan RM, Deci EL. Intrinsic and Extrinsic Motivations: Classic Definitions and New Directions. Contemp Educ Psychol 2000;25:54-67.

27. Drife J. Reducing risk in obstetrics. Qual Health Care 1995;4:108-14.

28. Gold KJ, Kuznia AL, Hayward RA. How physicians cope with stillbirth or neonatal death: a national survey of obstetricians. Obstet Gynecol 2008;112:29-34.

29. Veltman LL. Getting to havarti: moving toward patient safety in obstetrics. Obstet Gynecol 2007;110:1146-50.

30. Pronovost PJ, Holzmueller CG, Ennen CS, Fox HE. Overview of progress in patient safety. Am J Obstet Gynecol 2011;204:5-10.

31. Hove LD, Bock J, Christoffersen JK, Hedegaard M. Analysis of 127 peripartum hypoxic brain injuries from closed claims registered by the Danish Patient Insurance Association. Acta Obstet Gynecol Scand 2008;87:72-5.

32. Berglund S, Grunewald C, Pettersson H, Cnattingius S. Severe asphyxia due to delivery-related malpractice in Sweden 1990-2005. BJOG 2008;115:316-23.

33. Cantwell R, Clutton-Brock T, Cooper G, Dawson A, Drife J, Garrod D, Harper A, Hulbert D, Lucas S, McClure J, Millward-Sadler H, Neilson J, Nelson-Piercy C, Norman J, O'Herlihy C, Oates M, Shakespeare J, de SM, Williamson C, Beale V, Knight M, Lennox C, Miller A, Parmar D, Rogers J, Springett A. Saving Mothers' Lives: Reviewing maternal deaths to make motherhood safer: 20062008. The Eighth Report of the Confidential Enquiries into Maternal Deaths in the United Kingdom. BJOG 2011;118 Suppl 1:1-203.

34. Bodker B, Hvidman L, Weber T, Moller M, Aarre A, Nielsen KM, Sorensen JL. Maternal deaths in Denmark 2002-2006. Acta Obstet Gynecol Scand 2009;88:556-62.

35. Johannsson H, Ayida G, Sadler C. Faking it? Simulation in the training of obstetricians and gynaecologists. Curr Opin Obstet Gynecol 2005;17:557-61.

36. Sørensen JL, Van der Vleuten C, Lindschou J, Gluud C, Ostergaard D, Leblanc V, Johansen M, Ekelund K, Albrechtsen CK, Pedersen BW, Kjaergaard H, Weikop P, Ottesen B. 'In situ simulation' versus 'off site simulation' in obstetric emergencies and their effect on knowledge, safety attitudes, team performance, stress, and motivation: study protocol for a randomized controlled trial. Trials 2013;14:220.

37. Boet S, Bould MD, Layat BC, Reeves S. Twelve tips for a successful interprofessional team-based high-fidelity simulation education session. Med Teach 2014;36:853-7.

38. SimMom Mannequin. 2014. http://www.laerdal.com/dk/SimMom

39. Royal College of Obstetricans and Gynaecologists course: PROMPT, Train the trainers. 2015. https://www.rcog.org.uk/globalassets/documents/courses-exams-and-events/trainingcourses/prompt-2-train-the-trainers-mar2015.pdf.

40. Rudolph JW, Simon R, Dufresne RL, Raemer DB. There's no such thing as "nonjudgmental" debriefing: a theory and method for debriefing with good judgment. Simul Healthc 2006;1:49-55.

41. Thistlethwaite JE, Davies D, Ekeocha S, Kidd JM, MacDougall C, Matthews P, Purkis J, Clay D. The effectiveness of case-based learning in health professional education. A BEME systematic review: BEME Guide No. 23. Med Teach 2012;34:e421-e444.

42. Sørensen JL, Thellensen L, Strandbygaard J, Svendsen KD, Christensen KB, Johansen M., LanghoffRoos P., Ekelund K, Ottesen B, Vleuten van der C. Development of a knowledge test for multidisciplinary emergency training: a review and an example. Acta Anaesthesiol Scand 2015;59:12333.

43. Remmen R, Scherpbier A, Denekens J, Derese A, Hermann I, Hoogenboom R, van d, V, van RP, Bossaert L. Correlation of a written test of skills and a performance based test: a study in two traditional medical schools. Med Teach 2001;23:29-32. 
44. Crofts JF, Ellis D, Draycott TJ, Winter C, Hunt LP, Akande VA. Change in knowledge of midwives and obstetricians following obstetric emergency training: a randomised controlled trial of local hospital, simulation centre and teamwork training. BJOG 2007;114:1534-41.

45. Sørensen JL, Løkkegaard E, Johansen M, Ringsted C, Kreiner S, McAleer S. The implementation and evaluation of a mandatory multi-professional obstetric skills training program. Acta Obstet Gynecol Scand 2009;88:1107-17.

46. Kristensen S, Sabroe S, Bartels P, Mainz J, Christensen KB. Adaption and validation of the Safety Attitudes Questionnaire for the Danish hospital setting. Clin Epidemiol 2015;7:149-60.

47. Sexton JB, Helmreich RL, Neilands TB, Rowan K, Vella K, Boyden J, Roberts PR, Thomas EJ. The Safety Attitudes Questionnaire: psychometric properties, benchmarking data, and emerging research. BMC Health Serv Res 2006;6:44.

48. Deilkas ET, Hofoss D. Psychometric properties of the Norwegian version of the Safety Attitudes Questionnaire (SAQ), Generic version (Short Form 2006). BMC Health Serv Res 2008;8:191.

49. Spielberger CD, Gorsuch RL, Lushene RE. Manual for the State-Trait Anxiety Inventory. Palo Alto, Calif.: Consulting Psychologists Press; 1970.

50. Bech P. [Klinisk psykometri]. 1.udgave, 2 oplag ed. Munksgaard Danmark, København, Danmark, 2011.

51. Self-Determination Theory (SDT). 2015. http://www.selfdeterminationtheory.org/intrinsicmotivation-inventory/

52. Cooper S, Cant R, Porter J, Sellick K, Somers G, Kinsman L, Nestel D. Rating medical emergency teamwork performance: development of the Team Emergency Assessment Measure (TEAM). Resuscitation 2010;81:446-52.

53. McKay A, Walker ST, Brett SJ, Vincent C, Sevdalis N. Team performance in resuscitation teams: comparison and critique of two recently developed scoring tools. Resuscitation 2012;83:1478-83.

54. Ukoumunne OC, Gulliford MC, Chinn S, Sterne JA, Burney PG. Methods for evaluating area-wide and organisation-based interventions in health and health care: a systematic review. Health Technol Assess 1999;3:iii-92.

55. Campbell MK, Piaggio G, Elbourne DR, Altman DG. Consort 2010 statement: extension to cluster randomised trials. BMJ 2012;345:e5661.

56. Liang KY, Zeger SL. Longitudinal data analysis using generalized linear models. Biometrika 1986;73:13-22.

57. Benjamini Y, Hochberg Y. Controlling the False Discovery Rate: A Practical and Powerful Approach to Multiple Testing. Journal of the Royal Statistical Society Series B (Methodological) 1995;57:289300.

58. Carayon P, Schoofs HA, Karsh BT, Gurses AP, Alvarado CJ, Smith M, Flatley BP. Work system design for patient safety: the SEIPS model. Qual Saf Health Care 2006;15 Suppl 1:i50-i58.

59. Sorensen JL, Lottrup P, Vleuten van der C, Andersen KS, Simonsen M, Emmersen P, Rosthoj S, Ottesen B. Unannounced in situ simulation of obstetric emergencies: staff perceptions and organisational impact. Postgrad Med J 2014;90:622-9.

60. Kobayashi L, Parchuri R, Gardiner FG, Paolucci GA, Tomaselli NM, Al-Rasheed RS, Bertsch KS, Devine J, Boss RM, Gibbs FJ, Goldlust E, Monti JE, O'Hearn B, Portelli DC, Siegel NA, Hemendinger $D$, Jay GD. Use of in situ simulation and human factors engineering to assess and improve emergency department clinical systems for timely telemetry-based detection of life-threatening arrhythmias. BMJ Qual Saf 2013;22:72-83.

61. Wheeler DS, Geis G, Mack EH, Lemaster T, Patterson MD. High-reliability emergency response teams in the hospital: improving quality and safety using in situ simulation training. BMJ Qual Saf 2013;22:507-14.

62. Durning SJ, Artino AR, Jr., Pangaro LN, van d, V, Schuwirth L. Perspective: redefining context in the clinical encounter: implications for research and training in medical education. Acad Med 2010;85:894-901.

63. Durning SJ, Artino AR. Situativity theory: a perspective on how participants and the environment can interact: AMEE Guide no. 52. Med Teach 2011;33:188-99.

64. Koens F, Mann KV, Custers EJ, Ten Cate OT. Analysing the concept of context in medical education. Med Educ 2005;39:1243-9.

65. Teteris E, Fraser K, Wright B, McLaughlin K. Does training learners on simulators benefit real patients? Adv Health Sci Educ Theory Pract 2012;17:137-44. 
66. Grierson LE. Information processing, specificity of practice, and the transfer of learning: considerations for reconsidering fidelity. Adv Health Sci Educ Theory Pract 2014;19:281-9.

67. Ellis D, Crofts JF, Hunt LP, Read M, Fox R, James M. Hospital, simulation center, and teamwork training for eclampsia management: a randomized controlled trial. Obstet Gynecol 2008;111:72331.

68. Sharma S, Boet S, Kitto S, Reeves S. Interprofessional simulated learning: the need for 'sociological fidelity'. J Interprof Care 2011;25:81-3.

69. Sørensen JL, Navne LE, Martin HM, Ottesen B, Albrechtsen CK, Pedersen BW, Kjaergaard H, Vleuten van der C. Clarifying the learning experiences of healthcare professionals with in situ versus off-site simulation-based medical education: a qualitative study. BMJ Open 2015;5:e008345. doi:10.1136/bmjopen-2015-008345.

70. Roediger HL, Karpicke JD. Test-enhanced learning: taking memory tests improves long-term retention. Psychol Sci 2006;17:249-55.

71. Larsen DP, Butler AC, Roediger HL, III. Test-enhanced learning in medical education. Med Educ 2008;42:959-66.

72. Schwendimann R, Zimmermann N, Kung K, Ausserhofer D, Sexton B. Variation in safety culture dimensions within and between US and Swiss Hospital Units: an exploratory study. BMJ Qual Saf 2013;22:32-41.

73. Sexton JB, Berenholtz SM, Goeschel CA, Watson SR, Holzmueller CG, Thompson DA, Hyzy RC, Marsteller JA, Schumacher K, Pronovost PJ. Assessing and improving safety climate in a large cohort of intensive care units. Crit Care Med 2011;39:934-9.

74. Shoushtarian M, Barnett M, McMahon F, Ferris J. Impact of introducing Practical Obstetric MultiProfessional Training (PROMPT) into maternity units in Victoria, Australia. BJOG 2014;121:1710-8.

75. Siassakos D, Fox R, Hunt L, Farey J, Laxton C, Winter C, Draycott T. Attitudes toward safety and teamwork in a maternity unit with embedded team training. Am J Med Qual 2011;26:132-7.

76. Pottier P, Hardouin JB, Dejoie T, Bonnaud A, Le Loupp AG, Planchon B, Leblanc V. Stress responses in medical students in ambulatory and in-hospital patient consultations. Med Educ 2011;45:67887.

77. Piquette D, Tarshis J, Sinuff T, Fowler RA, Pinto R, LeBlanc VR. Impact of acute stress on resident performance during simulated resuscitation episodes: a prospective randomized cross-over study. Teach Learn Med 2014;26:9-16.

78. Reeves S, Goldman J. Medical education in an interprofessional context. In: Dornan T, Mann K, Scherpbier A., Spencer J, editors. Medical Education: Theory and Practice.Edinburgh, London, New York, Oxford, Philadelphia, St Louis, Sydney, Toronto: Churchill Livingstone Elsevier; 2011. p. 51-64.

79. Wood L, Egger M, Gluud LL, Schulz KF, Juni P, Altman DG, Gluud C, Martin RM, Wood AJ, Sterne JA. Empirical evidence of bias in treatment effect estimates in controlled trials with different interventions and outcomes: meta-epidemiological study. BMJ 2008;336:601-5.

80. Savovic J, Jones HE, Altman DG, Harris RJ, Juni P, Pildal J, Is-Nielsen B, Balk EM, Gluud C, Gluud LL, Ioannidis JP, Schulz KF, Beynon R, Welton NJ, Wood L, Moher D, Deeks JJ, Sterne JA. Influence of reported study design characteristics on intervention effect estimates from randomized, controlled trials. Ann Intern Med 2012;157:429-38.

81. Lundh A, Sismondo S, Lexchin J, Busuioc OA, Bero L. Industry sponsorship and research outcome. Cochrane Database Syst Rev 2012;12:MR000033.

82. Lingard L. Rethinking Competence in the Context of teamwork. In: Hodges B, Lingard L, editors. The Question of Competence. Reconsidering Medical Education in the Twenty-First Century. First ed. New York: ILR Press an imprent of Cornell University Press; 2012. p. 42-69.

83. van der Vleuten C, Van Luyk SJ, Beckers HJ. A written test as an alternative to performance testing. Med Educ 1989;23:97-107.

84. Kramer AW, Jansen JJ, Zuithoff P, Dusman H, Tan LH, Grol RP, van der Vleuten C. Predictive validity of a written knowledge test of skills for an OSCE in postgraduate training for general practice. Med Educ 2002;36:812-9.

85. Ram P, van der Vleuten C, Rethans JJ, Schouten B, Hobma S, Grol R. Assessment in general practice: the predictive value of written-knowledge tests and a multiple-station examination for actual medical performance in daily practice. Med Educ 1999;33:197-203.

86. Arthur W, Bennett W, Stanush PL, Mc Nelly TL. Factors That Influence Skill Decay and Retention: A Quantitative Review and Analysis. Human Performance 1998;11:57-101. 
87. Hamilton R. Nurses' knowledge and skill retention following cardiopulmonary resuscitation training: a review of the literature. J Adv Nurs 2005;51:288-97.

88. Trevisanuto D, Ferrarese $P$, Cavicchioli P, Fasson A, Zanardo V, Zacchello F. Knowledge gained by pediatric residents after neonatal resuscitation program courses. Paediatr Anaesth 2005;15:944-7.

89. Jakobsen JC, Gluud C, Winkel P, Lange T, Wetterslev J. The thresholds for statistical and clinical significance - a five-step procedure for evaluation of intervention effects in randomised clinical trials. BMC Med Res Methodol 2014;14:34.

90. Fraenkal JR, Wallen NE, Hyde A. Internal validity. In: Fraenkal JR, Wallen NE, Hyde A, eds. How to Design and Evaluate Research in Education. New York: McGraw-Hill, 2012:166-83. 
Supplementary material on line: Table S1. Suggestions for practical and organisational changes identified during ISS and OSS classified according to the model of work system or structure from the Systems Engineering Initiative for Patient Safety. ${ }^{58}$

\begin{tabular}{|c|c|c|c|}
\hline & \multicolumn{2}{|c|}{$\begin{array}{l}\text { Identified } \\
\text { during }\end{array}$} & \multirow[t]{2}{*}{ SEIPS component } \\
\hline & oss & ISS & \\
\hline \multicolumn{4}{|l|}{ Introduction of new employees } \\
\hline Better introduction of new employees, including guided tour of trauma centre, acute admission centre, and blood bank & $\mathrm{x}$ & $\mathrm{x}$ & Person \\
\hline \multicolumn{4}{|l|}{ Identification of staff } \\
\hline Name badges visible on uniforms at all times and improved name badges for easier identification of the various healthcare professions & $\mathrm{x}$ & $\mathrm{x}$ & Person \\
\hline Inclusion of people's names and also healthcare profession during staff presentation rounds in emergency situations & $\mathrm{x}$ & $\mathrm{x}$ & Organisation \\
\hline \multicolumn{4}{|l|}{ Call systems, telephones and telephone numbers } \\
\hline Pros and cons involved in changing the emergency call system from calling people individually to calling them as a group & $\mathrm{x}$ & $\mathrm{x}$ & Organisation \\
\hline Request for more well-defined telephone chain for emergency calls; doctors preferred briefing to be from doctor to doctor & $\mathrm{x}$ & $\mathrm{x}$ & Organisation \\
\hline More well-defined criteria for using emergency alarm button in delivery room & $\mathrm{x}$ & $\mathrm{x}$ & Organisation \\
\hline Identical numbers to call night and day for anaesthesia assistance in obstetric emergencies & $\mathrm{x}$ & $\mathrm{x}$ & Organisation \\
\hline A clearly visible list of relevant numbers in operating theatre for emergency situations & & $\mathrm{x}$ & Tools \& technology \\
\hline Stickers with brief list of emergency numbers on back of name badges & & $\mathrm{x}$ & Tools \& technology \\
\hline \multicolumn{4}{|l|}{ Clinical handover in emergency situations } \\
\hline $\begin{array}{l}\text { Repetition upon arrival in delivery room and operating theatre of clinical details and indication for procedures provided in telephone } \\
\text { handover }\end{array}$ & $\mathrm{x}$ & $\mathrm{x}$ & Organisation \\
\hline Consistent use of terminology from local guidelines and when grading emergency caesarean sections & $\mathrm{x}$ & $\mathrm{x}$ & Organisation \\
\hline \multicolumn{4}{|l|}{ Patient identification and "time out" in operating theatre in emergency situations } \\
\hline More clearly defined designation of who is responsible for identifying the patient and confirming the indication for procedure & $\mathrm{x}$ & $\mathrm{x}$ & Organisation \\
\hline Improvement of computer system that is too difficult and slow for emergency situations & & $\mathrm{x}$ & Tools \& technology \\
\hline
\end{tabular}




\begin{tabular}{|c|c|c|c|}
\hline & \multicolumn{2}{|c|}{$\begin{array}{l}\text { Identified } \\
\text { during }\end{array}$} & \multirow[t]{2}{*}{ SEIPS component } \\
\hline & OSS & ISS & \\
\hline \multicolumn{4}{|l|}{ Presence of partners during emergency caesarean sections } \\
\hline $\begin{array}{l}\text { Various opinions on whether partners should be allowed in operating theatre; more well-defined criteria for designating who communi- } \\
\text { cates with partners }\end{array}$ & $\mathrm{x}$ & $x$ & Organisation \\
\hline \multicolumn{4}{|l|}{ Medication - postpartum haemorrhage } \\
\hline $\begin{array}{l}\text { Placement of tranexamic acid in the haemorrhage medication box; clinical guidelines on its administration should be made easily acces- } \\
\text { sible }\end{array}$ & $\mathrm{X}$ & $\mathrm{X}$ & Tools \& technology \\
\hline Pre-prepared drips with oxytocin & $\mathrm{X}$ & $\mathrm{x}$ & Tools \& technology \\
\hline $\begin{array}{l}\text { Midwives generally found administering medicine in operating theatre difficult; requested more clarity for designating who is responsi- } \\
\text { ble for the haemorrhage medication box there }\end{array}$ & $\mathrm{x}$ & $\mathrm{x}$ & Person, Task \\
\hline $\begin{array}{l}\text { Clarification of who is to document administration of medicine in operating theatre, especially when administered directly in the uterus } \\
\text { and/or per rectum }\end{array}$ & $x$ & $\mathrm{x}$ & Tools \& technology \\
\hline \multicolumn{4}{|l|}{ Medication - emergency caesarean sections } \\
\hline $\begin{array}{l}\text { Pros and cons involved in administering terbutaline for tocolysis during foetal distress; informing anaesthesia staff important due to } \\
\text { subsequent risk of maternal tachycardia }\end{array}$ & $\mathrm{x}$ & $\mathrm{x}$ & Tools \& technology \\
\hline Placement of terbutaline for tocolysis (intrauterine resuscitation) in delivery room and operating theatre to allow quick administration & $\mathrm{X}$ & $\mathrm{X}$ & Tools \& technology \\
\hline $\begin{array}{l}\text { Address the knowledge gap among auxiliary nurses and midwives on administration of sodium citrate to prevent aspiration during } \\
\text { general anaesthesia }\end{array}$ & $\mathrm{X}$ & $\mathrm{X}$ & Person, Task \\
\hline $\begin{array}{l}\text { Amend action card and clinical guidelines on emergency caesarean sections to specifically address oral administration of sodium citrate } \\
\text { to prevent aspiration during general anaesthesia }\end{array}$ & $\mathrm{X}$ & $\mathrm{X}$ & Organisation \\
\hline Make sodium citrate more easily accessible in the delivery room & $\mathrm{X}$ & $\mathrm{X}$ & Tools \& technology \\
\hline \multicolumn{4}{|l|}{ Staff members in operating theatre during postpartum haemorrhage } \\
\hline Two operating theatre nurses ideally present in severe cases of postpartum haemorrhage & $\mathrm{X}$ & $\mathrm{x}$ & Person, Task \\
\hline $\begin{array}{l}\text { Obstetric team members (midwife, specialised midwife, and auxiliary nurse) should ideally prioritise remaining in operation theatre to } \\
\text { assist }\end{array}$ & $\mathrm{x}$ & $\mathrm{x}$ & Person, Task \\
\hline
\end{tabular}




\section{Fluid resuscitation and blood transfusion in operating theatre}

Clarification of whether lactated Ringer's solution is superior to sodium chloride

Easy access to a blood heater and pressure bags to improve IV infusion in delivery room

Clarification of which healthcare professional should ideally collect blood at the blood bank in an emergency situation

Clearly posted telephone number in operating theatre for the blood bank and its location

Training/retraining of midwives in management of blood transfusions to allow them to assist the anaesthesia team correctly Transfer of patient from delivery room to operating theatre and type of operating table

Clarification of who is responsible for birthing bed (preparations for transport)

Mechanisms to ensure clear passage (e.g. no beds, transport cages) along corridors for emergency transport of patients on delivery ward

Clarification of when and how to ideally transfer patients from delivery room to operating theatre; clarification of who determines timing of patient transport in emergency situations

Improved standards for where to keep the remote control for the operating table and for recharging its batteries; have easy-to-use instructions available

Pros and cons of continuous use of birthing beds in emergency situations when patient transferred to operating theatre; address the knowledge gap on functionality of birthing beds among operating theatre staff; establish standards for their use

\section{Practical issues in operating theatre}

Better labelling of equipment in operating theatre and standardised placement of equipment in the two operating theatres for obstetric emergencies to streamline management

Improve use of remote control to the operation table, which is difficult due to a lack of clarity about which direction the table moves

A more suitable walking distance between the cabinet with surgical caps and the operating theatre
X $\quad X \quad$ Tools + technology

$X \quad X$ Tools + technology

$\mathrm{X} \quad \mathrm{X}$ Person, Task

$X \quad X$ Tools + technology

$\mathrm{X} \quad \mathrm{X}$ Person, Task

X Person

Tools \& technology

X Person,

Tools \& technology

$X \quad X \quad$ Person, Organisa-

X Tools \& technology

X Tools \& technology

X Tools \& technology

X Person,

Tools \& technology

$X$ Tools and technolo-

A more suitable walking distance between the cabinet with surgical caps and the operating theatre 


\begin{tabular}{|c|c|c|c|}
\hline & \multicolumn{2}{|c|}{$\begin{array}{l}\text { Identified } \\
\text { during }\end{array}$} & \multirow[t]{2}{*}{ SEIPS component } \\
\hline & oss & ISS & \\
\hline \multicolumn{4}{|l|}{ Operating theatre nurses } \\
\hline $\begin{array}{l}\text { Clarification on role of responsibility for clinical decision making for urinary bladder catheter and/or shaving the pubic area, communica- } \\
\text { tion and actual management hereof; general agreement that obstetricians make the clinical decision and then inform the operating } \\
\text { theatre nurse, who then places the catheter and/or shaves the area }\end{array}$ & $\mathrm{X}$ & $\mathrm{X}$ & $\begin{array}{l}\text { Person, Organisa- } \\
\quad \text { tion }\end{array}$ \\
\hline \multicolumn{4}{|l|}{ Anaesthesia team in operating theatre } \\
\hline $\begin{array}{l}\text { More assistance from midwives when transferring patients from birthing bed to operating table and with positioning of patient; mid- } \\
\text { wives requested more guidance from the anaesthesia team on the ideal way to do transfers }\end{array}$ & $\mathrm{X}$ & $\mathrm{X}$ & $\begin{array}{l}\text { Person, Organisa- } \\
\quad \text { tion }\end{array}$ \\
\hline Improved procedures for checking equipment to ensure that it works (e.g. problem with no light in a laryngoscope) & & $\mathrm{x}$ & $\begin{array}{l}\text { Tools \& technology, } \\
\text { Organisation }\end{array}$ \\
\hline $\begin{array}{l}\text { More detailed introduction of new employees, including presentation of equipment for management of the difficult airway and equip- } \\
\text { ment for blood heating and rapid infusion }\end{array}$ & & $\mathrm{x}$ & Person \\
\hline \multicolumn{4}{|l|}{ Observation charts and boards } \\
\hline Improved observation charts for emergency situations, especially for postpartum haemorrhage & $\mathrm{x}$ & $\mathrm{x}$ & $\begin{array}{l}\text { Tools \& technology, } \\
\text { Organisation }\end{array}$ \\
\hline Greater use of white boards in delivery rooms in emergency situations for temporary observational charting & $\mathrm{X}$ & $\mathrm{X}$ & $\begin{array}{c}\text { Tools \& technology, } \\
\text { Organisation }\end{array}$ \\
\hline Use of white boards in operating theatre in emergency situations & $\mathrm{X}$ & $\mathrm{x}$ & $\begin{array}{c}\text { Tools \& technology, } \\
\text { Organisation }\end{array}$ \\
\hline \multicolumn{4}{|l|}{ Mode of anaesthesia in emergency situations } \\
\hline Determine who makes final clinical decision about mode of anaesthesia; generally agreed to be the anaesthetist's responsibility & $\mathrm{X}$ & $\mathrm{X}$ & Person \\
\hline Preoxygenation necessary prior to induction of spinal anaesthesia in case general anaesthesia is required & $\mathrm{X}$ & $\mathrm{X}$ & Task, Organisation \\
\hline $\begin{array}{l}\text { Clear communication on mode of anaesthesia to all staff in the room crucial so operating theatre nurses can prepare for e.g. sterile } \\
\text { drapes, leg holders }\end{array}$ & $\mathrm{X}$ & $\mathrm{x}$ & Task, Organisation \\
\hline
\end{tabular}




\section{Identified SEIPS component \\ during \\ OSS ISS}

$\mathrm{X}$

X Task, Organisation

Use, when feasible, obstetric manoeuvres like bimanual compression with severe postpartum haemorrhage and replacement of foeta head during cord prolapse with the parturient woman in side position (for attempt of spinal anaesthesia); communicate this during training/retraining of staff and address in clinical guidelines

\section{Guidelines}

Greater clarity in postpartum haemorrhage guidelines on indications and general clinical management principles for blood product transfusion and risk of hypothermia

Addition of pointers in local clinical guidelines on how to choose the best team leader and this individual's role in emergency situations

X $\quad$ Task, Organisation

ISS: in situ simulation; OSS: off site simulation; SEIPS: Systems Engineering Initiative for Patient Safety 
CHAPTER 7

\section{Clarifying the learning experiences of healthcare professionals with in situ and off site simulation-based medical education: a qualitative study}

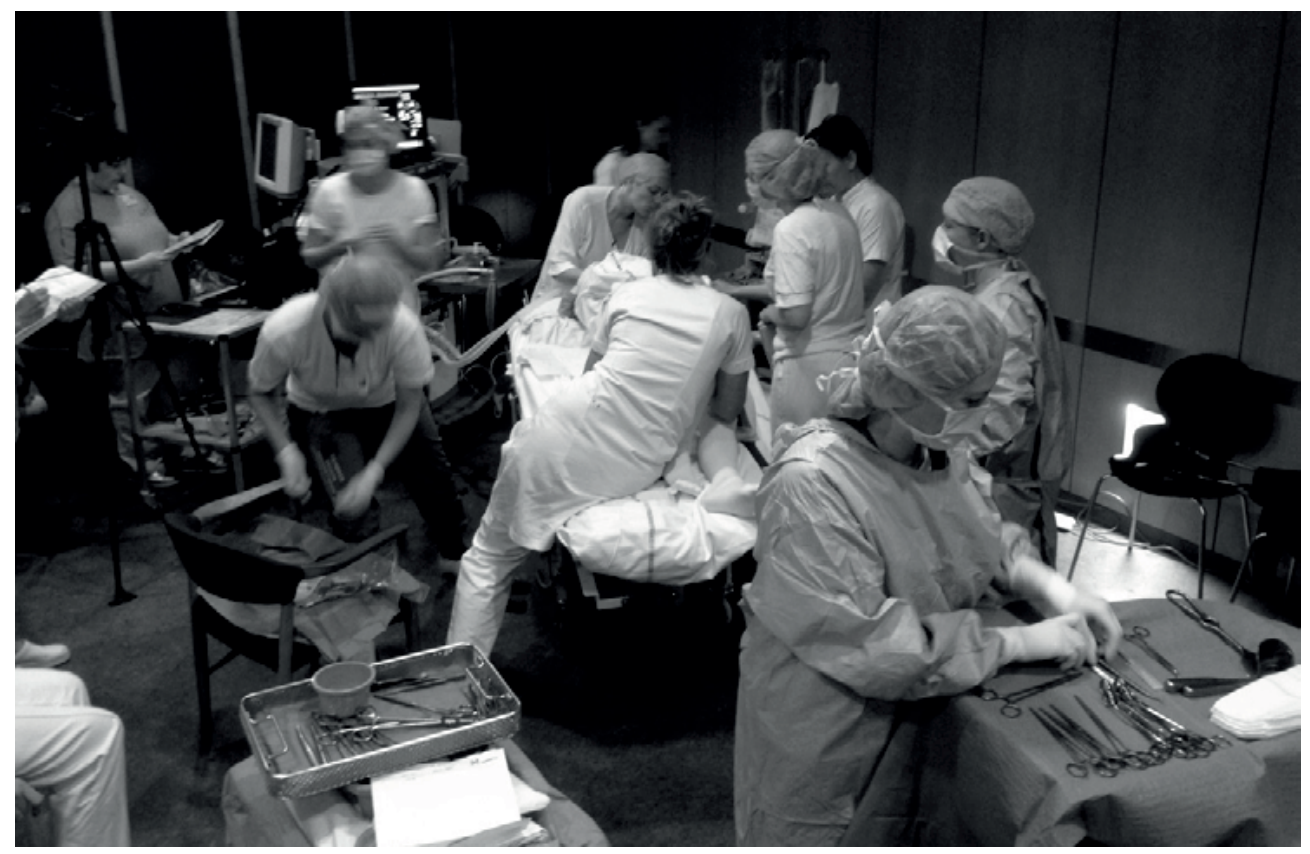

Jette Led Sørensen, Laura Emdal Navne, Helle Max Martin, Bent Ottesen, Charlotte Krebs Albrechtsen, Berit Woetmann Pedersen, Hanne Kjærgaard, Cees van der Vleuten. Published in BMJ Open 2015;5:e008345. 


\section{Abstract}

Objective: To examine how the setting in in situ simulation (ISS) and off-site simulation (OSS) in simulation-based medical education affects the perceptions and learning experience of healthcare professionals.

Design: Qualitative study using focus groups and content analysis.

Participants: Twenty-five healthcare professionals (obstetricians, midwives, auxiliary nurses, anaesthesiologists, a nurse anaesthetist and operating theatre nurse) participated in four focus groups and were recruited due to their exposure to either ISS or OSS in multidisciplinary obstetric emergencies in a randomised trial.

Setting: Departments of obstetrics and anaesthesia, Rigshospitalet, Copenhagen, Denmark.

Results: Initially participants preferred ISS, but this changed after the training when the simulation site became of less importance. There was a strong preference for simulation in authentic roles. These perceptions were independent of the ISS or OSS setting. Several positive and negative factors in simulation were identified, but these had no relation to the simulation setting. Participants from ISS and OSS generated a better understanding of and collaboration with the various health professionals. They also provided individual and team reflections on learning. ISS participants described more experiences that would involve organisational changes than the OSS participants did.

Conclusions: Many psychological and sociological aspects related to the authenticity of the learning experience are important in simulation, but the physical setting of the simulation as an ISS and OSS is the least important. Based on these focus groups OSS can be used provided that all other authenticity elements are taken into consideration and respected. The only difference was that ISS had an organisational impact and ISS participants talked more about issues that would involve practical organisational changes. ISS and OSS participants did, however, go through similar individual and team learning experiences. 


\section{Strengths and limitation of this study}

$>\quad$ In situ simulation is fairly new and involves conducting simulations in the actual patient care unit, and based on the much-discussed topic of learning in context, in situ simulation is expected to increase fidelity and thereby learning. We had been unable to identify any qualitative studies exploring participant experiences of in situ versus off site simulation (i.e. simulation in training rooms).

Based on findings from these focus groups the simulation settings in situ and off site had the same effect on individual and team learning. In situ simulation had more organisational impact and provided more information for practical organisational changes than off site simulation.

$>$ Conclusions from the present focus groups indicated that healthcare professionals think that the physical context and physical fidelity of ISS and OSS were not the most important aspects for learning provided other psychological and sociological authenticity elements were respected. The participants in the focus groups highlighted the importance of participating in authentic teams in their own roles as healthcare professionals. This emerged in the focus groups as participants reflected upon previous negative experiences of simulation in other professional roles.

$>\quad$ The findings from the focus groups in this study show that staff in obstetrics and anaesthesiology appeared to be more familiar with working in different places, which they saw as an important skill, but we cannot say whether study findings are transferable to other groups of healthcare professionals working in medical areas with less emergency work or or health-care professionals without simulation experience.

$>$ A limitation was the composition of the focus groups, which did not entirely mirror the distribution of healthcare professionals during the clinical work, and some groups were underrepresented. 


\section{Introduction}

Simulation-based medical education is an important training modality for training skills, teams and how to perform in emergency situations [1-4]. If emergencies are rare and hence can be difficult to learn about in real life, simulation-based medical education is warranted, for instance in obstetric emergencies [5]. Simulation-based medical education involves "devices, trained persons, lifelike virtual environments, and contrived social situations that mimic problems, events, or conditions that arise in professional encounters" [4]. There are many unanswered questions as to how simulation-based medical education is best conducted, one of which concerns the fidelity of the setting. An unresolved issue is how in situ simulation (ISS) versus off-site simulation (OSS) affects learning. ISS involves simulation-based medical education in the actual patient care unit $[6,7]$. OSS, on the other hand, entails training in facilities outside the patient care unit. ISS is believed to increase fidelity and thereby learning because it takes place in the clinical setting [7-9]. In a classic sense fidelity refers to the degree of faithfulness that exists between two entities, and these entities are fundamental for the transfer of simulation-based medical education and performance in the clinical settings [10]. The rationale behind this idea on the authenticity of simulation is the traditional assumption that the closer the learning context is to the context of practice, the better the learning and situativity theory argues that knowledge, thinking and learning are situated in experience [11-15]. Therefore, ISS is believed to increase learning because it takes place in the clinical setting, where the learning context is more similar to the context of practice.

We conducted a randomised controlled trial to reveal whether ISS was superior in facilitating learning compared to OSS [16]. We concluded that participant perception of the authenticity of ISS and OSS differed significantly but did not find any differences between knowledge, safety attitudes, motivation, stress, perceptions of the simulation and team performance [16]. We were unable to identify any qualitative studies exploring how participants experience differences in the simulation setting and found that studies clarifying participants' experiences were of relevance [17]. Consequently we determined that carrying out qualitative research in combination with the randomised controlled trial, which involved a complex intervention, would provide deeper insight into the learning experience of healthcare professionals participating in ISS and OSS [18].

This study attempts to shed light on the general assumption that context and fidelity are a determinant for how different kinds of simulation-based medical education are experienced and to determine the veracity of the common assumption that ISS is a more effective learning tool than OSS [8]. The research question was: How does the setting in simulation-based medical education (OSS or ISS) affect the perceptions and learning experience of healthcare professionals? 


\section{Method}

\section{Design}

We chose to do a qualitative study using focus groups, deeming this to be an appropriate method with regard to the research question. Focus groups, which can be defined as "a form of group interview that capitalises on communication between research participants in order to generate data"[19], are useful for gathering information about the points of view of different participants and can be used to explore and explain phenomena [20]. We also wanted to examine data from the randomised controlled trial more closely [16] and using focus groups is described as a valuable way of further analysing and interpreting data subsequently [18-20]. The focus groups were conducted based on criteria in the literature [19,20-24].

Participant selection and intervention before the focus groups

Prior to the present qualitative study a randomised trial [16] was conducted that recruited individuals from among 265 healthcare professionals working shifts on a labour ward. After giving written informed consent, randomisation was performed by the Copenhagen Trial Unit using a computer-generated allocation sequence concealed to the investigators. The randomisation was conducted in two steps, first, 1:1 to the ISS or the OSS group, then randomisation into 10 teams for either the ISS or OSS. Based on a power calculation 100 participants were randomised, and of these 97 participated in the randomised controlled trial [16].

The focus group participants, recruited from among 97 healthcare professionals enrolled in an randomised controlled trial, comprised consultant and trainee obstetricians, midwives, consultant and trainee anaesthesiologists, auxiliary nurses, operating theatre nurses and nurse anaesthetists [16]. The trial included two multidisciplinary simulation cases conducted using ISS or OSS: an emergency caesarean section and the management of postpartum haemorrhage. A simulated patient was given instructions and then acted as the patient in the real labour room (ISS) and in the simulated labour room (OSS). When the simulation was transferred to the operating theatre, a full-scale birthing simulator (SimMom) was the patient in the real operating theatre (ISS) and in the simulated operating theatre (OSS). The simulated emergency scenarios were designed to allow standardised training in both the ISS and OSS groups [16]. The instructors running the simulation scenarios also carried out the debriefing sessions [25].

Recruitment and composition of the focus groups

Eligible participants were informed by email and a personal letter. If they agreed to participate they were contacted by the principal investigator ( JLS) and enrolled after informed written consent.

Only very few minor conflicts occurred during the randomised controlled trial [16] and they did not involve anxiety or power dominance, indicating that using homogenous focus groups was not a necessity. Hence we also determined that the participants 
would feel comfortable in multidisciplinary focus groups. We also expected heterogeneous groups to add to the richness of data due to the process of co-construction. All four groups were to comprise individuals who had participated in ISS and OSS based on the assumption that this would add to the co-construction process. In accordance with recommendations in the literature [20] each focus group was limited to 6-8 participants.

\section{Moderators and conduction of the focus groups}

Two anthropologists (LEN, HMM) with comprehensive experience in moderating and analysing data from focus groups led the focus groups. They did not have any experience with obstetric-anaesthesia emergencies or simulation-based medical education. The principal investigator ( JLS), who is an experienced obstetrician and an expert in simulation, introduced the moderators to the randomised controlled trial [16]. LEN observed an ISS training day and part of an OSS day. In addition to viewing videos on ISS and OSS, both moderators observed clinical work in the departments of obstetrics and anaesthesia for a total of $28 \mathrm{~h}$. Neither moderators had any professional connection to the participants and did not know them personally.

The four focus groups, scheduled to begin immediately after end of the randomised controlled trial [16], lasted $105 \mathrm{~min}$ and took place in the afternoon in a quiet room located in the same building as the labour ward and the operating theatre but on a different floor. Participant remuneration was the equivalent of the participants' normal salary per hour.

Scheduled to come on a specific day, participants were welcomed on arrival by the principal investigator (JLS) or one of the midwives responsible for doing simulations. After briefly introducing the participants to the moderators, the principal investigator or midwife would leave the room.

The moderators were provided with the names of the participants in the focus groups and some of their baseline characteristics based on information from the randomised controlled trial [16].

Interview guide

The interview guide (box 7.1) was based on previous experience, the anthropologists' observations of clinical work and OSS and ISS, and the literature [1-3,8,26-28].

Data capture, coding and analysis of qualitative data

Conventional content analysis, a method used for the subjective interpretation of written data through a classification process of coding and identifying themes or patterns, was used to study the focus group data [29-32]. The method involves repeatedly reading and discussing the text to identify units of meaning and codes, followed by a step that entails repeatedly analysing the data and condensing it into themes [29-31]. 
The analytical used was mainly deductive and the transcribed text was analysed as manifest content $[20,30,31]$.

Box 7.1 Interview guide for the focus group.

$>\quad$ What were your expectations concerning what you would learn during the simulation (ISS/OSS)? Were these expectations met?

$>\quad$ What was of most importance for your learning in the simulation (ISS/OSS)? What elements of the simulation were important?

$>$ To what degree did you find the simulation (ISS/OSS) realistic/authentic? What made the simulation (ISS/OSS) realistic and unrealistic?

$>\quad$ Was it possible to identify yourself with the simulation (ISS/OSS)? Examples?

$>\quad$ Did you find it important for your learning that the simulation (ISS/OSS) was realistic/authentic? To what degree and why?

$>\quad$ Which elements contributed to making the simulation (ISS/OSS) authentic/realistic? Perhaps compare your experience with previous experiences with simulation?

$>$ Do you think that participating in the simulation (ISS/OSS) has influenced your clinical work and daily routines? Examples?

$>$ How does, in your experience, learning through simulation-based training differ from and benefit you compared to daily clinical learning?

$>\quad$ Do you think that the ISS/OSS setting influenced your level of stress and anxiety?

$>\quad$ Do you think that the ISS/OSS setting influenced the cooperation and communication in your simulation team?

$>$ How did you learn about roles and responsibility in the simulation? Were you influenced by the ISS/OSS setting?

$>\quad$ Other suggested elements of importance in the focus groups

$>$ The rooms

$>$ The time spent on the simulation

$>$ Placement and organisation of physical objects

$>$ Sounds

$>$ Technical equipment

$>\quad$ Patient surrogate or the actress

$>$ Manikin, for example, SimMom

$>$ Participants' clothing

$>$ Authentic roles in the simulation teams

$>$ Simulation with colleagues from own workplace.

The data generated in the focus groups were audio recorded and transcribed verbatim and the moderators also took field notes. NVivo10 was used for analysis. The transcription was primarily coded by the two moderators. The interview guide provided an initial structure for identifying units of meaning. The text was then reread and analysed to derive unanticipated units of meaning. The next step involved recoding and dividing the material into ISS and OSS to identify trends related to the simulation setting. The principal investigator (JLS) independently interpreted the data, after which the three authors (LEN, HMM, JLS) discussed, reread and validated the interpretations. The themes 
then underwent a selection process. The initial transcripts from the four focus groups were also read by CKA and BWP, both of whom are experienced clinicians and work with simulation. The purpose of their involvement was to integrate their interpretations into the themes. Finally, the transcripts were reread to identify crosscutting themes and perspectives. The participants did not receive a copy of the transcripts or the quotations taken from them.

\section{Results}

\section{Sample characteristics and composition of focus groups}

We recruited 31 healthcare professionals, but three of them could not participate at the scheduled time and three others cancelled at the last minute. Every effort was made to meet the principles of composition of the focus groups described above. The final number of participants was 25 (table 7.1). The moderators described the group dynamics in the four focus groups as good and did not experience any tensions between participants. The moderators and principal investigator discussed data saturation and concluded it was achieved.

\section{Units of meaning and identification of themes}

The text was analysed and units of meaning were identified (box 7.2). The overall research question addressed the influence of setting (OSS or ISS) on what the participants experienced, which provided an overarching structure for establishing the following six themes and subthemes (box 7.3.).

\section{Theme 1: initial participant expectations for in situ and off-site simulation}

When asked about their expectations in the beginning participants predominantly responded that prior to participating in the randomised controlled trial intervention they had a preconceived preference for participating in ISS because they believed that ISS better matched reality and assumed that this would affect their ability to involve themselves. They also thought that ISS would enhance their ability to transfer learning to everyday practice. An initial preference for ISS was visible in the four focus groups, but as discussion progressed this preference waned and the amount of value participants put on an ISS setting as a crucial factor for their experience of learning in simulation shifted as other factors were deemed as more crucial (box 7.4, quotations 1-3). 
Table 7.1 Distribution of recruited healthcare professional groups in the four focus groups and baseline characteristics of participants in in situ simulations (ISS) and offsite simulation (OSS).

\begin{tabular}{|c|c|c|c|c|c|c|c|}
\hline & Recruited & Participated & $\begin{array}{l}\text { Mean age } \\
\text { (minimum- } \\
\text { maximum) }\end{array}$ & $\begin{array}{l}\text { Mean Years of } \\
\text { obstetric work } \\
\text { experience } \\
\text { (minimum- } \\
\text { maximum) }\end{array}$ & Healthcare professionals groups & $\begin{array}{l}\text { Previous simulation } \\
\text { experiences* }^{*} \\
\text { No experiences/ } \\
\text { simple simulation/ } \\
\text { full-scale simulation }\end{array}$ & ISS/OSS \\
\hline Focus group 1 & 6 & 6 & $44(34-55)$ & $10(2-16)$ & $\begin{array}{l}1 \text { midwife } \\
1 \text { specialised midwife } \\
2 \text { consultant obstetricians } \\
1 \text { nurse anaesthetist } \\
1 \text { trainee anaesthesiologist }\end{array}$ & $0 / 4 / 2$ & $3 / 3$ \\
\hline Focus group 2 & 7 & 7 & $50(36-64)$ & $17(1-39)$ & $\begin{array}{l}1 \text { midwife } \\
1 \text { specialised midwife } \\
1 \text { trainee obstetrician } \\
2 \text { consultant obstetricians } \\
1 \text { operatimg theatre nurse } \\
1 \text { trainee anaesthesiologist }\end{array}$ & $1 / 5 / 1$ & $5 / 2$ \\
\hline Focus group 3 & 7 & 7 & $42(31-62)$ & $12(2-38)$ & $\begin{array}{l}1 \text { midwife } \\
1 \text { specialised midwife } \\
1 \text { trainee obstetrician } \\
1 \text { consultant obstetricians } \\
3 \text { trainee anaesthesiologists }\end{array}$ & $0 / 3 / 4$ & $2 / 5$ \\
\hline Focus group 4 & 8 & 5 & $46(39-54)$ & $14(2-26)$ & $\begin{array}{l}2 \text { auxiliary nurses } \\
1 \text { specialised midwife } \\
1 \text { trainee anaesthesiologist } \\
1 \text { trainee anaesthesiologist }\end{array}$ & $0 / 4 / 1$ & $2 / 3$ \\
\hline $\begin{array}{l}\text { Did not show up due to } \\
\text { clinical duties or illness }\end{array}$ & 3 & & & & $\begin{array}{l}3 \text { cancellations } \\
\text { (all focus group 4) } \\
1 \text { consultant anaesthesiologist } \\
1 \text { nurse anaesthetist } \\
1 \text { trainee obstetrician }\end{array}$ & & \\
\hline $\begin{array}{l}\text { Recruited but a scheduling } \\
\text { issue precluded participa- } \\
\text { tion }\end{array}$ & 3 & & & & 3 midwifes & & \\
\hline Total & 31 & 25 & $45(31-64)$ & $13(1-39)$ & 31 & $1 / 16 / 8$ & $12 / 13$ \\
\hline
\end{tabular}


Box 7.2 Units of meaning derived from the interview guide and from repeatedly reading and discussing transcripts from the focus groups.

$>\quad$ In situ versus off-site

$>$ Expectations for the simulation

$>$ Expected benefits

$>$ Realisme in the simulation

$>$ Significance of setting

$>$ Significance of the manikin

$>$ Significance of sounds

$>$ Tempo

$>$ Identifying oneself with the simulation

$>$ Multidisciplinary training

$>$ Training in own role and the role of others

$>$ Authentic roles

$>$ Routines

$>$ mplication for practice

$>$ Debriefing

$>$ Performance

$>$ Authenticity

\section{Box 7.3 Themes and subthemes.}

1. Initial participant expectations for in situ and off-site simulation

2. Importance of simulation site

3. Preference for simulation in authentic roles in own workplace

4. Positive and negative factors in simulation
A. Practical organisation of the simulation
B. Cases in simulation scenario
C. Reversed hierarchies
D. Involvement in simulation
E. Debriefing

5. Individual and team learning

6. Suggested organisational changes

Theme 2: importance of simulation site

Some OSS participants mentioned that being in an unfamiliar location had some unexpected positive effects, as it forced the participants to practice their ability to adapt to new places and people, which several participants emphasised as an important skill in 
clinical practice and in emergencies. Both ISS and OSS participants experienced practical challenges or barriers, but argued that this could produce learning outcomes of their own. Some argued that the OSS setting in a small room, where things were organised differently and not in their normal place, forced them to see their own routines from the outside. This was considered positive even though it increased the risk of failing to follow normal procedures (box 7.5, quotation 1 and 2).

\section{Box 7.4 Theme 1: Initial participant expectations concerning in situ and off-site} simulation as illustrated by quotations.

1. In the beginning I was excited about whether I would be in situ or off-site. I don't really know which one I would have preferred. In a way, in situ because then you know where everything is. But the other way would be a challenge. I thought that getting a grip on the room, which was quite different, happened fast, you very quickly get an impression of what was where [....] Even though it was an off-site simulation, everyone was aware of each other, of whether there was something that needed to be done that you could do. I think it was actually pretty exciting. I thought, who knows how l'll react? Maybe it wouldn't get my adrenalin going because it wasn't the real thing. But that's not what it was like [....] (OSS participant).

2. I had absolutely no idea whether it would be in situ or off-site. Practicing in the conference room was fine. It could have also been in the hallway or somewhere else. My experience with scenario training in situ is that the artificial aspects will always be there, in contrast to a real situation. I know full well that it's scenario training and that no one is lying there bleeding to death, but I can totally get into it regardless of the surroundings [....] The same things that I work with are there. The room didn't interfere with how well I concentrated on the situation. I simply didn't give it a single thought [....] (OSS participant).

3. I didn't have very many expectations, but I hoped that I'd be able to do in situ training because I thought it would be the most educational. But I have to agree with you [another participant] about that, because I participated in off-site training and when I left, I'd learned a lot anyway. Distancing yourself a bit from everyday life makes you even more aware that you're in fact practicing communicating. It might perhaps even be a tad easier to remember that you're practicing in that situation. I didn't think it was a disadvantage. Of course it's artificial, but I'm not sure that that has a negative impact (OSS participant).

The discussions about ISS and OSS seemed to vary between healthcare professional groups. Auxiliary and operating theatre nurses appeared to have a greater need to have equipment in the right place. They felt that unfamiliarity with where items were located meant they had trouble finding, for example medicine, thus taking their attention away from their main tasks: teamwork and communication. Since the professional groups were not well represented in all the focus groups the differences between them can only be viewed as a trend (box 7.5, quotation 2). 


\section{Box 7.5 Theme 2: Importance of simulation site as illustrated by quotations.}

1. Maybe we ended up not talking about other things because we were on the third floor [OSS setting]. But there were, for example, some ordinary practical things that didn't go so well [....], but there are of course some things that you more or less do on autopilot and in the correct order when you're in your everyday surroundings (OSS participant).

2. [.... But for me, it wasn't all that different from working at another department, for example, working at the trauma centre. I'm pretty used to being in lots of different places and just using what's available. So it didn't really bother me to be in a strange place [....] (OSS participant).

3. It matters where things are, if the room is different, things aren't in their usual place. I was offsite and we were on top of each other in an on-call room and couldn't really access things. We would've been much more on the ball in a delivery room (OSS participant).

Theme 3: preference for simulation in authentic roles in own workplace

The participants emphasised a heavy preference for simulation in authentic roles in their own professional groups. Some participants created a hierarchy of import- ant factors in the simulation, prioritising individuals before location and ranking realistic teamwork ahead of a realistic location. Describing negative prior experiences with simulation in professional roles other than their own, they argued that they felt their roles became too much of a caricature and that this was not helpful for learning (box 7.6, quotations 1-3).

Theme 4: positive and negative factors in the simulation

The statements from participants about positive and negative factors were not related to the ISS or OSS setting but rather to other factors, which are presented in subthemes $4 a-4 e$.

\section{Subtheme 4a: practical organisation of the simulation}

Some of the important positive factors mentioned that contributed to a realistic simulation were wearing an ordinary uniform, working with a patient (actress), and using an appropriate full-scale manikin. The researchers who observed the simulations (JLS, LEN, HMM) and the instructors (CKA, BWP) observed examples of the participants comforting the actress and the manikin, touching them gently, which exemplifies the level of authenticity. Participants stated, for example that they were not always aware of whether it was an actress or a manikin, which also supports the interpretation that the level of authenticity experienced was high. These observations were similar for ISS and OSS participants (Box 7.7, quotations 1-2). 
Box 7.6 Theme 3: Preference for simulation in authentic roles in own workplace as illustrated by quotations.

1. [...] But I was looking forward to being with the professionals I work with on a daily basis. Because we play different roles in anaesthesiology [....] (ISS participant).

2. [.... It's more important that it's the right professionals. Because that hasn't been the case with the other simulations we've had. Then it's of course also important that it's the right place. So you're able to find where things are [....] The people are the most important and then perhaps the place (ISS participants).

3. [....] If you have to play other roles it becomes too much of a caricature. You don't really feel at home in the role [....] It's not just you. It's also the others-you might end up giggling a bit because you're taking on another role (OSS participants).

A recurring topic in the focus groups was phones and call procedures. During ISS and OSS participants were given a list of telephone numbers but found that calling numbers other than the ones they were used to in the clinical setting was difficult and caused confusion. For example, they called the wrong number, forgot to call staff members, called in the wrong order or phones were disconnected. ISS and OSS participants described the provided list of telephone numbers, which failed to give the intended authenticity and had the opposite effect, as a disruptive element that added negatively to the artificiality of the simulation. This was mentioned by both ISS and OSS participants (Box 7.7, quotations 3).

\section{Subtheme $4 b$ : cases in simulation scenario}

The ability of the cases to contribute to a realistic simulation was discussed. The participants had different approaches, some arguing for the necessity of highly realistic cases in simulation, where others saw this as less important, arguing that it did not matter if cases were artificial. These discussions were not related to ISS or OSS. Some participants emphasised the relief they felt because the simulated patient, that was, the actress or manikin, was not actually in real danger, which thus contributed to creating a comfortable setting for learning. Others argued that they would like to have experienced a more complex, infrequent clinical scenario because they believed that would have encouraged greater learning (box 7.7, quotations 4).Challenges to traditional professional hierarchies were a central aspect of the negative experiences of some participants. Some participants said that when the instructors or participants asked a junior doctor to take on the role of team leader it negatively influenced the simulation and their involvement in the simulation. Reversed hierarchies occurred in both ISS and OSS (box 7.7, quotation 5). 
Box 7.7 Theme 4: Positive and negative factors in the simulation as illustrated by quotations.

Subtheme 4a: Practical organisation of the simulation

1. We were asked to show up dressed for work, which helps set the tone that this is realistic training [...] We were given phones so that we could call the right people [....] And there was a manikin in the bed that looked like a patient. The lower part was a manikin, but there was also a live model [actress] in the bed. That worked really well. And there was blood on the sheet and the pads were heavy. This made it [seem quite realistic] (ISS participant).

2. With regard to the manikin, I have a hard time remembering when it was a manikin and when it was a patient. It must mean that it's close to reality when you can't tell the difference (ISS participant).

3. [....] There were also some OP personnel that didn't get called.The phones were generally a mess. Which is probably why some people thought it was a bit more baffling (ISS participant).

Subtheme $4 \mathrm{~b}$ : Cases in simulation scenario

4. [....] This time I was kind a expecting [....] it to go crazy! I practically expected them [the actress and the manikin] to die. So I was a bit disappointed that it didn't involve more than that. I really thought that we'd have to go through everything, that we'd have to use HELLP and DIC and who knows what else. Which means that every time we stopped, I thought, but we just got started? Things were in fact pretty acute and it looked like more, but it's actually very, very rare that things run the entire gamut. It's just that this is what I was mentally prepared for (ISS participant). Subtheme 4c: Reversed hierarchies

5. [....] Two obstetricians in our session had a secret agreement that we didn't know anything about. They had set up a training situation within the training situation that the attending physician wouldn't respond. The trainee obstetrician was supposed to be in charge. They didn't tell anyone, which created a lot of confusion. At least for me because I talked to the attending senior obstetrician when I came in [...] it was a muddle [....] (ISS participant).

Subtheme 4d: Involvement in simulation

6. I think that throwing yourself into things is absolutely essential to learn something. You have to be willing to play the game that's being played. Because sometimes you meet people who refuse to do that. And you expose yourself when you play a role-will I know what to do? What if I say something wrong? But if people hold back, are too inhibited and start to giggle, then the whole thing's a wash. It's really important that people give it their best shot. That's nearly the most important (ISS participant).

Subtheme 4e: Debriefing

7. It's [debriefing] still really on my mind and it was also an eye- opener for me to see how other professionals work. During the debriefing various tasks were explained that I wasn't totally sure about (OSS participant).

8. But then you take the time afterwards [at the debriefing] to break it down and get input from other groups. And you really get a better understanding of each other and where misunderstandings arise [....] (OSS participant).

9. I think that I often experience situations [in clinical practice] where we need to talk things through so we can do better next time. The problem is that there isn't time for that. During train- ing, time is set aside for debriefing and that's wonderful. It would be great if we had time to do that on a daily basis (ISS participant). 


\section{Subtheme 4c: reversed hierarchies}

Challenges to traditional professional hierarchies were a central aspect of the negative experiences of some participants. Some participants said that when the instructors or participants asked a junior doctor to take on the role of team leader it negatively influenced the simulation and their involvement in the simulation. Reversed hierarchies occurred in both ISS and OSS (box 7.7, quotation 5).

\section{Subtheme 4d: involvement in simulation}

Participants thought that it was disruptive if participants or facilitators laughed, giggled or joked during the simulation as this behaviour influenced how seriously they became involved in performing the simulation, which in turn affected their learning outcome negatively. This was the case for both ISS and OSS (box 7.7, quotation 6).

\section{Subtheme 4e: debriefing}

ISS and OSS participants viewed debriefings as a central, exceedingly positive factor for ensuring learning. During the focus groups participants talked about what they learned and described how the simulation, followed by a debriefing, encouraged them to see their own healthcare group as part of an entire team. The participants stressed the importance of the debriefing process to ensure learning and to facilitate the transfer of that learning to clinical practice. Some of the participants even saw the focus groups as an extra debriefing. The participants also indicated that they would like to see debriefing applied in everyday work situations (box 7.7, quotations 7-9).

\section{Theme 5: individual and team learning}

The participants stated that their interprofessional communication, collaboration and teamwork skills had improved greatly. Focus group discussions showed that ISS and OSS offered participants the opportunity to gain new perspectives on their own work practices and areas of responsibility, as well as those of their colleagues. They gained a new understanding and respect for the efforts of other team members. Some people expressed a new understanding of why other team members did not have time for the tasks they previously had expected them to carry out. The simulation process can thus be seen as a way of crossing professional boundaries. Participants stated that the simulation process reminded them of their own and colleagues' roles as important contributors to the entire team (box 7.8, quotations 1-3).

\section{Theme 6: suggested organisational changes}

The participants discussed the opportunities available for changing some everyday organisational practices and routines based on experiences from the simulation. Most of the learning points were mentioned by both ISS and OSS participants, for example communication, cooperation, teamwork, situations with unclear responsibility, feedback, a lack of general observation forms and a lack of specific observation forms, for 


\section{Box 7.8 Theme 5: Individual and team learning as illustrated by quotations.}

1. [....] The day after we had something acute at OP theatre and three of us had participated ... which means we knew each other much better [....] It was a nice situation [....] The atmos- phere is much friendlier and more pleasant (OSS participant).

2. [....] it occurred to me along the way, [....] something that I might have let frustrate me on a daily basis. It's that a team consists of many small subprocesses. And you know what the others are doing, but not in any detail (ISS participant).

3. It dawned on me how differently we hear what's being said in the OP theatre. How the anaesthesiologist hears anaesthesia things and the obstetrician hears the midwife (OSS participant).

4. Once again this just shows that you have to talk to people, look at them, say their names, ask them to do something and then note whether they've actually understood. Because that's the only way that we can work together as a team. We bury ourselves in our own tasks (OSS participant)

example, postpartum haemorrhage. Some issues were only mentioned by ISS participants, such as where operation caps were located or messy corridors, which complicated the transport of beds in emergency situations and poor access to some medicines. These discussions indicate what kind of information is required to promote more practical organisational learning (box 7.9, quotation 1 ).

\section{Box 7.9 Theme 6: Suggested organisational changes as illustrated by quotations.}

1. We couldn't get the bed out the door because a porter had put a bed in the way and they were in the middle of moving a bunch of cabinets. We had to spend a lot of time moving the bed out of the delivery room. So there were lots of times where you thought, this is just unbelievable (ISS participant). 


\section{Discussion}

Our analysis indicates that authenticity in all aspects of simulation is important and that the physical setting in simulations was of less significance, indicating that OSS is just as useful if other elements of authenticity in the simulation are respected. ISS played a role at the system level and the focus group provided information pointing toward possible organisational changes. For individual and team learning, however, ISS and OSS seemed to contribute equally. Findings in the randomised controlled trial support these conclusions [16].

Viewed straight forwardly the context is just the setting, but the concept of context can be expanded to also include the physical, semantic and commitment context [33]. One of the arguments in favour of ISS is the contextual similarity to the context for working $[7,8,34,35]$. Learning in context is a highly discussed topic in medical education $[2,12,36]$ Learning is said to be better recalled when the learning environment resembles the retrieval environment $[12,14,15]$. Whether this traditional finding [37] can be generalised to medical education is debated and empirical findings increasingly question it $[10,26,33,36]$. In medical education the context may be physical, as in this study regarding the physical surroundings in ISS versus OSS [12,33]. Physical surroundings or context appear to be parallel to the aspect of fidelity described as physical, that is, the degree to which the simulator resembles the appearance and perception of the real system $[26,38]$. Conclusions from the present focus groups indicate that healthcare professionals think that the physical context and physical fidelity of ISS and OSS were not the most important aspects for learning.

This also indicates that the semantic context, which reflects how well the context contributes to the learning task, and the commitment context, which reflects motivation and responsibility, are important aspects distinguishable from the physical context $[33,36]$. The semantic and commitment dimensions of context resemble the psychological fidelity dimension, that is, the degree to which the trainee perceives the simulation to be an authentic surrogate for the task being trained [26,38]. Factors in ISS and OSS, such as problems with practical organisation, case scenarios, changes in hierarchies and engagement were considered important elements in the simulations. These factors were related to interaction between participants in the simulation, but they were not related to the physical ISS or OSS setting, which is why they appear to better represent a more complex perception of context that includes semantic and commitment elements and that can also be viewed as a part of the psychological fidelity.

The participants in the focus groups highlighted the importance of participating in authentic teams in their own roles as healthcare professionals. The interview guide (box 7.1) encouraged participants to compare their current ISS and OSS experiences with previous simulation experiences. The focus groups had a clearly preferred simulation in authentic roles in their own workplace. The concept of training in other roles socalled 
cross training, is recommended in the simulation literature and considered a strategy for simulation-based medical education $[3,39]$. Cross training is defined as "an instructional strategy in which each team member is trained in the duties of his or her teammates" [40]. It is argued that if all team members have a shared understanding of other people's roles then the risk of making errors decreases [41]. Although there are examples of empirical studies that address cross training, they only comprise small teams in an experimental laboratory setting and mainly use computer-based simulation, and there are no medical studies that involve multiprofessional teams [40-42]. Since the simulations in the present study were complex and included teams of 10 from 6 different healthcare professional groups, we concluded that the authenticity and psychological fidelity would have been damaged by changing professional roles. This finding on cross training, however, will need to be investigated in future studies using outcomes other than the perceptions of participants.

The current concept of fidelity is under debate $[10,26,43,44]$ and may not be adequate enough to explain the fidelity practiced in interprofessional simulation. The simulation literature tends to overlook the importance of social practice [44], hierarchy, power relations and other factors affecting interprofessional teamwork [45]. The concept sociological fidelity has thus been introduced and aims to enhance the quality of interprofessional simulation and to improve its transferability to interprofessional practice $[45,46]$.

The interprofessional teams in our study were highly appreciated by the participants in the focus groups and can have contributed positively to the so-called sociological fidelity. Planning simulation for interprofessional groups is challenging, especially with regard to planning and designing case scenarios that provide each profession with a significant, balanced role $[28,46]$. Even though we appointed a multiprofessional working committee with representatives from each healthcare group to avoid conflicts [16] disagreement concerning the complexity of cases still arose.

\section{Strenghs and limitations}

The present study adhered to criteria for focus groups [20,23] to support the transparency and add to the credibility of the study findings from the focus groups. The study was performed in the obstetrics and anaesthesiology departments of a high-risk hospital. Its transfer- ability [20] to other settings can be discussed, but our impression is that the findings are transferable to other emergency medical specialities. The findings from the focus groups in this study show that staff in obstetrics and anaesthesiology appear to be more familiar with working in different places, which they see as an important skill, but we cannot say whether study findings are transferable to other groups of healthcare professionals working in medical areas with less emergency work. We found a tendency that auxiliary and operating theatre nurses appeared to have a greater need for higher authenticity or fidelity of setting. These professional groups had very little or no simulation experience, and this finding is in contradiction with 
some of the literature finding showing that non-experts or novice- participants in simulation can accept a lower level of authenticity or fidelity [3].

Findings in the present focus group were comparable with the results in the randomised controlled trial conducted prior to this qualitative study [16].

To avoid bias only moderators who had never worked with the participants were selected. One element of the study with the potential for bias, however, was recruitment of participants for the focus groups because they were enlisted from among participants in the randomised controlled trial [16]. They may have had a special interest in simulation and interprofessional activities, perhaps making them more motivated and less representative of all staff. Co-construction in the focus groups, however, meant that a broad variety of views were presented.

Half of the people in the focus groups participated in ISS and the other half in OSS. The central purpose of the focus groups was to bring out the differences in what people experienced and to enable them to co-construct and make indirect comparisons between the learning outcomes they experienced from doing either ISS or OSS. The participants also used their previous simulation experiences to mirror their new experiences. Many of the participants knew each other, which may have prevented them from openly providing sensitive information or completely expressing their opinions and feelings. The heterogeneity of the groups may have influenced the group dynamics and the potential power relationships between groups. Experienced moderators were used in the attempt to avoid this.

Another limitation was the composition of the focus groups, which did not entirely mirror the distribution of healthcare professionals during the clinical work and that some groups were under-represented.

\section{Conclusion}

This study presents a new finding, which is that, in the eyes of healthcare professionals, OSS can be used just as well as ISS if other authenticity elements are taken into consideration and respected. This finding needs to be confirmed in other institutions and medical specialities as well as among other kinds of healthcare professionals and participants with less experience in simulation-based learning.

Analysis of the focus groups indicates that cross training is not an optimal solution, but additional testing of the concept [39-41] among larger medical teams composed of a larger variety of healthcare professionals in more complex simulations needs to be carried out to confirm and explore this conclusion further.

Findings in the present study are supported by the randomised controlled trial compared ISS to OSS conducted as in-house training at the hospital in rooms allocated to training [16]. The results from this study on the setting of simulations adds knowledge 
that may be useful in the planning and decision-making process for building and rebuilding new hospitals, facilities for training and simulation centres.

The study findings were based on focus groups and on the participants' immediate perceptions. Measuring the outcome of medical education [47] is a complex process, which is why including long-term feedback from participants in future studies, as well as the effect on outcome in patient care practices or patient outcomes would be useful. This study concludes that the psychological and socalled sociological fidelity elements of the simulation are important and that the physical context of the simulation is less important. Based on findings from the focus groups, OSS can be employed if other authenticity elements are considered and respected. 


\section{Acknowledgements}

The authors would like to thank the doctors, midwives and nurses who took part in the working committee that planned the intervention, specifically midwife Pernille Langhoff-Roos (Obstetrics Department, Rigshospitalet, University of Copenhagen) for assisting in the recruitment of participants. The authors would also like to thank copy editor and translator Nancy Aaen for revising the manuscript and for translating quotations from the focus groups from Danish to English.

\section{Contributors}

JLS created the idea for this study, aided by HKt. All authors, but specifically JLS, LEN and HMM, contributed to the study's design. BO and CVdV were supervisors. JLS, assisted by BO, was responsible for acquiring funding. JLS, LEN and HMM performed the initial data processing. All authors, except HK† provided critical review of the paper and approved the final manuscript.

\section{Funding}

The non-profit Danish Regions Development and Research Foundation provided the majority of the funding for the randomised controlled trial [16] and this study, while two additional non-profit funds, the Laerdal Foundation for Acute Medicine and the Aase and Ejnar Danielsen Foundation, provided the remaining funding. None of the foundations had a role in the design or conduct of the study.

\section{Competing interests}

None declared.

\section{Ethics approval}

The Regional Ethics Committee (protocol no. H-2-2012-155) and the Danish Data Protection Agency (no. 2007-58-0015) approved the study. Participants gave written informed consent. Participants were assured that their personal data would remain anonymous during reporting and were asked to respect the confidentiality of everything said in the focus group.

\section{Provenance and peer review}

Not commissioned; externally peer reviewed.

\section{Data sharing statement}

No additional data are available.

\section{Open Access}

This is an Open Access article distributed in accordance with the Creative Commons Attribution Non Commercial (CC BY-NC 4.0) license, which permits others to distribute, remix, adapt, build upon this work noncommercially, and license their derivative works on different terms, provided the original work is properly cited and the use is non-commercial. See: http:// creativecommons.org/licenses/by-nc/4.0/ 


\section{References}

1. Issenberg SB, McGaghie WC, Petrusa ER, Lee GD, Scalese RJ. Features and uses of high-fidelity medical simulations that lead to effective learning: a BEME systematic review. Med Teach 2005;27:10-28.

2. McGaghie WC, Issenberg SB, Petrusa ER, Scalese RJ. A critical review of simulation-based medical education research: 2003-2009. Med Educ 2010;44:50-63.

3. Motola I, Devine LA, Chung HS, Sullivan JE, Issenberg SB. Simulation in healthcare education: a best evidence practical guide. AMEE Guide No. 82. Med Teach 2013;35:e1511-e1530.

4. McGaghie WC, Issenberg SB, Barsuk JH, Wayne DB. A critical review of simulation-based mastery learning with translational outcomes. Med Educ 2014;48:375-85.

5. Merien AE, Van der Ven J, Mol BW, Houterman S, Oei SG. Multidisciplinary team training in a simulation setting for acute obstetric emergencies: a systematic review. Obstet Gynecol 2010;115:1021-31.

6. Riley W, Davis S, Miller KM, Hansen H, Sweet RM. Detecting breaches in defensive barriers using in situ simulation for obstetric emergencies. Qual Saf Health Care 2010;19 Suppl 3:i53-i56.

7. Walker ST, Sevdalis N, McKay A, Lambden S, Gautama S, Aggarwal R, Vincent C. Unannounced in situ simulations: integrating training and clinical practice. BMJ Qual Saf 2013 Jun;22:453-8.

8. Rosen MA, Hunt EA, Pronovost PJ, Federowicz MA, Weaver SJ. In situ simulation in continuing education for the health care professions: a systematic review. J Contin Educ Health Prof 2012;32:24354.

9. Patterson MD, Geis GL, Falcone RA, Lemaster T, Wears RL. In situ simulation: detection of safety threats and teamwork training in a high risk emergency department. BMJ Qual Saf 2013;22:46877.

10. Grierson LE. Information processing, specificity of practice, and the transfer of learning: considerations for reconsidering fidelity. Adv Health Sci Educ Theory Pract 2014;19:281-9.

11. Kneebone RL, Kidd J, Nestel D, Barnet A, Lo B, King R, Yang GZ, Brown R. Blurring the boundaries: scenario-based simulation in a clinical setting. Med Educ 2005;39:580-7.

12. Teunissen PW, Wilkinson TJ. Learning and teaching in workplaces. In: Dornan T, Mann K, Scherpbier A., Spencer J, editors. Medical Education: Theory and Practice.Edinburgh, London, New York, Oxford, Philadelphia, St Louis, Sydney, Toronto: Churchill Livingstone Elsevier; 2011. p. 193209.

13. Teteris E, Fraser K, Wright B, McLaughlin K. Does training learners on simulators benefit real patients? Adv Health Sci Educ Theory Pract 2012;17:137-44.

14. Durning SJ, Artino AR, Jr., Pangaro LN, van d, V, Schuwirth L. Perspective: redefining context in the clinical encounter: implications for research and training in medical education. Acad Med 2010;85:894-901.

15. Durning SJ, Artino AR. Situativity theory: a perspective on how participants and the environment can interact: AMEE Guide no. 52. Med Teach 2011;33:188-99.

16. Sørensen JL, Vleuten van $\operatorname{der} \mathrm{C}$, Rosthoj S, Oestergaard D, Leblanc V, Johansen M, Ekelund $\mathrm{K}$, Starkopf L, Lindschou J, Gluud C, Weikop P, Ottesen B. Simulation-based multiprofessional obstetric anaesthesia training conducted in situ versus off-site leads to similar individual and team outcomes: results from a randomised educational trial. BMJ Open 2015;5:e008344. doi:10.1136.

17. Cook DA, Bordage G, Schmidt HG. Description, justification and clarification: a framework for classifying the purposes of research in medical education. Med Educ 2008;42:128-33.

18. Lewin S, Glenton C, Oxman AD. Use of qualitative methods alongside randomised controlled trials of complex healthcare interventions: methodological study. BMJ 2009;339:b3496.

19. Kitzinger J. Qualitative research. Introducing focus groups. BMJ 1995;311:299-302.

20. Stalmeijer RE, Mcnaughton N, Van Mook WN. Using focus groups in medical education research: AMEE Guide No. 91. Med Teach 2014;36:923-39.

21. Kuper A, Reeves S, Levinson W. An introduction to reading and appraising qualitative research. BMJ 2008;337:a288.

22. Malterud K. Qualitative research: standards, challenges, and guidelines. Lancet 2001;358:483-8.

23. Tong A, Sainsbury P, Craig J. Consolidated criteria for reporting qualitative research (COREQ): a 32item checklist for interviews and focus groups. Int J Qual Health Care 2007;19:349-57. 
24. Fraenkal JR, Wallen NE, Hyun H.H. Observation and Interviewing. In: Fraenkal JR, Wallen NE, Hyun H.H, editors. How to Design and Evaluate Research in Education. Eighth ed. New York: McGrawHill; 2012. p. 444-76.

25. Rudolph JW, Simon R, Dufresne RL, Raemer DB. There's no such thing as "nonjudgmental" debriefing: a theory and method for debriefing with good judgment. Simul Healthc 2006;1:49-55.

26. Norman G, Dore K, Grierson L. The minimal relationship between simulation fidelity and transfer of learning. Med Educ 2012;46:636-47.

27. Sørensen JL, Lokkegaard E, Johansen M, Ringsted C, Kreiner S, McAleer S. The implementation and evaluation of a mandatory multi-professional obstetric skills training program. Acta Obstet Gynecol Scand 2009;88:1107-17.

28. Sørensen JL, Lottrup P, Vleuten van $\operatorname{der} C$, Andersen KS, Simonsen M, Emmersen P, Rosthoj S, Ottesen $B$. Unannounced in situ simulation of obstetric emergencies: staff perceptions and organisational impact. Postgrad Med J 2014;90:622-9.

29. Hsieh HF, Shannon SE. Three approaches to qualitative content analysis. Qual Health Res 2005;15:1277-88.

30. Graneheim U.H, Lundman B. Qualitative content analysis in nursing research: concepts, procedures and measures to achieve trustworthiness. Nurse Education Today 2003;24:105-12.

31. Fraenkal JR, Wallen NE, Hyun H.H. Content Analysis. In: Fraenkal JR, Wallen NE, Hyun H.H, editors. How to Design and Evaluate Research in Education. Eight ed. New York: McGraw-Hill; 2012. p. 477504.

32. Malterud K. Systematic text condensation: a strategy for qualitative analysis. Scand J Public Health 2012;40:795-805.

33. Koens F, Mann KV, Custers EJ, Ten Cate OT. Analysing the concept of context in medical education. Med Educ 2005;39:1243-9.

34. Patterson MD, Geis GL, Lemaster T, Wears RL. Impact of multidisciplinary simulation-based training on patient safety in a paediatric emergency department. BMJ Qual Saf 2013;22:383-93.

35. Raemer DB. Ignaz semmelweis redux? Simul Healthc 2014;9:153-5.

36. Koens F, Ten Cate OT, Custers EJ. Context-dependent memory in a meaningful environment for medical education: in the classroom and at the bedside. Adv Health Sci Educ Theory Pract 2003;8:155-65.

37. Godden DR, Baddeley AD. Context-dependent memory in two natural environments: on land and underwater. British Journal of Psychology 1975;66:325-31.

38. Beaubien JM, Baker DP. The use of simulation for training teamwork skills in health care: how low can you go? Qual Saf Health Care 2004;13 Suppl 1:i51-i56.

39. Wilson KA, Burke CS, Priest HA, Salas E. Promoting health care safety through training high reliability teams. Qual Saf Health Care 2005;14:303-9.

40. Volpe CE, Cannon-Bowers JA, Salas E, Spector PE. The impact of cross-training on team functioning: an empirical investigation. Hum Factors 1996;38:87-100.

41. Marks MA, Sabella MJ, Burke CS, Zaccaro SJ. The impact of cross-training on team effectiveness. J Appl Psychol 2002;87:3-13.

42. Gorman JC, Cooke NJ, Amazeen PG. Training adaptive teams. Hum Factors 2010;52:295-307.

43. Hamstra SJ, Brydges R, Hatala R, Zendejas B, Cook DA. Reconsidering fidelity in simulation-based training. Acad Med 2014;89:387-92.

44. Dieckmann P, Gaba D, Rall M. Deepening the theoretical foundations of patient simulation as social practice. Simul Healthc 2007;2:183-93.

45. Sharma S, Boet S, Kitto S, Reeves S. Interprofessional simulated learning: the need for 'sociological fidelity'. J Interprof Care 201;25:81-3.

46. Boet S, Bould MD, Layat BC, Reeves S. Twelve tips for a successful interprofessional team-based high-fidelity simulation education session. Med Teach 2014;36:853-7.

47. Cook DA, West CP. Perspective: Reconsidering the focus on "outcomes research" in medical education: a cautionary note. Acad Med 2013;88:162-7. 



\section{CHAPTER 8 \\ Twelve tips for choice of simulation setting and design of simulation-based medical education}

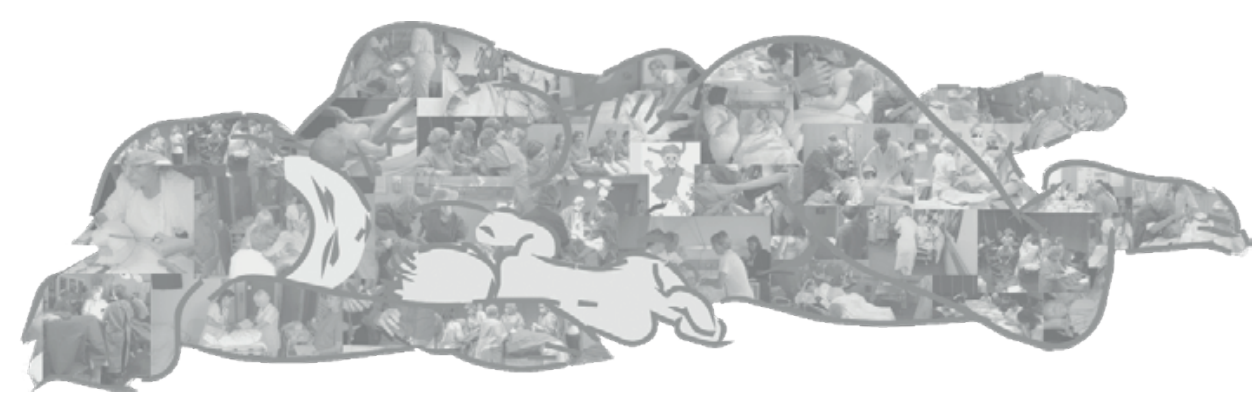

Jette Led Sørensen, Doris $\emptyset$ stergaard, Vicki Leblanc, Bent Ottesen, Lars Konge, Peter Dieckman, Cees van der Vleuten.

Submitted, September 2015. 


\begin{abstract}
This article provides tips for designing simulation-based medical education (SBME). In addition to discussing the design of SBME, we consider the advantages and disadvantages of different simulation settings, such as simulation centres, in-house simulations in hospital departments, announced or unannounced in situ simulations. The importance of setting, context and fidelity are discussed. Various non-randomised studies hypothesise that in situ simulation is more effective for educational purposes than other types of simulation settings. However, comparison studies show that choice of setting does not seem to influence individual or team learning, but that hospital-based simulations, such as in-house simulation and in-situ simulations, lead to a gain in organisational learning. We conclude that fidelity of some of the aspects of physical simulation setting appears to be of minor importance. This article adds to current discussion on fidelity by qualifying and exploring the partly weak relationship between physical fidelity and the transfer of learning.
\end{abstract}




\section{Introduction}

Simulation-based medical education (SBME) is increasingly recommended, both as an educational strategy and for improving patient safety [1-8]. One review concluded that future research should clarify the mechanisms behind effective simulation-based education by asking: "What works, for whom, in what contexts?" [6]. However, reviews only seldom address the choice of setting for SBME [1-8]. Avoiding unwanted setting effects when designing simulation environments for research and training is crucial, but little is known about the effect of the physical setting on the practice of simulation [9] A few minor studies showed mixed, inconclusive or no effects from a change in the physical setting [9].

This article provides a variety of tips for designing SBME, putting special emphasis on simulation settings. We distinguish between four different types of settings: 1) simulation-centres, 2) in-house simulations in hospital departments, 3) announced in situ simulation (ISS) and 4) unannounced ISS, in addition to discussing the importance of setting, context and simulation fidelity.

\section{Tip 1: Familiarise yourself with the simulation terminology}

SBME is a complex educational intervention, where: "In broad, simple terms a simulation is a person, device, or set of conditions which attempts to present education and evaluation problems authentically. The student or trainee is required to respond to the problems as he or she would under natural circumstances [1]." Simulation techniques and devices can comprise, for example high-tech virtual reality simulators, full-scale mannequins, plastic models, instructed or standardised patients, animal or animal products, human cadavers or screen-based simulators. SBME can target individuals, teams or both, but also organisational learning, the latter understood as ideas concerning any type of practical changes in equipment, guidelines or the physical clinical environment.

SBME has been conducted largely as off-site simulation (OSS) in simulation centres, which range widely from publically financed simulation centres at hospitals and universities to simulation centres that are detached facilities funded by sponsors and user payment.

Some hospital departments also provide OSS using in-house training room(s) specifically set up for simulation training away from the clinical setting [10-13]. In-house training facilities can be part of hospital departments and resemble to some extent simulationcentres but often have fewer technical devices, such as permanent audio-visual recording equipment. OSS in-house activities require that departments are able to provide simulation equipment and to ensure that simulation instructors are trained well enough to supply professionally and educationally sound simulations. 
Introduced over the past decade, ISS is mainly described as team-based activities that occur in patient care units involving actual healthcare team members in their own working environment [14]. Rosen et al. describe ISS as a blend of simulation and real working environments designed to provide training where people actually work [15]. ISS can also focus on individual skills and be conducted either announced or unannounced $[15,16]$, the latter also termed as a drill [16].

Table 8.1 provides a schematic overview of how simulation settings are potentially related to various components in SBME, which we will discuss in subsequent tips.

\section{Tip 2: Define the learning objectives and integrate SBME into the overall curriculum}

Learning objectives are an essential part of curriculum design for every type of educational intervention $[17,18]$. Therefore, having scenarios based on well-defined learning objectives is also crucial in SBME. It is also important to integrate simulations into an overall curriculum, and simulation activities can only be as good as the educational programme in which they are embedded $[1,3,19,20]$.

SBME can focus on individual skills training or on team training for various healthcare professional groups. The objectives must be defined clearly, for example within the framework of relevant knowledge, skills and attitudes - each of which could focus more on team-based activities such as communication, cooperation and teamwork but also on cognitive skills like decision making or on technical and clinical topics.

Objectives for individuals and teams can also be viewed as an integrated whole. For instance a surgical simulator can be used in a real (ISS) or simulated (OSS) operating theatre, where the objectives involve both the individual's technical surgical skills and team performance. Adopting this kind of more holistic view is described as helpful in inter-professional postgraduate simulation [21].

Practicing teamwork integrated with simulation-based skills training that encompasses a clinical approach is preferable and has been shown to be associated with significant improvements, whereas focusing solely on teamwork, however, is not recommended [22-25].

Inter-professional simulation is on the agenda in many organisations but requires substantial planning. Simulations must be developed that provide each healthcare professional group with a significant role to play and involve incorporating a variety of objectives for each group. Inter-professional planning requires the use of inter-professional curriculum committees $[12,21,26]$. Boet et al. provide ample information on how to create simulations inter-professionally [21]. A variety of ISS programmes are designed to test organisational practice [15], but can cause confusion among participants due to 
Table 8.1 A schematic overview of how different simulation settings are potentially affected by various aspects of simulation-based medical education. Blank spaces indicate that the item has little or no effect; $x$ that the item can have an effect; $x x$ that the item can have a strong effect.

\begin{tabular}{|c|c|c|c|c|}
\hline & $\begin{array}{l}\text { Off site } \\
\text { simulation } \\
\text { in simula- } \\
\text { tion centre }\end{array}$ & $\begin{array}{l}\text { Off site } \\
\text { simulation } \\
\text { in-house in } \\
\text { department }\end{array}$ & $\begin{array}{c}\text { In situ } \\
\text { simulation } \\
\text { announced }\end{array}$ & $\begin{array}{l}\text { In situ simu- } \\
\text { lation } \\
\text { unannounced }\end{array}$ \\
\hline Less risk of cancellation due to heavy patient load & $x x$ & $\mathrm{xx}$ & $\mathrm{x}$ & \\
\hline Not described as anxiety provoking & $\mathrm{x}$ & $\mathrm{x}$ & $x$ & \\
\hline $\begin{array}{l}\text { May potentially give a greater feeling of safety } \\
\text { psychologically }\end{array}$ & $\mathrm{x}$ & & & \\
\hline Enhances individual learning & $\mathrm{x}$ & $\mathrm{x}$ & $\mathrm{x}$ & $x$ \\
\hline Enhances team learning & $\mathrm{x}$ & $x x$ & $\mathrm{xx}$ & $x x$ \\
\hline No risk of staff being called away for clinical work & $x x$ & $x$ & & \\
\hline $\begin{array}{l}\text { Ideas for organisational changes brought back to the } \\
\text { organisation (latent patient safety issues) }\end{array}$ & & $\mathrm{x}$ & $\mathrm{xx}$ & $x x$ \\
\hline $\begin{array}{l}\text { Does not require travel time; accessibility for staff } \\
\text { easier }\end{array}$ & & $\mathrm{xx}$ & $x x$ & $x x$ \\
\hline $\begin{array}{l}\text { Reported to promote better involvement of all } \\
\text { postgraduate healthcare professionals }\end{array}$ & & $\mathrm{x}$ & $\mathrm{x}$ & $\mathrm{x}$ \\
\hline $\begin{array}{l}\text { Popular and promotes recruitment of postgraduate } \\
\text { healthcare professionals }\end{array}$ & & & $\mathrm{x}$ & $\mathrm{x}$ \\
\hline $\begin{array}{l}\text { More efficient use of simulation equipment, which } \\
\text { can be shared by many departments, and better } \\
\text { facilities to ensure efficient use of high-tech simula- } \\
\text { tion equipment }\end{array}$ & $x x$ & & & \\
\hline $\begin{array}{l}\text { More time potentially set aside, especially for de- } \\
\text { briefing }\end{array}$ & $x x$ & $\mathrm{x}$ & $\mathrm{x}$ & \\
\hline $\begin{array}{l}\text { Team-based and low-tech simulation can be cheap- } \\
\text { er due to use of local facilities and equipment }\end{array}$ & & $\mathrm{x}$ & $\mathrm{xx}$ & $x x$ \\
\hline $\begin{array}{l}\text { No potential risk of safety hazards due to mixing up } \\
\text { medical equipment and utensils }\end{array}$ & $x x$ & $x$ & & \\
\hline $\begin{array}{l}\text { No potential risk of unintentional involvement of } \\
\text { patients and relatives }\end{array}$ & $x x$ & $x x$ & $x$ & \\
\hline $\begin{array}{l}\text { Easier access for technicians if simulation equip- } \\
\text { ment has technical problems }\end{array}$ & $x x$ & & & \\
\hline $\begin{array}{l}\text { Potentially more efficient simulations due to devel- } \\
\text { opment of simulation curriculum }\end{array}$ & $x x$ & $x$ & $x$ & $x$ \\
\hline $\begin{array}{l}\text { Potentially more efficient simulations due to better } \\
\text { training of simulation instructors }\end{array}$ & $x x$ & $x$ & $x$ & $x$ \\
\hline
\end{tabular}


their multi-level focus on the individual, team and organisational setup, which is why clearly defined objectives are vital. Learning on an organisational level can differ from individual and team learning $[12,15,26,27]$.

\section{Tip 3: Determine whether the aim is to train or to assess}

Be aware of the difference between simulation-based training and assessing simulation participants $[17,18]$. In the pre-briefing it is important to tell simulation participants what is expected of them [21]. Assessing participants individually may be relevant and participants who have been tested have been shown to have better retention as a result of what is known as the testing effect $[28,29]$. However, some simulation participants may experience that being assessed disrupts the feeling of being in a safe learning environment [24]. Developing a test to be applied in an interprofessional context will require involvement of all the healthcare professional groups involved in the simulation intervention [30].

Simulation will probably increasingly be used for assessment. A review concludes that simulation-based tools may replace work-based assessment of selected procedural skills [8]. Less evidence is found on the benefit of SBME in teams, as there is still a lack of team-based metrics and standards [4].

Tip 4: Meticulously plan unannounced ISS and be aware that unexpected events and cancellations can occur

All simulation requires detailed planning, but particularly unannounced ISS requires multifaceted planning and the need for good management support [12,31,32]. Wellestablished cooperation between educational planners and the departmental management is required, and actively involving representatives from all healthcare professional groups results in better planning of postgraduate inter-professional simulation $[11,12,21,26,33,34]$. Still, simulation instructors must be prepared to cancel or postpone scheduled unannounced ISS in the event of heavy patient loads or a shortage of staff [12]. The average reported rate of cancellation for unannounced ISS is $28-50 \%$ $[12,31]$ but the percentage seems to go down as training matures [31].

Unannounced ISS must not pose any risk to real-life patients, which means extra staff must replace staff participating in the unannounced ISS [12]. Ensuring that simulation equipment (e.g. expired medications) is not left in patient areas is also important; see tip 10.

\section{Tip 5: Respect the feelings of anxiety healthcare professionals may have}

Some individuals who have participated in unannounced ISS describe it as intimidating [16], but this topic is poorly explored in the literature. One study found that approximately one-third of all staff members thought that unannounced ISS was stressful and 
unpleasant, despite the fact that all staff members had been told that a number of unannounced ISS would take place within a specific period [12].

Conducting OSS or an announced ISS can potentially ensure a safer learning environment, even though it is also reported to be perceived as stressful or intimidating [35]. Boet et al. also reported widespread anxiety concerning inter-professional learning as it entails various difficult interactions involving people from a range of professional groups and perceived status [21]. The precise interplay of the many factors impacting how safe simulation participants feel during simulation remains to be explored. This underlines the importance of training programmes for simulation instructors [36].

\section{Tip 6: Expect individual and team outcomes independent of simulation setting}

Several non-randomised studies hypothesise that the physical setting can influence learning and that ISS is more effective for educational purposes than OSS because the simulation is conducted in a more authentic environment [14,31,37-39]. A randomised trial involving training ISS versus OSS in-house tested this hypothesis [26]. The ISS and OSS scenarios were standardised and the simulation instructors were trained. The ISS participants scored the authenticity of the simulation scenarios significantly higher than the OSS participants, but the comparison of ISS versus OSS in-house did not reveal any significant differences regarding individual knowledge, patient safety attitudes, stress measurements, perceptions of the simulations or video-assessed team performance [26]. These findings were confirmed in a subsequent qualitative study [33].

Another randomised trial comparing OSS in a simulation centre with OSS in-house training showed that the simulation setting was not of importance for the outcome, as expressed by no difference in the acquisition of knowledge and no differences in completion for basic tasks and teamwork $[10,13]$.

Finally, a retrospective study comparing OSS in a simulation-centre with ISS found the same outcome in video ratings of team performance in the two simulation settings [32]. However, survey-based data showed that participants favoured ISS [29], which can be seen as an argument to apply ISS to improve recruitment [32].

Some argue in favour of conducting OSS in a simulation centre where the staff cannot be called away for clinical work and where personal relationships between simulation instructors and professional healthcare staff can be avoided [40]. The comparison studies on simulation settings mentioned above do not specifically address these issues. To our knowledge, only a handful of studies exist in the medical domain that compares various simulation settings in terms of outcomes [10,13,26,32,33]. Further studies are needed that include outcome on long-term retention and patient-based outcomes. 


\section{Tip 7: Use in situ simulation to achieve greater learning at the organisational level}

Simulation can be used to test equipment, new procedures and physical environments. Articles on ISS discuss the value of ISS for identifying latent safety threats in organisations $[12,15,26,31,37,41]$. Testing equipment and procedures can take place in simulation centres, but the literature focuses on ISS. Studies describe how ISS can successfully be used to test the renovation of wards and the construction of new wards [42-45] or to determine how to perform individual procedures $[46,47]$. Although convincing and inspiring, these studies may reflect a publication bias as only successful studies are described.

A randomised trial and a subsequent qualitative study confirm that more information on organisational deficiencies come from ISS participants compared to OSS participants in-house [26,33]. OSS in-house training is described as useful for identifying organisational deficiencies $[11,12,23,26,33]$, but the ISS setting in particular provided more information than OSS on deficiencies concerning technology and tools $[26,27]$.

\section{Tip 8: Use simulations to test new building facilities}

Simulation can involve using a mock-up or sandbox technique $[48,49]$. The former is a 1:1 construction of a unit or other rooms that allows architects and designers, in cooperation with clinical staff, to test ideas and solutions [48]. The sandbox technique allows staff to practice new care delivery in new buildings [49]. Applying these methods in the early phases of planning and decision making when building new wards and hospitals is important. Recent literature on the design of new hospitals stresses the lack of integration between physical learning spaces and underlying teaching strategies $[50,51]$.

\section{Tip 9: Consider which simulation activity to establish when building new hospitals}

Simulation is expected in the future to be an increasingly recommended educational strategy for all kinds of healthcare professionals, just as an increase in interprofessional simulation programmes is expected [21]. One idea is to make simulation facilities more accessible for staff and to integrate simulation into the educational strategy of departments. This approach can prevent simulation sessions from becoming stand-alone events [21]. As a result, establishing simulation rooms when constructing new hospitals should be considered. These rooms should preferably be located close to departments where various specialties work together and team training can take place. New wards, emergency rooms, operating theatres and delivery wards can also be designed to facilitate ISS, e.g. in the form of video-recording equipment and rooms nearby for debriefing. Cooperation between departments can enable better use of rooms and simulation equipment. Further coordination between local simulation in hospital departments and simulation centres will help to avoid the purchase of equipment that will be underutilised. Department-based simulations could be supported by simulation 
centres to ensure that simulation programmes are adequately developed and standardised. Further this might help to guarantee that simulation instructors are sufficiently trained, in addition to encouraging and coordinating simulation research $[36,40]$.

Research on inter-professional postgraduate simulation shows that simulation conducted in close proximity to the clinical setting has a positive impact and that the departments involved gain useful organisational information for improving care $[10,11,13,22-26,30,33]$, which are arguments for incorporating simulation facilities in new hospitals.

Simulation-based activities involving high-tech simulation for technically advanced clinical procedures are most often centralised in simulation centres due to the advanced level of the simulators and the requirements they pose on their users [52].

Although several studies show that successful ISS can take place with a minimum of costs compared to simulation centres [15,32,53-55], ISS can require extra space for clinical activities, hence increasing its cost.

Tip 10: Be aware that simulations that take place close to or in the clinical setting may compromise patient safety

Conducting OSS in-house and ISS requires storage space for equipment, and simulation instructors have to schedule time to organise mannequins and equipment. ISS will most often involve the use of equipment from the clinical site, thus making it simpler to plan, whereas OSS in-house simulation instructors must organise all relevant equipment. A potential disadvantage of doing simulations that take place outside a simulation centre is that ISS and OSS in-house can compromise patient safety. For example medication prepared for ISS or OSS in-house can potentially get mixed up with real medication, or equipment used for ISS might be returned without being made ready for use in real clinical situations $[32,40,56]$. Using labels marked "Simulation only" is a precaution that can be taken to avoid these problems, but planning simulations must also incorporate clean-up procedures and an awareness among simulation instructors of how patient safety can be compromised due to poor planning [56]. ISS can also potentially upset patients [56], but providing useful information for patients and relatives may also result in a positive effect. Signage can help them to recognise the training nature of the activities. If a research approach is taken in this process, knowledge on the perspective of patients can be gathered.

\section{Tip 11: Explore, discuss and reflect on the context and fidelity}

To some extent, this article uses the term context synonymously with setting or physical surroundings. However, context can be expanded to also include the semantic and commitment context [57]. Semantic context reflects how well the context contributes to the learning task while commitment context reflects motivation and responsibility $[57,58]$. One argument in favour of ISS is the contextual similarity to the context of 
working. The rooms and the equipment, for example are "real", even though they are used for simulation purposes [15,37,56,59].

Learning in context is a highly discussed topic in medical education $[2,60,61]$ and various studies indicate that learning can be better applied or recalled when the learning environment resembles the retrieval environment [60,62-64]. Medical educators and empirical findings, however, increasingly question this assumption [57,58,65-67].

Comparison studies (tip 6) indicate that the physical context and physical fidelity of the simulation setting, such as OSS or ISS, are not the most important aspects for individual and team learning $[10,13,26,33]$, indicating that the semantic and motivational context are more important $[54,55]$.

Tip 12: Apply future research on simulation in authentic teams versus cross training and explore the term sociological fidelity

Recently introduced in the field of simulation, sociological fidelity is understood within inter-professional simulation as the focus on interactions between learners to create authenticity with high levels of social realism [21,34,68]. Applying this understanding may be relevant as simulation factors related to the interaction between simulation participants appear to be of more importance than the simulation's physical setting.

The current understanding of fidelity is under debate $[65,66,68,69]$ and may not be adequate enough to explain the learning-relevant processes in inter-professional simulation. Discussing the importance of social practice, hierarchy, power relations and other factors affecting inter-professional teamwork is rather new in the simulation literature $[21,34,69,70]$, and exploring terms like sociological fidelity may prove useful in future research on simulation.

In a classical sense, fidelity refers to the degree of faithfulness that exists between two entities, and these entities are fundamental for the transfer of SBME and performance in the clinical setting [65]. The rationale behind this idea on the authenticity of simulation is the traditional assumption that the closer the learning context resembles the context of practice, the better the learning. Situativity theory argues that knowledge, thinking and learning are situated in experience $[60,62,63,71,72]$. However, results from comparison studies (tip 6) on different simulation settings seem to show that some of the physical aspects of the simulation setting play a minor role compared to other factors. This assumption appears to be inconsistent with traditional situated learning theory, which in general states that increased fidelity leads to improved learning $[62,63]$.

Participants in postgraduate simulation thought that participating in authentic teams in their own roles as healthcare professionals was important [26,33]; however, we need to know if this perception affects learning and clinical performance. This perception stands in contrast to the premise behind cross training, which is recommended in the 
simulation literature $[3,73]$ and defined as "an instructional strategy in which each team member is trained in the duties of his or her teammates" [74]. It is argued that if all team members have a shared understanding of other people's roles the risk of making errors decreases [75]. Although there are empirical studies that address cross training, they only comprise small teams in an experimental laboratory setting and, to our knowledge, no medical studies have been undertaken that involve postgraduate multiprofessional teams [73-75].

\section{Conclusion}

We conclude that the choice of physical setting for simulations does not seem to influence individual and team learning. Department-based local simulation, such as OSS inhouse and especially ISS, leads to gains in organisational learning. The overall aim of a simulation and factors such as feasibility can help determine which simulation setting to choose. Studies on postgraduate inter-professional training show that local training, such as ISS or OSS in-house, offers various advantages, e.g. locally run courses benefit local organisational learning, reduce costs and increase the accessibility of training for professional staff. Some of the disadvantages of holding courses locally are organisational problems and poor quality content due to badly organised simulations and a lack of qualified simulation instructors. These disadvantages need to be specifically addressed, but explicit collaboration and coordination between the organisers of local simulation and simulation centres is recommended and can help avoid some of these issues.

SBME is expected to increase substantially in the coming years and simulation is a costly intervention. Specific areas that would benefit from future research include the implementation of simulation [76] and the role of local organisers of simulations and of simulation centres. Research would profit greatly by encouraging collaboration between practical organisers of simulations and medical education researchers. The use of cross training is also a relevant area for future research.

In summary the choice of physical simulation setting appears to be of less importance for individual and team learning but more research is necessary to better understand what other aspects of simulation are fundamental to learning, in addition to examining more closely what kind of simulation works best and for whom. 


\section{Contributors}

JETTE LED SØRENSEN, MD, MMEd from Dundee University, associate professor, and specialist in obstetrics and gynaecology, University of Copenhagen. Her research interest is in inter-professional simulation and SBME. She is in the final phase of completing her PhD thesis at Maastricht University on designing simulationbased medical education and the role of physical fidelity.

DORIS OESTERGAARD MD, DSci, professor and director for the Copenhagen Academy for Medical Education and Simulation, Denmark. Her research interest is simulation-based medical education.

VICKI LEBLANC, PhD, is the chair of and an associate professor at the Department of Innovation in Medical Education, Ottawa, and the director of the University of Ottawa Skills and Simulation Centre. Her research interest is the optimisation of simulation-based education and the use of simulation to study performanceshaping factors as emotions.

BENT OTTESEN MD, DSci, professor of obstetrics and gynaecology. His research interests include SBME, gynaecological cancer, neuropeptides and reproduction. At present he heads the planning process for a new mother-child hospital in Denmark focused on integrating training, research and clinical work.

LARS KONGE, MD, PhD, associate professor, specialist in cardio-thoracic surgery, University of Copenhagen. Head of the Simulation Centre at Rigshospitalet, Copenhagen Academy for Medical Education and Simulation, Denmark. His primary research interests are assessment and simulation-based training of technical skills.

PETER DIECKMANN, PhD, Dipl.Psych, is organisational psychologist and head of research at the Copenhagen Academy for Medical Education and Simulation. His research interest is how simulation can best be used for education, training and research. He also uses various types of simulation to investigate human factors and organisational safety issues.

CEES VAN DER VLEUTEN, PhD, is Professor of Education, Scientific. Director of the School of Health Professions Education, Faculty of Health, Medicine and Life Sciences, Maastricht University, the Netherlands. http://ceesvandervleuten.com/biography

\section{Declaration of Interest}

The authors report no conflict of interest. The authors alone are responsible for the content and writing of this article.

\section{Acknowledgments}

Non-profit foundations, including the Danish Regions Development and Research Foundation, the Laerdal Foundation for Acute Medicine, and the Aase and Ejnar Danielsen Foundation funded the research on the role of setting and fidelity in simulation [26,33]. None of the funding providers contributed to the content or writing of this article. 


\section{References}

1. Issenberg SB, McGaghie WC, Petrusa ER, Lee GD, Scalese RJ. Features and uses of high-fidelity medical simulations that lead to effective learning: a BEME systematic review. Med Teach 2005 Jan;27:10-28.

2. McGaghie WC, Issenberg SB, Petrusa ER, Scalese RJ. A critical review of simulation-based medical education research: 2003-2009. Med Educ 2010 Jan;44:50-63.

3. Motola I, Devine LA, Chung HS, Sullivan JE, Issenberg SB. Simulation in healthcare education: a best evidence practical guide. AMEE Guide No. 82. Med Teach 2013 Oct;35:e1511-e1530.

4. McGaghie WC, Issenberg SB, Barsuk JH, Wayne DB. A critical review of simulation-based mastery learning with translational outcomes. Med Educ 2014 Apr;48:375-85.

5. Cook DA, Hatala R, Brydges R, Zendejas B, Szostek JH, Wang AT, Erwin PJ, Hamstra SJ. Technologyenhanced simulation for health professions education: a systematic review and meta-analysis. JAMA 2011 Sep 7;306:978-88.

6. Cook DA, Hamstra SJ, Brydges R, Zendejas B, Szostek JH, Wang AT, Erwin PJ, Hatala R. Comparative effectiveness of instructional design features in simulation-based education: systematic review and meta-analysis. Med Teach 2013;35:e867-e898.

7. Zendejas B, Brydges R, Hamstra SJ, Cook DA. State of the evidence on simulation-based training for laparoscopic surgery: a systematic review. Ann Surg 2013 Apr;257:586-93.

8. Brydges R, Hatala R, Zendejas B, Erwin PJ, Cook DA. Linking simulation-based educational assessments and patient-related outcomes: a systematic review and meta-analysis. Acad Med 2015 Feb;90:246-56.

9. Manser T, Dieckmann P, Wehner T, Rallf M. Comparison of anaesthetists' activity patterns in the operating room and during simulation. Ergonomics 2007 Feb;50:246-60.

10. Ellis D, Crofts JF, Hunt LP, Read M, Fox R, James M. Hospital, simulation center, and teamwork training for eclampsia management: a randomized controlled trial. Obstet Gynecol 2008 Mar;111:723-31.

11. Sørensen JL, Løkkegaard E, Johansen M, Ringsted C, Kreiner S, McAleer S. The implementation and evaluation of a mandatory multi-professional obstetric skills training program. Acta Obstet Gynecol Scand 2009;88:1107-17.

12. Sørensen JL, Lottrup P, Vleuten van $\operatorname{der} C$, Andersen KS, Simonsen M, Emmersen P, Rosthoj S, Ottesen B. Unannounced in situ simulation of obstetric emergencies: staff perceptions and organisational impact. Postgrad Med J 2014 Nov;90:622-9.

13. Crofts JF, Ellis D, Draycott TJ, Winter C, Hunt LP, Akande VA. Change in knowledge of midwives and obstetricians following obstetric emergency training: a randomised controlled trial of local hospital, simulation centre and teamwork training. BJOG 2007 Dec;114:1534-41.

14. Riley W, Davis S, Miller KM, Hansen H, Sweet RM. Detecting breaches in defensive barriers using in situ simulation for obstetric emergencies. Qual Saf Health Care 2010 Oct;19 Suppl 3:i53-i56.

15. Rosen MA, Hunt EA, Pronovost PJ, Federowicz MA, Weaver SJ. In situ simulation in continuing education for the health care professions: a systematic review. J Contin Educ Health Prof 2012;32:24354.

16. Anderson $E$, Black R, Brocklehurst P. Acute obstetric emergency drill in England and Wales: a survey of practice. BJOG 2005 Mar;112:372-5.

17. Thomas PA. Goals and objectives. In: Kern DE, Thomas PA, Howard DM, Bass EB, editors. Curriculum development for medical education. A six step approach. 2 ed. London: The John Hopkins University Press; 2009. p. 43-51.

18. Harden RM. Ten questions to ask when planning a course or curriculum. Med Educ 1986 Jul;20:356-65.

19. Bradley P, Bligh J. Clinical skills centres: where are we going? Med Educ 2005 Jul;39:649-50.

20. Maran NJ, Glavin RJ. Low- to high-fidelity simulation - a continuum of medical education? Med Educ 2003 Nov;37 Suppl 1:22-8.

21. Boet S, Bould MD, Layat BC, Reeves S. Twelve tips for a successful interprofessional team-based high-fidelity simulation education session. Med Teach 2014 Oct;36:853-7.

22. Siassakos D, Crofts JF, Winter C, Weiner CP, Draycott TJ. The active components of effective training in obstetric emergencies. BJOG 2009 Jul;116:1028-32. 
23. Cornthwaite K, Edwards S, Siassakos D. Reducing risk in maternity by optimising teamwork and leadership: an evidence-based approach to save mothers and babies. Best Pract Res Clin Obstet Gynaecol 2013 Aug;27:571-81.

24. Draycott TJ, Collins KJ, Crofts JF, Siassakos D, Winter C, Weiner CP, Donald F. Myths and realities of training in obstetric emergencies. Best Pract Res Clin Obstet Gynaecol 2015;29:1067-76.

25. Bergh AM, Baloyi S, Pattinson RC. What is the impact of multi-professional emergency obstetric and neonatal care training? Best Pract Res Clin Obstet Gynaecol 2015;29:1028-1043.

26. Sørensen JL, Vleuten van der C, Rosthoj S, Oestergaard D, Leblanc V, Johansen M, Ekelund K, Starkopf L, Lindschou J, Gluud C, Weikop P, Ottesen B. Simulation-based multiprofessional obstetric anaesthesia training conducted in situ versus off-site leads to similar individual and team outcomes: results from a randomised educational trial. BMJ Open 2015;5:e008344. doi:10.1136/bmjopen-2015-008344.

27. Carayon P, Schoofs HA, Karsh BT, Gurses AP, Alvarado CJ, Smith M, Flatley BP. Work system design for patient safety: the SEIPS model. Qual Saf Health Care 2006 Dec;15 Suppl 1:i50-i58.

28. Larsen DP, Butler AC, Roediger HL, III. Test-enhanced learning in medical education. Med Educ 2008 Oct;42:959-66.

29. Kromann CB, Jensen ML, Ringsted C. The effect of testing on skills learning. Med Educ 2009 Jan;43:21-7.

30. Sørensen JL, Thellensen L, Strandbygaard J, Svendsen KD, Christensen KB, Johansen M., LanghoffRoos P., Ekelund K, Ottesen B, Vleuten van der C. Development of a knowledge test for multidisciplinary emergency training: a review and an example. Acta Anaesthesiol Scand 2015;59:12333.

31. Patterson MD, Geis GL, Falcone RA, Lemaster T, Wears RL. In situ simulation: detection of safety threats and teamwork training in a high risk emergency department. BMJ Qual Saf 2013 Jun;22:468-77.

32. Couto TB, Kerrey BT, Taylor RG, FitzGerald M, Geis GL. Teamwork Skills in Actual, In Situ, and InCenter Pediatric Emergencies: Performance Levels Across Settings and Perceptions of Comparative Educational Impact. Simul Healthc 2015 Apr;10:76-84.

33. Sørensen JL, Navne LE, Martin HM, Ottesen B, Albrechtsen CK, Pedersen BW, Kjaergaard H, Vleuten van der C. Clarifying the learning experiences of healthcare professionals with in situ versus off-site simulation-based medical education: a qualitative study. BMJ Open 2015;5:e008345. doi:10.1136/bmjopen-2015-008345.

34. Sharma S, Boet S, Kitto $S$, Reeves $S$. Interprofessional simulated learning: the need for 'sociological fidelity'. J Interprof Care 2011 Mar;25:81-3.

35. Savoldelli GL, Naik VN, Hamstra SJ, Morgan PJ. Barriers to use of simulation-based education. Can J Anaesth 2005 Nov;52:944-50.

36. Dieckmann P, Molin FS, Lippert A, Ostergaard D. The art and science of debriefing in simulation: Ideal and practice. Med Teach 2009 Jul;31:e287-e294.

37. Walker ST, Sevdalis N, McKay A, Lambden S, Gautama S, Aggarwal R, Vincent C. Unannounced in situ simulations: integrating training and clinical practice. BMJ Qual Saf 2013 Jun;22:453-8.

38. Stocker M, Burmester M, Allen M. Optimisation of simulated team training through the application of learning theories: a debate for a conceptual framework. BMC Med Educ 2014;14:69.

39. Kobayashi L, Dunbar-Viveiros JA, Sheahan BA, Rezendes MH, Devine J, Cooper MR, Martin PB, Jay GD. In situ simulation comparing in-hospital first responder sudden cardiac arrest resuscitation using semiautomated defibrillators and automated external defibrillators. Simul Healthc 2010 Apr;5:82-90.

40. Møller TP, $\varnothing$ stergaard D, Lippert A. Facts and fiction - Training in centres or in situ. Trends in Anaesthesia and Critical Care 2012;2:174-9.

41. Wheeler DS, Geis G, Mack EH, Lemaster T, Patterson MD. High-reliability emergency response teams in the hospital: improving quality and safety using in situ simulation training. BMJ Qual Saf 2013 Jun;22:507-14.

42. Bender GJ. In situ simulation for systems testing in newly constructed perinatal facilities. Semin Perinatol 2011 Apr;35:80-3.

43. Geis GL, Pio B, Pendergrass TL, Moyer MR, Patterson MD. Simulation to assess the safety of new healthcare teams and new facilities. Simul Healthc 2011 Jun;6:125-33. 
44. Preston P, Lopez C, Corbett N. How to integrate findings from simulation exercises to improve obstetrics care in the institution. Semin Perinatol 2011 Apr;35:84-8.

45. Kobayashi L, Shapiro MJ, Sucov A, Woolard R, Boss RM, III, Dunbar J, Sciamacco R, Karpik K, Jay G. Portable advanced medical simulation for new emergency department testing and orientation. Acad Emerg Med 2006 Jun;13:691-5.

46. Kobayashi L, Dunbar-Viveiros JA, Devine J, Jones MS, Overly FL, Gosbee JW, Jay GD. Pilot-Phase Findings From High-fidelity In Situ Medical Simulation Investigation of Emergency Department Procedural Sedation. Simul Healthc 2012 Jan 26;7.

47. Kobayashi L, Parchuri R, Gardiner FG, Paolucci GA, Tomaselli NM, Al-Rasheed RS, Bertsch KS, Devine J, Boss RM, Gibbs FJ, Goldlust E, Monti JE, O'Hearn B, Portelli DC, Siegel NA, Hemendinger $D$, Jay GD. Use of in situ simulation and human factors engineering to assess and improve emergency department clinical systems for timely telemetry-based detection of life-threatening arrhythmias. BMJ Qual Saf 2013;22:72-83.

48. Moss C, Walsh K, Mitchell J. Plotting care: a modelling technique for visioning nursing practice in current and future contexts. Contemp Nurse 2010 Jun;35:188-201.

49. Ecoff L, Thomason T. Moving into a new hospital: strategies for success. J Nurs Adm 2009 Dec;39:499-503.

50. Nordquist J, Laing A. Spaces for learning--A neglected area in curriculum change and strategic educational leadership. Med Teach 2014 Jul;36:555-6.

51. Kitto S, Nordquist J, Peller J, Grant R, Reeves S. The disconnections between space, place and learning in interprofessional education: an overview of key issues. J Interprof Care 2013 Sep;27 Suppl 2:5-8.

52. Konge L, Ringsted C, Bjerrum F, Tolsgaard MG, Bitsch M, Sorensen JL, Schroeder TV. The simulation centre at rigshospitalet, copenhagen, denmark. J Surg Educ 2015 Mar;72:362-5.

53. Calhoun AW, Boone MC, Peterson EB, Boland KA, Montgomery VL. Integrated in-situ simulation using redirected faculty educational time to minimize costs: a feasibility study. Simul Healthc 2011 Dec;6:337-44.

54. van Schaik SM, Plant J, Diane S, Tsang L, O'Sullivan P. Interprofessional team training in pediatric resuscitation: a low-cost, in situ simulation program that enhances self-efficacy among participants. Clin Pediatr (Phila) 2011 Sep;50:807-15.

55. Edler AA, Chen M, Honkanen A, Hackel A, Golianu B. Affordable simulation for small-scale training and assessment. Simul Healthc 2010 Apr;5:112-5.

56. Raemer DB. Ignaz semmelweis redux? Simul Healthc 2014 Jun;9:153-5.

57. Koens F, Mann KV, Custers EJ, Ten Cate OT. Analysing the concept of context in medical education. Med Educ 2005 Dec;39:1243-9.

58. Koens F, Ten Cate OT, Custers EJ. Context-dependent memory in a meaningful environment for medical education: in the classroom and at the bedside. Adv Health Sci Educ Theory Pract 2003;8:155-65.

59. Patterson MD, Geis GL, Lemaster T, Wears RL. Impact of multidisciplinary simulation-based training on patient safety in a paediatric emergency department. BMJ Qual Saf 2013 May;22:383-93.

60. Teunissen PW, Wilkinson TJ. Learning and teaching in workplaces. In: Dornan T, Mann K, Scherpbier A., Spencer J, editors. Medical Education: Theory and Practice.Edinburgh, London, New York, Oxford, Philadelphia, St Louis, Sydney, Toronto: Churchill Livingstone Elsevier; 2011. p. 193209.

61. Beaubien JM, Baker DP. The use of simulation for training teamwork skills in health care: how low can you go? Qual Saf Health Care 2004 Oct;13 Suppl 1:i51-i56.

62. Durning SJ, Artino AR. Situativity theory: a perspective on how participants and the environment can interact: AMEE Guide no. 52. Med Teach 2011;33:188-99.

63. Durning SJ, Artino AR, Jr., Pangaro LN, van d, V, Schuwirth L. Perspective: redefining context in the clinical encounter: implications for research and training in medical education. Acad Med 2010 May;85:894-901.

64. Godden DR, Baddeley AD. Context-dependent memory in two natural environments: on land and underwater. British Journal of Psychology 1975;66:325-31.

65. Grierson LE. Information processing, specificity of practice, and the transfer of learning: considerations for reconsidering fidelity. Adv Health Sci Educ Theory Pract 2014 May;19:281-9. 
66. Norman G, Dore K, Grierson L. The minimal relationship between simulation fidelity and transfer of learning. Med Educ 2012 Jul;46:636-47.

67. Chen R, Grierson LE, Norman GR. Evaluating the impact of high- and low-fidelity instruction in the development of auscultation skills. Medical Education 2015 Mar;49:276-85.

68. Hamstra SJ, Brydges R, Hatala R, Zendejas B, Cook DA. Reconsidering fidelity in simulation-based training. Acad Med 2014 Mar;89:387-92.

69. Dieckmann P, Gaba D, Rall M. Deepening the theoretical foundations of patient simulation as social practice. Simul Healthc 2007;2:183-93.

70. Sydor DT, Bould MD, Naik VN, Burjorjee J, Arzola C, Hayter M, Friedman Z. Challenging authority during a life-threatening crisis: the effect of operating theatre hierarchy. Br J Anaesth 2013 Mar;110:463-71.

71. Kneebone RL, Kidd J, Nestel D, Barnet A, Lo B, King R, Yang GZ, Brown R. Blurring the boundaries: scenario-based simulation in a clinical setting. Med Educ 2005 Jun;39:580-7.

72. Teteris E, Fraser K, Wright B, McLaughlin K. Does training learners on simulators benefit real patients? Adv Health Sci Educ Theory Pract 2012 Mar;17:137-44.

73. Wilson KA, Burke CS, Priest HA, Salas E. Promoting health care safety through training high reliability teams. Qual Saf Health Care 2005 Aug;14:303-9.

74. Volpe CE, Cannon-Bowers JA, Salas E, Spector PE. The impact of cross-training on team functioning: an empirical investigation. Hum Factors 1996 Mar;38:87-100.

75. Marks MA, Sabella MJ, Burke CS, Zaccaro SJ. The impact of cross-training on team effectiveness. J Appl Psychol 2002 Feb;87:3-13.

76. Bergh AM, Allanson E, Pattinson RC. What is needed for taking emergency obstetric and neonatal programmes to scale? Best Pract Res Clin Obstet Gynaecol 2015;29:1017-27. 


\section{CHAPTER 9 \\ Discussion}




\section{Discussion}

The focus of this thesis was the choice of setting for simulation-based medical education. We included descriptive, explanatory and exploratory research questions. First we studied off site simulation (OSS) in-house conducted in hospital training rooms $[1,2]$ and then unannounced in situ simulation (ISS), i.e. simulation conducted in the patientcare units. [3]. We then compared OSS in-house with announced ISS in a randomised trial and in a qualitative study [4-7]. The thesis did not explore the outcomes of simulation conducted in a simulation centre. We will discuss the results of these studies in relation to the research questions and chapter 1 , figure $2 \mathrm{~B}$.

Research question I: Is there interaction between training design interventions (in situ and off site simulation) and healthcare professionals' reactions and work environment?

We found that the healthcare professionals' perceptions of simulation were not affected by whether the setting was OSS or announced ISS. In both settings in different simulation training programmes, we found a high level of participant satisfaction (chapters 2,6 , and 7) [1,5,6]. The unannounced ISS (chapter 4) [3] intervention, however, caused some stress and anxiety.

We investigated whether a specific obstetric event and whether different kinds of simulation modalities were considered stressful or unpleasant (chapters 2 and 4) [1,3] and whether the staff were anxious (chapter 4) [3]. Chapter 6 [5], which contains outcomes for objective and subjective measurements of stress [8-13] shows that stress was triggered to the same extent in ISS and OSS settings. However, we found that approximately one-third of the staff considered unannounced ISS (chapter 4) to be stressful and unpleasant [3]. Although poorly explored in the literature, participant responses to unannounced ISS have been described by other researchers, who also found that participants perceived unannounced ISS as intimidating [14]. Participants in our OSS inhouse and announced ISS studies (chapters 2, 6 and 7) [1,5,6] did not experience stress and anxiety to the same extent as participants in the unannounced ISS (chapter 4) [3], indicating that the unannounced ISS was potentially stressful and anxiety provoking.

According to our findings, educational planners and simulation-instructors should be aware that participants may experience simulation, especially unannounced ISS, as threatening. Consequently simulation-instructor training programmes must take into consideration the comprehensive nature of the responsibilities simulation instructors have in terms of safeguarding the participants [15].

A related issue addressed in the literature is whether inter-professional learning alone provokes anxiety as it involves a range of difficult interactions linked to authority and status among various professional groups [16]. Our studies (chapters 2, 4, 6 and 7) $[1,3,5,6]$ indicated that the multi-professional and multi-disciplinary approach was high- 
ly appreciated by participants. This is to some extent in opposition to arguments by some authors [16], who put forward that inter-professional education in itself can be anxiety provoking.

Self-perceived confidence was only explored in the first OSS intervention (chapter 2) [1]. In general, improved confidence may not necessarily be translated into greater competence, and the validity of self-assessment is disputable $[17,18]$. We found (chapter 2) [1] that participants had a tendency to underestimate their own skills, a phenomenon hypothesised to increase the risk of experiencing burnout [19]. This issue will be discussed further as burnout and high levels of sick leave are a problem among midwives. Self-assessment of professional skills seems to be of importance for the ability of healthcare professionals to continuously develop professionally, and some [20] argue that guided self-assessment should be incorporated as an essential skill in continuous professional development as it encourages reflection on practice.

To our knowledge, motivation [21-23] has not previously been examined in simulation studies and a gap arguably exists in the literature on motivational factors, hence they call for further research $[22,24,25]$. Some maintain that simulation in real clinical settings like ISS increases motivation [26], but use of the Intrinsic Motivation Inventory $[21,27]$ in our studies indicated no differences between ISS and OSS $[5,6]$.

Our studies on the influence of simulation-based medical education in obstetric emergency training on work environment (chapter 1, figure 2B) confirmed (chapter 2, 4 and 6) $[1,3,5]$ the hypothesis that simulation-based interventions can improve perceptions of personal intentions to change work behaviour and clinical management (chapter 1 , figure $2 \mathrm{~B}$ ). All of the participants in our studies reported that participating in simulation-based training had a positive influence on their work, including their level of confidence, coordination of safety and security, multi-professional efforts, the staff taking responsibility and changes in clinical management (chapter 2) [1]. Almost all staff members participating in unannounced ISS (chapter 4) [3] stated that it was important for future collaboration.

Data collected by the research group and steering committee after every training session for the different interventions (chapters 2, 4, 6 and 7) [1,3,5,6] provided information on a variety of individual incentives for organisational change. These data, however, can only be considered as a process outcome as our studies did not investigate whether clinical practice actually changed.

We found a decline in sick leave among midwives after implementing the OSS programme (chapter 2) [1]. The causality of this reduction, however, is unclear as causality cannot be assigned in observational studies as the study presented in chapter 2 [1]. One topic of discussion, work conditions in labour wards, is argued to affect the wellbeing of staff, work performance and competencies. Kristensen et al. [28] carried out a study on human public sector services in Denmark that indicated a high rate of burnout 
among midwives compared to other professionals, even comparable to that found in prison wards [28-30]. The study concluded that the lack of resources at work was a stress factor and that the emotional demands and feelings involved in midwifery significantly appear to affect the relationship between motivation and burnout [30]. Established procedures such as debriefing and collegial supervision after traumatic births were viewed as insufficient and thought to result in posttraumatic stress symptoms. A British study also discussed the risk of poor work conditions creating a stressful work environment for midwives, subsequently inferring that this put patients at greater risk [31]. Future research should therefore examine the organisation of work in more detail, as well as focus on interventions for reducing the risk of stress and burnout.

Research question II: Do training design interventions (in situ and off site simulation) affect learning and organisation?

We then investigated the influence of the simulation setting on an individual level in areas such as knowledge testing, learning intentions and safety attitudes, and on a team level in areas such as team performance and, finally, on an organisational level for the effect training may have had on clinical outcomes in management of postpartum bleeding, on participant proposals for organisational changes and on the research team's observation of needed changes (chapter 1 , figure $2 \mathrm{~B}$ ).

Knowledge was tested using a knowledge of skills test [32,33] (chapter 2) [1] and a multiple-choice question test (chapters 5 and 6) [5,7]. Overall, we found that all simulation interventions resulted in knowledge gain independent of simulation setting. No association was found between a high number of correct answers on the knowledge of skills test and many years of work experience [1]. This is in accordance with the literature [18], which concluded that an inverse relationship exists between years of work experience and the quality of care doctors provide. Based on these observations and what is known from the literature, the department management and the team responsible for simulation came to the conclusion that all healthcare professionals, independent of number of years of work experience, should be included in multi-professional obstetric skills training. Overall, we found a decline in knowledge after 9-15 months, emphasising the need for regular re-training. However, there were also areas where knowledge almost was retained throughout the observation period. Evidence confirms the common sense assumption that the greater the period of non-use, the greater the decay [34]. The single most important determinant of skill and knowledge retention is the amount of additional learning that takes place beyond that required for initial proficiency [35]. A meta-analysis concluded that skill loss was greatest on cognitive, artificial and accuracy-based tasks and lower on physical, natural and speed-based tasks [34]. Literature on retention of skills in medicine suggests that deterioration of non-used skills appears to occur around 3-18 months after training [36-41]. Acquiring the necessary resources to provide simulation-based training for all staff members that requires being released from clinical duties represents, however, a major practical and financial 
challenge. The relatively short retention time of acquired knowledge puts demands on hospital departments and healthcare management to deliver training to obstetric staff more frequently than is generally currently the case. Other options available for development are less comprehensive refresher courses, such as computer-based teaching tools and self-instruction videos, but little evidence exists on this area and some contend that the efficacy of so-called booster courses is lower than initially anticipated $[36,42]$. Carrying out more research on retention and examining the effect of short booster courses are of importance for future research.

An ongoing issue is how and how much unannounced ISS only involving a few staff members' influences other staff in the organisation. As a result we asked participants about their learning intentions, defined as whether they felt encouraged to e.g. read guidelines and study textbooks. Our unannounced ISS study (chapter 4) [3] indicated that the effect of the intervention can only partially be extrapolated to all staff members as only one-third of them felt that their learning intentions were positively affected [3] . We have been unable to find other studies focusing on learning intentions triggered by the introduction of an intervention like the unannounced ISS.

Several studies use a safety attitudes questionnaire (SAQ) as an outcome parameter when describing the effect of simulation or other interventions [43-46]. We did not find any differences in the effect from announced ISS and OSS on patient safety attitudes (chapter 6) [5]. The pre-values for the SAQ were generally high compared to other studies and a high pre-intervention level implies that neither of the interventions, conducted as ISS or OSS, was able influence the level of SAQ [43-46]. Still it is needed to be verified if a positive or high level of SAQ reflects good patient safety [47].

We found no differences between team performance $[48,49]$ in the ISS versus the OSS setting (chapter 6) [5], but we found that teams performed significantly better in the second simulation compared to the first one, which indicates that the simulations were effective.

We also looked at the effect on the organisational level. The studies involving OSS inhouse (chapter 2) [1], unannounced ISS (chapter 4) [3] and announced ISS versus OSS in-house (chapter 6 and 7) [5,6] all demonstrated a positive impact on the organisational level that involved suggested changes in guidelines, work organisation and available equipment on the labour ward and in the operating theatre, in addition to changes in the organisation in general. In both the randomised trial and the qualitative study (chapters 6 and 7) [5,6], however, ISS had a greater impact at the organisational level than OSS. This is in accordance with several non-randomised studies describing a positive impact from the ISS on the organisational level [3,50-54]. To the best of our knowledge, however, this has never before been described in a randomised design. Arguably, some of the system weaknesses identified during the unannounced ISS (chapter 4) [3] may also have been identified in announced ISS (chapters 6 and 7) [5,6], which 
we found easier to organise and implement. However, the problems with the calling systems including the telephones may not have been exposed quite as easily as was the case during the unannounced ISS. Overall, we concluded that most of the identified system weaknesses were discovered during OSS in-house and that announced ISS identified some additional weaknesses and unannounced ISS a few more. We found that five unannounced ISSs (chapter 4) [3] were sufficient to provide the organisation with valuable information on weaknesses in the system, but we assume that also fewer training sessions would have been sufficient as well.

The studies on simulation-based interventions conducted in this thesis (chapters 2-7) [1-3,5,6] took place at the Obstetric Department and parts of the studies (Chapters 5,6 and 7) [5-7] also in the Anaesthesia department in Centre for Children, Women and Reproduction at Rigshospitalet. This promoted close collaboration between the steering committee, the research group, members of the management team and a midwife working as the clinical quality coordinator. This organisational set-up was useful and deemed highly necessary for successfully conducting the studies and for implementing any proposed organisational and/or system changes. The literature confirms that there are important incentives for training in a multi-professional postgraduate context at the institutional level, thus reinforcing that our organisational approach was beneficial [14,55-59].

Another area of exploration in this thesis was the effect on patient-related results on the organisational level of simulation conducted in various settings. Based on a comparison with a historical cohort used as a control group, we concluded that managing postpartum bleeding received more focus following the OSS in-house study (chapter 2) [1]. These outcomes, however, as well as most previous studies on the effect of obstetric training, focused on easily available proxy variables, and only few studies manage to include relevant patient-based outcomes [58-61], Consequently, we decided to study red blood cell transfusions as an outcome measure for severe postpartum bleeding (chapter 3) [2]. We were, however, unable to confirm our hypothesis that multiprofessional obstetric skills training reduced the number of women who suffered from excessive bleeding and subsequently needed red blood cell transfusions. We concluded that the lack of effect on the number of transfusions may have been a result of delayed or insufficient staff involvement from anaesthesiology and operating room nurses during training sessions. As a consequence we decided to expand from multi-professional training to multi-disciplinary training, which is the approach we then applied in our subsequent studies (chapters 6 and 7) [5,6]. Whether or not the transition from multiprofessional to multi-disciplinary simulation affected the number of blood transfusions or other direct patient-related data remains to be shown in future studies. Another issue under discussion was whether the failure to reduce transfusion rates after vaginal delivery might be related to too heavily spotlighting pharmacological treatment as opposed to early surgical interventions. Another topic of discussion is whether mid- 
wives may become overconfident after obstetric skills training and therefore delay involving the doctors on call. These assumptions remain to be investigated further. Findings from a similar Norwegian study showed a significant reduction in blood transfusions after birth to be associated with mandatory simulation-based skills training and argued that this was due to a continued focus on local implementation to achieve improvements [62].

To our knowledge, our randomised trial [5] comprises the first prospectively performed studies comparing OSS in-house with ISS. A recent retrospective study compared OSS in a simulation centre with ISS and found the same outcome in video ratings of team performance in the two simulation settings, while survey-based data showed that the participants favoured the ISS [63]. The same study [63] called for prospective studies, which we carried out in the studies presented in chapters 6 and $7[5,6]$. Another randomised controlled trial compared OSS in a simulation centre with OSS in-house training $[64,65]$ and showed no additional benefit from training OSS in a simulation centre versus OSS in-house training $[64,65]$. Hence, the findings in these studies are in accordance with the findings of the studies presented in this thesis, further indicating that the simulation setting is of minor importance.

Research question III: What does the literature reveal about knowledge testing in a simulated multi-disciplinary training programme and how can a multiple choice question test be developed and validated?

A multiple choice question test [7] was used to determine the effect of various simulation modalities conducted as either OSS or ISS (chapter 6) [5].

Knowledge test development is often considered a simple task; however, designing valid and reliable tests is very time-consuming. In a clinical setting this is often underestimated and poor tests are unfortunately all too often used. We developed a multiple choice question test and presented a template (chapter 5, table 1) [7] for developing a test that others may find useful and that may enhance the overall quality of tests applied in the postgraduate clinical setting. Developing a valid and reliable multiple choice question test demonstrated that involving experts such as a test statistician and individuals with in-depth knowledge of the test content in the early phases is important [66-73].

An additional challenge in the test development process was the multidisciplinary approach taken and the need to involve representatives from the various relevant healthcare professional groups and medical specialties. This was addressed in the initial part of the test development process; which consisted of a qualitative part involving relevant healthcare professionals to ensure that the content and diction were understandable to a broad group of healthcare professionals. Since testing individual participants was not the aim of the study (chapter 6) [5], a criterion-referenced score for the test was neither discussed nor defined [74]. 
One argument for including testing in a training programme is because it enhances learning and can be a motivating factor for learning [75]. Moreover, relevant testing has been shown to lead to more knowledge gain than teaching without testing [76]. The present studies did not address these issues, which remain relevant topics for future research.

The multiple choice question test is known for its reliability and if well-constructed can test more than simple facts [67]. We chose to use a multiple choice question test because large groups of participants can be examined efficiently and the scoring is less time-consuming than other types of testing. Multiple choice question tests, however, can only be used to measure certain competencies. Miller's pyramid of assessment measures clinical competence and multiple choice question tests only gauge the two lowest competence levels, i.e. the "knows" and "knows how" aspects [77]. Some educational studies indicate, however, that performance on a written knowledge test can relate to a clinical performance-based test $[32,33,78,79]$. This may not apply to multiprofessional teams as another study did not find a relationship in the simulated setting between team performance and cumulative individual multiple-choice question test, skill or safety attitude scores [80]. The same study concluded that unidentified characteristics may play a crucial role in the efficiency of teams in managing emergencies and also highlighted the need to understand what makes a team efficient in dealing with clinical emergencies [80]. More research on the interplay between individual knowledge and performance in teams is relevant for future research.

Research question IV: What are the characteristics of simulation that healthcare professionals perceive to be influential for learning and the transfer of learned skills and knowledge to a clinical setting?

Based on the qualitative study (chapter 7) [6], we concluded that multiple psychological and sociological aspects affected the authenticity of the participants learning experience and that all of them were important for simulation-based training to be successful, but that the physical setting of the simulation (ISS or OSS) appeared to be the least important. We concluded that OSS in-house can be used provided that all other aspects of authenticity are taken into consideration and respected. The only difference was that ISS had a superior organisational impact as ISS participants provided more information about practical organisational changes than participants in the other types of simulation.

These conclusions from the qualitative study (chapter 7) [6] stand in contrast to the traditional literature on learning in context $[25,81,82]$. Learning is usually assumed to be more easily recalled when the learning environment resembles the retrieval environment [81,83-85], but this idea [85] is increasingly being questioned in the medical education literature [86-89]. The context can be defined as the physical context, which was the case in the studies described in chapters 6 and $7[5,6]$ on the physical surround- 
ings in ISS versus OSS $[81,88]$. Physical surroundings or context appear to be parallel to the aspect of fidelity described as physical $[82,87]$. One of the arguments in favour of ISS in the literature is the contextual similarity to the context of working [51,52,90,91], but findings from the studies in this thesis do not support this conclusion.

Findings from the qualitative study (chapter 7) [6] based on responses from participants in the ISS and OSS show that some important aspects of the simulations were, for example: problems with practical organisation, case scenarios, changes in hierarchies and engagement. These factors were related to interaction between participants in the simulation and not related to the physical ISS or OSS setting. This interaction between participants appeared to better represent a more complex perception of context that includes semantic and commitment elements [88,89], which can also be viewed as a part of the psychological fidelity.

Participants in the focus groups (chapter 7) [6] emphasised the importance of participating in authentic teams, i.e. in their own roles as healthcare professionals. The concept of training in other roles, i.e. cross training, is recommended in the simulation literature and considered by some as a strategy for simulation-based medical education [92-96]. This hypothesis was not confirmed in our study, indicating that the effect of cross training versus simulation in authentic teams also needs to be addressed in future studies.

The current concept of fidelity is under debate [86,87,97-99] and does not adequately explain the fidelity practiced in inter-professional simulation. The traditional simulation literature tends to overlook the importance of social practice [98], hierarchy, power relations and other factors affecting inter-professional teamwork [100]. We found the recently introduced concept of sociological fidelity, which aims to explain and enhance the quality of inter-professional simulation and to improve its transferability to interprofessional practice, to be useful $[16,100]$.

\section{Conclusions}

The overall aim of this thesis was to study how different simulation settings influenced learning in simulation-based medical education. By and large, we demonstrated the positive impact of all types of simulation, conducted as OSS in-house, unannounced ISS or announced ISS, on various aspects of individual outcomes, such as self-perceived confidence, perceptions of personal intentions to change behaviour, midwives' sick leave, knowledge, retention of knowledge and learning intentions. We found no differences in the effect of OSS versus announced ISS on motivation and patient safety attitudes. There was a mixed response to the perception of stress and anxiety that seemed to be the same in the OSS and announced ISS setting, with unannounced ISS provoking more anxiety and stress. Studies of simulated team performance revealed the same results for simulation conducted as ISS and OSS in-house. The simulations were effective since the teams performed better in the second simulation compared to the first. 
We found that OSS had an effect on some patient-related outcomes for the management of postpartum bleeding, but not on the need for subsequent blood transfusions. We identified the need for a stronger multi-disciplinary approach to simulation and we applied this approach in the subsequent studies in this thesis.

In general, we found that choice of setting does not seem to influence individual and team learning. Our findings showed that the ISS and OSS settings affect organisational learning and that the announced ISS setting provided the organisation with more suggested changes than the OSS in-house setting and that unannounced ISS added further suggestions for organisational changes to those identified in the other settings.

As a result, this thesis adds to the discussion on the weak relationship between physical fidelity and transfer of learning.

\section{Limitations and strengths}

One of the overall strengths of the studies [1-7] presented in this thesis is the variety of research methodologies used and that the findings in the studies are all comparable and complement each other, thus supporting the conclusions in this thesis as a whole.

Implementing a large-scale training programme in a postgraduate clinical setting is challenging $[101,102]$. One of the strengths of this thesis is that all of the studies successfully involved staff at all hierarchical levels, as well as received support from the management teams. This was indicated by a high satisfaction rate and high participation rates. Hence, with almost all of the eligible staff members participating, the implementation of the mandatory training programme (chapter 2) [1] was shown to be practically feasible. Almost all of the enrolled participants showed up for the trial (chapter 6) [5] and enrolment in the focus groups was also feasible. All study questionnaires achieved a high response rate. We found that achieving successful postgraduate simulation training requires incentives at the local institutional level, as is emphasised in the literature $[14,55,56,58,59]$, but also that achieving ownership and impact entails the involvement of all staff, with no exceptions. The research group, steering committees, training programme coordinators and the management team proved to be capable of collaborating on implementing this type of locally organised and embedded multiprofessional training programme.

An additional strength shared by each study in this thesis was the involvement of authentic teams that mirrored postgraduate teams in real life. According to the questionnaires and focus groups this multi-professional approach was highly appreciated.

A limitation of the observational studies (chapters 2, 3 and 4) [1-3] was the lack of randomisation and control groups. The observational study design comprised a compromise design, which is a common approach in educational research [103]. It can be argued that the changes observed may have happened regardless of the training programmes, and the changes cannot be assigned causality in observational studies. The 
departmental management team, however, thought that implementing the training programmes played a major role in the observed changes in the department. The seriousness of this limitation is reduced by the fact that the randomised trial (chapter 6) [5] supported the same conclusions. In addition to being well planned and conducted, the randomised trial was preceded by a protocol paper and adhered to all criteria for randomised controlled trials [4].

A limitation of the studies described in chapters 2 [1] and 4 [3] was the lack of validated questionnaires, which the study in chapter 6 [5] attempted to redress by using inventories validated in previous studies. We also employed a methodology study to develop a multiple choice question test (chapter 5) [7] in an effort to achieve a more valid knowledge test outcome.

In general ISS has been criticised for its lack of meaningful evaluation of programme effectiveness [51], which is a pitfall this thesis tried to avoid. Hence a strength of this thesis is that we were able to describe the effect on the individual, team and organisational level by including a broad variety of outcomes in our studies.

We used Kirkpatrick's four-level model $[104,105]$ described in the introduction in chapter 1 and in the study in chapter 2, to evaluate the programme described in chapter 2 [1]. A weakness, however, was that the evaluations carried out on level 4 on results for patients and the organisation were limited to a few outcomes. Few simulation-based studies manage to document an effect on patient-based outcomes [55,58-61]. However, Cook et al. [106] maintain that focusing too intensely on the patient level distracts researchers in their research process, focusing solely on patient outcomes rendering many studies infeasible and underpowered [106] It is also asserted that non-patient outcomes continue to hold value, particularly in theory-building research and in the evaluation of programme implementation, which was also a topic of focus in this thesis [106]. The lack of assessment of performance in clinical work was replaced by a compromise in the form of knowledge testing, which was a proxy for performance. Knowledge as an outcome measure is disputable, but various studies maintain that it is a relevant substitute $[32,33,78,79]$.

A strength of the observational study (chapter 2) [1] was that it covered long-term retention of perception and knowledge. This was a limitation in the trial presented in chapter 6 [5], where outcomes were based only on immediate measurements of knowledge and team performance. At this time, the long-term outcomes for participants in this trial remain to be studied.

The risk of type II errors was present for all of the studies in this thesis, especially for the randomised controlled trial, which, like many educational trials, was likely to have been underpowered. On the other hand, the question is whether performing a larger trial to detect a statistically significant effect is relevant or feasible, also due to the lack of a final clinically or educationally relevant effect $[107,108]$. 
Another limitation was that the studies in the chapters 1, 2, 3, 4, 6 and 7 [1-6] were carried out in a single hospital. This meant a standardisation of training and measurements and allowed local opportunities for measuring effects; however, it also raised the issues of external validity and whether the studies would be applicable to other institutions. The studies were performed in obstetric and anaesthesiology departments, and their transferability to other settings and specialities remains undetermined. Healthcare professionals who work in obstetrics and anaesthesiology are often familiar with working in a variety of places, which they see as a part of their emergency skills and which may be why they coped well with both OSS and ISS. It therefore remains uncertain whether the study findings in this thesis are transferable to healthcare professionals who do less emergency work.

\section{Implications for practice and future research}

The new findings from the studies presented in this thesis are, when looking at individual and the team learning, that OSS in-house can be used as equally well as ISS if other authenticity elements are taken into consideration and respected. Hence, we concluded that the psychological and sociological fidelity aspects of the simulation were important and that the physical fidelity of the simulation was less important. These findings need to be confirmed by research from other medical specialities and types of healthcare professionals using various types of simulation and settings. We conclude that the authenticity of teams is important and that cross training [93-95] is not an optimal solution, but additional research involving larger medical teams in more complex simulations must be conducted to explore cross training in greater depth. Announced and unannounced ISS, however, are of greater use than OSS in-house when identifying weaknesses and obtaining more information on changes needed in the organisation. Our studies show that only a few ISS are needed to achieve learning on the organisational level and to reveal areas that OSS in-house does not cover. These findings also need to be confirmed in other research. The studies presented in this thesis did not study how OSS conducted in simulation centres affects organisational learning, which remains a topic for future research. We conclude that continuously integrating simulation into the clinical work of a department is of importance to guarantee implementation in the clinical setting and to ensure that the need for change in the organisation becomes visible. Results from this thesis may be useful in the planning and decision-making process for building and rebuilding new hospitals that need to integrate facilities for simulation-based medical education.

Similar to Couto et al. [63], our finding is that ISS is popular among staff members $[5,6]$. We believe that its popularity can likely be used to help recruit new staff, especially doctors, as the literature [109] indicates that recruiting doctors to participate in interprofessional education is a challenge. Conducting research on the barriers and incentives that affect the recruitment of participants to simulation-based medical education is relevant. 
All simulation, regardless of setting, entails detailed planning, unannounced ISS in particular requiring highly multifaceted preparation $[3,63,110]$. Management teams and simulation instructors must be prepared to cancel or postpone scheduled unannounced ISS and extra staff must be available to replace staff participating in the unannounced ISS [3]. More research on how to plan and conduct unannounced ISS would therefore also be useful.

Planning simulation for inter-professional groups is challenging, which is why good management support and involvement of inter-professional working committees with representatives from all healthcare groups is crucial. Training simulation instructors must focus specifically on inter-professional interactions and differences due to the range of difficult interactions linked to authority and status between the professional groups involved [16]. In future research the interplay of factors involved in how secure simulation-participants feel in the simulation environment still remains to be explored and must be addressed in simulation-instructor training programmes [15]. More research also needs to be conducted on how to best educate simulation instructors.

Local ISS and OSS in-house training function well for postgraduate inter-professional training. Running courses locally offers advantages such as reduced costs and, logistically, easy accessibility for staff [56-59]. In addition, ISS and OSS in-house provide local organisational learning. Some of the possible disadvantages of local courses, on the other hand, are organisational problems, logistics and content of low quality due to badly organised simulations and a lack of qualified simulation instructors. These disadvantages need be addressed by having instructors attend education courses and by encouraging knowledge sharing with other institutions at a regional, national and international level. A research approach to simulation-based activities can promote these activities.

In all organisations there is a need to ensure that continuous simulation-based training is implemented as an integral part of departments to ensure that the skills and knowledge of staff remain up to date [102]. For department-based training programmes like the ones presented in the studies in this thesis, it is crucial to have an updated staff database. Departments need to offer simulation-based education on a regular basis while also taking into consideration that releasing staff from clinical duties puts demands on the entire department. Hence, more research on implementation strategies is warranted $[58,101,102]$.

Though simulation interventions are costly, simulation-based medical education is expected to expand substantially in the coming years. Locally based simulation courses may have advantages and future research can focus on implementation and on the interplay between local organisers and organisers such as simulation centres. Simpler simulation-based activities can also be necessary and helpful. The literature is scant regarding comparison of different kinds of educational interventions in the postgradu- 
ate setting. There is only little knowledge on whether other types of educational interventions in the postgraduate setting demonstrate the same effectiveness as simulationbased medical education. Doing more research comparing various kinds of educational interventions, also less costly ones, is relevant and can involve, for example a comparison of the learning effect of simulation-based medical education with case-based learning [111].

The studies in this thesis provided some information on the relationship between stress and learning and concluded that the unannounced ISS seemed to provoke more stress and anxiety. In future research it can be helpful to investigate how to train healthcare professionals to respond more favourably and resiliently to stressful events and hence depathologize stress reactions [112,113].

An area that deserves more attention with regard to simulation is the patient perspective and the active involvement of patients and relatives. Actively including the perspective of patients and relatives in the staff's management, communication and cooperation concerning simulation events is one way to address this overlooked area. Further education of patients and relatives to more actively take care of their own diseases and home treatment will enter the agenda and applying simulation in this regard may be a relevant and useful strategy.

A major focus in simulation-based medical education is evaluating whether simulation interventions document translational outcomes in terms of improved patient care practices [25]. This is difficult in obstetrics as a high number of deliveries are required to measure patient-relevant outcomes [114]. Data from the medical birth registries and other relevant databases can be used to obtain information on which skills need to be trained and, if possible, to gauge the effect of training. Collaboration between departments and hospitals to achieve a critical mass of participants is also of importance for future research. Recently introduced studies aiming to integrate the patients' perspective in assessment of quality of care during pregnancy and delivery looks promising and should be in focus in future research $[61,115]$.

In conclusion, adding to the current literature on the minimal relationship between physical fidelity and transfer of learning, the findings presented in this thesis show that the physical fidelity of the simulation setting appears to be of minor significance $[86,87,99]$. This thesis also contributes new insight into the effect of various simulation settings, providing information relevant for advancing research in medical simulation. More research is necessary, however, to better understand other aspects of simulationbased medical training important for learning and to learn more about what kind of simulation works best, for whom and why $[58,59,116]$. 


\section{References}

1. Sørensen JL, Løkkegaard E, Johansen M, Ringsted C, Kreiner S, McAleer S. The implementation and evaluation of a mandatory multi-professional obstetric skills training program. Acta Obstet Gynecol Scand 2009;88:1107-17.

2. Markova V, Sørensen JL, Holm C, Norgaard A, Langhoff-Roos J. Evaluation of multi-professional obstetric skills training for postpartum hemorrhage. Acta Obstet Gynecol Scand 2012;91:346-52.

3. Sørensen JL, Lottrup P, Vleuten van $\operatorname{der} C$, Andersen KS, Simonsen M, Emmersen P, Rosthoj S, Ottesen B. Unannounced in situ simulation of obstetric emergencies: staff perceptions and organisational impact. Postgrad Med J 2014;90:622-9.

4. Sørensen JL, Van der Vleuten C, Lindschou J, Gluud C, Ostergaard D, Leblanc V, Johansen M, Ekelund K, Albrechtsen CK, Pedersen BW, Kjaergaard H, Weikop P, Ottesen B. 'In situ simulation' versus 'off site simulation' in obstetric emergencies and their effect on knowledge, safety attitudes, team performance, stress, and motivation: study protocol for a randomized controlled trial. Trials 2013;14:220.

5. Sørensen JL, Vleuten van der C, Rosthoj S, Oestergaard D, Leblanc V, Johansen M, Ekelund K, Starkopf L, Lindschou J, Gluud C, Weikop P, Ottesen B. Simulation-based multiprofessional obstetric anaesthesia training conducted in situ versus off-site leads to similar individual and team outcomes: results from a randomised educational trial. BMJ Open 2015;5:e008344. doi:10.1136/bmjopen-2015-008344.

6. Sørensen JL, Navne LE, Martin HM, Ottesen B, Albrechtsen CK, Pedersen BW, Kjaergaard H, Vleuten van der C. Clarifying the learning experiences of healthcare professionals with in situ versus off-site simulation-based medical education: a qualitative study. BMJ Open 2015;5:e008345. doi:10.1136/bmjopen-2015-008345.

7. Sørensen JL, Thellensen L, Strandbygaard J, Svendsen KD, Christensen KB, Johansen M., LanghoffRoos P., Ekelund K, Ottesen B, Vleuten van der C. Development of a knowledge test for multidisciplinary emergency training: a review and an example. Acta Anaesthesiol Scand 2015;59:12333.

8. LeBlanc VR. The effects of acute stress on performance: implications for health professions education. Acad Med 2009;84:S25-S33.

9. LeBlanc VR, Manser T, Weinger MB, Musson D, Kutzin J, Howard SK. The study of factors affecting human and systems performance in healthcare using simulation. Simul Healthc 2011;6 Suppl:S24S29.

10. Arora S, Sevdalis N, Aggarwal R, Sirimanna P, Darzi A, Kneebone R. Stress impairs psychomotor performance in novice laparoscopic surgeons. Surg Endosc 2010;24:2588-93.

11. Harvey A, Nathens AB, Bandiera G, LeBlanc VR. Threat and challenge: cognitive appraisal and stress responses in simulated trauma resuscitations. Med Educ 2010;44:587-94.

12. Harvey A, Bandiera G, Nathens AB, LeBlanc VR. Impact of stress on resident performance in simulated trauma scenarios. J Trauma Acute Care Surg 2012;72:497-503.

13. Finan E, Bismilla Z, Whyte HE, Leblanc V, McNamara PJ. High-fidelity simulator technology may not be superior to traditional low-fidelity equipment for neonatal resuscitation training. J Perinatol 2012;32:287-92.

14. Anderson E, Black R, Brocklehurst P. Acute obstetric emergency drill in England and Wales: a survey of practice. BJOG 2005;112:372-5.

15. Dieckmann P, Molin FS, Lippert A, Ostergaard D. The art and science of debriefing in simulation: Ideal and practice. Med Teach 2009;31:e287-e294.

16. Boet S, Bould MD, Layat BC, Reeves S. Twelve tips for a successful interprofessional team-based high-fidelity simulation education session. Med Teach 2014;36:853-7.

17. Ward M, Gruppen L, Regehr G. Measuring self-assessment: current state of the art. Adv Health Sci Educ Theory Pract 2002;7:63-80.

18. Choudhry NK, Fletcher RH, Soumerai SB. Systematic review: the relationship between clinical experience and quality of health care. Ann Intern Med 2005;142:260-73.

19. Maslach C, Schaufeli WB, Leiter MP. Job burnout. Annu Rev Psychol 2001;52:397-422.

20. Duffy FD, Holmboe ES. Self-assessment in lifelong learning and improving performance in practice: physician know thyself. JAMA 2006;296:1137-9.

21. Kusurkar RA, Ten Cate TJ, van AM, Croiset G. Motivation as an independent and a dependent variable in medical education: a review of the literature. Med Teach 2011;33:e242-e262. 
22. Ten Cate TJ, Kusurkar RA, Williams GC. How self-determination theory can assist our understanding of the teaching and learning processes in medical education. AMEE guide No. 59. Med Teach 2011;33:961-73.

23. Ryan RM, Deci EL. Intrinsic and Extrinsic Motivations: Classic Definitions and New Directions. Contemp Educ Psychol 2000;25:54-67.

24. McGaghie WC, Issenberg SB, Petrusa ER, Scalese RJ. A critical review of simulation-based medical education research: 2003-2009. Med Educ 2010;44:50-63.

25. McGaghie WC, Issenberg SB, Barsuk JH, Wayne DB. A critical review of simulation-based mastery learning with translational outcomes. Med Educ 2014;48:375-85.

26. Stocker $\mathrm{M}$, Burmester $\mathrm{M}$, Allen M. Optimisation of simulated team training through the application of learning theories: a debate for a conceptual framework. BMC Med Educ 2014;14:69.

27. Self-Determination Theory (SDT) http://www.selfdeterminationtheory.org/intrinsic-motivationinventory/. 2015. Ref Type: Internet Communication

28. Kristensen TS, Borritz M, Villadsen E Christensen KB. The Copenhagen Burnout Inventory: A new tool for the assessment of burnout. Work \& Stress 2005;19:192-207.

29. Kristensen TS, Hannerz H, Hogh A, Borg V. The Copenhagen Psychosocial Questionnaire--a tool for the assessment and improvement of the psychosocial work environment. Scand J Work Environ Health 2005;31:438-49.

30. Engelbrecht S. The case of Midwifery in Denmark National Institute og Occupational Health, Copenhagen and Roskilde University, Faculty of Psychology, Philosophy and Sciences Studies; 2006.

31. Ashcroft B, Elstein M, Boreham N, Holm S. Prospective semistructured observational study to identify risk attributable to staff deployment, training, and updating opportunities for midwives. BMJ 2003;327:584.

32. Remmen R, Scherpbier A, Denekens J, Derese A, Hermann I, Hoogenboom R, van d, V, van RP, Bossaert L. Correlation of a written test of skills and a performance based test: a study in two traditional medical schools. Med Teach 2001;23:29-32.

33. Kramer AW, Jansen JJ, Zuithoff P, Dusman H, Tan LH, Grol RP, van der Vleuten C. Predictive validity of a written knowledge test of skills for an OSCE in postgraduate training for general practice. Med Educ 2002;36:812-9.

34. Arthur W, Bennett W, Stanush PL, Mc Nelly TL. Factors That Influence Skill Decay and Retention: A Quantitative Review and Analysis. Human Performance 1998;11:57-101.

35. Kneebone RL, Scott W, Darzi A, Horrocks M. Simulation and clinical practice: strengthening the relationship. Med Educ 2004;38:1095-102.

36. Hamilton R. Nurses' knowledge and skill retention following cardiopulmonary resuscitation training: a review of the literature. J Adv Nurs 2005;51:288-97.

37. Trevisanuto D, Ferrarese $P$, Cavicchioli P, Fasson A, Zanardo V, Zacchello F. Knowledge gained by pediatric residents after neonatal resuscitation program courses. Paediatr Anaesth 2005;15:944-7.

38. Vertongen VM, Ramsay MP, Herbison P. Skills retention for insertion of the Combitube and laryngeal mask airway. Emerg Med (Fremantle ) 2003;15:459-64.

39. Wik L, Myklebust H, Auestad BH, Steen PA. Retention of basic life support skills 6 months after training with an automated voice advisory manikin system without instructor involvement. Resuscitation 2002;52:273-9.

40. Woollard M, Whitfeild R, Smith A, Colquhoun M, Newcombe RG, Vetteer N, Chamberlain D. Skill acquisition and retention in automated external defibrillator (AED) use and CPR by lay responders: a prospective study. Resuscitation 2004;60:17-28.

41. Maagaard M, Sorensen JL, Oestergaard J, Dalsgaard T, Grantcharov TP, Ottesen BS, Larsen CR. Retention of laparoscopic procedural skills acquired on a virtual-reality surgical trainer. Surg Endosc 2011;25:722-7.

42. Kaczorowski J, Levitt C, Hammond M, Outerbridge E, Grad R, Rothman A, Graves L. Retention of neonatal resuscitation skills and knowledge: a randomized controlled trial. Fam Med 1998;30:70511.

43. Schwendimann R, Zimmermann N, Kung K, Ausserhofer D, Sexton B. Variation in safety culture dimensions within and between US and Swiss Hospital Units: an exploratory study. BMJ Qual Saf 2013;22:32-41. 
44. Sexton JB, Berenholtz SM, Goeschel CA, Watson SR, Holzmueller CG, Thompson DA, Hyzy RC, Marsteller JA, Schumacher K, Pronovost PJ. Assessing and improving safety climate in a large cohort of intensive care units. Crit Care Med 2011;39:934-9.

45. Shoushtarian M, Barnett M, McMahon F, Ferris J. Impact of introducing Practical Obstetric MultiProfessional Training (PROMPT) into maternity units in Victoria, Australia. BJOG 2014;121:1710-8.

46. Siassakos D, Fox R, Hunt L, Farey J, Laxton C, Winter C, Draycott T. Attitudes toward safety and teamwork in a maternity unit with embedded team training. Am J Med Qual 2011;26:132-7.

47. Kristensen S, Sabroe S, Bartels P, Mainz J, Christensen KB. Adaption and validation of the Safety Attitudes Questionnaire for the Danish hospital setting. Clin Epidemiol 2015;7:149-60.

48. Cooper S, Cant R, Porter J, Sellick K, Somers G, Kinsman L, Nestel D. Rating medical emergency teamwork performance: development of the Team Emergency Assessment Measure (TEAM). Resuscitation 2010;81:446-52.

49. McKay A, Walker ST, Brett SJ, Vincent C, Sevdalis N. Team performance in resuscitation teams: comparison and critique of two recently developed scoring tools. Resuscitation 2012;83:1478-83.

50. Guise JM, Lowe NK, Deering S, Lewis PO, O'Haire C, Irwin LK, Blaser M, Wood LS, Kanki BG. Mobile in situ obstetric emergency simulation and teamwork training to improve maternal-fetal safety in hospitals. Jt Comm J Qual Patient Saf 2010;36:443-53.

51. Rosen MA, Hunt EA, Pronovost PJ, Federowicz MA, Weaver SJ. In situ simulation in continuing education for the health care professions: a systematic review. J Contin Educ Health Prof 2012;32:243-54.

52. Patterson MD, Geis GL, Lemaster T, Wears RL. Impact of multidisciplinary simulation-based training on patient safety in a paediatric emergency department. BMJ Qual Saf 2013;22:383-93.

53. Kobayashi L, Parchuri R, Gardiner FG, Paolucci GA, Tomaselli NM, Al-Rasheed RS, Bertsch KS, Devine J, Boss RM, Gibbs FJ, Goldlust E, Monti JE, O'Hearn B, Portelli DC, Siegel NA, Hemendinger $D$, Jay GD. Use of in situ simulation and human factors engineering to assess and improve emergency department clinical systems for timely telemetry-based detection of life-threatening arrhythmias. BMJ Qual Saf 2013;22:72-83.

54. Wheeler DS, Geis G, Mack EH, Lemaster T, Patterson MD. High-reliability emergency response teams in the hospital: improving quality and safety using in situ simulation training. BMJ Qual Saf 2013;22:507-14.

55. Draycott T, Sibanda T, Owen L, Akande V, Winter C, Reading S, Whitelaw A. Does training in obstetric emergencies improve neonatal outcome? BJOG 2006;113:177-82.

56. Siassakos D, Crofts JF, Winter C, Weiner CP, Draycott TJ. The active components of effective training in obstetric emergencies. BJOG 2009;116:1028-32.

57. Cornthwaite K, Edwards S, Siassakos D. Reducing risk in maternity by optimising teamwork and leadership: an evidence-based approach to save mothers and babies. Best Pract Res Clin Obstet Gynaecol 2013;27:571-81.

58. Draycott TJ, Collins KJ, Crofts JF, Siassakos D, Winter C, Weiner CP, Donald F. Myths and realities of training in obstetric emergencies. Best Pract Res Clin Obstet Gynaecol 2015;29:1067-76.

59. Bergh AM, Baloyi S, Pattinson RC. What is the impact of multi-professional emergency obstetric and neonatal care training? Best Pract Res Clin Obstet Gynaecol 2015;29:1028-43.

60. Merien AE, Van der Ven J, Mol BW, Houterman S, Oei SG. Multidisciplinary team training in a simulation setting for acute obstetric emergencies: a systematic review. Obstet Gynecol 2010;115:1021-31.

61. Truijens SE, Banga FR, Fransen AF, Pop VJ, van Runnard Heimel PJ, Oei SG. The Effect of Multiprofessional Simulation-Based Obstetric Team Training on Patient-Reported Quality of Care: A Pilot Study. Simul Healthc 2015;10:210-6.

62. Egenberg S, Oian P, Bru LE, Sautter M, Kristoffersen G, Eggebo TM. Can inter-professional simulation training influence the frequency of blood transfusions after birth? Acta Obstet Gynecol Scand 2015;94:316-23.

63. Couto TB, Kerrey BT, Taylor RG, FitzGerald M, Geis GL. Teamwork Skills in Actual, In Situ, and InCenter Pediatric Emergencies: Performance Levels Across Settings and Perceptions of Comparative Educational Impact. Simul Healthc 2015;10:76-84.

64. Crofts JF, Ellis D, Draycott TJ, Winter C, Hunt LP, Akande VA. Change in knowledge of midwives and obstetricians following obstetric emergency training: a randomised controlled trial of local hospital, simulation centre and teamwork training. BJOG 2007;114:1534-41. 
65. Ellis D, Crofts JF, Hunt LP, Read M, Fox R, James M. Hospital, simulation center, and teamwork training for eclampsia management: a randomized controlled trial. Obstet Gynecol 2008;111:72331.

66. Downing SM. Written tests. Constructed-Response and Selected-Response Formats. In: Downing SM, Yudkowsky R, editors. Assessment in Health Professions Education. First ed. New York, Oxon: Routhledge; 2009. p. 149-84.

67. Schuwirth LW, van der Vleuten C. ABC of learning and teaching in medicine: Written assessment. BMJ 2003;326:643-5.

68. Schuwirth LW, van der Vleuten C. Different written assessment methods: what can be said about their strengths and weaknesses? Med Educ 2004;38:974-9.

69. Schuwirth LW, van der Vleuten C. Written assessments. In: Dent JA, Harden RM., editors. A Practical Guide for Medical Teachers.Edinburgh, London, New York, Oxford, Philadelphia, St Louis, Sydney, Toronto: Churchill Livingstone Elsevier; 2009. p. 325-32.

70. Case SM, Swanson DB. Constructing Written Test Questions For the Basic and Clinical Sciences. 3rd edition ed. National Board of Medical Examiners; 2002.

71. Downing SM. Twelve Steps for Effective Test Development. In: Downing SM, Haladyna TM, editors. Handbook of Test Development.Mahwah, New Jersey: Lawrence Erlbaum Associates, Inc.Publishers; 2011. p. 3-25.

72. Naeem N, van der Vleuten C, Alfaris EA. Faculty development on item writing substantially improves item quality. Adv Health Sci Educ Theory Pract 2012;17:369-76.

73. Strandbygaard J, Maagaard M, Larsen CR, Schouenborg L, Ottosen C, Ringsted C, Grantcharov T, Ottesen B, Sorensen JL. Development and validation of a theoretical test in basic laparoscopy. Surg Endosc 2013;27:1353-9.

74. Downing SM, Tekian A, Yudkowsky R. Procedures for establishing defensible absolute passing scores on performance examinations in health professions education. Teach Learn Med 2006;18:50-7.

75. Larsen DP, Butler AC, Roediger HL, III. Test-enhanced learning in medical education. Med Educ 2008;42:959-66.

76. Kromann C, Koefoed M, Jensen M, Ringsted C. Test af viden og færdigheder $\varnothing$ ger indlæring [Test of knowledge and skills enhances learning]. Ugeskr Laeger 2012;174:716-9.

77. Miller GE. The assessment of clinical skills / competence / performance. Acad Med 1990;65:S63S67.

78. Ram P, van der Vleuten C, Rethans JJ, Schouten B, Hobma S, Grol R. Assessment in general practice: the predictive value of written-knowledge tests and a multiple-station examination for actual medical performance in daily practice. Med Educ 1999;33:197-203.

79. van der Vleuten C, Van Luyk SJ, Beckers HJ. A written test as an alternative to performance testing. Med Educ 1989;23:97-107.

80. Siassakos D, Draycott TJ, Crofts JF, Hunt LP, Winter C, Fox R. More to teamwork than knowledge, skill and attitude. BJOG 2010;117:1262-9.

81. Teunissen PW, Wilkinson TJ. Learning and teaching in workplaces. In: Dornan T, Mann K, Scherpbier A., Spencer J, editors. Medical Education: Theory and Practice.Edinburgh, London, New York, Oxford, Philadelphia, St Louis, Sydney, Toronto: Churchill Livingstone Elsevier; 2011. p. 193209.

82. Beaubien JM, Baker DP. The use of simulation for training teamwork skills in health care: how low can you go? Qual Saf Health Care 2004;13 Suppl 1:i51-i56.

83. Durning SJ, Artino AR. Situativity theory: a perspective on how participants and the environment can interact: AMEE Guide no. 52. Med Teach 2011;33:188-99.

84. Durning SJ, Artino AR, Jr., Pangaro LN, van d, V, Schuwirth L. Perspective: redefining context in the clinical encounter: implications for research and training in medical education. Acad Med 2010;85:894-901.

85. Godden DR, Baddeley AD. Context-dependent memory in two natural environments: on land and underwater. British Journal of Psychology 1975;66:325-31.

86. Grierson LE. Information processing, specificity of practice, and the transfer of learning: considerations for reconsidering fidelity. Adv Health Sci Educ Theory Pract 2014;19:281-9.

87. Norman G, Dore K, Grierson L. The minimal relationship between simulation fidelity and transfer of learning. Med Educ 2012;46:636-47. 
88. Koens F, Mann KV, Custers EJ, Ten Cate OT. Analysing the concept of context in medical education. Med Educ 2005;39:1243-9.

89. Koens F, Ten Cate OT, Custers EJ. Context-dependent memory in a meaningful environment for medical education: in the classroom and at the bedside. Adv Health Sci Educ Theory Pract 2003;8:155-65.

90. Walker ST, Sevdalis N, McKay A, Lambden S, Gautama S, Aggarwal R, Vincent C. Unannounced in situ simulations: integrating training and clinical practice. BMJ Qual Saf 2013;22:453-8.

91. Raemer DB. Ignaz semmelweis redux? Simul Healthc 2014;9:153-5.

92. Motola I, Devine LA, Chung HS, Sullivan JE, Issenberg SB. Simulation in healthcare education: a best evidence practical guide. AMEE Guide No. 82. Med Teach 2013;35:e1511-e1530.

93. Wilson KA, Burke CS, Priest HA, Salas E. Promoting health care safety through training high reliability teams. Qual Saf Health Care 2005;14:303-9.

94. Volpe CE, Cannon-Bowers JA, Salas E, Spector PE. The impact of cross-training on team functioning: an empirical investigation. Hum Factors 1996;38:87-100.

95. Marks MA, Sabella MJ, Burke CS, Zaccaro SJ. The impact of cross-training on team effectiveness. J Appl Psychol 2002;87:3-13.

96. Gorman JC, Cooke NJ, Amazeen PG. Training adaptive teams. Hum Factors 2010;52:295-307.

97. Hamstra SJ, Brydges R, Hatala R, Zendejas B, Cook DA. Reconsidering fidelity in simulation-based training. Acad Med 2014;89:387-92.

98. Dieckmann P, Gaba D, Rall M. Deepening the theoretical foundations of patient simulation as social practice. Simul Healthc 2007;2:183-93.

99. Chen R, Grierson LE, Norman GR. Evaluating the impact of high- and low-fidelity instruction in the development of auscultation skills. Medical Education 2015;49:276-85.

100. Sharma S, Boet S, Kitto S, Reeves S. Interprofessional simulated learning: the need for 'sociological fidelity'. J Interprof Care 2011;25:81-3.

101. Campbell M, Fitzpatrick R, Haines A, Kinmonth AL, Sandercock P, Spiegelhalter D, Tyrer P. Framework for design and evaluation of complex interventions to improve health. BMJ 2000;321:694-6.

102. AM, Allanson E, Pattinson RC. What is needed for taking emergency obstetric and neonatal programmes to scale? Best Pract Res Clin Obstet Gynaecol 2015 ;29:1017-27.

103. Cohen L, Manion I, Morrison K. Research Methods in Education. London and New York: Routhledgefalmer; 2003.

104. Kirkpatrick DL, Kirkpatrick JD. Evaluating Training Programs: The Four Levels. 3rd ed. San Francisco, CA: Berrett-Koehler Publishers; 2006.

105. Morrison J. ABC of learning and teaching in medicine: Evaluation. BMJ 2003;326:385-7.

106. Cook DA, West CP. Perspective: Reconsidering the focus on "outcomes research" in medical education: a cautionary note. Acad Med 2013;88:162-7.

107. Jakobsen JC, Gluud C, Winkel P, Lange T, Wetterslev J. The thresholds for statistical and clinical significance - a five-step procedure for evaluation of intervention effects in randomised clinical trials. BMC Med Res Methodol 2014;14:34.

108. Cook DA, Bordage G, Schmidt HG. Description, justification and clarification: a framework for classifying the purposes of research in medical education. Med Educ 2008;42:128-33.

109. Bristowe K, Siassakos D, Hambly H, Angouri J, Yelland A, Draycott TJ, Fox R. Teamwork for clinical emergencies: interprofessional focus group analysis and triangulation with simulation. Qual Health Res 2012;22:1383-94.

110. Patterson MD, Geis GL, Falcone RA, Lemaster T, Wears RL. In situ simulation: detection of safety threats and teamwork training in a high risk emergency department. BMJ Qual Saf 2013;22:46877.

111. Thistlethwaite JE, Davies D, Ekeocha S, Kidd JM, MacDougall C, Matthews P, Purkis J, Clay D. The effectiveness of case-based learning in health professional education. A BEME systematic review: BEME Guide No. 23. Med Teach 2012;34:e421-e444.

112. Regehr C, Glancy D, Pitts A, LeBlanc VR. Interventions to reduce the consequences of stress in physicians: a review and meta-analysis. J Nerv Ment Dis 2014;202:353-9.

113. McNaughton N, Leblanc V. The Central Role of Emotional Competence in Medical Training. In: Hodges B, Lingard L, editors. The Question of Competence. Reconsidering Medical Education in the 
Twenty-First Century. First ed. New York: ILR Press an imprent of Cornell University Press; 2012. p. 70-96.

114. Mongelli M, Chung TK, Chang AM. Obstetric intervention and benefit in conditions of very low prevalence. Br J Obstet Gynaecol 1997;104:771-4.

115. Truijens SE, Pommer AM, van Runnard Heimel PJ, Verhoeven CJ, Oei SG, Pop VJ. Development of the Pregnancy and Childbirth Questionnaire (PCQ): evaluating quality of care as perceived by women who recently gave birth. Eur J Obstet Gynecol Reprod Biol 2014;174:35-40.

116. Truijens SE, Wijnen HA, Pommer AM, Oei SG, Pop VJ. Development of the Childbirth Perception Scale (CPS): perception of delivery and the first postpartum week. Arch Womens Ment Health 2014;17:411-21.

117. Cook DA, Hamstra SJ, Brydges R, Zendejas B, Szostek JH, Wang AT, Erwin PJ, Hatala R. Comparative effectiveness of instructional design features in simulation-based education: systematic review and meta-analysis. Med Teach 2013;35:e867-e898. 


\title{
CHAPTER 10
}

\author{
Summary in English \\ Samenvatting (summary in Dutch) \\ Dansk resume (summary in Danish) \\ Acknowledgement \\ Valorisation \\ Curriculum vitae \\ SHE dissertations series
}




\section{Summary}

Chapter 1 contains the introduction of the thesis. The thesis presents research on the design and conduction of simulation-based medical education, focusing on the choice of simulation setting. Simulation-based medical education is a complex intervention and gaps exist in, for example, how various simulation settings and contexts impact learning. The studies in this thesis focused on three different simulation settings: 1) Off site simulation (OSS) conducted in-house, which means simulation in training rooms in hospitals away from the patient care unit; 2) announced in situ simulation (ISS), which means simulation-based medical education in the actual patient care unit; and 3) unannounced ISS, also called drills. In the literature ISS is believed to increase fidelity, the assumption being that ISS, compared to OSS, is more realistic and more effective because it is conducted in a real context and thus considered to have a positive impact on learning. Consequently, ISS is hypothesised to be more effective for learning.

We applied Baldwin and Ford's transfer model to operationalise variables such as the training input (trainee characteristics, training design and work environment), training outputs and conditions of transfer. The training design was the independent variable and we aimed to study how variations in the training design, i.e. setting as OSS inhouse, announced ISS or unannounced ISS, affected other aspects of the transfer model, e.g. trainee characteristics, work environment, training outputs and conditions of transfer.

We focused the simulation-based medical education on obstetric emergencies, their rarity making them difficult to learn about in real-life clinical practice. Descriptive, exploratory and explanatory, the studies in the thesis addressed the following research questions: I) Is there interaction between training design interventions (ISS and OSS) and healthcare professionals' reactions and work environment?; II) Do training design interventions (ISS and OSS) affect learning and organisation?; III) What does the literature reveal about knowledge testing in a simulated multi-disciplinary training programme and how can a multiple choice test be developed and validated?; and IV) What are the characteristics of simulation that healthcare professionals perceive to be influential for learning and the transfer of learned skills and knowledge to a clinical setting?

Chapter 2 presents the first study, "The implementation and evaluation of a mandatory multi-professional obstetric skills training programme", which was an observational study with an OSS setting that addressed research questions I and II. The study implemented and evaluated a simulation-based, multi-professional mandatory programme for obstetric teams consisting of midwives, obstetric nurses, auxiliary nurses, obstetric trainees and specialist doctors. Outcome variables were on trainee characteristics, i.e. the characteristics of healthcare professionals as perceptions of simulation, selfperceived confidence and stress. Outcome variables on work environment were conceptualised in perceptions of personal intentions to change behaviour in work and 
clinical management and the frequency of sick leave among midwives. Learning and retention were measured with a knowledge test. On the level of generalisation and maintenance, we integrated data on changes in work routines and data from the Danish Medical Birth Registry for information on the diagnosis and management of postpartum bleeding. We found that the mandatory simulation-based training programme in a large obstetric department demonstrated a positive impact on the participants' satisfaction, gain in learning, and changes in work routines. Organisationally, the impact involved changes in guidelines and equipment on the labour ward and reduced sick leave among midwives, the data also indicating a greater subsequent focus on the identification and management of postpartum bleeding. Implementing a large-scale multiprofessional training programme for all staff in a clinical setting was complex, support from the management team considered a prerequisite for success.

Chapter $\mathbf{3}$ describes the second study, "Evaluation of multi-professional obstetric skills training for postpartum haemorrhage", which involved an evaluation of patient-related outcomes. Data from databases were obtained through linkage of the Danish Medical Birth Registry and the local transfusion database, in addition to a subsequent audit of medical records. This study addressed research question II, providing information on generalisation and maintenance in the transfer model. This study aimed to evaluate the effect of the programme described in chapter 2 on the incidence of postpartum bleeding, indicated by red blood cell transfusion and time delay in surgical interventions before, during and after implementation of the training programme described in the second chapter. We concluded there was no effect of multi-professional obstetric skills training on the rate of red blood cell transfusion on postpartum bleeding. We also found an unchanged delay in surgical interventions, which we concluded indicated the need for a stronger multi-disciplinary approach to simulation in collaboration with staff from anaesthesiology and the operation theatre. As a result, the studies in chapters 6 and 7 involve this approach.

Chapter 4 presents the third study, "Unannounced in situ simulation of obstetric emergencies: Staff perceptions and organisational Impact", which was also an observational study but focused on the unannounced ISS setting and mainly addressed research question I. Some data from the chapter 2 study, collected prior to implementation of the unannounced ISS, were also used in this study by compiling them with data from the perceptions of healthcare professionals after implementation of unannounced ISS. We investigated both healthcare professionals actively involved in the unannounced ISS and other healthcare professionals in the organisation (controls). This study was designed to provide information on the effect of unannounced ISS on trainee characteristics, including subjective stress, anxiety, learning and retention. This study also collected information on the effect of unannounced ISS on training output such as learning intentions and transfer intentions triggered by implementation of unannounced ISS. We found that more staff had a positive perception of unannounced ISS after imple- 
mentation, though one-third thought ISS was stressful and unpleasant, especially midwives. Implementing ISS provided information concerning changes that had an organisational impact, as was indicated by the debriefing sessions.

Chapter 5 presents the fourth study, "Development of knowledge tests for multidisciplinary emergency training: A review and an example". We identified a need for developing a knowledge test for future use in training programmes involving simulation-based medical education, as evidenced by the use of a non-validated knowledge test in the chapter 2 study and the sparse amount of guidance available on how to develop written tests for a post-graduate multi-disciplinary setting. This study addressed research question III and introduced a template for developing a knowledge test, in addition to providing a detailed description of the process for developing and evaluating this knowledge test for use in a multi-disciplinary training programme in obstetric-anaesthesia emergencies. We found that the content and construct validity and reliability were acceptable; hence, our multiple-choice test template and how it was developed could be useful to others when developing knowledge tests and may enhance the overall quality of test development. This study was a prerequisite for the primary outcome (knowledge) of the study presented in chapter 6.

Chapter 6 presents a two-part study. Part 1 comprises a protocol article describing the study design in detail, while part 2, "Simulation-based multi-professional obstetric anaesthesia training conducted in situ versus off site leads to similar individual and team outcomes: A randomised educational trial", describes the original research. Using an explanatory approach, we addressed research questions I and II for a second time and a randomised trial was used to compare the training design for OSS and announced ISS. Based on chapter 3 study, we decided to involve not only the obstetric team but also the anaesthesia operation team. The intervention comprised two multi-disciplinary simulations conducted in authentic teams in either the ISS or the OSS setting. Outcome variables for trainee characteristics were perceptions of the simulation, salivary cortisol, stress and motivation, the last two variables measured using previously validated scales. For learning on the individual level we used a knowledge test (described in chapter 5) and a previously validated safety attitude scale, while video was used to assess team performance. On the organisational level we collected input from participants on suggested organisational changes. Although perception of participants on the authenticity of ISS versus OSS differed significantly, there were no differences in any other outcomes on the individual and team levels. On the organisational level the ISS group generated additional suggestions for organisational changes.

Chapter 7 describes "Clarifying the learning experiences of healthcare professionals with in situ and off site simulation-based medical education: A qualitative study", which explored how ISS and OSS settings in simulation-based medical education affect the perceptions and learning experiences of healthcare professionals and addressed research question IV. We aimed to shed light on the general assumption that context and 
fidelity are determinants for how different kinds of simulation-based medical education are experienced. We recruited healthcare professionals who had participated in the randomised trial (chapter 6 ) and used a qualitative design comprising focus groups. We applied conventional content analysis to the data and found that initially participants preferred ISS, but this attitude changed after the training, at which point the simulation site was viewed to be of less importance. The data indicate a strong preference for simulation in authentic roles and several positive and negative factors about simulation were identified, but all perceptions were independent of the ISS or OSS setting. ISS and OSS participants generated a better understanding of and collaboration with the various health professionals and also provided individual and team reflections on learning. ISS participants described more experiences that would involve organisational changes compared to OSS participants. Overall we concluded that many psychological and sociological aspects related to the authenticity of the learning experience were important in simulation but that the simulation's physical setting was the least important.

Chapter 8 contains a review, "Twelve tips for designing simulation-based medical education and choosing the simulation setting", which focused on translating conclusions from previous chapters and compiling them with the literature to discuss the advantages and disadvantages of the different simulation settings. The importance of setting, context and fidelity are discussed, leading to the conclusion that the fidelity of the physical simulation setting appears to be of minor importance. The twelve tips article adds to the current discussion on fidelity by qualifying and exploring the somewhat weak relationship between physical fidelity and the transfer of learning.

Finally, chapter 9 concludes the thesis with a presentation and discussion of its strengths, limitations and implications for practice and future research. In general, we found that choice of setting does not seem to influence individual and team learning. Participants' perception of the authenticity of ISS versus OSS differed significantly, but there were no differences in any other outcomes on the individual and the team levels in the randomised trial. On the organisational level we concluded that the announced ISS setting provided the organisation with more suggested changes than the OSS inhouse setting and that unannounced ISS added further suggestions for organisational changes to those identified in the other settings. There was a mixed response from staff as to how stress and anxiety were perceived that seemed to be the same for the OSS and announced ISS setting, though unannounced ISS appeared to provoke more anxiety and stress.

Some of the overall strengths of the studies presented in this thesis were the variety of research methodologies used and that the findings in the studies were all comparable and complementary, thus supporting the conclusions of this thesis as a whole. A specific strength of the studies was the involvement of authentic multi-disciplinary teams mirroring real-life teams, an aspect participants highly appreciated. A limitation of the studies was that they were all carried out in a single hospital in obstetric and anaesthe- 
siology departments, thus raising issues concerning external validity and whether the studies would be applicable in other organisations It remains uncertain whether the study findings in this thesis are transferable to healthcare professionals who do less emergency work. Another limitation was that outcome measurements only involved clinical outcomes to a limited extent.

The implications for practice and future research are discussed, the new findings from the studies indicating that OSS in-house can be used as equally well as ISS if other authenticity elements are taken into consideration and respected. Hence, based on the present studies, we concluded that the psychological and sociological fidelity aspects of the simulation were important and that the physical fidelity of the simulation was the least important. The semantic and commitment context were also of importance, but the physical context was of less importance.

Based on conclusions from the studies in this thesis and a review of the literature we discuss planning and conducting simulation-based medical education in obstetrics. In order to guarantee a staff with up-to-date skills and knowledge, hospital departments must ensure continuous implementation of simulation-based training. Running courses locally offers advantages such as reduced costs and easy accessibility for staff. In addition, ISS and OSS in-house provide important local organisational learning. Some of the potential disadvantages of local courses involve organisational problems and low quality content due to badly organised simulations and a lack of qualified simulation instructors. These issues need to be carefully addressed when planning and conducting simulations. Good management support, the involvement of inter-professional working committees with representatives from all healthcare groups and trained simulation instructors made the training programmes presented in this thesis feasible and successful. We focused in the studies in this theses on integrating teamwork training with simulation-based skills training to encompass a clinical approach.

This thesis contributes new insight into the effect of various simulation settings, providing information relevant for advancing research in medical simulation. More research is necessary, however, to better understand what additional aspects of simulation-based medical training are important for learning and to learn more about what kind of simulation works best, for whom and why. 
Samenvatting (summary in Dutch) 


\section{Samenvatting (summary in Dutch)}

Hoofdstuk 1 bevat de introductie van het proefschrift. Het proefschrift presenteert onderzoek naar het ontwerp en de uitvoering van medisch simulatieonderwijs, en richt zich meer specifiek op de keuze van de opzet ervan. Simulatieonderwijs is een complexe interventie en er bestaan hiaten onder andere in onze kennis van de invloed die verschillende simulatieopzetten en -contexten hebben op het leren. De studies in dit proefschrift richtten zich op drie verschillende simulatieopzetten, namelijk: 1) externe simulatie die plaatsvindt in trainingsruimten in ziekenhuizen weg van de patiëntenzorgafdeling (in dit proefschrift aangeduid met de afkorting "OSS", ofwel off-site simulation), 2) aangekondigde interne simulatie waarbij het medisch simulatieonderwijs zich afspeelt op de echte patiëntenzorgafdeling (in dit proefschrift aangeduid met de afkorting "ISS", ofwel in situ simulation), en 3) onaangekondigde interne simulatie, ook wel versnelde training genoemd. Volgens de literatuur verhoogt ISS de echtheid van het gesimuleerde, omdat zij in vergelijking met OSS realistischer en effectiever is, daar zij zich afspeelt in een authentieke context en zodoende het leren positief beïnvloedt. $\mathrm{Er}$ wordt dan ook verondersteld dat ISS het leren meer bevordert.

We pasten het overdrachtsmodel van Baldwin en Ford toe om variabelen zoals trainingsinput (eigenschappen van de student, onderwijsontwerp en werkomgeving), leerresultaten en overdrachtscondities te kunnen operationaliseren. Het onderwijsontwerp fungeerde daarbij als onafhankelijke variabele en ons doel was om te onderzoeken hoe de drie voornoemde variaties in het onderwijsontwerp, d.w.z. externe, aangekondigde interne en onaangekondigde interne simulatie, van invloed waren op andere aspecten van het overdrachtsmodel, bijv. eigenschappen van de student, werkomgeving, leerresultaten en overdrachtscondities.

Voor het medisch simulatieonderwijs richtten wij ons tot spoedgevallen in de verloskunde, aangezien deze door hun lage frequentie moeilijk in de echte klinische praktijk te leren waren. In de studies in dit proefschrift, die zowel beschrijvend als verkennend en verklarend van aard waren, werden de volgende onderzoeksvragen aan de orde gesteld: I) bestaat er een wisselwerking tussen de gekozen interventie (ISS en OSS) en de wijze waarop gezondheidszorgprofessionals reageren en hun werkomgeving?, II) Is de gekozen vorm (ISS of OSS) van invloed op het leren en op de organisatie?, III) Wat zegt de literatuur over het toetsen van kennis in een multidisciplinair simulatieonderwijsprogramma en hoe kan een multiplechoicetoets ontwikkeld en gevalideerd worden?, en IV) Welke simulatiekenmerken spelen volgens gezondheidszorgprofessionals een rol in het leren en in de overdracht van verworven kennis en vaardigheden naar een klinische setting?

Hoofdstuk 2 presenteert de eerste studie, getiteld “De uitvoering en evaluatie van een verplichte multiprofessionele vaardigheidstraining binnen de verloskundeopleiding"; dit is een observationele studie met een OSS-opzet waarbij onderzoeksvragen I en II aan 
de orde werden gesteld. Tijdens het onderzoek werd een verplicht multiprofessioneel simulatieprogramma voor verloskundeteams bestaande uit verloskundigen, obstetrisch verpleegkundigen, assistent verpleegkundigen, verloskundestudenten en artsen uitgevoerd en geëvalueerd. De variabelen die we maten m.b.t. de eigenschappen van de student waren respectievelijk: de visie van gezondheidszorgprofessionals ten aanzien van simulatie en de mate van stress en zelfvertrouwen die zij zelf ervoeren. De werkomgeving werd gemeten aan de hand van variabelen zoals het persoonlijk voornemen om gedrag t.a.v. werk en klinisch handelen te veranderen en het ziekteverzuim onder verloskundigen. Door middel van een kennistoets bepaalden we wat studenten hadden geleerd en wat was blijven hangen. Teneinde de mate van overdracht en behoud te kunnen bepalen, integreerden we gegevens betreffende veranderingen in de werkroutine en gegevens uit het Deense medische geboorteregister dat meer inzicht verschafte in de diagnose en behandeling van postpartumbloedingen. Onze bevinding was dat het verplichte simulatieonderwijsprogramma binnen een grote verloskundeafdeling een positieve invloed had op de tevredenheid, leerwinst en veranderingen in werkroutine van de deelnemers. Wat de organisatie betreft, bleek het programma ook te leiden tot wijzigingen in de richtlijnen en apparatuur op de verloskundeafdeling en tot verminderd ziekteverzuim onder verloskundigen; de resultaten lieten verder zien dat er na de interventie meer aandacht werd besteed aan het diagnosticeren en behandelen van postpartum bloedingen. Al met al was het op grote schaal invoeren van een multiprofessioneel onderwijsprogramma voor alle stafleden in een klinische setting een complexe aangelegenheid; om de interventie te laten slagen was de steun van het managementteam daarbij onontbeerlijk.

Hoofdstuk 3 beschrijft de tweede studie, getiteld "Evaluatie van een multiprofessionele vaardigheidstraining voor haemorrhagia post partum binnen de verloskundeopleiding", waarbij patiëntuitslagen werden geëvalueerd. Deze gegevens werden verkregen door gegevens uit het Deense medische geboorteregister en de plaatselijke bloedtransfusiedatabase aan elkaar te koppelen en door vervolgens patiëntendossiers zorgvuldig te inspecteren. In deze studie werd onderzoeksvraag II aan de orde gesteld door informatie te verschaffen over de overdracht en het behoud van kennis en vaardigheden volgens het overdrachtsmodel. Het doel van deze studie was om het effect van de in hoofdstuk 2 beschreven training op de incidentie van postpartumbloedingen te beoordelen, zoals dit bleek uit het aantal erytrocytentransfusies dat nodig was en hoe lang het duurde vooraleer men tot een chirurgische ingreep overging vóór, tijdens en na het volgen van de in hoofdstuk 2 beschreven training. We concludeerden dat de multiprofessionele vaardigheidstraining binnen de verloskundeopleiding geen effect had op het aantal erytrocytentransfusies ten behoeve van postpartumbloedingen. Verder vonden we geen verschil in de tijd die men nodig had om tot de behandeling van binnengehouden placenta's over te gaan. Hieruit maakten we op dat er behoefte is aan een effectievere multidisciplinaire simulatieaanpak waarbij ook stafleden uit de anesthesiologie- 
hoek en de operatiekamer betrokken worden. De studies in hoofdstuk 6 en 7 bouwen voort op deze bevindingen door nader in te gaan op een dergelijke aanpak.

Hoofdstuk 4 presenteert de derde studie, getiteld "Onaangekondigde interne simulatie (ISS) van noodgevallen bij verloskunde: percepties van stafleden en de invloed op de organisatie". Dit was eveneens een observationele studie die zich echter richtte op de onaangekondigde interne simulatieopzet en hoofdzakelijk onderzoeksvraag I aan de orde stelde. Voor het onderzoek maakten we gebruik van enkele gegevens die tijdens de in hoofdstuk 2 beschreven studie en vóór de uitvoering van de onaangekondigde ISS verzameld waren, alsmede van de na afloop van de onaangekondigde ISS verkregen gegevens omtrent de percepties van gezondheidszorgprofessionals. We ondervroegen zowel gezondheidszorgprofessionals die actief betrokken waren bij de onaangekondigde ISS als andere gezondheidszorgprofessionals binnen de organisatie (controlegroep). Het doel van deze studie was om meer inzicht te verschaffen in de invloed die de onaangekondigde ISS had op de eigenschappen van studenten, zoals subjectieve stress, bezorgdheid, het leren en behoud. Tijdens deze studie werd ook informatie verzameld omtrent de invloed van onaangekondigde ISS op leerresultaten, zoals het voornemen tot leren en overdracht, op gang gebracht door de invoering van onaangekondigde ISS. Onze bevinding was dat stafleden na afloop van de simulatie een positiever beeld hadden van onaangekondigde ISS, hoewel een derde, met name verloskundigen, ISS nog steeds als onaangenaam en een bron van stress ervoeren. Door deze ISS uit te voeren, kregen we ook meer inzicht in de wijzigingen die van invloed waren op de organisatie, zoals bleek uit de interviewsessies.

Hoofdstuk 5 presenteert het vierde onderzoek, getiteld "Ontwikkeling van kennistoetsen voor een multidisciplinaire training over het omgaan met spoedgevallen: een literatuuranalyse en voorbeeld". We constateerden dat er behoefte bestond aan een kennistoets voor toekomstig gebruik in onderwijsprogramma's waarin medisch simulatieonderwijs een rol speelde. Dit bleek uit het feit dat er in de in hoofdstuk 2 beschreven studie gebruik werd gemaakt van een niet-gevalideerde kennistoets en uit de geringe beschikbare ondersteuning bij het ontwikkelen van schriftelijke toetsen voor een multidisciplinaire vervolgopleidingssetting. In deze studie kwam onderzoeksvraag III aan de orde en werd een template geïntroduceerd voor het ontwikkelen van een kennistoets. Daarnaast werd uitvoerig beschreven hoe deze kennistoets voor gebruik in een multidisciplinair onderwijsprogramma over spoedgevallen binnen de verloskunde-anesthesie ontwikkeld en geëvalueerd kon worden. Onze bevinding was dat de inhouds- en constructvaliditeit en betrouwbaarheid acceptabel waren. Het template voor een multiplechoicetoets en de bijbehorende beschrijving kunnen dus nuttig zijn voor anderen die belast zijn met het ontwikkelen van kennistoetsen en kunnen de algehele kwaliteit van de toetsontwikkeling verbeteren. Deze studie was nodig om de basisresultaten (kennis) van de in hoofdstuk 6 gepresenteerde studie te kunnen verkrijgen. 
Hoofdstuk 6 presenteert een tweeledige studie. Deel 1 behelsde een gedetailleerd protocol waarin het studieontwerp uitvoerig werd beschreven, terwijl het originele onderzoek zelf uitvoerig werd beschreven in het tweede deel, getiteld "Interne versus externe multiprofessionele simulatietraining op het gebied van verloskunde en anesthesie leidt tot dezelfde resultaten voor individu en team: een gerandomiseerd onderwijskundig onderzoek". Vanuit een verklarende invalshoek werden onderzoeksvraag I en II opnieuw behandeld, terwijl de onderwijsontwerpen voor een OSS en aangekondigde ISS middels een gerandomiseerd onderzoek met elkaar werden vergeleken. Naar aanleiding van onze bevindingen uit de studie van hoofdstuk 3 besloten we niet alleen het verloskundeteam te betrekken, maar ook het team van anesthesisten uit de operatiezaal. De interventie bestond uit twee multidisciplinaire simulaties die door echte teams in ofwel de ISS-opzet ofwel de OSS-opzet werden uitgevoerd. De kenmerken van studenten werden bepaald door variabelen te meten zoals percepties van hun simulatie-ervaring, motivatie, stress en het cortisolgehalte in speeksel. Deze laatste drie variabelen werden gemeten aan de hand van eerder gevalideerde schalen. Om het leren op individueel niveau te kunnen bepalen, gebruikten we een kennistoets (beschreven in hoofdstuk 5) en een eerder gevalideerde schaal waarmee de houding t.o.v. patiëntveiligheid werd gemeten; met behulp van video-opnames werd verder het functioneren in teamverband bepaald. Op organisatieniveau verzamelden we de inbreng van de deelnemers met betrekking tot de wijzigingen die zij voorstelden om de organisatie te verbeteren. Hoewel de deelnemers aanzienlijk van mening verschilden over de echtheid van ISS ten opzichte van OSS, liet de rest van de resultaten op individueel niveau noch op teamniveau verschillen zien. Wat de organisatie betreft, deed de ISS-groep meer suggesties voor veranderingen ter verbetering van de organisatie.

Hoofdstuk 7 beschrijft de studie getiteld "De leerervaringen van gezondheidszorgprofessionals met intern en extern medisch simulatieonderwijs nader verklaard: een kwalitatief onderzoek". In deze studie werd onderzocht hoe een ISS- en OSS-opzet in het medische onderwijs de percepties en leerervaringen van gezondheidszorgprofessionals beïnvloeden en stelde onderzoeksvraag IV aan de orde. Ons doel was om licht te werpen op de algemene aanname dat context en de mate van echtheid van het gesimuleerde bepalend zijn voor de manier waarop verschillende medische simulatieonderwijsvormen ervaren worden. We selecteerden gezondheidszorgprofessionals die aan het gerandomiseerd onderzoek (hoofdstuk 6) hadden deelgenomen en kozen voor een kwalitatieve opzet met focusgroepen. We onderworpen de gegevens aan een inductieve inhoudsanalyse en constateerden dat de deelnemers aanvankelijk een voorkeur hadden voor ISS, maar deze houding veranderde na afloop van de training waarna deelnemers het minder belangrijk vonden waar de simulatie precies plaatsvond. De gegevens laten een sterke voorkeur zien voor simulatie van authentieke rollen, en ook constateerden we verschillende positieve en negatieve factoren van simulatie, maar deze hielden geen verband met de gekozen simulatieopzet (ISS of OSS). Zowel ISS- als OSS-deelnemers vertoonden een beter begrip van en een betere samenwerking met de 
verschillende gezondheidsprofessionals op de werkvloer en deelden hun persoonlijke reflecties en die van het team op het leren. In vergelijking met OSS-deelnemers beschreven ISS-deelnemers meer ervaringen die veranderingen binnen de organisatie teweeg zouden kunnen brengen. Over het geheel genomen kwamen we tot de conclusie dat vooral de psychologische en sociologische aspecten die de echtheid van de leerervaring beïnvloeden van belang zijn bij simulatie, terwijl de fysieke uitvoering van de simulatie het minst belangrijk is.

Hoofdstuk 8 bevat een literatuuranalyse, getiteld "Twaalf tips voor het ontwerpen van medisch simulatieonderwijs en het kiezen van de simulatieopzet". In dit hoofdstuk werden de voor- en nadelen van verschillende simulatieopzetten besproken aan de hand van conclusies uit eerdere hoofdstukken en aanvullingen uit de literatuur. Het belang van de opzet, context en mate van echtheid worden besproken en geconcludeerd wordt dat de mate van echtheid van de fysieke simulatieopzet niet zo relevant blijkt te zijn. Het 12 tips bevattende artikel draagt bij aan de actuele discussie over echtheid door het tamelijk zwakke verband tussen fysieke echtheid en de overdracht van het geleerde nader te specificeren en te onderzoeken.

Ten slotte sluit hoofdstuk $\mathbf{9}$ het proefschrift af met een presentatie en discussie van zijn sterke punten, beperkingen en gevolgen voor de praktijk en toekomstig onderzoek. Over het algemeen constateerden we dat de opzetkeuze geen invloed lijkt te hebben op het individuele leren, noch op het leren in teamverband. De deelnemers verschilden aanzienlijk van mening over de echtheid van ISS ten opzichte van OSS, maar de rest van de resultaten van het gerandomiseerde onderzoek lieten op individueel niveau noch op teamniveau verschillen zien. Op organisatieniveau concludeerden we dat de onaangekondigde ISS-opzet de organisatie van meer voorgestelde wijzigingen bediende dan dat de OSS-opzet dat deed en dat onaangekondigde ISS leidde tot meer suggesties ter verbetering van de organisatie dan in beide andere opzetten het geval was. De meningen van stafleden over de hoeveelheid stress en bezorgdheid die zij ervoeren waren verdeeld, maar vertoonden gelijkenis voor zowel de OSS- als aangekondigde ISS-opzet, terwijl de onaangekondigde ISS-opzet voor meer bezorgdheid en stress bleek te zorgen.

Enkele sterke punten van de studies die in dit proefschrift werden gerapporteerd waren over het algemeen de diversiteit aan gebruikte onderzoeksmethoden en het feit dat zij tot vergelijkbare, elkaar aanvullende bevindingen leidden, waarmee ze de centrale conclusies van dit proefschrift onderschraagden. Een duidelijk sterk punt bleek verder het betrekken van echte multidisciplinaire teams die de teams uit de echte praktijk nabootsten, iets dat door de deelnemers zeer gewaardeerd werd. Een beperking van de studies was het gegeven dat zij allemaal in één ziekenhuis in verloskunde- en anesthesieafdelingen werden uitgevoerd, en dit roept vragen op over de externe validiteit en of de studies ook in andere organisaties zouden gelden. Het blijft onzeker of de onderzoeksbevindingen overdraagbaar zijn naar gezondheidszorgprofessionals die minder 
met spoedgevallen te maken hebben. Een andere beperking was het feit dat de variabelen die we maten alleen in beperkte zin betrekking hadden op klinische resultaten.

De gevolgen voor de praktijk en toekomstig onderzoek worden besproken en de nieuwe bevindingen van de studies laten zien dat OSS en ISS even goed ingezet kunnen worden, zolang er rekening gehouden wordt met andere elementen die de echtheid beïnvloeden en deze ook worden gerespecteerd. Op basis van de huidige studies concludeerden we dus dat de psychologische en sociologische aspecten die de echtheid van de simulatie beïnvloeden van belang zijn, en dat de echtheid van de fysieke uitvoering van de simulatie het minst belangrijk is. Ook de semantische context en de mate van toewijding speelden geen onbeduidende rol, maar de fysieke context was minder van belang.

Op basis van de conclusies uit de in dit proefschrift beschreven studies en een literatuuranalyse wordt de planning en de uitvoering van medisch simulatieonderwijs in de verloskunde besproken. Om te kunnen garanderen dat stafleden over up-to-date vaardigheden en kennis beschikken, dienen ziekenhuisafdelingen doorlopend simulatietrainingen aan te bieden. Het ter plaatse aanbieden van cursussen brengt voordelen met zich mee in de vorm van lagere kosten en een goede toegankelijkheid voor staf. Bovendien kan de organisatie veel over zichzelf leren wanneer ISS en OSS binnen de instelling zelf wordt ingevoerd. Enkele mogelijke nadelen van het ter plaatse aanbieden van cursussen zijn organisatieproblemen en een lage inhoudelijke kwaliteit te wijten aan een slecht georganiseerde simulatie of een tekort aan geschikte simulatie-instructeurs. Deze zaken dienen zorgvuldig tijdens de planning en uitvoer van simulaties te worden aangepakt. Een goede ondersteuning vanuit het managementteam, de betrokkenheid van interprofessionele werkgroepen met vertegenwoordigers uit alle gezondheidszorggroepen en getrainde simulatie-instructeurs maakten de in dit proefschrift gepresenteerde onderwijsprogramma's tot een succes en haalbaar. Bij de studies in dit proefschrift richtten wij ons op de integratie van trainen in teamverband met simulatievaardigheidsonderwijs teneinde een klinische aanpak te bewerkstelligen.

Dit proefschrift verschaft nieuw inzicht in het effect van verschillende simulatieopzetten en levert relevante informatie voor het bevorderen van onderzoek naar medische simulatie. Er is echter meer onderzoek nodig om beter te kunnen begrijpen welke bijkomende aspecten van medisch simulatieonderwijs belangrijk zijn voor het leren en om een antwoord te vinden op de vraag welk soort simulatie het beste werkt, voor wie en waarom. 



\section{Dansk resume (summary in Danish)}




\section{Dansk resumé}

Kapitel 1 indeholder introduktionen til afhandlingen. Her gennemgås forskning indenfor design og gennemførelsen af simulationsbaseret medicinsk uddannelse med fokus på valg af lokalisation eller fysiske rammer for gennemførelsen af simulationsbaseret træning. Simulationsbaseret medicinsk uddannelse er en kompleks intervention, og en række spørgsmål omkring f.eks. effekten af simulation er fortsat uafklarede; herunder hvordan læring påvirkes af lokalisationen eller de fysiske rammer, der anvendes ved simulationen. Studierne i denne afhandling fokuserer på tre forskellige former for fysiske rammer eller lokalisation, der benyttes til simulationsbaseret træning: 1) Off site simulation (OSS), som gennemføres lokalt på et hospital, i træningslokaler, hvor der ikke foregår patientbehandling; 2) Varslet "in situ" simulation (ISS), dvs planlagt simulationsbaseret medicinsk uddannelse på selve stedet for patientbehandling (i dette tilfælde fødegangen og operationsgangen); 3) Uvarslet "in situ" simulation (ISS), der også gennemføres på selve stedet for patientbehandling, men er karakteriseret ved at være uvarslet, og også går under betegnelsen uvarslet $\varnothing v e l s e . ~ I$ litteraturen beskrives, at ISS øger autenticiteten, og det er en udbredt opfattelse, at ISS sammenlignet med OSS er mere realistisk og derfor mere effektivt i forhold til læring, fordi den gennemføres på det virkelige sted og i den rigtige kontekst. Der er således hypoteser om, at ISS er en mere effektiv læringsmetode.

Vi anvendte Baldwin og Fords klassiske transfer model til at operationalisere de forskellige variable, såsom hvilke delelementer, der har betydning for træning (dvs kendetegn ved træningsdeltagere, træningsdesign og arbejdsomgivelser), effekt af træning og betingelser for transfer, dvs. overførsel af det tillærte fra den simulationsbaserede undervisning til den kliniske virkelighed. Træningsdesignet var den uafhængige variable og formålet var at undersøge, hvordan ændringer i træningsdesign, såsom ændringer i lokalisationen eller de fysiske rammer (OSS, varslet ISS eller uvarslet ISS) påvirker de afhængige variable, dvs. andre elementer i transfer modellen, såsom kendetegn ved træningsdeltagerne, arbejdsomgivelser, effekt af træning og betingelser for transfer (se figur 1.2B i kapitel 1)

Vi fokuserede på simulationsbaseret medicinsk uddannelse i sjældne obstetriske akutte hændelser, da disse kan være vanskelige at lære og fastholde i daglig klinisk praksis. Vi anvendte både deskriptive og interventionelle samt eksplorative studier $i$ afhandlingen, som adresserede følgende forskningsspørgsmål: I) Hvorledes påvirker interventioner udført i forskellige træningsdesign (ISS og OSS) sundhedsprofessionelles reaktioner og arbejdsomgivelser?; II) Hvorledes påvirker interventioner udført i forskellige træningsdesign (ISS og OSS) læring og organisationen?; III) Hvad afdækker den eksisterende litteratur omkring test af viden i et simuleret multidisciplinært træningsprogram og hvordan udvikler og validerer man en multiple-choice test? og IV) Hvad kendetegner simulationsbaseret træning, som af sundhedsprofessionelle opfattes som vigtigt for læring og for transfer af lærte færdigheder og viden til klinisk praksis? 
I kapitel 2 præsenteres det første studie "Implementering og evaluering af et multiprofessionelt obstetrisk træningsprogram", som var et observationelt studie, gennemført i et OSS træningsdesign med formålet at besvare forskningsspørgsmålene I og II. I studiet beskrives implementering af et simulationsbaseret multiprofessionelt obligatorisk program for obstetriske multiprofessionelle teams, sammensat af jordemødre, obstetriske sygeplejersker, social- og sundhedsassistenter, obstetriske uddannelsess $\varnothing$ gende læger og speciallæger. Outcome variable var deltagernes opfattelse af simulationsinterventionen, selvvurderet fortrolighed og stress. Outcome variable omkring arbejdsforhold blev begrebsliggjort $i$ opfattelsen af personlige intentioner for at forandre adfærd $\mathrm{i}$ arbejdsrutiner og $\mathrm{i}$ den kliniske håndtering af en lignende klinisk situation og i frekvensen af sygefravær blandt jordemødre. Læring og retention af det lærte blev målt med en videnstest. Vurdering af generalisering og fastholdelse af det tillærte, blev operationaliseret ved at indhente information om forandringer i arbejdsrutiner og data fra det medicinske fødselsregister om behandling ved postpartum blødning. $\mathrm{Vi}$ fandt, at implementering af et obligatorisk simulationsbaseret træningsprogram $\mathrm{i}$ en stor obstetrisk afdeling havde positiv indflydelse på deltagernes tilfredshed med træningsprogrammet og det gav læringsudbytte og forandringer $\mathrm{i}$ arbejdsrutiner. Organisatorisk indebar implementering af det simulationsbaserede træningsprogram, at der blev gennemført ændringer i guidelines og i udstyr på fødegange og svangre- barselsafsnit som tog udgangspunkt i erfaringer herfra. Sygefravær blandt jordemødre mindskedes. Efter implementering fandt vi at kodning for postpartum blødning blev anvendt hyppigere og den primære medicinske behandling oftere blev opstartet. Implementering af et omfattende multiprofessionelt træningsprogram for alle sundhedsprofessionelle var komplekst, og støtte fra ledelsen blev vurderet som en nødvendig forudsætning for træningsprogrammets succes.

Kapitel 3 beskriver det andet studie "Evaluering af et multiprofessionelt obstetrisk træningsprogram for håndtering af postpartum blødning". Dette studie indbefattede evaluering af patient-relaterede outcomes. Data fra databaser blev indhentet ved registerkobling mellem det danske fødselsregister og den lokale transfusions database, efterfulgt af journal audit. Dette studie adresserede forskningsspørgsmål II og bidrog med information om generalisering og fastholdelse i transfer modellen. Dette studie havde til formål at evaluere effekten af træningsprogrammet, som blev beskrevet i kapitel 2. Det blev gjort ved at vurdere antallet af blodtransfusioner og tidsforsinkelse ved kirurgiske indgreb for postpartum blødning $f ø r$, under og efter implementeringen af træningsprogrammet beskrevet i kapitel 2. Vi konkluderede, at der ikke var effekt af det multiprofessionelle obstetriske træningsprogram vurderet ud fra omfanget af blodtransfusion. Vi fandt også en uændret tidsforsinkelse i kirurgiske indgreb i forbindelse med postpartum blødning. Vi konkluderede, at resultaterne indikerede et st $\varnothing$ rre behov for en multidisciplinær indsats ved postpartum blødning med involvering af medarbejdere fra anæstesiologisk og operations afdelingen. Disse faggrupper indgik i 
studierne præsenteret i kapitel 6 og 7.

Kapitel 4 præsenterer det tredje studie "Uvarslet in situ simulering af obstetriske akutte hændelser: medarbejder opfattelser og organisatorisk indflydelse", som var et observationelt studie og fokuserede på uvarslet ISS og overvejende adresserede forskningsspørgsmål I. Data fra studiet i kapitel 2, der var indsamlet forud for gennemførelsen af uvarslet ISS, blev anvendt i dette studie, idet vi samstillede disse data med nye data om sundhedsprofessionelles opfattelser af uvarslet ISS indhentet efter implementering. Vi undersøgte både data for medarbejdere der var aktivt involveret i uvarslet ISS og de øvrige medarbejdere i organisationen (kontroller). Studiet var designet til at give oplysninger om effekten af uvarslet ISS, om deltagernes opfattelser af stress, angst, og læring. Studiet indhentede også oplysninger om effekten af uvarslet ISS på træningsoutput, såsom om læringsintentioner og om den transfer, der blev udløst efter implementeringen af uvarslet ISS. Vi fandt, at flere medarbejdere havde en positiv opfattelse af uvarslet ISS efter gennemførelsen, men også at en tredjedel mente ISS var stressende og ubehagelig, især blandt jordemødre. Implementering af ISS medførte, at der blev indhentet mange informationer om behov for organisatorisk ændringer, bl.a. ved debriefing sessionerne.

Kapitel 5 præsenterer det fjerde studie "Udvikling af en videnstest til brug for tværfaglig multidisciplinær træning i akutte hændelser: et review og et eksempel". I kapitel 2 brugte vi en ikke-valideret videnstest, og vi identificerede et behov for at udvikle en videnstest, der kan bruges i fremtidige træningsprogrammer, der involverer multiprofessionel simulationsbaseret medicinsk uddannelse. Der er begrænset litteratur med anvisninger til, hvordan sådanne skriftlige tests udvikles. Dette studie adresserede forskningsspørgsmål III og præsenterede en skabelon til at udvikling af en videnstest, og gav en detaljeret beskrivelse af processen med at testudvikle og validere en videnstest, der kan bruges i et tværdisciplinært træningsprogram ved obstetrisk anæstesiologiske akutte hændelser. Vi fandt, at testen var indholdsmæssigt og diskriminativ valid og pålideligheden af testen var acceptabel. Skabelonen for multiplechoice test skabelonen kan være nyttig for andre der skal udvikle en videnstests og kan bidrage til at forbedre den generelle kvalitet af tests. Dette studie var en forudsætning for det primære outcome (viden) i studiet, der præsenteres i kapitel 6.

Kapitel 6 omfatter to studier. Del 1 omfatter en protokol artikel, der beskriver studiets design i detaljer, mens del 2 beskriver det originale studie "Simulationsbaseret multiprofessionel obstetrisk anæstesiologisk træning gennemf $\varnothing r t$ in situ versus off site medfører samme resultater på individ og team niveau: Et randomiseret fors $\varnothing g^{\prime \prime}$. Der blev brugt et eksplanatorisk design, der adresserede forskningsspørgsmål I og II - denne gang i et randomiseret design, der sammenlignede træning udført i lokalisationer som OSS og ISS. Med udgangspunkt i studiet i kapitel 3 besluttede vi, udover det obstetriske team at inddrage det anæstesiologiske og det operative team. Interventionen bestod af to tværfaglige simulationer, udført i autentiske teams enten ISS eller OSS. Outcome 
variable for at adressere deltagerkendetegn var deltagernes vurdering af simulationerne, spyt cortisol, stress og motivation, hvoraf de sidste to blev målt med tidligere validerede skalaer. Til læring på det individuelle plan, brugte vi en videnstest (beskrevet i kapitel 5), og en tidligere valideret skala for patientsikkerhed samt videooptagelser for at vurdere team-præstationer. På det organisatoriske plan indsamlede vi input fra deltagerne til foreslåede organisatoriske ændringer. Deltagere, der havde indgået i ISS, havde en signifikant højere score for hvor autentisk de opfattede simulationerne sammenholdt med deltagerne, der indgik i OSS, med der var ingen forskelle på andre outcome, hverken på det individuelle eller på team niveau. På det organisatoriske plan bidrog ISS interventionen med flere forslag til organisatoriske ændringer end OSS.

Kapitel 7 beskriver "Afklaring om sundhedsprofessionelles læring ved in situ og off-site simulationsbaseret medicinsk uddannelse: Et kvalitativt studie". I det studie unders $\varnothing$ gte vi $\mathrm{i}$ et eksplorativt design hvordan ISS og OSS ved simulationsbaseret medicinsk uddannelse påvirkede sundhedsprofessionelles opfattelser af og læringserfaringer og adresserede forskningsspørgsmål IV. Formålet var at belyse og unders $\emptyset$ ge den generelle antagelse, at kontekst og autenticitet af simulation er bestemmende for, hvordan forskellige former for simulationsbaseret medicinsk uddannelse har effekt på læring. Vi rekrutterede sundhedspersonale, der havde deltaget i det randomiserede fors $\emptyset \mathrm{g}$ (kapitel 6), og benyttede et kvalitativt design bestående af fokusgrupper. Vi anvendte konventionel indholdsanalyse til dataanalyse. Vi fandt, at deltagerne umiddelbart foretrak ISS, men denne holdning ændrede sig efter træningen, og lokalisationen for simulation (ISS eller OSS) blev anset for at være mindre betydningsfuldt. Analysen viste en stærk præference for simulering $\mathrm{i}$ autentiske roller. Flere positive og negative faktorer omkring simulation blev identificeret, og opfattelser af faktorerne var uafhængig af, om lokalisationen for simulationen var ISS eller OSS. Både ISS og OSSdeltagerne fik en bedre gensidig forståelse for hinandens roller og et bedre interprofessionelt samarbejde og havde refleksioner over individuel læring og teamlæring. Sammenlignet med OSS-deltagerne beskrev ISS deltagerne flere oplevelser af betydning for organisatoriske ændringer. Samlet konkluderede vi, at der er mange psykologiske og sociologiske aspekter i forbindelse med autenticiteten af simulation, der har betydning for læring, mens simulationens fysiske rammer var uden betydning.

Kapitel 8 indeholder en oversigtartikel, "Tolv tips om design af simulationsbaseret medicinsk uddannelse og valg af fysiske rammer til simulering". Her fokuseres på at overføre konklusioner fra alle de tidligere kapitler og sammenholde dem med litteraturen for at diskutere fordele og ulemper ved de forskellige fysiske rammer for simulation. Betydningen af de fysiske rammer, kontekst og autenticitet blev diskuteret, og vi konkluderede at autenticitet af de fysiske rammer er af mindre betydning. Denne tolv tips artikel bidrager til den aktuelle diskussion om autenticitet ved at kvalificere og yderligere uddybe de manglende sammenhænge mellem fysisk autenticitet og transfer 
af læring.

Afslutningsvis i kapitel 9 er en diskussion af afhandlingens styrker og begrænsninger og konsekvenser for praksis og fremtidig forskning. Generelt fandt vi, at valget af fysiske rammer for simulation ikke så ud til at påvirke hverken individuel eller team læring. Deltagerne ved ISS havde den opfattelse at autenticiteten af ISS var højere end OSS, men der var ingen forskel i alle øvrige outcome på individuelt og teamniveau i det randomiserede fors $\varnothing$ g. På det organisatoriske niveau konkluderede vi, at den varslede ISS bidrog til flere foreslåede ændringer end OSS, og at uvarslet ISS bidrog med lidt flere forslag til organisatoriske ændringer. Der var en blandet reaktion blandt medarbejderne omkring, hvorvidt simulationerne provokerede stress og angst. Det blev opfattet som værende den samme for OSS og varslet ISS, mens uvarslet ISS provokerede mere angst og stress.

De samlede styrker af studierne, der præsenteres $\mathrm{i}$ afhandlingen, var de mange anvendte og varierende forskningsmetoder og at resultaterne i studierne alle var sammenlignelige og supplerede hinanden, hvilket underst $\varnothing$ tter konklusionerne i afhandlingen som helhed. En styrke ved studierne var inddragelse af autentiske tværfaglige teams, der afspejler virkelige teams - et aspekt, som deltagere værdsatte.

En begrænsning af studierne var, at de alle blev udført på et enkelt hospital, hvilket rejser tvivl om den eksterne validitet, og om studiernes konklusioner er gyldige i andre organisationer. Det er således usikkert, om resultaterne i denne afhandling kan overføres til alle sundhedsprofessionelle, der fx i mindre omfang arbejder indenfor akut arbejde. En anden begrænsning er at outcome kun i begrænset omfang involverede kliniske data med patient outcome.

Konsekvenserne for praksis og fremtidig forskning diskuteres. Resultaterne af studierne indikerede, at lokal OSS på hospitalsafdelinger er ligeså effektivt som ISS, hvis der tages hensyn til $\varnothing$ vrige forhold af betydning for autenticitet af simulation. Derfor, baseret på de foreliggende studier, konkluderer vi, at den psykologiske og sociologiske autenticitet af simulation er vigtigere end de fysiske rammer og dermed den fysiske autenticitet er den mindst vigtige. Andre elementer end den fysiske kontekst er vigtigere, og kontekstbegrebet skal ses bredere, herunder inddrage den semantiske kontekst og den engagerende kontekst.

Baseret på konklusionerne fra studierne $i$ denne afhandling og en gennemgang af litteraturen, diskuterer vi hvordan planlægning og gennemførsel af simulationsbaseret medicinsk uddannelse i obstetrik kan foregå. For at sikre at alle medarbejdere har up-todate færdigheder og viden, bør hospitalsafdelinger sikre kontinuerlig implementering af simulationsbaseret træning. Gennemførsel af kurser lokalt giver fordele, såsom reducerede omkostninger og let tilgængelighed for medarbejderne. Hertil kommer, lokalt gennemført ISS og OSS giver vigtig lokal organisatorisk læring. Nogle af de potentielle ulemper ved lokale kurser er, at de kan have organisatoriske problemer og lav kvalitet i 
indhold på grund af dårligt organiserede simulation og en mangel på kvalificerede simulatorinstruktører. Disse problemstillinger skal adresseres, når der planlægges og gennemføres simulationsbaseret uddannelse. God ledelsesopbakning, og inddragelse af tværfaglige arbejdsgrupper med repræsentanter fra alle sundhedsprofessionelle faggrupper og uddannelse af simulatorinstruktører kan bidrage til at facilitere træningsprogrammers gennemførlighed og succes. Vi har i studierne i denne afhandling fokuseret på at integrere teamwork træning med simulationsbaseret færdighedstræning tæt på det kliniske arbejde, og vurderer at det har stor værdi.

Denne afhandling bidrager med ny indsigt om effekten af forskellige fysiske rammer eller lokalisationer for simulationsbaseret uddannelse, og bidrager med information, der kan danne basis for og fremme forskning i medicinsk simulation. Mere forskning er nødvendig, for bedre at kunne forstå, hvilke andre aspekter af simulationsbaseret medicinsk uddannelse, der er vigtig for læring og med henblik på at afklare, hvilken form for simulation, der virker bedst, for hvem og hvorfor. 

Acknowledgement 


\section{Acknowledgement}

Years of work in labour wards have taught me how inspiring, joyful, unpredictable, challenging, stressful and full of emotions working there can be. I am extremely grateful to and have the deepest respect for the many midwives, obstetricians, obstetric anaesthesiologists, nurses and dedicated labour ward staff who have shared their knowledge and skills with me, and also teaching me about decision-making and teamwork. Over the years I have reflected on how challenging learning conditions on labour wards are, all too often highly unsystematic and random. As a junior doctor I have often wondered how manikins and cases could be used to improve learning and better prepare labour ward staff to work under time pressure, also at night, in critical situations. As a result I chose to write my dissertation on obstetric simulation, a topic I have long been passionate about.

In the late 1990s while employed at Denmark's largest labour ward at Hvidovre Hospital, I had my first opportunity to design and implement an obstetric skills training programme under the inspiring tutelage of chief consultant of obstetrics Tom Weber. Since 2003 I have been employed at the Juliane Marie Centre for Children, Women and Reproduction (JMC), Rigshospitalet, Copenhagen. A dedicated management team and a strategy focused on integrating working with patients, education and research provided excellent conditions for conducting educational research in obstetric simulation and obstetric-anaesthesia simulation. Along the way, the management team at JMC with former director Bent Ottesen and former chief nurse Sanne Wilsdahl provided remarkable support. I would especially like to thank the former director of JMC, Professor Bent Ottesen, for his invaluable support and help in all aspects of my work, first with my master thesis in medical education and later with my dissertation at Maastricht University. I am most grateful to the Department of Obstetrics management team, Morten Hedegaard, Pernille Emmersen and former chief midwife Mette Simonsen, and to the Department of Anaesthesiology team, Steen Henneberg, Lisbeth Jørgensen and Pernille Lohse, for making the projects feasible. I also owe a debt of gratitude to the staff at these departments for patiently filling out numerous questionnaires, taking tests and participating in focus groups. Working with them has been a pleasure, the atmosphere of professionalism, dedication and good humour greatly aiding the progress of my work and my sanity.

I am also hugely indebted to my co-authors and co-workers, many of whom are mentioned in the acknowledgements of the individual papers. I would particularly like to thank midwife Pernille Langhoff-Roos for her enthusiasm and inspiration concerning the design and implementation of the simulation programme, not to mention her aid in recruiting staff for training sessions and in undertaking the practicalities involved in administering questionnaires. She worked tenaciously to implement all the suggested changes, crucially benefiting the entire organisation and making the simulation programme a success. I would also like to thank my good friend and colleague, obstetrician 
Marianne Johansen, for her persistent help and cooperation in developing the teaching materials and for her critical feedback on protocols, questionnaires, publications and also the introduction and discussion in my dissertation.

This multi-disciplinary obstetric simulation project has taught me that involving staff at all levels is vital. Experiencing the various approaches to obstetric simulation and the diverse needs of the different professional groups was highly inspiring and rewarding, especially in the working committee for the last stage of the projects, hence a deep-felt thanks to Pernille Langhoff-Roos, Marianne Johansen, Charlotte Albrectssen, Kim Ekelund, Kristine Sylvan Andersen, Berit Woetmann Pedersen, Birgitte Otzen, Pernille Schou, Vibeke Ladefoged, Marianne Flindt, Charlotte Glob and Gitte Hemme Hvolgaard for their enthusiasm and commitment.

While working at the Copenhagen Trial Unit on the initial phase of the randomised trial, Christan Gluud and Jane Lindschou generously guided me and shared their knowledge, for that I owe my greatest appreciation. I have also highly benefited from statistician Susanne Rosthøj's immense assistance and expertise with the statistical analyses, especially her persistence and patience in executing the demanding analyses in the final phase. Working with anthropologists Laura Emdal Navne and Helle Max Martin has also been a great pleasure and a privilege, opening new doors for me into the world of qualitative research.

I also shared many constructive discussions in the good company of PhD students Jeanett Strandbygaard, Line Thellesen, Flemming Bjerrum, Charlotte Holm and Martin Tolsgaard on projects, data processing and presentations. Thank you to all of you.

The studies in this dissertation would not have been possible without the international collaboration of Dundee University; Scotland where I completed my master thesis, and of Maastricht University, the Netherlands, where I participated in many inspiring and instructive courses and meetings. I have also profited immensely from courses at the Wilson Centre, University of Toronto and, especially, from my cooperation with Vicki LeBlanc. I also would sincerely like to thank Professor Tim Draycott, midwife Cathy Winter and the RiSQ group at Southmead Hospital and the University of Bristol for their inspiration and beneficial discussions. All of these institutions and people have contributed to the advancement of obstetric simulation in Copenhagen.

I would also like to extend my deepest appreciation to Charlotte Ringsted, Centre for Clinical Education, Copenhagen, for her early interest in my studies. Working with Doris $\emptyset$ stergaard, Danish Institute of Medical Simulation, on developing more complex, fullscale simulations was also exceptionally valuable, not to mention her contribution, together with Lars Konge and Peter Dieckmann, as excellent discussion partners in the final phase of my dissertation and regarding the last paper. 
Thank you very much to Nancy Aaen for her professional assistance in editing the English in various chapters of my dissertation and also to Pernille Dehn for her expert help with the layout, tables, figures and references.

I would also like to express my deepest gratitude to my two supervisors, Professor Cees van der Vleuten from Maastricht University and Professor Bent Ottesen, for their professional guidance, constructive criticism, always prompt and relevant feedback, and assistance with taming the vast amounts of data, background literature and my studies into a cohesive whole. Working with Cees van der Vleuten, who has been Honorary Professor of University of Copenhagen, has certainly been a tremendous privilege.

Finally, I owe my deepest gratitude to my family. To my brother Steffen, a photographer, who willingly helped with videos and figures at a moment's notice, and my elderly mother, who trained as a nurse 60 years ago at Rigshospitalet, for providing historical insights on healthcare education and for always believing in me and my work. Most of all, to my husband Peter and our children, Fiona and Simon. Thank you for your constant acceptance of my work and your support in helping me pursue new avenues - this time my dissertation. I couldn't have done it without your love and inspiration. 


\section{Valorisation}




\section{Valorisation}

This chapter meets the requirements of Article 23 of the Regulation Governing the Attainment of Doctoral Degrees on the inclusion of a valorisation paragraph in all PhD dissertations at Maastricht University as of 1 September 2014. Knowledge valorisation is the "process of creating value from knowledge by making knowledge suitable and/or available for social (and/or economic) use and by making knowledge suitable for translation into competitive products, services, processes and new commercial activities".

\section{Relevance and background}

The focus of this doctoral thesis, "Obstetric simulation: Designing simulation-based medical education and the role of physical fidelity", is the design of simulation and choice of setting in simulation-based medical education (SBME).

SBME [1-3] can broadly and simply be defined as: "a person, device, or set of conditions which attempts to present education and evaluation problems authentically. The student or trainee is required to respond to the problems as he or she would under natural circumstances" [1].

SBME has traditionally been conducted off site in settings or contexts such as simulation centres, but some hospitals also provide in-house training in rooms specifically allocated to training [4-6]. In this thesis off site simulation (OSS) is defined as SBME where the setting is either a simulation centre or in-house training facilities consisting of hospital rooms set up for simulation training and resembling simulation centre facilities to some extent. Introduced over the past decade, in situ simulation (ISS) is defined by Riley et al. as "a team-based simulation strategy that occurs on patient care units involving actual healthcare team members within their own working environment" [7]. Rosen et al. describe in a review ISS as a blend of simulation and real working environments providing training where people actually work [8]. ISS can be conducted as either announced or unannounced, the latter of which is also called a drill $[8,9]$. The search for literature on ISS and related terms resulted in approximately 120 hits for original research papers, but to the best of our knowledge, no randomised trials and only few comparison studies have been conducted comparing the ISS versus the OSS setting.

In the thesis we use the following four terms for simulation settings: 1) OSS in simulation centres; 2) OSS in-house in training rooms in hospitals; 3) announced ISS; and 4) unannounced ISS.

This doctoral thesis is based on original studies conducted in obstetric and anaesthesia departments focusing on obstetric emergencies, e.g. clinical management of obstetric emergency situations such as shoulder dystocia, postpartum bleeding, preeclampsia, neonatal resuscitation and emergency caesarean sections [6,10-15], but also a review (twelve tips article) with a general summation. This is relevant as labour wards are challenging workplaces where patient safety and medical litigation are high on the 
agenda [16-22]. In emergency situations, managing labouring women may require the involvement of several healthcare professional groups, including midwives, auxiliary nurses, obstetric nurses, obstetricians, anaesthesiologists, nurse anaesthetists, operating room nurses and neonatologists, and when the parturient woman is severely ill, involvement of medical and surgical specialists may be required. Hence ordinary situations like pregnancy and labour can become potentially life threatening, calling for multi-professional and multi-disciplinary clinical management. Obstetric emergencies are rare and require complex skills. However their rarity means training and learning in real-life clinical practice is difficult. Therefore there is a need for SBME in obstetric emergencies.

ISS is believed to increase fidelity (or authenticity in more layman's terms), the assumption being that ISS, compared to OSS, is more realistic and more effective because it is conducted in a real context and thus considered to have a positive impact on learning [7,8,23-26]. Consequently, ISS is argued to be more effective for learning, and this assumption is investigated and discussed in this doctoral thesis.

\section{Conclusions and implications}

The innovative value of the conclusions drawn in this doctoral thesis can be boiled down to this short, pragmatic conclusion when looking at outcome on individual and team learning: "You can simulate anywhere".

The results differ for organisational outcome and our results show that for organisational learning outcome, OSS conducted in-house provides important local organisational practical learning, but announced ISS provides more and unannounced ISS provides even more organisational learning [6,10-15]. For a schematic overview of how different simulation settings are potentially affected by various aspects of SBME, see Table 8.1.

\section{Health management, hospitals and departments planning SBME}

Based on this thesis and the current literature, our recommendation for hospitals, departments and other institutions planning SBME is that they can conduct simulation in all kinds of simulation settings and that they can decide their choice of simulation setting based on the available facilities and level of feasibility in their organisation. However, to achieve organisational learning, hospitals and department are recommended to occasionally conduct announced or unannounced ISS to identify weaknesses and to obtain more information on changes needed in the organisation. Our studies show that only a few ISS are needed to achieve learning on the organisational level and to reveal areas that OSS in-house does not expose. But we also found that unannounced ISS or drills provoked more anxiety and stress among the healthcare professionals, especially midwives, than simulation conducted as announced ISS or OSS in-house simulation does. This must therefore be taken into consideration in institutions, hospitals and departments when planning simulation. 
An implementation advantage of announced ISS is also that it was found to be more popular among staff members, especially doctors. The popularity of ISS indicates that it can therefore be used as a means to help recruit staff to participate in interprofessional simulation $[14,15,27]$.

Another important implementation point is that all planning of SBME requires very detailed planning [1-3,28-30], but based on conclusions from this thesis $[6,11,14,15]$, unannounced ISS in particular requires multifaceted planning and the need for excellent management support [11]. Even when planning is well conducted, simulation instructors must be prepared to cancel or postpone scheduled unannounced ISS in the event of heavy patient loads, shortage of staff or the unavailability of patient care rooms for conducting ISS, such as emergency rooms, delivery suites or operation theatres [11].

An additional aspect of facilitating the implementation of SBME is the importance of establishing cooperation between local educational planners and the departmental management. An additional recommendation is thus to actively involve representatives from all healthcare professional groups in planning postgraduate inter-professional simulation [6,11-15]. This can help clarify inter-professional differences, identify hidden conflicts between healthcare professionals and promote agreement concerning the aims and content of simulation events [30,31].

For hospitals and departments to meet some of the major challenges they face in guaranteeing that all staff have up-to-date skills and knowledge, and to ensure continuous implementation of simulation-based training, we recommend, based on our research, running courses locally due to advantages such as reduced costs and easy accessibility for staff $[6,11,14,15]$. Moreover ISS and OSS in-house simulation approaches also provide important local organisational learning $[6,11,14,15]$. Hospital departments must also be aware, however, of the potential disadvantages of local courses as they can involve organisational problems and low quality content due to badly organised simulations and a lack of qualified simulation instructors. Local hospital departments need to address these issues by having local simulation instructors and by participating in training in locally organised courses or in national or international courses, which was the case in our current studies $[6,11,14,15]$. If relevant, simulation centres can also provide assistance with training simulation instructors.

In the complex process of planning and implementing multi-professional SMBEs, hospital departments should apply a broad approach that includes a wide range of experts and stakeholders in the planning to ensure that the simulation programme is feasible and successful $[6,11,14,15,30,31]$. One more important implementation aspect is to focus on integrating teamwork training with simulation-based clinical skills training to continually incorporate a clinical approach $[6,11,14,15]$. Other studies also argue that practicing teamwork integrated with simulation-based skills training that encompasses 
a clinical approach is preferable and has been shown to be associated with significant improvements, whereas focusing solely on teamwork is not recommended $[21,22,32,33]$.

\section{The medical education research domain}

In the domain of medical education research this doctoral thesis is important due to its contribution to the discussion of setting, context and fidelity [34,35]. The conclusions from this thesis challenge the much-discussed topic of learning in context, as we conclude that the ISS setting did not increase fidelity and thereby learning [36-41]. We conclude that the fidelity of the physical simulation setting appears to be of minor importance. This thesis adds to the current discussion on fidelity by qualifying and exploring the somewhat weak relationship between physical fidelity and the transfer of learning. The new findings from the studies in this thesis contribute to research discussions as our conclusions indicate that OSS in-house can be used as equally as well as ISS if other authenticity elements are taken into consideration and respected. Hence, based on the present studies, we concluded that the psychological and sociological fidelity aspects of the simulation were important and that the physical fidelity of the simulation was the least important. The semantic and commitment context were also of importance compared to the physical context, which was of less importance.

\section{Implications for future research}

The overall strengths of the studies [6,10-15] presented in this doctoral thesis were the variety of research methodologies used and that the findings in the studies were all comparable and complementary, thus supporting the conclusions of this thesis as a whole. A specific strength of the studies was the involvement of authentic multidisciplinary teams mirroring real-life teams. A limitation of the studies was that they were all carried out in a single hospital, thus raising issues concerning whether the studies would be applicable in other organisations. Another limitation was that outcome measurements only involved clinical outcomes to a limited extent. As with other research, conclusions from this thesis need to be confirmed by more research from other medical specialities and among other types of healthcare professionals using various types of simulation and settings.

A major focus in SBME is evaluating whether simulation interventions can document translational outcomes in terms of improved patient care practices [42,43]. This is difficult in obstetrics as a high number of deliveries are required to measure patientrelevant outcomes [44]. In future research collaboration between departments and hospitals is recommended as a means for achieving a critical mass of participants. Data from medical birth registries and other relevant databases are a possible source for obtaining information on which skills need to be trained and, if possible, to gauge the effect of training. 
Another avenue for future research is to examine the importance of authenticity of teams versus cross training, which involves team members are trained in the duties of his or her teammates. Simulation literature supports cross training [3,45-48] , but this needs to be researched further with the involvement of larger medical teams in postgraduate and more complex simulations.

Though simulation interventions are costly, SBME is expected to expand substantially in the coming years. For postgraduate and multi-professional training we recommend locally based simulation courses due to their various advantages. A relevant focus for future research is implementation strategies [49] and the interplay between local organisers and organisers such as simulation centres.

Another relevant area for future research is to compare various kinds of educational interventions, also less costly ones. The literature is scant regarding comparison of different kinds of educational interventions in the postgraduate setting. More knowledge is warranted on whether other types of educational interventions among postgraduate multi-professional staff demonstrate the same effectiveness as SBME, for example a comparison of the learning effect of SBME with case-based learning [50].

In the future an area that deserves more research attention with regard to simulation is the patient perspective and the active involvement of patients and relatives. Actively including the perspective of patients and relatives in, for example, the staff's management, communication and cooperation on simulation are highly relevant.

\section{Conclusion}

To sum up, continuously integrating simulation into the clinical work of a department is recommended in order to guarantee implementation in the clinical setting and to ensure that the need for change in the organisation becomes visible. Results from this thesis may also be useful in the planning and decision-making process for building new hospitals and for renovating old ones in order to provide facilities for SBME in close proximity to relevant clinical departments. 


\section{References}

1. Issenberg SB, McGaghie WC, Petrusa ER, Lee GD, Scalese RJ. Features and uses of high-fidelity medical simulations that lead to effective learning: a BEME systematic review. Med Teach 2005;27:10-28.

2. McGaghie WC, Issenberg SB, Petrusa ER, Scalese RJ. A critical review of simulation-based medical education research: 2003-2009. Med Educ 2010;44:50-63.

3. Motola I, Devine LA, Chung HS, Sullivan JE, Issenberg SB. Simulation in healthcare education: a best evidence practical guide. AMEE Guide No. 82. Med Teach 2013;35:e1511-e1530.

4. Ellis D, Crofts JF, Hunt LP, Read M, Fox R, James M. Hospital, simulation center, and teamwork training for eclampsia management: a randomized controlled trial. Obstet Gynecol 2008;111:72331.

5. Crofts JF, Ellis D, Draycott TJ, Winter C, Hunt LP, Akande VA. Change in knowledge of midwives and obstetricians following obstetric emergency training: a randomised controlled trial of local hospital, simulation centre and teamwork training. BJOG 2007;114:1534-41.

6. Sørensen JL, Løkkegaard E, Johansen M, Ringsted C, Kreiner S, McAleer S. The implementation and evaluation of a mandatory multi-professional obstetric skills training program. Acta Obstet Gynecol Scand 2009;88:1107-17.

7. Riley W, Davis S, Miller KM, Hansen H, Sweet RM. Detecting breaches in defensive barriers using in situ simulation for obstetric emergencies. Qual Saf Health Care 2010;19 Suppl 3:i53-i56.

8. Rosen MA, Hunt EA, Pronovost PJ, Federowicz MA, Weaver SJ. In situ simulation in continuing education for the health care professions: a systematic review. J Contin Educ Health Prof 2012;32:243-54.

9. Anderson E, Black R, Brocklehurst P. Acute obstetric emergency drill in England and Wales: a survey of practice. BJOG 2005;112:372-5.

10. Markova V, Sørensen JL, Holm C, Norgaard A, Langhoff-Roos J. Evaluation of multi-professional obstetric skills training for postpartum hemorrhage. Acta Obstet Gynecol Scand 2012;91:346-52.

11. Sørensen JL, Lottrup P, Vleuten van $\operatorname{der} C$, Andersen KS, Simonsen M, Emmersen P, Rosthoj S, Ottesen B. Unannounced in situ simulation of obstetric emergencies: staff perceptions and organisational impact. Postgrad Med J 2014;90:622-9.

12. Sørensen JL, Van der Vleuten C, Lindschou J, Gluud C, Ostergaard D, Leblanc V, Johansen M, Ekelund K, Albrechtsen CK, Pedersen BW, Kjaergaard H, Weikop P, Ottesen B. 'In situ simulation' versus 'off site simulation' in obstetric emergencies and their effect on knowledge, safety attitudes, team performance, stress, and motivation: study protocol for a randomized controlled trial. Trials 2013;14:220.

13. Sørensen JL, Thellensen L, Strandbygaard J, Svendsen KD, Christensen KB, Johansen M., LanghoffRoos P., Ekelund K, Ottesen B, Vleuten van der C. Development of a knowledge test for multidisciplinary emergency training: a review and an example. Acta Anaesthesiol Scand 2015;59:12333.

14. Sørensen JL, Vleuten van $\operatorname{der} C$, Rosthoj S, Oestergaard D, Leblanc V, Johansen M, Ekelund K, Starkopf L, Lindschou J, Gluud C, Weikop P, Ottesen B. Simulation-based multiprofessional obstetric anaesthesia training conducted in situ versus off-site leads to similar individual and team outcomes: results from a randomised educational trial. BMJ Open 2015;5:e008344. doi:10.1136/bmjopen-2015-008344.

15. Sørensen JL, Navne LE, Martin HM, Ottesen B, Albrechtsen CK, Pedersen BW, Kjaergaard H, Vleuten van der C. Clarifying the learning experiences of healthcare professionals with in situ versus off-site simulation-based medical education: a qualitative study. BMJ Open 2015;5:e008345. doi:10.1136/bmjopen-2015-008345.

16. Drife J. Reducing risk in obstetrics. Qual Health Care 1995;4:108-14.

17. Hove LD, Bock J, Christoffersen JK, Hedegaard M. Analysis of 127 peripartum hypoxic brain injuries from closed claims registered by the Danish Patient Insurance Association. Acta Obstet Gynecol Scand 2008;87:72-5.

18. Veltman LL. Getting to havarti: moving toward patient safety in obstetrics. Obstet Gynecol 2007;110:1146-50.

19. Johannsson H, Ayida G, Sadler C. Faking it? Simulation in the training of obstetricians and gynaecologists. Curr Opin Obstet Gynecol 2005;17:557-61. 
20. Merien AE, Van der Ven J, Mol BW, Houterman S, Oei SG. Multidisciplinary team training in a simulation setting for acute obstetric emergencies: a systematic review. Obstet Gynecol 2010;115:1021-31.

21. Draycott TJ, Collins KJ, Crofts JF, Siassakos D, Winter C, Weiner CP, Donald F. Myths and realities of training in obstetric emergencies. Best Pract Res Clin Obstet Gynaecol 2015;29:1067-76.

22. Bergh AM, Baloyi S, Pattinson RC. What is the impact of multi-professional emergency obstetric and neonatal care training? Best Pract Res Clin Obstet Gynaecol 2015;29:1028-43.

23. Hamman WR, Beaudin-Seiler BM, Beaubien JM, Gullickson AM, Gross AC, Orizondo-Korotko K, Fuqua $W$, Lammers R. Using in situ simulation to identify and resolve latent environmental threats to patient safety: case study involving a labor and delivery ward. J Patient Saf 2009;5:184-7.

24. Barbeito A, Bonifacio A, Holtschneider M, Segall N, Schroeder R, Mark J. In situ simulated cardiac arrest exercises to detect system vulnerabilities. Simul Healthc 2015;10:154-62.

25. Wetzel EA, Lang TR, Pendergrass TL, Taylor RG, Geis GL. Identification of latent safety threats using high-fidelity simulation-based training with multidisciplinary neonatology teams. Jt Comm J Qual Patient Saf 2013;39:268-73.

26. Guise JM, Mladenovic J. In situ simulation: identification of systems issues. Semin Perinatol 2013;37:161-5.

27. Couto TB, Kerrey BT, Taylor RG, FitzGerald M, Geis GL. Teamwork Skills in Actual, In Situ, and InCenter Pediatric Emergencies: Performance Levels Across Settings and Perceptions of Comparative Educational Impact. Simul Healthc 2015;10:76-84.

28. Cook DA, Hatala R, Brydges R, Zendejas B, Szostek JH, Wang AT, Erwin PJ, Hamstra SJ. Technologyenhanced simulation for health professions education: a systematic review and meta-analysis. JAMA 2011;306:978-88.

29. Cook DA, Hamstra SJ, Brydges R, Zendejas B, Szostek JH, Wang AT, Erwin PJ, Hatala R. Comparative effectiveness of instructional design features in simulation-based education: systematic review and meta-analysis. Med Teach 2013;35:e867-e898.

30. Spurr J, Gatward J, Joshi N, Carley SD. Top $10(+1)$ tips to get started with in situ simulation in emergency and critical care departments. Emerg Med J 2016.

31. Boet S, Bould MD, Layat BC, Reeves S. Twelve tips for a successful interprofessional team-based high-fidelity simulation education session. Med Teach 2014;36:853-7.

32. Siassakos D, Crofts JF, Winter C, Weiner CP, Draycott TJ. The active components of effective training in obstetric emergencies. BJOG 2009;116:1028-32.

33. Cornthwaite K, Edwards S, Siassakos D. Reducing risk in maternity by optimising teamwork and leadership: an evidence-based approach to save mothers and babies. Best Pract Res Clin Obstet Gynaecol 2013;27:571-81.

34. Norman G, Dore K, Grierson L. The minimal relationship between simulation fidelity and transfer of learning. Med Educ 2012;46:636-47.

35. Grierson LE. Information processing, specificity of practice, and the transfer of learning: considerations for reconsidering fidelity. Adv Health Sci Educ Theory Pract 2014;19:281-9.

36. Koens F, Ten Cate OT, Custers EJ. Context-dependent memory in a meaningful environment for medical education: in the classroom and at the bedside. Adv Health Sci Educ Theory Pract 2003;8:155-65.

37. Koens F, Mann KV, Custers EJ, Ten Cate OT. Analysing the concept of context in medical education. Med Educ 2005;39:1243-9.

38. Teunissen PW, Wilkinson TJ. Learning and teaching in workplaces. In: Dornan T, Mann K, Scherpbier A., Spencer J, editors. Medical Education: Theory and Practice.Edinburgh, London, New York, Oxford, Philadelphia, St Louis, Sydney, Toronto: Churchill Livingstone Elsevier; 2011. p. 193209.

39. Godden DR, Baddeley AD. Context-dependent memory in two natural environments: on land and underwater. British Journal of Psychology 1975;66:325-31.

40. Durning SJ, Artino AR. Situativity theory: a perspective on how participants and the environment can interact: AMEE Guide no. 52. Med Teach 2011;33:188-99.

41. Durning SJ, Artino AR, Jr., Pangaro LN, van d, V, Schuwirth L. Perspective: redefining context in the clinical encounter: implications for research and training in medical education. Acad Med 2010;85:894-901. 
42. McGaghie WC, Issenberg SB, Barsuk JH, Wayne DB. A critical review of simulation-based mastery learning with translational outcomes. Med Educ 2014;48:375-85.

43. Cook DA, West CP. Perspective: Reconsidering the focus on "outcomes research" in medical education: a cautionary note. Acad Med 2013;88:162-7.

44. Mongelli M, Chung TK, Chang AM. Obstetric intervention and benefit in conditions of very low prevalence. Br J Obstet Gynaecol 1997;104:771-4.

45. Volpe CE, Cannon-Bowers JA, Salas E, Spector PE. The impact of cross-training on team functioning: an empirical investigation. Hum Factors 1996;38:87-100.

46. Marks MA, Sabella MJ, Burke CS, Zaccaro SJ. The impact of cross-training on team effectiveness. J Appl Psychol 2002;87:3-13.

47. Wilson KA, Burke CS, Priest HA, Salas E. Promoting health care safety through training high reliability teams. Qual Saf Health Care 2005;14:303-9.

48. Gorman JC, Cooke NJ, Amazeen PG. Training adaptive teams. Hum Factors 2010;52:295-307.

49. Bergh AM, Allanson E, Pattinson RC. What is needed for taking emergency obstetric and neonatal programmes to scale? Best Pract Res Clin Obstet Gynaecol 2015;29:1017-27.

50. Thistlethwaite JE, Davies D, Ekeocha S, Kidd JM, MacDougall C, Matthews P, Purkis J, Clay D. The effectiveness of case-based learning in health professional education. A BEME systematic review: BEME Guide No. 23. Med Teach 2012;34:e421-e444. 

Curriculum vitae 


\section{Curriculum vitae}

Jette Led Sørensen, born in Lyngby, Denmark in 1957, went to medical school in Copenhagen (1977-1984). After earning her degree she worked full-time until 2003 with clinical obstetrics and gynaecology, surgery, anaesthesia, paediatrics and neonatology at various hospitals in Denmark, as well as for a period in Greenland and in Glasgow, Scotland. In 1998 Jette completed specialist training in obstetrics and gynaecology and in 2003 became Head of Education at the Juliane Marie Centre for Children, Women and Reproduction, Rigshospitalet, where she did clinical work part time and also focused on development and research in medical education. In 2006 she obtained a master's degree in Medical Education from the Centre for Medical Education, University of Dundee, Scotland.

In early 2000 Jette became responsible for the development, writing and implementation of the first postgraduate training curriculum for a specialist training programme for doctors in obstetrics and gynaecology in Denmark. She is currently involved and responsible for specialist training in Eastern Denmark. In 2002 she was responsible for the development, writing and implementation of a curriculum for a two-year MSc for nurses, midwives and physiotherapist at the Faculty of Health and Medical Sciences, University of Copenhagen and in 2015 she became head of the study board.

In addition to having taught and planned numerous courses and workshops, Jette has experience with education for all types of professional healthcare staff. She has worked with various kinds of teaching, including lectures, small groups, problem-based learning, participatory learning, skills training, communication training, e-learning, simulation-based education, virtual reality training and knowledge testing. She has also planned and executed training the trainers courses. Jette has conducted research in multi-disciplinary simulation-based medical education and team training in obstetrics, as well as supervised research in laparoscopic virtual reality simulation in laparoscopic surery, and taken part in research in simulation-based ultrasound simulation.

Jette has received various awards for her contributions in education and medical educational research. She has approximately 60 publications in peer-reviewed journals and has edited and contributed multiple book chapters on the clinical management of obstetric emergencies.

Jette lives on a houseboat in Christianshavn in Copenhagen, is married to Peter Bauder Sørensen and they have two children, Fiona and Simon. 
SHE dissertations series 


\section{SHE dissertations series}

The SHE Dissertation Series publishes dissertations of PhD candidates from the School of Health Professions Education (SHE) who defended their PhD theses at Maastricht University. The most recent ones are listed below. For more information go to: www.maastrichtuniversity.nl/she.

Van den Eertwegh, V. (11-11-2015) Unravelling postgraduate communication learning; from transfer to transformative learning

Gingerich, A. (03-09-2015) Questioning the rater idiosyncrasy explanation for error variance, by searching for multiple signals within the noise

Goldszmidt, M. (02-09-2015) Communication and reasoning on clinical teaching teams, the genres that shape care and education

Slootweg, I. (19-06-2015) Teamwork of Clinical Teachers in Postgraduate Medical Training

Al-Eraky, M. (21.05.15) Faculty development for medical professionalism in an Arabian context

Wearne, S. (08-04-2015) Is it remotely possible? Remote supervision of general practice registrars

Embo, M. (13-03-2015) Integrating workplace learning, assessment and supervision in health care education

Zwanikken, P. (23-01-2015) Public health and international health educational programmes for low- and middle-income countries: questioning their outcomes and impact

Hill, E. (11-12-2014) A cutting culture: gender and identification in the figured world of surgery

Diemers, A. (03-10-2014) Learning from pre-clinical patient contacts

Tjiam, I. (17-09-2014) Learning in Urology. Designing simulator based skills Training \& Assessment

Berkenbosch, L. (30-06-2014) Management and leadership education for medical residents

Bergman, E.M. (30-06-2014) Dissecting anatomy education in the medical curriculum

Dijkstra, J. (25-06-2014) Guidelines for designing programmes of assessment

Van Loon, M.H. (08-05-2014) Fostering monitoring and regulation of learning

Frambach, J.M. (26-03-2014) The cultural complexity of problem-based learning across the world

Hommes, J.E. (26-02-2014) How relations, time \& size matter in medical education

Van der Zwet, J. (30-01-2014) Identity, Interaction and Power. Explaining the affordances of doctor-student interaction during clerkships

Watling, C.J. (22-01-2014) Cognition, Culture, and Credibility. Deconstructing Feedback in Medical Education

Winston, K. (12-12-2013) Remediation Theory and Practice: Transforming At-Risk Medical Students

Kamp, R.J.A. (28-11-2013) Peer Feedback to Enhance Learning in Problem-Based Tutorial Groups 
Junod Perron, N. (24-10-2013) Towards a learner-centered approach to postgraduate communications skills teaching

Pratidina Susilo, A. (24-10-2013) Learning to be the Patient Advocate

The Development of a Communication Skills Course to Enhance Nurses' Contribution to the Informed Consent Process

Alves de Lima, A. (23-10-2013) Assessment of clinical competence: Reliability, Validity, Feasibility and Educational Impact of the mini-CEX

Sibbald, M. (09-10-2013) Is that your final answer? How doctors should check decisions

Ladhani, Z. (05-07-2013) Competency based education and professional competencies: a study of institutional structures, perspectives and practices in Pakistan

Jippes, M. (01-02-2013) Culture matters in medical schools: How values shape a successful curriculum change

Duvivier, R. J. (12-12-2012) Teaching and Learning Clinical Skills. Mastering the Art of Medicine

De Feijter, J.M. (09-11-2012) Learning from error to improve patient safety

Prescott, L. (09-11-2012) Ensuring the Competence of Dental Practitioners through the Development of a Workplace-Based System of Assessment

Cilliers, F.J. (05-09-2012) The Pre-assessment Learning Effects of Consequential Assessment: Modelling how the Examination Game is Played

Spanjers, I. A.E. (05-07-2012) Segmentation of Animations: Explaining the Effects on the Learning Process and Learning Outcomes

Al-Kadri, H.M.F. (28-06-2012) Does Assessment Drive Students' Learning?

Leppink, J. (20-06-2012) Propositional manipulation for conceptual understanding of statistics

Van Zundert, M.J. (04-05-2012) Conditions of Peer Assessment for Complex Learning

Claramita, M. (30-03-2012) Doctor-patient communication in a culturally hierarchical context of Southeast Asia: A partnership approach

Kleijnen, J.C.B.M. (21-03-2012) Internal quality management and organizational values in higher education

Persoon, M.C. (19-01-2012) Learning in Urology; The influence of simulators and human factors

Pawlikowska, T.R.B. (21-12-2011) Patient Enablement; A Living Dialogue

Sok Ying Liaw, (14-12-2011) Rescuing A Patient In Deteriorating Situations (RAPIDS): A programmatic approach in developing and evaluating a simulation-based educational program

Singaram, V.S. (7-12-2011) Exploring the Impact of Diversity Factors on Problem-Based Collaborative Learning

Balslev, T. (24-11-2011) Learning to diagnose using patient video cases in paediatrics: Perceptive and cognitive processes

Widyandana, D. (19-10-2011) Integrating Pre-clinical skills training in skills laboratory and primary health care centers to prepare medical students for their clerkships 
Durning, S.J. (09-09-2011) Exploring the Influence of Contextual Factors of the Clinical Encounter on Clinical Reasoning Success (Unraveling context specificity)

Govaerts, M.J.B. (08-09-2011) Climbing the Pyramid;Towards Understanding Performance Assessment

Stalmeijer, R. E. (07-07-2011) Evaluating Clinical Teaching through Cognitive Apprenticeship

Malling, B.V.G. (01-07-2011) Managing word-based postgraduate medical education in clinical departments

Veldhuijzen, J.W. (17-06-2011) Challenging the patient-centred paradigm: designing feasible guidelines for doctor patient communication

Van Blankenstein, F. (18-05-2011) Elaboration during problem-based, small group discussion: A new approach to study collaborative learning

Van Mook, W. (13-05-2011) Teaching and assessment of professional behavior: Rhetoric and reality

De Leng, B. (8-12-2009). Wired for learning. How computers can support interaction in small group learning in higher education

Maiorova, T. (29-05-2009). The role of gender in medical specialty choice and general practice preferences

Bokken, L. (04-03-2009). Innovative use of simulated patients for educational purposes

Wagenaar, A. (18-09-2008). Learning in internships. What and how students learn from experience

Driessen, E. (25-06-2008). Educating the self-critical doctor. Using portfolio to stimulate and assess medical students' reflection

Derkx, H. (18-06-2008). For your ears only. Quality of telephone triage at out-of-hours centres in the Netherlands

Niessen, Th. (30-11-2007). Emerging epistemologies: making sense of teaching practice

Budé, L. (05-10-2007). On the improvement of students' conceptual understanding in statistics education

Niemantsverdriet, S. (26-07-2007). Learning from international internships: A reconstruction in the medical domain

Marambe, K. (20-06-2007). Patterns of student learning in medical education - A Sri Lankan study in traditional curriculum

Pleijers, A. (19-01-2007). Tutorial group discussion in problem-based learning

Sargeant, J. (21-09-2006). Multi-source feedback for physician learning and change

Dornan, T. (12-06-2006). Experience-based learning

Wass, V. (12-05-2006). The assessment of clinical competence in high stakes examination

Prince, K. (21-04-2006). Problem-based learning as a preparation for professional practice 


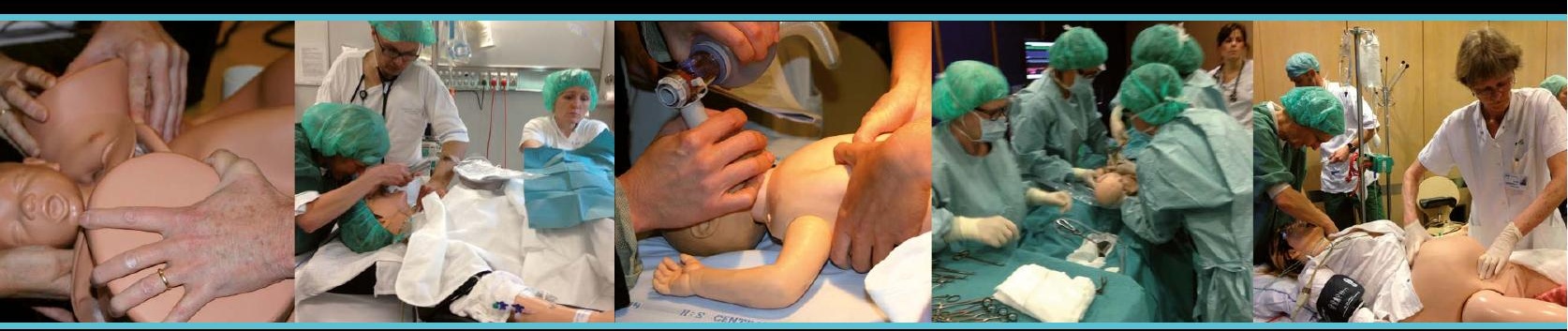

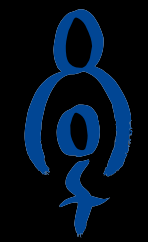

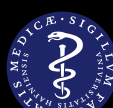

此 sitis 